\title{
EFEITO DE GENÓTIPOS DE FEIJOEIRO E DE PÓS DE ORIGEM VEGETAL SOBRE Zabrotes subfasciatus (BOH.) E Acanthoscelides obtectus (SAY) (COL.: BRUCHIDAE)
}

\section{FÁBIO MAZZONETTO}

\begin{abstract}
Tese apresentada à Escola Superior de Agricultura "Luiz de Queiroz", Universidade de São Paulo, para obtenção do título de Doutor em Ciências, Área de Concentração: Entomologia.
\end{abstract}

P I R A C I C A B A Estado de São Paulo - Brasil

Fevereiro - 2002 


\section{EFEITO DE GENÓTIPOS DE FEIJOEIRO E DE PÓS DE ORIGEM VEGETAL SOBRE Zabrotes subfasciatus (BOH.) E Acanthoscelides obtectus (SAY) (COL.: BRUCHIDAE)}

Fábio Mazzonetto

Engenheiro Agrônomo

Orientador: Prof. Dr. JOSÉ DJAIR VENDRAMIM

Tese apresentada à Escola Superior de Agricultura "Luiz de Queiroz", Universidade de São Paulo, para obtenção do título de Doutor em Ciências, Área de Concentração:

Entomologia.

P I R A C I C A B A

Estado de São Paulo - Brasil

Fevereiro - 2002 


\title{
Dados Internacionais de Catalogação na Publicação (CIP)
} DIVISÃO DE BIBLIOTECA E DOCUMENTAÇÃO - ESALQ/USP

\author{
Mazzonetto, Fá bio \\ Efeito de genótipos de feijoeiro e de pós de origem vegetal sobre \\ Zabrotes subfasciatus (BOH.) e Aca nthosc elides obtec tus (SAY) (Col. : \\ Bruchidae) / Fá bio Mazzonetto. - - Pira cicaba, 2002. \\ 134 p. : il. \\ Tese (doutorado) - Escola Superior de Agricultura Luiz de Queiroz, 2002. \\ Bibliografia.
}

1. Carunchos 2. Feijão 3. Genótipos I. Título

CDD 632.652

"Permitida a cópia total ou parcial deste documento, desde que citada a fonte - $\mathrm{O}$ autor" 
Aos meus pais, Sérgio e Sônia, e aos meus irmãos, Renato e Marisa, que me apoiaram, transmitiram confiança e vontade durante o curso.

\section{OFEREÇO}

Minha avó Ana (in memorian).

\section{HOMENAGEIO}

À minha esposa, Mônica e aos meus filhos, Leonardo, Alexandre e Cristiano, as pessoas mais importantes em minha vida.

\section{DEDICO}




\section{AGRADECIMENTOS}

Ao amigo Dr. José Djair Vendramim, Professor Associado do Departamento de Entomologia, Fitopatologia e Zoologia Agrícola da Escola Superior de Agricultura "Luiz de Queiroz", Universidade de São Paulo (ESALQ/USP), pela valiosa orientação, apoio e incentivo.

Aos Professores do Programa de Pós-Graduação em Entomologia do Departamento de Entomologia, Fitopatologia e Zoologia Agrícola da ESALQ/USP, pelos ensinamentos transmitidos no decorrer do Programa.

À Fundação de Amparo à Pesquisa do Estado de São Paulo (FAPESP), pela concessão de bolsa de estudos.

Às Seções de Leguminosas e de Genética do Instituto Agronômico de Campinas, pelo fornecimento de sementes dos genótipos de feijoeiro utilizados neste estudo.

Ao Prof. Dr. Antônio Furlan do Departamento de Botânica da Unesp/Rio Claro, pela identificação de algumas das espécies vegetais.

Aos funcionários do Departamento de Entomologia, Fitopatologia e Zoologia Agrícola da ESALQ/USP, pelos auxílios prestados.

As bibliotecárias, Kátia e Eliana, pela colaboração na elaboração final deste trabalho.

Aos companheiros do Setor de Resistência de Plantas a Insetos, pela colaboração, apoio e amizade.

A todos os colegas do Programa de Pós-graduação em Entomologia, mestrandos e doutorandos, pela amizade e carinho.

E a Deus e a todos que, diretamente ou indiretamente, colaboraram para a realização desse trabalho. 


\section{SUMÁRIO}

Página

RESUMO .............................................................................. viii

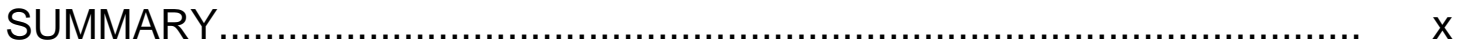

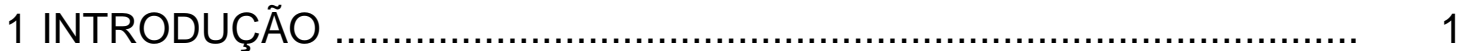

2 REVISÃO DE LITERATURA ........................................................... 3

2.1 Considerações gerais sobre Zabrotes subfasciatus (Boh.) e Acanthoscelides obtectus (Say) ....................................................

2.1.1 Origem e distribuição................................................................. 3

2.1.2 Descrição e biologia.................................................................

2.1.2.1 Z. subfasciatus...............................................................

2.1.2.2 A. obtectus.................................................................... 5

2.1.3 Danos de Z. subfasciatus e A. obtectus........................................ 6

2.2 Resistência de genótipos de feijoeiro a $Z$. subfasciatus e $A$.

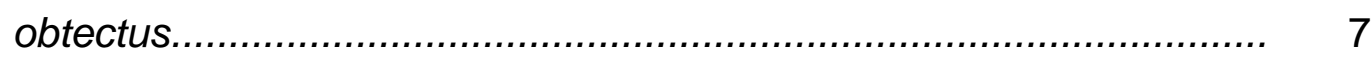

2.3 Efeito de substâncias de origem vegetal sobre $Z$. subfasciatus e $A$.

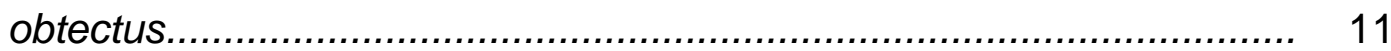

2.3.1 Efeito sobre Z. subfasciatus................................................... 11

2.3.2 Efeito sobre A. obtectus.......................................................... 14

3 MATERIAL E MÉTODOS............................................................. 18

3.1 Efeito de pós vegetais sobre Z. subfasciatus e A. obtectus................. 19

3.1.1 Avaliação da repelência sobre os adultos ...................................... 19

3.1.2 Avaliação da mortalidade dos adultos e oviposição.......................... 20 
Página

3.2 Resistência de genótipos de feijoeiro a $Z$. subfasciatus e $A$. obtectus...................................................................... 27

3.2.1 Efeito dos genótipos sobre a preferência para oviposição ................ 27

3.2.1.1 Teste com chance de escolha ...................................................... 27

3.2.1.2 Teste sem chance de escolha ................................................. 28

3.2.2 Efeito dos genótipos de feijoeiro sobre a biologia dos insetos........... 28

3.3 Efeito associado de genótipos resistentes de feijoeiro e pós vegetais sobre Z. subfasciatus e A. obtectus.............................................. 29

3.3.1 Avaliação da repelência sobre os adultos ...................................... 29

3.3.2 Estimativa da $C_{50}$ do pó de C. ambrosioides (f.2) para $Z$. subfasciatus e A. obtectus....................................................... $\quad 30$

3.3.3 Avaliação da mortalidade dos adultos e oviposição.......................... 31

3.3.4 Efeito na biologia....................................................................... 31

3.3.5 Efeito no dano causado pelos insetos.......................................... 31

3.4 Análise estatística..................................................................... 32

4 RESULTADOS E DISCUSSÃO......................................................... 33

4.1 Efeito de pós vegetais sobre Zabrotes subfasciatus (Boh.) e $A$. obtectus (Say) ..................................................................... 33

4.1.1 Avaliação da repelência sobre os adultos........................................ 33

4.1.1.1 Z. subfasciatus.................................................................. 33

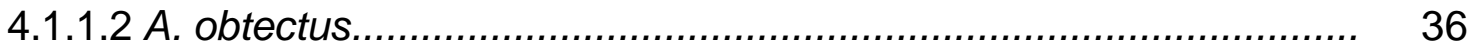

4.1.2 Avaliação da mortalidade dos adultos e oviposição.......................... 38

4.1.2.1 Z. subfasciatus..................................................................... 38

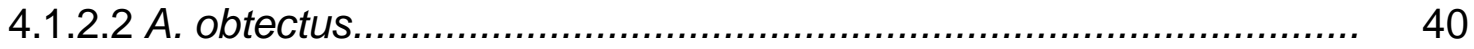

4.2 Resistência de genótipos de feijoeiro a $Z$. subfasciatus e $A$.

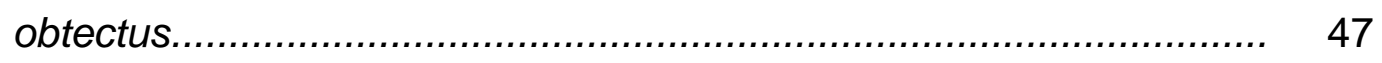

4.2.1 Efeito dos genótipos sobre a preferência para oviposição ................ 47

4.2.1.1 Teste com chance de escolha .................................................... 47 
Página

4.2.1.1.1 Z. subfasciatus..................................................................... 47

4.2.1.1.2 A. obtectus................................................................. 49

4.2.1.2 Teste sem chance de escolha................................................. 51

4.2.1.2.1 Z. subfasciatus................................................................... 51

4.2.1.2.2 A. obtectus............................................................. 52

4.2.2 Efeito dos genótipos de feijoeiro sobre a biologia dos insetos........... 54

4.2.2.1 Z. subfasciatus......................................................................... 54

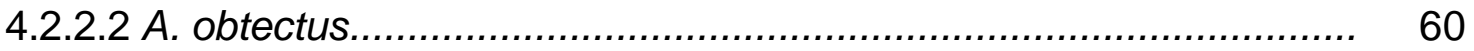

4.3 Efeito associado de genótipos resistentes de feijoeiro e pós vegetais sobre Z. subfasciatus e A. obtectus................................................. 64

4.3.1 Avaliação da repelência sobre os adultos..................................... 64

4.3.1.1 Z. subfasciatus................................................................... 64

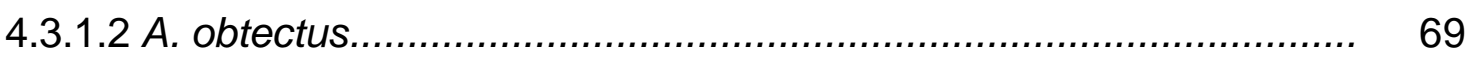

4.3.2 Estimativa da $C L_{50}$ do pó de C. ambrosioides (f.2) para $Z$. subfasciatus e A. obtectus........................................................... 73

4.3.3 Avaliação da mortalidade dos adultos e oviposição.......................... 75

4.3.3.1 Z. subfasciatus..................................................................

4.3.3.2 A. obtectus................................................................ 80

4.3.4 Efeito na biologia................................................................ 84

4.3.4.1 Z. subfasciatus............................................................. 84

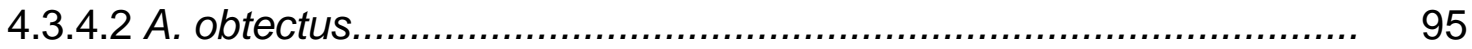

4.3.5 Efeito no dano causados pelos insetos....................................... 107

4.3.5.1 Z. subfasciatus..................................................................... 107

4.3.5.2 A. obtectus................................................................ 112

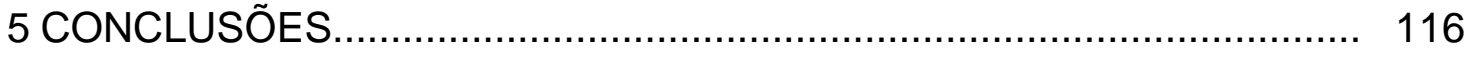

5.1 Efeito de pós vegetais sobre Zabrotes subfasciatus (Boh.) e Acanthoscelides obtectus (Say)................................................... 116 
5.2 Resistência de genótipos de feijoeiro a $Z$. subfasciatus e $A .117$ obtectus.

5.2.1 Teste de preferência para oviposição............................................. 117

5.2.2 Teste de biologia.................................................................. 117

5.2 Efeito associado de genótipos resistentes de feijoeiro e pós vegetais sobre Z. subfasciatus e A obtectus................................................. 118

REFERÊNCIAS BIBLIOGRÁFICAS.................................................... 119 


\title{
EFEITO DE GENÓTIPOS DE FEIJOEIRO E DE PÓS DE ORIGEM VEGETAL SOBRE Zabrotes subfasciatus (BOH.) E Acanthoscelides obtectus (SAY) (COL.: BRUCHIDAE)
}

\author{
Autor: Fábio Mazzonetto \\ Orientador: Prof. José Djair Vendramim
}

\section{RESUMO}

Avaliou-se o efeito isolado e associado de pós de origem vegetal e de genótipos de feijoeiro sobre o comportamento, biologia e danos de Zabrotes subfasciatus (Boh.) e Acanthoscelides obtectus (Say). Inicialmente, foi avaliado o efeito dos pós obtidos de 18 plantas sobre a atratividade e mortalidade dos adultos, e oviposição. A seguir, foi testado o efeito de 12 genótipos de feijoeiro incluindo materiais melhorados contendo arcelina (Arc1, Arc2, Arc3 e Arc4) e sem essa proteína (IAC Carioca Aruã, IAC Carioca Pyatã, IAC Carioca Akytã, IAC Maravilha, IAC Una, IAC Bico de Ouro, Porrillo 70 e Goiano Precoce) sobre a oviposição (com e sem chance de escolha) e biologia dos insetos. Com base nestes resultados, foram selecionados, para cada espécie de inseto, quatro genótipos (três resistentes e um suscetível) e quatro pós vegetais, para os quais foi avaliado o efeito associado sobre a atratividade e mortalidade dos adultos, preferência para oviposição, biologia e danos causados pelos insetos. Concluiu-se que: a) os pós obtidos da parte aérea de Chenopodium ambrosioides (erva-de-santa-maria), f. (forma) 1 e f.2; de folhas de Eucalyptus citriodora (eucalipto cheiroso), de Mentha pulegium (poejo) e de Ruta 
graveolens (arruda), e de cascas de frutos de Citrus reticulata (laranja cv. Murcote) são repelentes aos adultos das duas pragas; b) os pós obtidos de folhas de Ocimum basilicum (alfavaca) e de O. minimum (manjericão) são repelentes apenas para $Z$. subfasciatus, enquanto os pós de cascas de frutos de Citrus sinensis (laranja cv. Pêra) e de frutos de Lafoensia glyptocarpa (mirindiba) apresentam efeito repelente apenas em relação a $A$. obtectus; $\mathrm{c}$ ) $\mathrm{O}$ pó de folhas de L. glyptocarpa apresenta atratividade a Z. subfasciatus; d) os pós de $C$. ambrosioides (f.2), M. pulegium, $O$. basilicum e $R$. graveolens apresentam efeito altamente tóxico aos adultos de $Z$. subfasciatus, causando $100 \%$ de mortalidade e impedindo a oviposição; e) em relação a $A$. obtectus, há total mortalidade de adultos e ausência de oviposição, com o uso de pós de $C$. ambrosioides (f.2) e de folhas de Coriandrum sativum (coentro); f) em teste sem chance de escolha, o genótipo Arc3 é menos ovipositado por $Z$. subfasciatus que 'IAC Carioca Pyatã' e 'IAC Bico de Ouro', enquanto, em relação a $A$. obtectus os materiais são igualmente preferidos para oviposição; g) os materiais contendo arcelina (Arc1, 2, 3 e 4) apresentam resistência do tipo nãopreferência para alimentação e/ou antibiose a $Z$. subfasciatus, alongando o período de desenvolvimento (ovo-adulto) e reduzindo o peso dos adultos, a longevidade e a fecundidade; h) em relação a $A$. obtectus, a resistência do tipo não-preferência para alimentação e/ou antibiose só ocorre com o Arc1, genótipo em que há alongamento do período de desenvolvimento e menor peso dos adultos; i) 'Goiano Precoce' é o material mais adequado ao desenvolvimento dos dois insetos; j) com o emprego associado de pós vegetais e genótipos resistentes de feijoeiro, ocorre apenas efeito aditivo (e não sinérgico) das duas técnicas de controle para ambas as espécies de insetos; k) o peso consumido de grãos de feijão por $Z$. subfasciatus e A. obtectus não é afetado pelos pós inseticidas; esse peso, entretanto, é menor nos genótipos contendo arcelina para os dois insetos. 


\title{
EFFECT OF BEAN GENOTYPES AND POWDERS FROM VEGETAL ORIGIN ON Zabrotes subfasciatus (BOH.) AND Acanthoscelides obtectus (SAY) (COL.: BRUCHIDAE)
}

\author{
Author: Fábio Mazzonetto \\ Adviser: Prof. José Djair Vendramim
}

\section{SUMMARY}

It was evaluated the isolated and associated effects of powders from different vegetal and bean genotypes on the behaviour, biology and damage of Zabrotes subfasciatus (Boh.) and Acanthoscelides obtectus (Say). Initially, it was evaluated the effect of powders of 18 plants on the attractivity and mortality of the adults, and oviposition. Then, the effect of 12 bean genotypes was tested including materials with arcelin (Arc1, Arc2,Arc3 and Arc4) and without this protein (IAC Carioca Aruã, IAC Carioca Pyatã, IAC Carioca Akytã, IAC Maravilha, IAC Una, IAC Bico de Ouro, Porrillo 70 and Goiano Precoce) on the oviposition (free-choice and no-choice tests) and biology of the insects. Based on these results, four genotypes (three resistant and one susceptible) and four powders were selected for each insect species. It was evaluated the associated effect on the attractivity and mortality of the adults, preference for oviposition, biology and damage caused by the insects. It was concluded that: powders of the aerial part from Chenopodium ambrosioides f. (form) 1 and f.2; leaves from Eucalyptus citriodora, from Mentha pulegium and from Ruta graveolens, and rinds of fruits from Citrus reticulata (cv. Murcote) are repellents to the adults of 
the two pests; b) powders of leaves from Ocimum basilicum and O. minimum are repellent only for $Z$. subfasciatus, while powders of rinds of fruits from Citrus sinensis (cv. Pêra) and fruits from Lafoensia glyptocarpa shows repellent effect only on A. obtectus; c) powder of leaves from L. glyptocarpa shows attractivity on Z. subfasciatus; d) powders from $C$. ambrosioides (f.2), M. pulegium, $O$. basilicum and $R$. graveolens show high toxicity on adults of $Z$. subfasciatus, causing $100 \%$ mortality and inhibiting the oviposition; e) in relation to $A$. obtectus, total mortality of adults and no oviposition is observed with the use of powders from C. ambrosioides (f.2) and leaves from Coriandrum sativum; $f$ ) in no-choice test, Arc3 was less oviposited by $Z$. subfasciatus than IAC Carioca Pyatã and IAC Bico de Ouro, while in relation to $A$. obtectus the materials are equally preferred for oviposition; g) the materials with arcelin (Arc1, 2, 3 and 4) show non-preference resistance for feeding and/or antibiose to the $Z$. subfasciatus, prolonging the time for insect development (egg-adult) and reducing the adult weight, longevity and fecundity; h) in relation to A. obtectus, non-preference resistance for feeding and/or antibiose only occurs with Arc1, genotype that prolongs the development period and reduces the adult weight; i) Goiano Precoce is the most suitable material for the development of both insects; j) with the association of vegeta powders and resistant bean genotypes, only additive effect (and not syhngistic) is observed with the two control tactics for both insect species; $k$ ) the weight of consumed bean grains for $Z$. subfasciatus and $A$. obtectus was not affected by insecticide powders; however the weight, however, was lower in the genotypes with arcelin for both insects. 


\section{INTRODUÇÃO}

O feijoeiro-comum Phaseolus vulgaris L. constitui-se não só no Brasil, como em outros países da América Latina, num dos alimentos básicos e fonte acessível de proteína, vitaminas e minerais, além de apresentar elevado conteúdo energético (Guzmàn-Maldonado et al., 1996). Seu teor de proteínas varia de 15 a 33\%; na maioria das cultivares nacionais esse teor varia de 20 a $25 \%$, no entanto, apresentam deficiência dos aminoácidos essenciais metionina e cistina, apesar do alto conteúdo de lisina (Vieira, 1992).

Segundo Oliveira et al. (1979), as estimativas colocam o Brasil como o maior consumidor mundial do produto. A produtividade média, entretanto, de aproximadamente $500 \mathrm{~kg} / \mathrm{ha}$, é muito baixa quando comparada com países desenvolvidos que chegam a produzir $1400 \mathrm{~kg} / \mathrm{ha}$ (Bastos Filho, 1995).

Dentre os vários fatores que levam a essa baixa produtividade encontram-se os insetos-pragas. Além das pragas de campo que atacam nos diversos estádios de desenvolvimento da cultura, também são importantes as pragas que atacam os grãos armazenados, dentre as quais incluem-se os bruquídeos Zabrotes subfasciatus (Boh.) e Acanthoscelides obtectus (Say).

O controle dessas pragas com a utilização de cultivares resistentes e plantas inseticidas por meio de pós, extratos e óleos vem sendo estudado como métodos alternativos para minimizar o uso de inseticidas químicos. Tais métodos podem favorecer principalmente o pequeno agricultor, já que são de fácil utilização não exigindo pessoal qualificado, são mais baratos e não afetam o meio ambiente. Além disso, no caso dos inseticidas vegetais, as 
plantas podem ser mantidas em cultivo na própria propriedade, facilitando a sua utilização.

O objetivo deste trabalho foi verificar o efeito isolado e associado de alguns genótipos de feijoeiro e substâncias de origem vegetal sobre o crescimento populacional e danos ocasionados por $Z$. subfasciatus e $A$. obtectus. 


\section{REVISÃO DE LITERATURA}

\subsection{Considerações gerais sobre Zabrotes subfasciatus (Boh.) e Acanthoscelides obtectus (Say)}

\subsubsection{Origem e distribuição}

Esses dois bruquídeos são as principais pragas de grãos armazenados ocorrendo em todas as regiões do globo onde se faz o armazenamento de feijões, sendo que $Z$. subfasciatus ocorre principalmente nas regiões tropicais da América Latina, onde aparece com maior freqüência (Rossetto, 1966), enquanto $A$. obtectus é mais freqüente em regiões temperadas (Gallo et al., 1988).

O centro de origem de $Z$. subfasciatus é a América Central e do Sul, expandindo-se daí para todo o mundo. Sua ocorrência em Phaseolus vulgaris L. é comum na África, Sudeste Asiático, Índia e Europa (Ferreira, 1960). No Brasil, está presente em todos os estados produtores de feijão, sendo registrado principalmente nos Estados da Bahia, Amazonas, Espírito Santo, Pará, Rio de Janeiro, Rio Grande do Sul e São Paulo (Silva et al., 1968).

Já em relação a $A$. obtectus, considera-se que tenha coevoluído com as espécies de Phaseolus, das Américas (Simmonds et al., 1989). Para Bondar (1936), tal espécie é descrita como sendo americana porém, propagada em todas as partes do mundo. No Brasil, ocorre em todos os estados produtores, com maior intensidade nos Estados da Bahia, Alagoas, Amazonas, 
Espírito Santo, Minas Gerais, Paraná, Santa Catarina, Rio Grande do Sul, São Paulo e Rio de Janeiro (Silva et al., 1968).

\subsubsection{Descrição e biologia}

\subsubsection{Z. subfasciatus}

O bruquídeo $Z$. subfasciatus apresenta, na fase adulta, 1,8 a 2,5 $\mathrm{mm}$ de comprimento e 1,4 a 1,8 mm de largura e tem coloração castanhoescura com manchas claras no pronoto fortemente pubescente. O dimorfismo sexual é bem nítido, permitindo a separação dos sexos. As fêmeas são maiores que os machos, além de apresentarem uma mancha clara triangular na parte posterior da cabeça, outra da mesma forma próximo ao escutelo e duas outras nos ângulos do pronoto, enquanto que, nos machos só é bem distinta a mancha pré-escutelar (Ferreira, 1960). Os ovos são ovóides quase arredondados medindo de 0,46 a 0,60 mm de comprimento e 0,44 a 0,50 mm de largura, ficando fortemente aderidos à superfície do grão. Os ovos férteis são opacos e os inférteis são translúcidos. As larvas são do tipo curculioniforme, com coloração branco-leitosa, dotadas de mandíbulas desenvolvidas com as quais são capazes de romper os grãos para alimentação interna. As pupas são maiores que os adultos, da mesma coloração das larvas, sem pêlos, medindo 2,5 a 3,5 mm de comprimento e 1,5 a 2,0 mm de largura (Ferreira, 1960; Gallo et al., 1988).

Ferreira (1960), avaliando a biologia dessa espécie, verificou que, a $27^{\circ} \mathrm{C}$ e $75 \%$ de UR, o período de desenvolvimento foi ao redor de 36 dias. Para outros autores, tal parâmetro foi de 24,5 dias a $32^{\circ} \mathrm{C}$ e $70 \%$ de UR (Howe \& Currie, 1964), entre 23 e 33 dias a $32^{\circ} \mathrm{C}$ e $70 \%$ de UR (Carvalho \& Rossetto, 1968) e 37 dias a $27^{\circ} \mathrm{C}$ e $75 \%$ de UR (Credland \& Dendy, 1992; GonzálesValenzuela et al., 1984). 
A longevidade dos adultos foi observada por vários autores, que constataram valores médios de 9 dias (Ferreira, 1960), 7,6 dias (Howe \& Currie, 1964), 13,8 dias para machos e 11 dias para fêmeas (Carvalho \& Rossetto, 1968), 8,8 dias para machos e 7,4 dias para fêmeas (Wiendl, 1969) e 12 a 13 dias tanto para machos como fêmeas (Gonzáles-Valenzuela et al., 1984). Condições ótimas para o seu desenvolvimento foram verificadas a $32,5^{\circ} \mathrm{C}$ e $70 \%$ de UR por Howe \& Currie (1964), enquanto que para Decheco \& Ortiz (1987), as temperaturas ótimas estão entre 27 e $30^{\circ} \mathrm{C}$.

A fecundidade total das fêmeas foi superior a 30 ovos com pico entre o $2^{0}$ e $3^{0}$ dias, segundo Howe \& Currie (1964) e Meik \& Dobie (1986), mas atingiram valores entre 56 e 63 ovos, segundo Ferreira (1960), Gonzáles Valenzuela et al. (1985) e Cardona et al. (1989) com pico ao $5^{0}$ dia, porém com valores elevados do $2^{0}$ ao $7^{0}$ dia (Ferreira, 1960). Para Carvalho \& Rossetto (1968), o valor médio mínimo registrado foi de 22 ovos, variando de 4 a 46 ovos. Já para Credland \& Dendy (1992), a fecundidade total variou de 36 a 58 ovos.

A proporção entre sexos é de aproximadamente 1:1, conforme os percentuais para fêmeas e machos de, respectivamente, 52,8 e $47,2 \%$ (Ferreira, 1960); 50 e 50\% (Howe \& Currie, 1964) e 46 e 54\% (Dendy e Credland, 1991).

\subsubsection{A. obtectus}

Os adultos de $A$. obtectus apresentam forma ovóide, com 2 a 4 $\mathrm{mm}$ de comprimento e coloração pardo-escura, com pontuações avermelhadas na parte vertical do abdome e no pigídio, pernas e antenas. Segundo Halstead (1963), a separação entre os sexos pode ser feita considerando-se o maior tamanho das fêmeas e a curvatura da extremidade do pigídio menos acentuada com inclinação oblíqua e abertura anal terminal nas fêmeas enquanto que nos machos, além da inclinação ser mais vertical e bastante recurvada, a abertura 
anal é ventral. As larvas são de coloração branco-leitosa com 3 a $4 \mathrm{~mm}$ de comprimento e as pupas são da mesma cor passando a marrom quando próximas àemergência dos adultos (Gallo et al., 1988).

O período de desenvolvimento de $A$. obtectus, segundo Constantino (1956), dura ao redor de 35 dias. Howe \& Currie (1964) observaram que o ambiente ótimo para um rápido desenvolvimento é $70 \%$ de UR e $30^{\circ} \mathrm{C}$; nessas condições o período total foi de cerca de 27,5 dias. Outros autores verificaram valores como 33,5 dias a $30^{\circ} \mathrm{C}$ e 46 dias a $25^{\circ} \mathrm{C}$ (AlvarezMarin \& Rodriguez-Noa, 1986) e 43 dias a $27^{\circ} \mathrm{C}$ (Willink et al., 1990).

A longevidade dos adultos desta espécie, que varia entre 10 e 15 dias, segundo diversos autores (Constantino, 1956; Howe \& Currie, 1964; Willink et al., 1990), pode atingir até 2 meses, segundo Bondar (1936).

Menusan (1935) constatou que a $30^{\circ} \mathrm{C}$ e $90 \%$ de UR, o número médio de ovos por fêmea foi 59 , enquanto a $25,2^{\circ} \mathrm{C}$ e $75 \%$ de UR, o valor médio atingiu 64,4 ovos. O autor considerou a temperatura de $27^{\circ} \mathrm{C}$, como a ótima para oviposição já que nesta, obteve a maior média (67 ovos por fêmea), chegando a valores próximos dos verificados por Constantino (1956) (63 ovos por fêmea) e por Howe \& Currie (1964) com pico no $3^{0}$ e $4^{0}$ dias. Já para Alvarez-Marin \& Rodriguez-Noa (1986), o valor médio ficou ao redor de 59 ovos por fêmea com pico no $3^{0}$ dia de oviposição.

A razão sexual para essa espécie é de aproximadamente 1:1 (Howe \& Currie, 1964).

\subsubsection{Danos de Z. subfasciatus e A. obtectus}

Os danos causados por estas duas pragas são semelhantes. Atacam os cotilédones, abrindo galerias podendo destruí-los completamente. Isso afeta a qualidade dos grãos, tanto daqueles destinados à semeadura, devido àdestruição do embrião, quanto dos destinados ao consumo, conferindo gosto desagradável ao produto, devido à presença de insetos, ovos e 
excrementos, prejudicando assim, a sua comercialização (Gallo et al., 1988; Vieira, 1967). Somam-se ainda, os danos indiretos, por favorecerem a entrada de microrganismos e ácaros, e aquecimento dos grãos (Rosolem \& Marubayashi, 1994).

As perdas de grãos devido aos danos causados por $Z$. subfasciatus chegam a atingir 35\% no México, América Central e Panamá e ficam em torno de 7 a 15\% no Brasil (Schoonhoven \& Cardona, 1982). No Sudeste e Sul do Brasil, as perdas chegam a 20\% (Wiendl, 1975) e no Nordeste a $40 \%$ (Oliveira et al., 1977). Já as perdas ocasionadas por A. obtectus variam de 20 a $30 \%$ da produção total de feijão no Brasil (Celestino Filho \& Almeida, 1980).

\subsection{Resistência de genótipos de feijoeiro a Z. subfasciatus e A. obtectus}

Em estudo para avaliar a resistência de materiais comerciais de feijoeiro armazenado a $A$. obtectus e $Z$. subfasciatus, Oliveira et al. (1979) observaram que em ambas espécies os genótipos Costa Rica, Linhagem Venezuela 350, Mulatinho Paulista, Preto 120, Preto 141, Preto 143, Preto 147, Preto 192 e Seleção Cuva apresentaram, em média, apenas 15\% de infestação aos 6 meses, enquanto o genótipo Rico 23, o mais suscetível, apresentou $61 \%$ dos grãos atacados. Aos 12 meses após a infestação, entretanto, o valor atingiu $100 \%$ em todos os genótipos.

Souza (1988) constatou que os genótipos Regente, Tayhu, SP7052, Carioca e Jalo foram menos danificados por $A$. obtectus que Rosinha G-2 e Goiano Precoce.

Pereira et al. (1995) confirmaram a alta suscetibilidade dos genótipos Porrillo-70 e Goiano Precoce ao ataque de Z. subfasciatus, sendo que o dano causado pelos carunchos neste último genótipo foi 7 vezes superior ao sofrido por linhagens selvagens. Resultados semelhantes com a verificação da suscetibilidade do genótipo Goiano Precoce também foram observados por 
Oriani et al. (1996) sendo que o genótipo FE 732007 apresentou certa resistência.

Testando vários materiais, Camargo-Lezama et al. (1997) verificaram que as linhagens CPG0065, CPG0100 e CPG0131 apresentaram resistência a $A$. obtectus, sendo o melhor resultado observado na CPG0131 quando comparadas com o material Jamapa utilizado como resistente padrão para os testes.

Vera-Graziano \& Domingues-Ruiz (1997) estudaram o efeito de seis genótipos sobre $Z$. subfasciatus e $A$. obtectus e verificaram que os materiais Canario 107 e Negro Huasteco foram resistentes a $Z$. subfasciatus. Canario 107 e Amarillo 154 apresentaram resistência também a A. obtectus.

A resistência a $Z$. subfasciatus foi verificada nos genótipos Preto 143, 2374 (202-19), 2395 (202-07), 2174 (202-27), 133 (233-01) e 115 (92-22401). Opostamente, a suscetibilidade de Goiano Precoce, IAPAR MD 808 e Diamante Negro a estes insetos foi caracterizada (Mazzonetto \& Boiça Jr., 1999).

Firdissa \& Abraham (2000) testaram dezenas de materiais em relação àresistência a $Z$. subfasciatus e verificaram que apenas os genótipos RAZ e Roba 1 foram resistentes.

Muitos foram os estudos utilizando materiais selvagens para constatação de fontes de resistência aos bruquídeos $Z$. subfasciatus e $A$. obtectus. Um estudo detalhado com acessos silvestres de $P$. vulgaris resistentes realizado por Osborn et al. (1986) revelou a presença de uma glicoproteína (um novelo protéico) nestes acessos. Tal proteína apresentava uma banda marcante, sendo o seu peso molecular entre 35.000 e 42.000 daltons. Esta proteína foi denominada arcelina, por ter sido originalmente encontrada na região de Arcélia, no México. Ela se mostrou associada à resistência aos bruquídeos, e estava presente em linhagens selvagens resistentes e ausentes em linhagens suscetíveis e em genótipos cultivados. 
Muitas variantes alélicas da proteína arcelina já foram isoladas e caracterizadas bioquimicamente. Quatro delas (Arc1, Arc2, Arc3 e Arc4) foram inicialmente descritas por Osborn et al. (1986) no estudo anteriormente citado. Mais duas variantes, Arc5 e Arc6, foram descritas por Lioi \& Bollini (1989) e Santino et al. (1991), respectivamente, e mais atualmente a variante Arc7 descrita por Acosta-Gallegos et al. (1998). As diferenças entre as variantes estão associadas a variações na seqüência de aminoácidos ou nas frações de carboidratos ligadas a ela. Tais variantes atuam de forma diferenciada em relação ao efeito antibiótico.

Altos níveis de resistência foram encontrados em linhagens selvagens de $P$. vulgaris a $A$. obtectus e $Z$. subfasciatus. Schoonhoven et al. (1983), realizando testes em acessos silvestres, verificaram altos níveis de resistência do tipo antibiose a Z. subfasciatus. Os acessos G12952 e G12953 mantiveram resistência por cinco gerações em insetos neles criados.

Gomes et al. (1987) verificaram que as linhagens selvagens G12952, G12891 e G10019 mostraram-se altamente resistentes a A. obtectus em diversos parâmetros biológicos testados quando comparados com materiais cultivados.

O acesso G12952 também foi estudado por Minney et al. (1990) que também verificou a resistência deste material. Já o acesso G12953 também foi estudado por Cardona et al. (1989) durante quatro gerações de $Z$. subfasciatus e a resistência deste material foi confirmada e mantida nestas gerações verificando-se resistência do tipo antibiose quando estudados vários parâmetros biológicos neste inseto.

Retrocruzamentos dessas linhagens selvagens com cultivares têm sido realizados visando transferir o fator de resistência presente nestas linhagens. Cardona \& Posso (1987) e Posso et al. (1992) utilizaram esse método com linhagens selvagens e cultivares de baixa resistência, e observaram que quanto maior o teor de arcelina transferido a tais cultivares, maior o efeito antibiótico. 
Harmsen et al. (1988) observaram os efeitos da transferência da arcelina de feijão silvestre para as cultivares Porrillo 70 e Sanilac e constataram que a presença dos alelos Arc1, Arc2, Arc3 e Arc4 nessas cultivares, principalmente Arc1, aumentou significativamente a resistência a $Z$. subfasciatus em alguns parâmetros biológicos quando comparados a essas cultivares padrões.

A transferência dos alelos Arc1, Arc2, Arc3 e Arc4 de feijão silvestre para cultivados foi realizada por Posso et al. (1992). Foram desenvolvidas linhagens avançadas denominadas RAZ, sendo que, aquelas contendo Arc1 apresentaram resistência igual ou superior à testemunha resistente, as com Arc2 mostraram níveis intermediários de resistência, enquanto que as contendo Arc3 e 4 não se mostraram resistentes a $Z$. subfasciatus. Resultados semelhantes nos níveis de resistência nestes alelos em linhagens avançadas RAZ também foram observados por Cardona et al. (1990), Cardona et al. (1992) e Padgham et al. (1992).

Para determinar o controle genético da arcelina e a resistência por ela conferida a Z. subfasciatus, Kornegay et al. (1993) realizaram bioensaios utilizando cinco variantes de arcelina. As variantes Arc4 e Arc5 apresentaram os mais altos níveis de resistência.

Em testes com sementes resultantes de plantios de inverno e das águas ao ataque de $Z$. subfasciatus, constatou-se resistência do tipo antibiose das linhagens Arc5S, Arc1 e Arc2, e do tipo não-preferência para alimentação em Arc3 e Arc4 (Lara, 1997, 1998).

Linhagens contendo Arc1, Arc2, Arc3 e Arc4 confirmaram também resistência do tipo antibiose em estudos realizados com $Z$. subfasciatus por Wanderley et al. (1997).

Barbosa et al. (2000 a, b) verificaram também com $Z$. subfasciatus, quando compararam genótipos suscetível com linhagens contendo arcelina, níveis de resistência satisfatórios nos genótipos Arc1, 2, 3 e 4. 
Baldin (2001) em estudos com $A$. obtectus verificou que os genótipos Arc1S, 3S e 5S e Arc1, 2, 3 e 4 apresentaram resistência a este inseto.

\subsection{Efeito de substâncias de origem vegetal sobre $Z$. subfasciatus e $A$. obtectus}

As plantas com ação inseticida têm sido utilizadas como método alternativo de controle por meio de produtos na forma de pós, óleos e extratos para as principais pragas de produtos armazenados em muitos países da América Latina, Ásia e África. Tais plantas provocam mortalidade, repelência, inibição da oviposição, redução no desenvolvimento larval e na fecundidade e fertilidade dos adultos. Por essa razão, muitos pesquisadores vêm tentando isolar compostos presentes em plantas para verificação de seus efeitos sobre certas pragas de importância econômica.

\subsubsection{Efeito sobre Z. subfasciatus}

Das folhas, caules e raízes da planta de canela já foram isolados cerca de 72 compostos, destacando-se o cinamaldeído, eugenol e cânfora (Senanayake et al., 1978), responsáveis, provavelmente, pelo efeito repelente a $Z$. subfasciatus, sem descartar, no entanto, outros compostos provocando esse efeito.

Lagunes-Tejeda \& Rodríguez (1989) verificaram efeito inseticida dos pós vegetais de Trichilia havanensis, Lavandula angustifolia, Eryngium cymosum, Castilleja arvensis, Hippocratea sp. e Tagetes fetidissima para Z. subfasciatus.

A pimenta-do-reino (Piper nigrum) moída constitui uma fonte segura e promissora de inseticida natural, sendo que seus frutos possuem 
alcalóides, especificamente do grupo amida insaturada com ação tóxica sobre muitas pragas de grãos armazenados (Miyakado et al., 1989).

Saito et al. (1989) estudaram a atividade inseticida de 30 espécies vegetais, das quais prepararam 240 extratos com diferentes partes vegetais que foram testadas contra várias espécies de insetos, incluindo $Z$. subfasciatus. Os extratos vegetais mais eficientes foram sementes de Annona cacans, Annona crassiflora, Annona squamosa e raízes de Potomorphe umbellata.

Testando folhas, flores e frutos de Chenopodium procerum, Ocimum americanum, Tetradentia ripariae Capsicum frutescens para avaliação de toxicidade e repelência para adultos de $Z$. subfasciatus, Kayitare \& Ntezurubanza (1991) verificaram que folhas de O. americanum e C. procerum, embora tenham sido as mais tóxicas a esse inseto, não apresentaram efeito repelente sobre os adultos.

Weaver et al. (1991) verificaram que nas folhas secas de Ocimun canum (planta utilizada para proteção de grãos armazenados em Rwanda), o óleo essencial contém cerca de 60 a 90\% da substância linalool, um monoterpenóide oxigenado volátil com ação inseticida. Tal substância, nas concentrações de 500 e $750 \mu \mathrm{g} / \mathrm{cm}^{2}$, proporcionou, após 48 horas, mortalidade de $50 \%$ de fêmeas e $100 \%$ de machos dessa espécie.

T. riparia, planta de uso medicinal tradicional em Rwanda, também apresentou ação inseticida em estudos realizados por Weaver et al. (1992). Tais autores verificaram que a adição de folhas trituradas em concentrações superiores a $4 \%$, reduziu significativamente a fecundidade e fertilidade de $Z$. subfasciatus.

Segundo Vasconcelos et al. (1993), o óleo de cravo apresentou melhor efeito para controle de $Z$. subfasciatus em grãos de caupi armazenado do que os óleos de cominho, pimenta e eucalipto.

Mordue \& Blackwell (1993) observaram que o limonóide azadiractina e outros compostos potencialmente bioativos encontrados no óleo 
e extrato de sementes de nim, Azadirachta indica, foram eficientes e promissores para controle de pragas de grãos armazenados.

Pó de $O$. canum, na concentração de $2 \%$, suprimiu completamente a postura de $Z$. subfasciatus em feijão, apresentando uma $\mathrm{CL}_{50}$ de $0,45 \%$. As ações de contato e fumigante foram devido ao linalool e outros componentes voláteis, como o $\beta$-cariofileno e $\alpha$-bergamotene presentes nas folhas (Weaver et al.,1994b). Estes mesmos autores verificaram que plantas de Tagetes minuta também se mostraram promissoras no controle desta espécie de inseto (Weaver et al., 1994 a).

Vasconcelos et al. (1995) observaram que óleo de folhas de canela nas dosagens de 5,0 e 7,5ml/kg misturados aos grãos foi eficiente no controle de $Z$. subfasciatus em feijão durante três meses de armazenamento, provocando mortalidade, redução no número de ovos férteis e na emergência de adultos. Quando misturado a óleo de soja a $5,0 \mathrm{ml} / \mathrm{kg}$ também foi efetivo durante o mesmo período de armazenamento (Vasconcelos et al., 1997).

Araya-González et al. (1996), verificando o efeito de pós de Ricinus communis, Gaura coccinea, Larrea tridentata, Ribes ciliatum, Castilleja tenuiflora, Alchemilla procumbens e Guazuma tomentosa sobre $Z$. subfasciatus constataram que o pó de $C$. tenuiflora mostrou-se bastante promissor no controle deste inseto.

Pó de Chenopodium ambrosioides na concentração de $0,075 \mathrm{~g} / 20 \mathrm{~g}$ de feijão provocou a mortalidade de $100 \%$ dos adultos de $Z$. subfasciatus um dia após a infestação (Vendramim \& Procópio, 1996).

Oliveira \& Vendramim (1999) estudaram o efeito de óleos essenciais e pós de origem vegetal sobre adultos de $Z$. subfasciatus e verificaram que as porcentagens de repelência aumentaram diretamente com as dosagens e concentrações dos produtos utilizados. Os melhores resultados com óleos foram verificados para canela (Cinnamomum zeylanicum), seguindose nim ( $A$. indica) e louro (Laurus nobilis). Os pós foram menos eficientes que 
os óleos essenciais, com melhores resultados para o pó de louro, seguido por canela e pimenta-do-reino.

Os pós de $P$. nigrum e folhas de $C$. zeylanicum causaram alta mortalidade e reduziram significativamente o número de ovos viáveis e a emergência de adultos em $100 \%$ quando comparados com a testemunha. Pimenta-do-reino misturada a pó de Cuminum cyminum também apresentou resultados satisfatórios em relação a estes parâmetros (Oliveira et al., 1999).

\subsubsection{Efeito sobre A. obtectus}

Salas \& Hernandez (1985), estudando o efeito de alguns óleos vegetais, verificaram que os óleos de soja, mamona, coco, gergelim e oliva foram tóxicos aos adultos de $A$. obtectus, causando alta mortalidade (até $100 \%$ após 1 hora) na dosagem de $10 \mathrm{ml} / \mathrm{kg}$ de sementes.

Avaliando o efeito de pós vegetais sobre algumas pragas de produtos armazenados, Lagunes-Tejeda \& Rodríguez (1989) verificaram que, para $A$. obtectus, dentre 64 pós testados, os mais eficientes foram os obtidos de Equisetum arvense, Hippocratea sp. e Sargassum vulgare.

A exemplo do que tinha sido constatado para $Z$. subfasciatus, Kayitare \& Ntezurubanza (1991) verificaram que, também para A. obtectus, folhas de $O$. americanum e $C$. procerum, apesar de terem sido tóxicas, não apresentaram efeito repelente sobre os adultos.

Óleos essenciais de gerânio, cipreste, eucalipto e amêndoa na forma de vapores foram testados por Stamopoulos (1991) contra A. obtectus, sendo que a maior ação repelente foi verificada com gerânio enquanto que o eucalipto reduziu a fecundidade e a viabilidade de ovos, e aumentou a mortalidade de larvas recém-eclodidas.

Niber et al. (1992) testaram extratos de $A$. indica (folhas e sementes), Chromolaena odorata (folhas), Cissampelos owariensis (folhas e raízes), Datura metel (sementes), Datura stramonium (sementes), $R$. communis 
(sementes), Erythrophleum suaveolens (folhas), Grewia carpinifolia (folhas), Sida acuta (folhas), Solanum nigrum (folhas) e Strophanthus hispidus (folhas) em relação a $A$. obtectus. Tal inseto se mostrou sensível a todos os materiais testados, sendo a maior toxicidade encontrada com $A$. indica, $R$. communis e $S$. nigrum, sendo que $S$. nigrum, $C$. owariensis e $E$. suaveolens também se mostraram bastante promissores.

A ação inseticida de $T$. riparia sobre $A$. obtectus foi verificada com a adição de folhas trituradas em concentrações superiores a $4 \%$,verificando-se redução da fecundidade e fertilidade destes insetos (Weaver et al.,1992).

Estudos realizados por Regnault et al. (1993) para determinar o efeito de 22 óleos essenciais de plantas aromáticas e medicinais sobre $A$. obtectus evidenciaram que isoprenóides e fenilpropanóides presentes em plantas do família Labiatae, dentre elas Origanum marjorana e Thymus serpyllum, foram bastante tóxicas a essa espécie.

Regnault \& Hamraoui (1993a) verificaram que plantas de Allium sativum, L. nobilis, Tilia cordata, Origanum serpyllum, Eucalyptus globulus, Andropogon nardus, T. serpyllum, Thymus vulgaris, Rosmarinus officinalis e Satureia hortensis mostraram bons efeitos na redução da oviposição e da sobrevivência de adultos de $A$. obtectus. Esses autores observaram também que Mentha piperita, Origanum vulgare e L. angustifolia provocaram redução satisfatória da sobrevivência dessa espécie (Regnault \& Hamraoui, 1993b).

Pimenta-do-reino moída, na concentração de $250 \mathrm{~g} / 60 \mathrm{~kg}$ de grãos, protegeu o feijão contra 0 ataque de $A$. obtectus durante oito meses de armazenamento e não afetou o poder germinativo das sementes (Faroni et al., 1995). O óleo de sementes de soja foi efetivo no controle até quatro meses de armazenamento.

Gakuru \& Buledi (1995), verificando o efeito de pós de Nicotiana tabacum e Cymbopogon citratus e do óleo de $R$. communis sobre A. obtectus, observaram, após cinco semanas, redução na infestação de 72,5, 74,5 e $49,5 \%$, respectivamente. 
O efeito dos pós de $R$. communis, G. coccinea, L. tridentata, Ribes ciliatum, C. tenuiflora, A. procumbens e $G$. tomentosa sobre A. obtectus foi estudada por Araya-González et al. (1996), que constataram resultados satisfatórios com os pós de R. communis e L. tridentata.

Ignatowicz \& Gersz (1997) avaliaram a repelência a $A$. obtectus provocada por 50 extratos de espécies vegetais, e verificaram que Matricaria chamomilla e Melilotus officinalis mostraram-se os mais repelentes em altas dosagens, seguidos por $T$. serpyllum, $T$. vulgaris e Artemisia dracunculus.

Em condições de laboratório, $A$. obtectus foi efetivamente controlado com óleo extraído de Lavandula officinalis, sendo que óleos extraídos de Origanum vulgare, $L$. nobilis, $T$. vulgaris e $R$. officinalis apresentaram menor efeito (Kalinovic et al., 1997).

Já Mateeva et al. (1997) verificaram que, em condições de campo e laboratório, extratos de plantas de $R$. communis nas dosagens de 0,5 e 1,0\% mostraram efeitos repelentes a adultos de $A$. obtectus.

Os pós provenientes de sementes e também os extratos de Trigonella foenum-graecum aplicados em feijão provocaram alta mortalidade e inibição na oviposição, além de diminuir a penetração de larvas de $A$. obtectus nos grãos. Estes materiais também provocaram efeitos na fecundidade e longevidade de adultos dessa espécie (Pemonge et al., 1997).

Testes realizados por Rakowski \& Ignatowicz (1997) mostraram que extratos de $M$. piperita e $A$. dracunculus reduziram a sobrevivência e fecundidade de $A$. obtectus.

Syam \& Annie (1997), estudando o efeito de extratos de plantas sobre $A$. obtectus, verificaram que o extrato de $A$. nardus apresentou efeito repelente a adultos e diminuiu a postura. Solução desse extrato a $3,5 \%$ foi altamente tóxica, dificultando a emergência de adultos desta espécie.

Três produtos comerciais naturais extraídos de $A$. indica (Cubanim - $\mathrm{t}$, Oleonim $80 \mathrm{CE}$ e Oleonim $50 \mathrm{CE}$ ) foram testados sobre $A$. obtectus por Perez et al. (1998). Nenhum dos produtos se mostrou altamente eficiente, 
porém diminuíram consideravelmente as populações em todos os experimentos. Os melhores resultados foram obtidos com Oleonim nas duas formulações testadas.

Kyamanywa et al. (1999) verificaram que pós de Nicotiana sp. e Chenopodium sp. foram efetivos no controle de $A$. obtectus.

Perez (1999) verificou a ação inseticida do óleo essencial de inflorescência, do extrato e do material vegetal liofilizado de Chrysanthemum coronarium sobre $A$. obtectus. O óleo essencial provocou alta repelência e mortalidade nessa espécie, enquanto que o material liofilizado apresentou-se pouco tóxico quando ingerido pelas larvas, apresentando efeito apenas no crescimento destas. $O$ extrato apresentou ação inseticida quando aplicado topicamente (30 $\mu \mathrm{g} / \mathrm{inseto})$.

Perez \& Pascual (1999) observaram que a destilação ao vapor de inflorescências de $C$. coronarium resulta num óleo essencial de coloração azul e odor desagradável, o qual, por aplicação tópica em larvas de A. obtectus, provoca alta mortalidade. 


\section{MATERIAL E MÉTODOS}

Os experimentos foram conduzidos nos laboratórios de Resistência de Plantas e de Plantas Inseticidas do Departamento de Entomologia, Fitopatologia e Zoologia Agrícola da ESALQ/USP à temperatura de $25 \pm 2^{\circ} \mathrm{C}$, umidade relativa de $60 \pm 10 \%$ e fotofase de 14 horas, com os carunchos Zabrotes subfasciatus (Boh.) e Acanthoscelides obtectus (Say) (Coleoptera: Bruchidae) em feijão armazenado.

Os insetos utilizados nos experimentos foram obtidos da criação estoque mantida no próprio laboratório, em feijão, Phaseolus vulgaris L., cultivar Bolinha. Essa criação era mantida em frascos de vidro de 2 a 3 litros, com a boca vedada com filó, e a cada 30 dias, o material era peneirado e os adultos utilizados para iniciar a infestação em novos frascos. Todos os experimentos foram desenvolvidos de forma independente para cada espécie de inseto.

Para os estudos de resistência, foram utilizados 12 genótipos de feijoeiro incluindo materiais melhorados com arcelina (Arc1, Arc2, Arc3 e Arc4) e sem essa proteína (IAC Carioca Aruã, IAC Carioca Pyatã, IAC Carioca Akytã, IAC Maravilha, IAC Una, IAC Bico de Ouro, Porrillo 70 e Goiano Precoce). As sementes dos genótipos utilizados foram fornecidas pelas Seções de Leguminosas e Genética do Instituto Agronômico de Campinas, multiplicadas em plantio realizado no campo experimental do Setor de Entomologia da ESALQ, colhidas e armazenadas até a utilização.

As espécies vegetais utilizadas para obtenção dos pós foram coletadas em diversos locais da área experimental da ESALQ/USP. Após a coleta, foram transferidas para estufa com circulação forçada de ar, regulada a 
$40^{\circ} \mathrm{C}$ para secagem, sendo posteriormente moídas, até se obter um pó fino. Os pós foram armazenados, individualmente, por espécie e por estrutura vegetal em recipientes de vidro hermeticamente fechados até a utilização.

Testaram-se várias espécies vegetais (Tabela 1 e Figuras 1 a 5) selecionadas com base em revisão de literatura e em informações coletadas com pesquisadores da área.

Tanto nos testes para determinação da bioatividade, como naqueles envolvendo os diferentes genótipos, utilizaram-se caixas plásticas circulares de $6,1 \mathrm{~cm}$ de diâmetro e 2,1 cm de altura.

\subsection{Efeito de pós vegetais sobre $Z$. subfasciatus e $A$. obtectus}

Para a realização dos testes, utilizou-se a concentração de $0,3 \mathrm{~g}$ de pó da substância de origem vegetal por $10 \mathrm{~g}$ de feijão (Vendramim \& Procópio, 1996).

\subsubsection{Avaliação da repelência sobre os adultos}

$\mathrm{Na}$ avaliação da repelência, cada espécie vegetal foi testada isoladamente, utilizando-se uma arena formada por cinco caixas plásticas circulares, sendo a caixa central interligada simetricamente às demais por tubos plásticos, em diagonal (Figura 6). Amostras de feijão tratadas com pós e testemunhas (sem pós) foram distribuídas, respectivamente, em dois recipientes simétricos opostos. No recipiente central foram liberados 10 casais recém-emergidos de uma das espécies de caruncho e, após 24 h, foi contado o número de insetos por recipiente. Para cada espécie vegetal e para cada espécie de inseto, foram utilizadas 10 repetições.

Os diversos tratamentos foram comparados entre si, através de um Índice de Repelência (IR), calculado pela fórmula $I R=2 G /(G+P)$, onde $\mathrm{G}=\%$ de insetos na planta teste e $\mathrm{P}=\%$ de insetos na testemunha. Os valores 
dos índices variam entre zero e dois, sendo que $I R=1$ indica planta neutra, $I R>1$ indica planta atraente e $\mid \mathrm{R}<1$ indica planta atraente. Este índice é uma adaptação da fórmula citada por Lin et al. (1990), para índice de consumo. Como margem de segurança para essa classificação, o desvio padrão de cada tratamento foi adicionado/subtraído do índice 1,00 (indicativo de neutralidade). Assim, a repelência ou atratividade de cada tratamento só foi considerada quando o IR do mesmo estava fora do intervalo 1,00 \pm DP.

\subsubsection{Avaliação da mortalidade dos adultos e oviposição}

Neste teste, foram liberados em cada recipiente, 10 casais recémemergidos de uma das espécies de inseto, utilizando-se 6 repetições para cada espécie/estrutura vegetal e para cada espécie de inseto.

A sobrevivência dos adultos foi avaliada diariamente, contando-se e retirando-se os indivíduos mortos durante 5 dias. Ao término desse período, os adultos sobreviventes foram retirados e contou-se o número de ovos férteis e inférteis por grão no caso de $Z$. subfasciatus e o número de ovos férteis e inférteis por recipiente no caso de $A$. obtectus (postura de forma dispersa no substrato). Após a contagem, os recipientes foram mantidos nas mesmas condições para avaliação do número de adultos emergidos. Isto foi feito diariamente, no período de 25 a 60 dias contar da infestação. A partir desses dados, calculou-se a porcentagem de ovos férteis em relação ao número total de ovos. 
Tabela 1. Espécies, partes utilizadas, nomes comuns e famílias das plantas testadas para Zabrotes subfasciatus e Acanthoscelides obtectus.

\begin{tabular}{lccc}
\hline \multicolumn{1}{c}{ Espécies } & Partes utilizadas & Nomes comuns & Famílias \\
\hline Azadirachta indica & Frutos & Nim & Meliaceae \\
Chenopodium ambrosioides (f.1 e f.2) ${ }^{1}$ & Parte aérea & Erva-de-santa-maria & Chenopodiaceae \\
Citrus reticulata (cv. Murcote) & Cascas dos frutos & Laranja 'Murcote' & Rutaceae \\
Citrus sinensis (cv. Pêra) & Cascas dos frutos & Laranja 'Pêra' & Rutaceae \\
Coriandrum sativum & Folhas & Coentro & Apiaceae \\
Eucalyptus citriodora & Folhas & Eucalipto cheiroso & Myrtaceae \\
Eucalyptus grandis & Folhas & Eucalipto comum & Myrtaceae \\
Euphorbia pulcherrima & Folhas & Bico-de-papagaio & Euphorbiaceae \\
Lafoensia glyptocarpa & Folhas e frutos & Mirindiba & Lythraceae \\
Lantana camara & Folhas & Lantana & Verbenaceae \\
Laurus nobilis & Folhas & Louro & Lauraceae \\
Melia azedarach & Cinamomo & Meliaceae \\
Mentha pulegium & Folhas, frutos e ramos & Poejo & Lamiaceae \\
Ocimum basilicum & Folhas & Alfavaca & Lamiaceae \\
Ocimum minimum & Folhas & Manjericão & Lamiaceae \\
Ricinus communis & Folhas & Mamona & Euphorbiaceae \\
Ruta graveolens & Folhas & Arruda & Rutaceae \\
Trichilia pallida & Folhas & Catiguá & Meliaceae \\
\hline I f forma & Folhas e ramos & &
\end{tabular}

$$
{ }^{1} \mathrm{f}=\text { forma }
$$



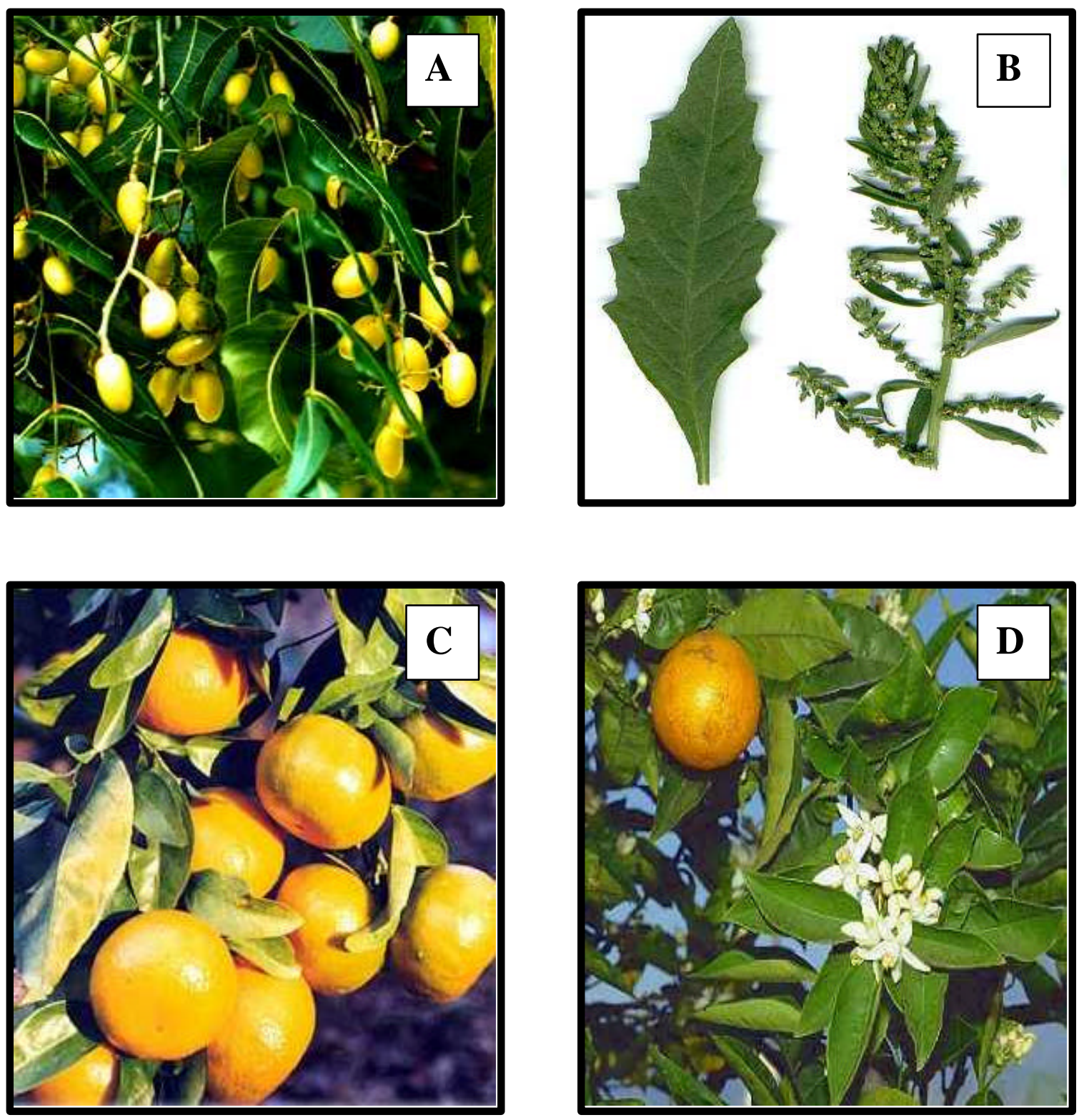

Figura 1- Plantas utilizadas nos testes com Zabrotes subfasciatus e Acanthoscelides obtectus.
A. Azadirachta indica (nim)
B. Chenopodium ambrosioides (erva-de-santa-maria)
C. Citrus reticulata (laranja 'Murcote')
D. Citrus sinensis (laranja 'Pêra') 

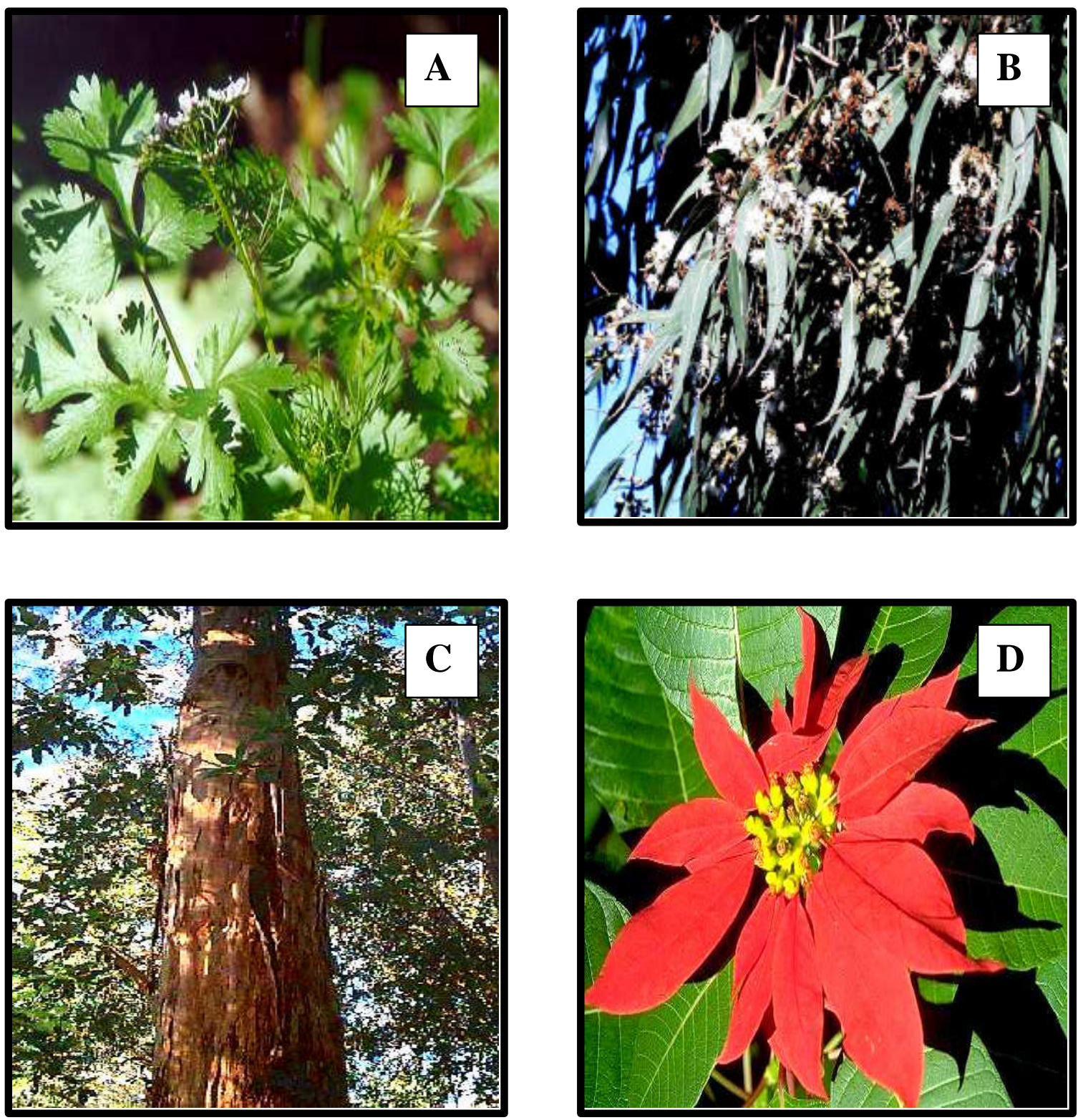

Figura 2- Plantas utilizadas nos testes com Zabrotes subfasciatus e Acanthoscelides obtectus.
A. Coriandrum sativum (coentro)
B. Eucalyptus citriodora (eucalipto cheiroso)
C. Eucalyptus grandis (eucalipto comum)
D. Euphorbia pulcherrima (bico-de-papagaio) 

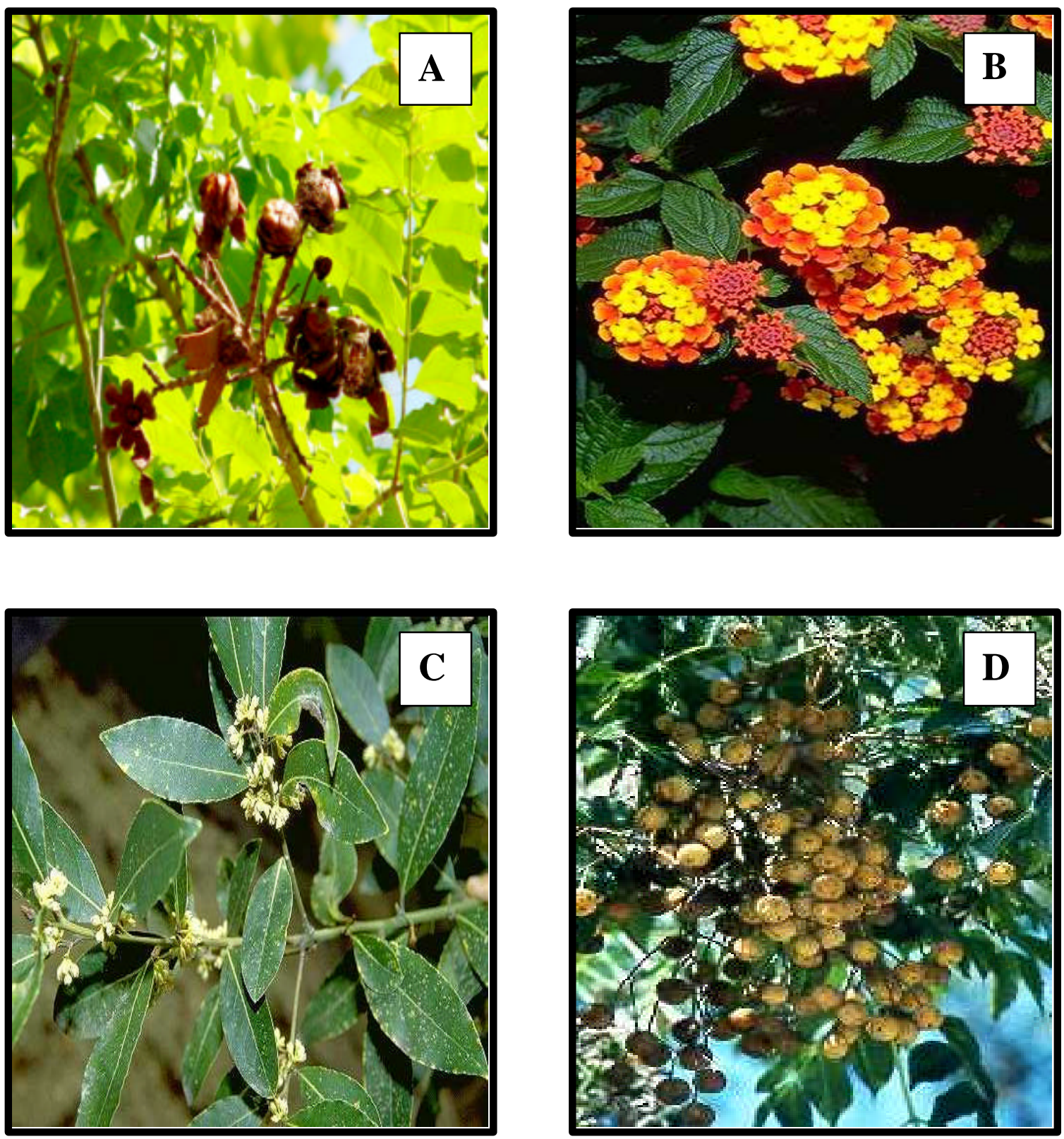

Figura 3- Plantas utilizadas nos testes com Zabrotes subfasciatus e Acanthoscelides obtectus.
A. Lafoensia glyptocarpa (mirindiba)
B. Lantana camara (lantana)
C. Laurus nobilis (louro)
D. Melia azedarach (cinamomo) 

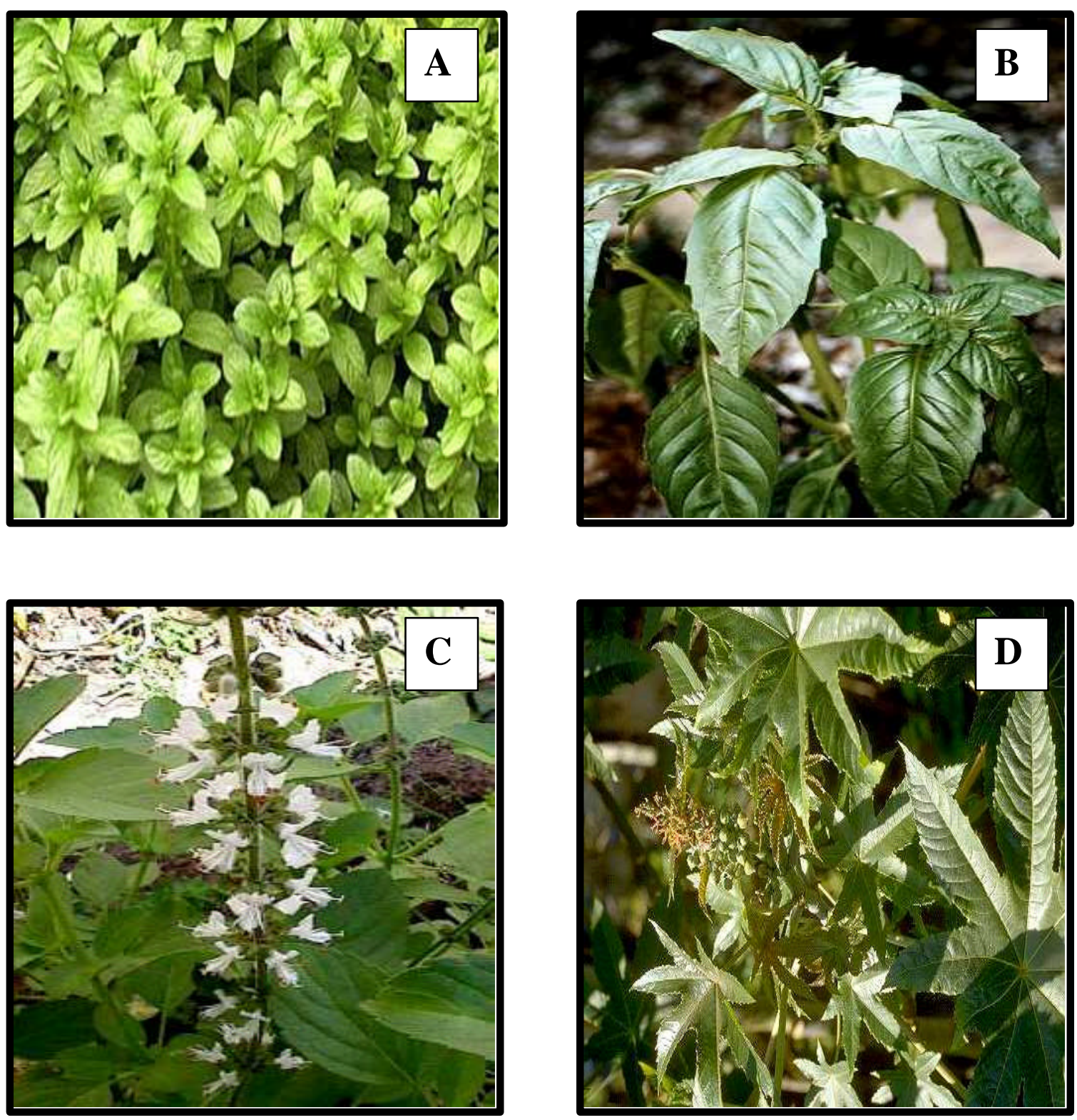

Figura 4- Plantas utilizadas nos testes com Zabrotes subfasciatus e Acanthoscelides obtectus.
A. Mentha pulegium (poejo)
B. Ocimum basilicum (alfavaca)
C. Ocimum minimum (manjericão)
D. Ricinus communis (mamona) 

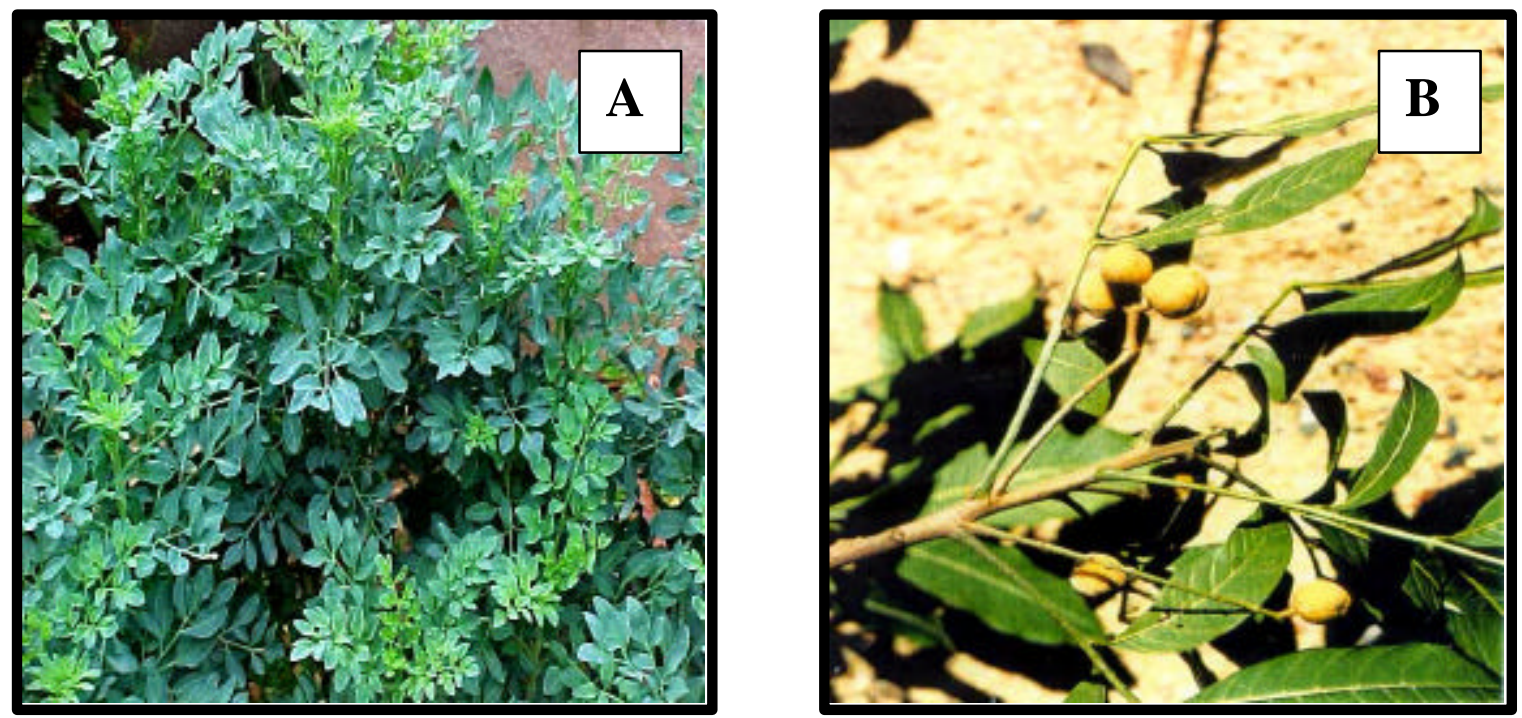

Figura 5- Plantas utilizadas nos testes com Zabrotes subfasciatus e Acanthoscelides obtectus.

A. Ruta graveolens (arruda)

B. Trichilia pallida (catiguá)

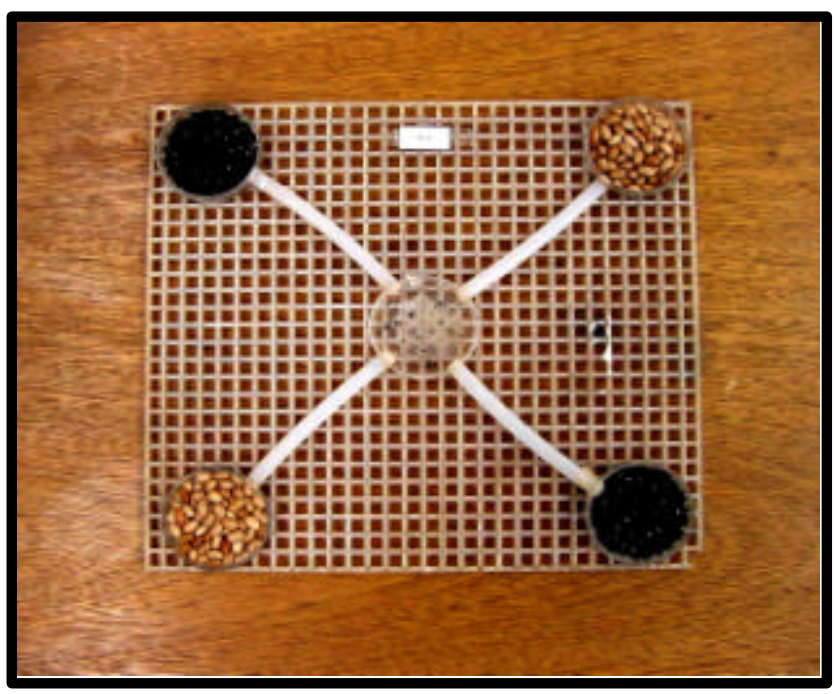

Figura 6- Arena utilizada nos experimentos de repelência com Zabrotes subfasciatus e Acanthoscelides obtectus. 


\subsection{Resistência de genótipos de feijoeiro a Z. subfasciatus e A. obtectus}

\subsubsection{Efeito dos genótipos sobre a preferência para oviposição}

\subsubsection{Teste com chance de escolha}

Este teste foi realizado em arena (bandeja) circular horizontal de alumínio (Oriani et al., 1996; Lara, 1997; Mazzonetto \& Boiça Jr., 1999) com 35 $\mathrm{cm}$ de diâmetro e $5 \mathrm{~cm}$ de altura, contendo em seu interior, uma placa de isopor com $34,5 \mathrm{~cm}$ de diâmetro e $2 \mathrm{~cm}$ de altura. Em sua periferia, foram feitas aberturas circulares eqüidistantes e com diâmetro um pouco superior ao diâmetro dos recipientes, de modo que estes podiam ser encaixados nas aberturas. O número de aberturas foi idêntico ao número de genótipos em teste. Em cada recipiente, colocaram-se $10 \mathrm{~g}$ de grãos dos diferentes genótipos, sendo liberados 84 adultos (proporção de 7 casais por genótipo). As arenas foram fechadas com tampas de mesmo diâmetro para impedir a fuga dos insetos e manter o ambiente escuro (Figura 7).

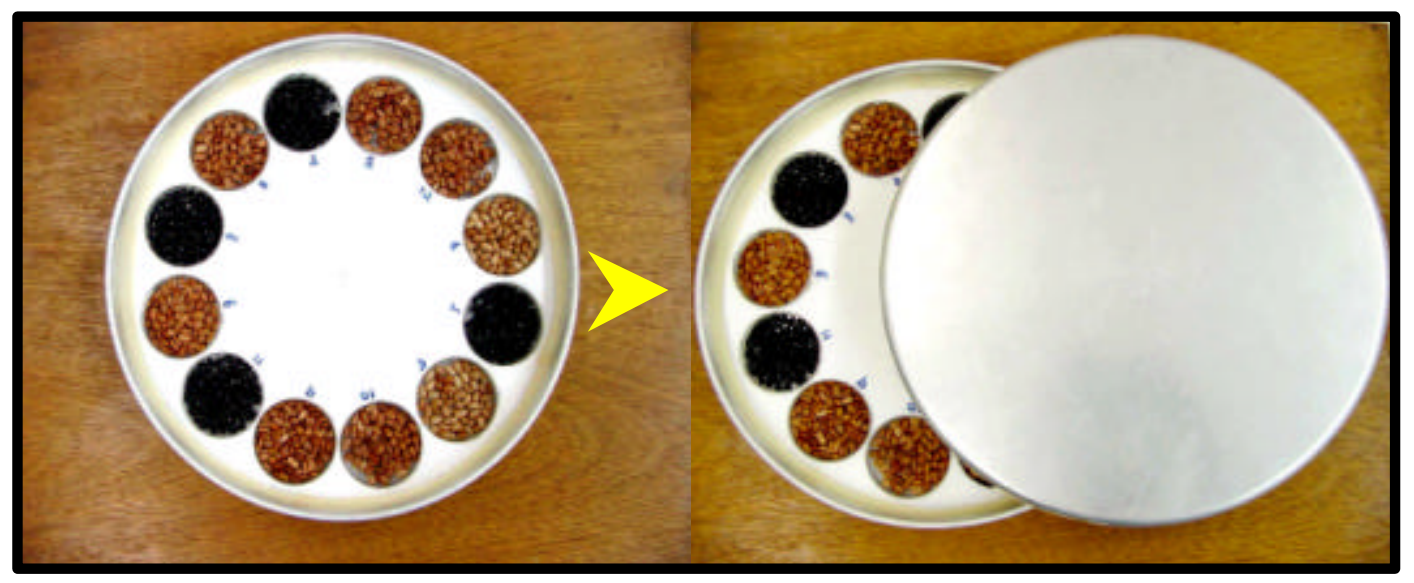

Figura 7- Arena (bandeja) circular de alumínio utilizada em testes com chance de escolha. 
Após 24 h, contou-se o número de indivíduos por genótipo para a determinação da atratividade dos insetos. Os insetos foram mantidos nos respectivos recipientes, nos quais os grãos permaneceram ainda disponíveis aos insetos por um período suplementar de 4 dias. Ao final desse período, os adultos sobreviventes foram retirados e foi contado o número de ovos férteis e inférteis por grão no caso de $Z$. subfasciatus e por recipiente no caso de $A$. obtectus. Para cada genótipo e cada espécie de inseto foram utilizadas 6 repetições.

\subsubsection{Teste sem chance de escolha}

Nesse experimento, 7 casais de cada espécie de adultos recémemergidos foram colocados por recipiente (contendo amostras de $10 \mathrm{~g}$ de grãos de cada um dos genótipos).

Os insetos permaneceram em contato com os grãos por 5 dias, avaliando-se, após esse período, a oviposição por meio da contagem do número de ovos férteis e inférteis. Para cada genótipo e espécie de inseto foram utilizadas 6 repetições.

\subsubsection{Efeito dos genótipos de feijoeiro sobre a biologia dos insetos}

Nesse teste, os adultos foram colocados nos recipientes (contendo os grãos de feijão) e retirados após 24 h (para se ter a certeza do dia de postura), ocasião em que foi feita a contagem do número de ovos férteis e inférteis. Após a contagem, os recipientes foram mantidos nas mesmas condições para avaliação do número de adultos emergidos, os quais foram sexados e pesados. Isto foi feito diariamente, no período de 25 a 60 dias a contar da infestação. A partir desses dados, calculou-se, para cada espécie de inseto, a viabilidade da fase imatura (em relação ao número total de ovos e ao número de ovos férteis), a duração do período de desenvolvimento (ovo à 
emergência do adulto) e o peso dos adultos. Dos adultos emergidos em cada genótipo foram separados 15 casais, os quais ficaram confinados individualmente em tubos de ensaio contendo $3 \mathrm{~g}$ de feijão 'Carioca' e tapados com plástico tipo PVC para evitar a fuga. Para estes insetos, avaliaram-se a longevidade e a fecundidade dos adultos provenientes dos respectivos genótipos, discriminando-se os ovos férteis e inférteis em cada tubo.

\subsection{Efeito associado de genótipos resistentes de feijoeiro e pós vegetais sobre Z. subfasciatus e A. obtectus}

Utilizaram-se nestes testes, 4 espécies vegetais e 4 genótipos de feijoeiro (1 suscetível e 3 resistentes) selecionados a partir dos experimentos descritos, respectivamente, nos itens 3.1 e 3.2.

\subsubsection{Avaliação da repelência sobre os adultos}

$\mathrm{Na}$ avaliação da repelência, foram feitos testes independentes para cada genótipo resistente, o qual foi comparado com o genótipo suscetível, utilizando-se sempre amostras tratadas com 0,3 g e não tratadas com os pós selecionados. Assim, em cada arena (Figura 6), os materiais tiveram a seguinte distribuição:

Caixa 1: genótipo resistente tratado com pó;

Caixa 2: genótipo suscetível tratado com pó;

Caixa 3: genótipo resistente não tratado com pó;

Caixa 4: genótipo suscetível não tratado com pó.

Para cada genótipo resistente e para cada espécie vegetal, foram utilizadas 10 repetições, sorteando-se, em cada uma delas, as posições 
ocupadas pelos quatro tratamentos. Os demais procedimentos foram semelhantes ao descrito no item 3.1.1.

\subsubsection{Estimativa da $\mathrm{CL}_{50}$ do pó de C. ambrosioides (f.2) para Z. subfasciatus e A. obtectus}

Para os testes de avaliação da mortalidade dos adultos e oviposição, do efeito na biologia e no dano causado pelos insetos, foram utilizadas as concentrações equivalentes à $C L_{50}$ determinada para cada espécie de insetos em relação ao pó de $C$. ambrosioides (f.2), utilizado como padrão. A partir de testes preliminares em que foram utilizadas diversas concentrações dos pós (misturados a $10 \mathrm{~g}$ de feijão) e 10 casais por repetição (3 repetições), foram estimadas as concentrações que mataram cerca de 5 e $95 \%$ dos insetos, as quais foram usadas na fórmula:

$$
q=n+1 \sqrt{a_{n} / a_{1}}
$$

onde:

$q$ = razão da progressão geométrica (p.g.)

$\mathrm{n}=$ número de concentrações a extrapolar

$a_{n}=$ limite superior da p.g. (concentração que provocou mortalidade de cerca de 95\%, determinada por meio de teste preliminar)

$a_{1}=$ limite inferior da p.g. (concentração que provocou mortalidade de cerca de $5 \%$, determinada por meio de teste preliminar)

Assim, foram determinadas as concentrações testadas $\left(a_{1} ; a_{1} q\right.$; $a_{1} q^{2} ; a_{1} q^{3} ; a_{1} q^{4}$ e $a_{1} q^{5}$ ), sendo o valor das $C L_{50}$ estimado por meio da análise de Probit com base no número de insetos mortos até o $5^{\circ}$ dia. 


\subsubsection{Avaliação da mortalidade dos adultos e oviposição}

Neste teste, foi utilizada metodologia semelhante à descrita no item 3.1.2, utilizando-se para cada genótipo, amostras tratadas com a concentração equivalente à $\mathrm{CL}_{50}$ e não tratadas com cada um dos pós selecionados, onde avaliou-se o número de insetos sobreviventes até o $5^{\circ}$ dia e o número de ovos férteis e inférteis conforme descrito no referido item.

\subsubsection{Efeito na biologia}

Neste teste, foi utilizada metodologia semelhante à descrita no item 3.2.2, utilizando-se para cada genótipo, amostras tratadas com a concentração equivalente à $\mathrm{CL}_{50}$ e não tratadas com cada um dos pós selecionados.

\subsubsection{Efeito no dano causado pelos insetos}

Neste teste, utilizaram-se amostras de grãos de feijão (10 g) de cada um dos genótipos, tratadas com a concentração equivalente à $C L 50$ e não tratadas com os pós selecionados. Em cada caixa, foram utilizados 10 casais, com 6 repetições para cada tratamento. Após 120 dias, foi feita nova pesagem para determinar a perda de peso dos grãos. Para correção do peso devido à variação da umidade do ambiente, utilizaram-se 3 caixas contendo $10 \mathrm{~g}$ de feijão de cada genótipo, porém sem infestação, as quais foram mantidas nas mesmas condições dos grãos infestados. Para se proceder a referida correção, considerou-se a média de perda ou ganho de peso das 3 repetições. 


\subsection{Análise estatística}

Os dados obtidos foram analisados estatisticamente pelo teste $\mathrm{F}$, sendo as médias comparadas pelo teste de Tukey, ao nível de $5 \%$ de probabilidade. Quando não foi possível a utilização dos referidos testes, a análise dos dados foi feita através de estatística não-paramétrica.

Nos testes do item 3.1.1, a análise dos dados foi feita através do teste $\mathrm{F}$, sendo as médias comparadas pelo teste "t" de Student, ao nível de 5\% de probabilidade.

Nos testes do item 3.3, a análise dos dados seguiu o esquema fatorial considerando-se como fatores, os genótipos e os pós vegetais. 


\section{RESULTADOS E DISCUSSÃO}

\subsection{Efeito de pós vegetais sobre Zabrotes subfasciatus (Boh.) e Acanthoscelides obtectus (Say)}

\subsubsection{Avaliação da repelência sobre os adultos}

\subsubsection{Z. subfasciatus}

Nos tratamentos à base de pós da parte aérea (caules, folhas, frutos e sementes) de Chenopodium ambrosioides (erva-de-santa-maria), f. (forma) 1 e f.2; de folhas de Eucalyptus citriodora (eucalipto cheiroso), Laurus nobilis (louro), Mentha pulegium (poejo), Ocimum basilicum (alfavaca), Ocimum minimum (manjericão) e Ruta graveolens (arruda) e de cascas dos frutos de Citrus reticulata (laranja 'Murcote') e Citrus sinensis (laranja 'Pêra'), as porcentagens de insetos atraídos foram menores do que nas respectivas testemunhas, podendo, por isso, os mesmos ser considerados repelentes com base nesse critério. As menores porcentagens de insetos atraídos foram observadas nos pós de $C$. ambrosioides (f.2), O. minimum, $C$. reticulata e $M$. pulegium, com, respectivamente, 7,57; 9,82; 10,00 e 11,08\% do total de insetos liberados nas arenas, sendo, portanto, as plantas mais repelentes para esta espécie de inseto. Com exceção dos pós de folhas de L. nobilis e de cascas dos frutos de $C$. sinensis, a ação repelente desses tratamentos foi confirmada pelos índices de repelência, os quais variaram de 0,15 a 0,62 (Tabela 2). 
L. nobilis, que apresentou efeito repelente no teste estatístico, foi estudada por Oliveira \& Vendramim (1999), que também verificaram também efeito repelente do pó proveniente desta espécie. Estes mesmos autores estudando o $\operatorname{nim}(A$. indica), verificaram efeito repelente a $Z$. subfasciatus. Efeitos promissores desta espécie vegetal também foram verificados por Mordue \& Blackwell (1993), o que não foi verificado neste experimento.

Opostamente, nos tratamentos com pós de folhas de Lafoensia glyptocarpa (mirindiba), Lantana camara (lantana) e Ricinus communis (mamona) e de ramos de Melia azedarach (cinamomo), as porcentagens de insetos atraídos foram maiores do que nas respectivas parcelas não tratadas, o que permitiria classificar os referidos materiais como tendo efeito atrativo a $Z$. subfasciatus. Com base nos índices de repelência, entretanto, essa atratividade só foi confirmada para L. glyptocarpa, tratamento em que foram constatados $63,72 \%$ do total de insetos liberados na arena e um índice de repelência de 1,27 (Tabela 2).

Resultados não satisfatórios com a utilização de $R$. communis também foram verificados por Araya-González et al. (1996), onde não se verificou efeito de repelência e nem de toxicidade a $Z$. subfasciatus.

Assim, levando-se em conta que cada pó vegetal só foi considerado ativo (repelente ou atrativo) quando isso foi constatado com base nos dois critérios (teste $t$ e índice de repelência), os tratamentos considerados repelentes foram a parte aérea de $C$. ambrosioides (f. 1 e f.2); as folhas de $E$. citriodora, $M$. pulegium, $O$. basilicum, $O$. minimum e $R$. graveolens e as cascas dos frutos de $C$. reticulata, enquanto o único pó atrativo foi o proveniente de folhas de L. glyptocarpa.

As demais espécies vegetais testadas, cujos índices de repelência estiveram dentro do intervalo de segurança (estabelecido com base no desvio padrão obtido em cada experimento), foram consideradas neutras, isto é, sem qualquer atividade sobre o comportamento da referida praga. 
Tabela 2. Repelência de adultos de Zabrotes subfasciatus por pós de origem vegetal.

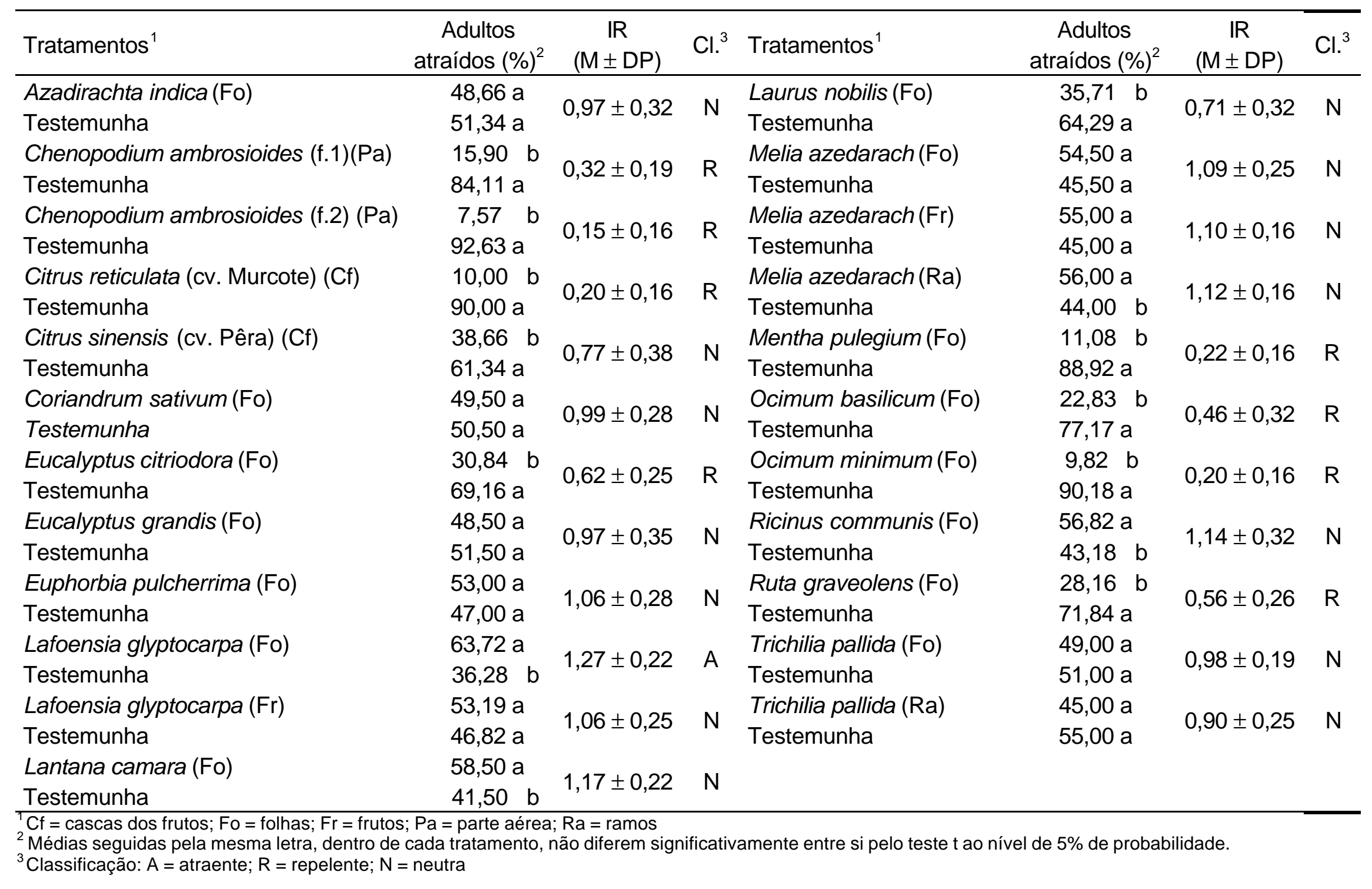




\subsubsection{A. obtectus}

Nos tratamentos àbase de pós da parte aérea de $C$. ambrosioides (f.1 e f.2); de folhas de E. citriodora, L. glyptocarpa, M. pulegium, O. basilicum, $O$. minimum e $R$. graveolens; de cascas dos frutos de $C$. reticulata e $C$. sinensis e de frutos de L. glyptocarpa e $M$. azedarach, as porcentagens de insetos atraídos foram menores do que nas respectivas testemunhas, podendo, os mesmos ser considerados repelentes com base nesse critério. As menores porcentagens de insetos atraídos foram observadas nos pós de $R$. graveolens, C. reticulata, C. ambrosioides (f.2) e C. sinensis, com, respectivamente, 28,43; 29,$34 ; 33,61$ e $33,68 \%$ do total de insetos liberados nas arenas, sendo então estes pós considerados os mais repelentes para esta espécie de inseto

Com base nos índices de repelência, entretanto, essa atividade não foi confirmada com os pós de folhas de L. glyptocarpa, $O$. basilicum e $O$. minimum e de frutos de $M$. azedarach. Para aqueles tratamentos em que a repelência foi confirmada, os índices variaram de 0,57 a 0,84 (Tabela 3).

Ao contrário do que foi observado para $Z$. subfasciatus, no caso de $A$. obtectus, nenhuma das espécies vegetais testadas apresentou efeito atrativo, quer com base no teste t, quer com base no índice de repelência.

Desse modo, considerando-se os critérios pré-estabelecidos, os únicos tratamentos com bioatividade foram aqueles com ação repelente representados pelos pós da parte aérea de $C$. ambrosioides (f.1 e f.2); de folhas de E. citriodora, M. pulegiume R. graveolens; de cascas dos frutos de $C$. reticulata e $C$. sinensis e de frutos de $L$. glyptocarpa.

As demais espécies vegetais testadas, com índices de repelência dentro do intervalo estabelecido com base no desvio padrão de cada experimento, foram consideradas neutras.

Efeitos repelentes a adultos de $A$. obtectus foram verificados utilizando R. communis por Mateeva et al. (1997), fato que não ocorreu neste experimento. 
Tabela 3. Repelência de adultos de Acanthoscelides obtectus por pós de origem vegetal.

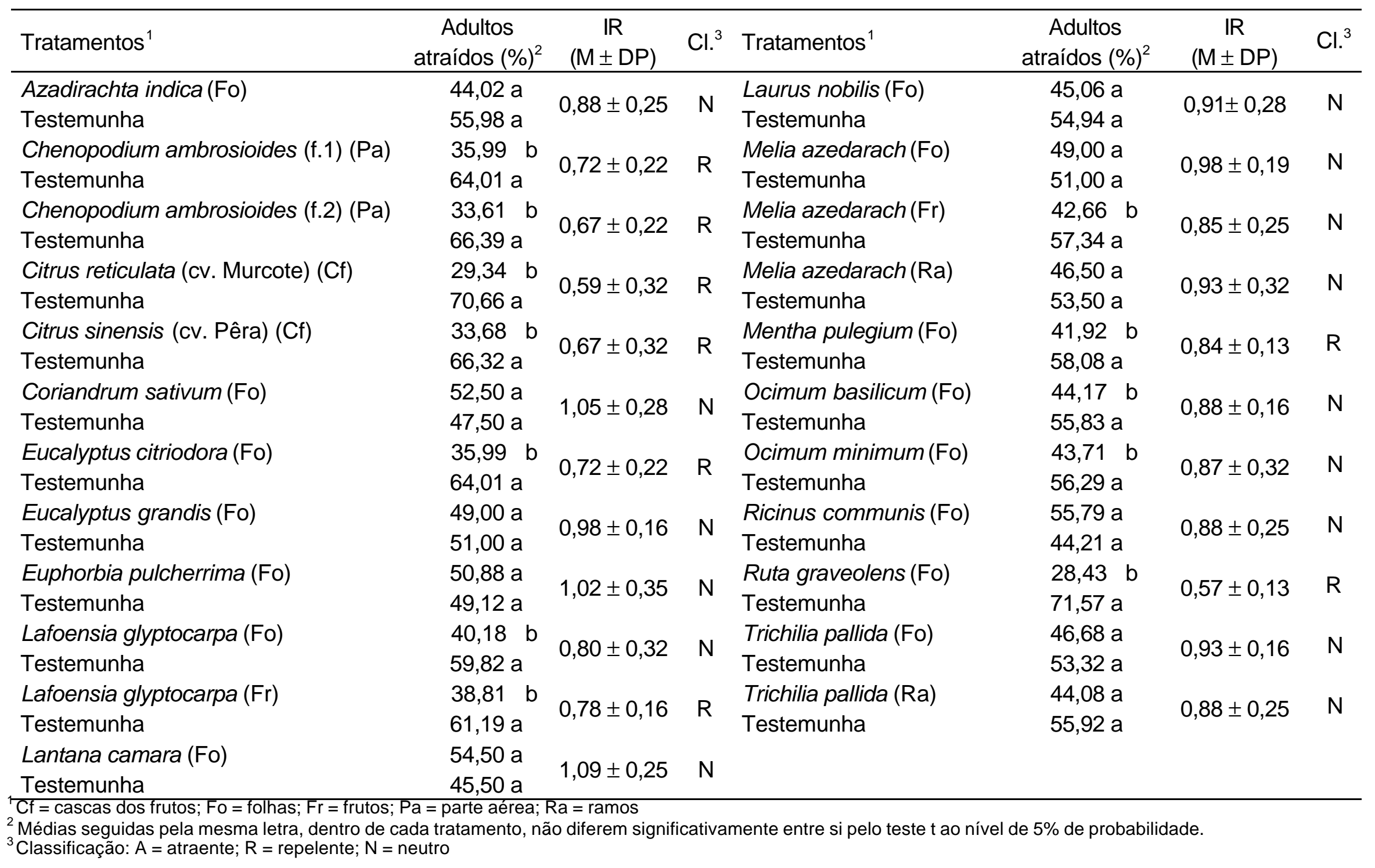


Comparando-se as duas espécies de insetos, verifica-se que ambas foram repelidas pelos pós da parte aérea de $C$. ambrosioides (f.1 e f.2); de folhas de E. citriodora, M. pulegium e R. graveolens e de cascas dos frutos de C. reticulata.

Por outro lado, pós de folhas de $O$. basilicum e $O$. minimum foram repelentes apenas para $Z$. subfasciatus, enquanto $C$. sinensis e frutos de $L$. glyptocarpa apresentaram efeito repelente apenas em relação a $A$. obtectus.

Dentre os diversos tratamentos testados, o único que apresentou atratividade foi o proveniente de folhas de L. glyptocarpa, a qual, ainda assim, ficou restrita a $Z$. subfasciatus.

\subsubsection{Avaliação da mortalidade dos adultos e oviposição}

\subsubsection{Z. subfasciatus}

No teste de sobrevivência dos adultos, foi verificado que dentre as 23 espécies vegetais testadas, $C$. ambrosioides (f.2), M. pulegium, $O$. basilicum e $R$. graveolens foram altamente tóxicas aos adultos de $Z$. subfasciatus, causando $100 \%$ de mortalidade ao final do período de avaliação ( $\left.5^{\circ} \mathrm{dia}\right)$. Opostamente, C. ambrosioides (f.1), $M$. azedarach (folhas) e $O$. minimum não causaram qualquer efeito na sobrevivência dos insetos, constatando-se ao $5^{0}$ dia, que todos os adultos estavam vivos, assemelhando-se ao tratamento sem pó (testemunha). Com L. glyptocarpa (folhas e frutos), C. sinensis, C. reticulata, A. indica e $R$. communis, as mortalidades (variáveis entre 10,00 e $15,83 \%$ ) foram maiores que na testemunha. Nas demais espécies vegetais testadas, a mortalidade variou de 0,83 a $9,17 \%$ (Tabela 4 ) .

Pó de C. ambrosioides apresentou efeito semelhante ao constatado por Vendramim \& Procópio (1996), onde, na concentração de $0,075 \mathrm{~g} / 20 \mathrm{~g}$ de feijão, provocou a mortalidade de $100 \%$ dos adultos de $Z$. subfasciatus um dia após a infestação. 
Tabela 4. Mortalidade ( $5^{0} \mathrm{dia}$ ) de adultos de Zabrotes subfasciatus em grãos de feijão tratados com pós de origem vegetal.

\begin{tabular}{|c|c|}
\hline Tratamentos $^{1}$ & Mortalidade $(\%)^{2}$ \\
\hline Testemunha & $\mathrm{a}$ \\
\hline Chenopodium ambrosioides (f.1) (Pa) & a \\
\hline Melia azedarach (Fo) & a \\
\hline Ocimum minimum $(\mathrm{Fo})$ & 0 \\
\hline Eucalyptus grandis (Fo) & $0,83 a b$ \\
\hline Trichilia pallida (Fo) & $1,67 \mathrm{ab}$ \\
\hline Trichilia pallida $(\mathrm{Ra})$ & $1,67 \mathrm{ab}$ \\
\hline Melia azedarach (Fr) & $1,67 \mathrm{ab}$ \\
\hline Melia azedarach (Ra) & $1,67 \mathrm{ab}$ \\
\hline Lantana camara (Fo) & $2,50 \mathrm{ab}$ \\
\hline Laurus nobilis (Fo) & $2,50 \mathrm{ab}$ \\
\hline Eucalyptus citriodora (Fo) & $4,17 \mathrm{abc}$ \\
\hline Coriandrum sativum (Fo) & $5,00 \mathrm{abcd}$ \\
\hline Euphorbia pulcherrima (Fo) & 9,17 abcde \\
\hline Azadirachta indica (Fo) & 10,00 bcde \\
\hline Citrus sinensis (cv. Pêra) (Cf) & 12,50 \\
\hline Citrus reticulata (cv. Murcote) (Cf) & 13,33 \\
\hline Lafoensia glyptocarpa (Fr) & 14,17 \\
\hline Ricinus communis (Fo) & 15,00 \\
\hline Lafoensia glyptocarpa (Fo) & 15,83 \\
\hline Chenopodium ambrosioides (f.2) (Fo) & 100,00 \\
\hline Mentha pulegium (Fo) & 100,00 \\
\hline Ocimum basilicum $(\mathrm{Fo})$ & 100,00 \\
\hline Ruta graveolens (Fo) & 100,00 \\
\hline $\mathrm{F}$ & $390,48^{* *}$ \\
\hline CV & 21,12 \\
\hline
\end{tabular}


Em relação à oviposição, além dessas quatro espécies vegetais que causaram a morte dos insetos antes que fizessem postura, houve ainda redução no número total de ovos com o emprego de L. glyptocarpa (frutos), $R$. communis e Euphorbia pulcherrima (Tabela 5). Além desses materiais, nenhum outro provocou redução no número de ovos férteis (Tabela 6).

A menor porcentagem de ovos férteis (em relação ao número total de ovos) foi constatada no tratamento com $O$. minimum $(73,61 \%)$, diferindo dos tratamentos com E. pulcherrima, $M$. azedarach (ramos, folhas e frutos), Eucalyptus grandis, L. glyptocarpa (folhas e frutos), C. reticulata e R. communis, além da testemunha, onde as referidas porcentagens variaram entre 86,07 e 83,32\% (Tabela 6).

Com base nos resultados de mortalidade e oviposição, foram selecionados para testes posteriores com $Z$. subfasciatus, os pós de $C$. ambrosioides (f.2), M. pulegium, O. basilicum e R. graveolens.

\subsubsection{A. obtectus}

Os pós de C. ambrosioides (f.2) e Coriandrum sativum provocaram efeito tóxico aos adultos de $A$. obtectus causando mortalidade de $100 \%$ dos insetos até o $5^{0}$ dia diferindo de todos os outros tratamentos. $C$. sinensis ('Pêra') e L. glyptocarpa (folhas) provocaram mortalidade de 25,00 e $19,17 \%$, respectivamente, valores maiores que os registrados em outros 13 tratamentos (incluindo a testemunha), nos quais a mortalidade variou entre 0,83 e 7,50\%. Nas demais espécies testadas ocorreram valores intermediários (Tabela 7).

Alguns resultados deste experimento não estiveram de acordo com trabalhos realizados anteriormente, onde outras espécies vegetais apresentaram efeito tóxico a $A$. obtectus, tais como $R$. communis (Salas \& Hernandez, 1985; Niber et al., 992; Gakuru \& Buledi, 1995 e Araya-González et al., 1996), A. indica (Niber et al., 1992) e L. nobilis (Regnault \& Hamraoui, 1993a e Kalinovic et al., 1997). 
Tabela 5. Oviposição total de Zabrotes subfasciatus em grãos de feijão tratados com pós de origem vegetal.

\begin{tabular}{|c|c|}
\hline Tratamentos $^{1}$ & $\begin{array}{l}\mathrm{N}^{0} \text { total de ovos/ } \\
\text { recipiente }^{2}\end{array}$ \\
\hline Trichilia pallida (Fo) & 238,67 a \\
\hline Trichilia pallida $(\mathrm{Ra})$ & 227,17 a \\
\hline Laurus nobilis (Fo) & 224,17 a \\
\hline Melia azedarach (Ra) & 219,50 a \\
\hline Melia azedarach (Fr) & $206,33 a b$ \\
\hline Eucalyptus grandis (Fo) & $197,00 a b$ \\
\hline Lantana camara (Fo) & $196,50 a b$ \\
\hline Ocimum minimum (Fo) & $195,83 a b$ \\
\hline Melia azedarach (Fo) & $195,83 a b$ \\
\hline Azadirachta indica (Fo) & $186,33 a b$ \\
\hline Lafoensia glyptocarpa (Fo) & $186,00 a b$ \\
\hline Citrus reticulata (cv. Murcote) (Cf) & $183,50 a b$ \\
\hline Testemunha & $181,00 a b$ \\
\hline Eucalyptus citriodora (Fo) & $180,00 a b$ \\
\hline Coriandrum sativum (Fo) & $173,50 a b$ \\
\hline Chenopodium ambrosioides (f.1) (Pa) & $172,00 a b$ \\
\hline Citrus sinensis (cv. Pêra) (Cf) & $169,17 \mathrm{ab}$ \\
\hline Euphorbia pulcherrima (Fo) & $144,67 \quad b$ \\
\hline Ricinus communis (Fo) & $140,83 \quad b$ \\
\hline Lafoensia glyptocarpa (Fr) & $138,67 \quad b$ \\
\hline Ocimum basilicum (Fo) & $0,00 \quad c$ \\
\hline Ruta graveolens (Fo) & $0,00 \quad c$ \\
\hline Chenopodium ambrosioides (f.2) (Pa) & $0,00 \quad c$ \\
\hline Mentha pulegium (Fo) & $0,00 \quad c$ \\
\hline $\mathrm{F}$ & $30,34^{\star *}$ \\
\hline $\mathrm{CV}$ & 21,53 \\
\hline
\end{tabular}


Tabela 6. Oviposição ( $n^{0}$ e \% de ovos férteis) de Zabrotes subfasciatus em grãos de feijão tratados com pós de origem vegetal.

\begin{tabular}{|c|c|c|}
\hline \multirow{2}{*}{ Tratamentos $^{1}$} & \multicolumn{2}{|c|}{ Ovos férteis $^{2}$} \\
\hline & $\mathrm{N}^{\circ} /$ recipiente & \% em relação ao total \\
\hline Trichilia pallida (Fo) & $196,33 \mathrm{ab}$ & $82,25 a b c$ \\
\hline Trichilia pallida (Ra) & $183,33 a b c$ & $80,52 a b c$ \\
\hline Laurus nobilis (Fo) & $182,00 \mathrm{abc}$ & $81,09 a b c$ \\
\hline Melia azedarach (Ra) & 202,67 a & 85,81 a \\
\hline Melia azedarach (Fr) & 175,00 abdce & $84,73 a b$ \\
\hline Eucalyptus grandis (Fo) & $182,17 \mathrm{abc}$ & $85,22 a b$ \\
\hline Lantana camara (Fo) & 157,33 abcde & $79,91 \mathrm{abc}$ \\
\hline Ocimum minimum (Fo) & 144,67 abcde & $73,61 \quad c$ \\
\hline Melia azedarach (Fo) & $177,67 \mathrm{abcd}$ & $83,58 \mathrm{ab}$ \\
\hline Azadirachta indica (Fo) & 152,83 abcde & $82,18 \mathrm{abc}$ \\
\hline Lafoensia glyptocarpa (Fo) & 139,00 bcde & $83,52 a b$ \\
\hline Citrus reticulata (cv. Murcote) (Cf) & 151,67 abcde & $82,32 a b$ \\
\hline Testemunha & 150,00 abcde & $82,33 a b$ \\
\hline Eucalyptus citriodora (Fo) & 147,83 abcde & $82,24 a b c$ \\
\hline Coriandrum sativum (Fo) & 141,83 abcde & $82,05 a b c$ \\
\hline Chenopodium ambrosioides (f.1) (Pa) & 133,50 cde & 77,12 bc \\
\hline Citrus sinensis (cv. Pêra) (Cf) & 140,17 bcde & $81,93 \mathrm{abc}$ \\
\hline Euphorbia pulcherrima (Fo) & 125,17 cde & 86,07 a \\
\hline Ricinus communis (Fo) & 117,83 de & $83,39 a b$ \\
\hline Lafoensia glyptocarpa (Fr) & 115,50 & $83,59 a b$ \\
\hline Ocimum basilicum (Fo) & 0,00 & - \\
\hline Ruta graveolens (Fo) & 0,00 & - \\
\hline Chenopodium ambrosioides (f.2) (Pa) & 0,00 & - \\
\hline Mentha pulegium (Fo) & 0,00 & - \\
\hline $\mathrm{F}$ & $29,98^{* *}$ & $2,97^{* *}$ \\
\hline$\frac{\mathrm{CV}}{\mathrm{Cf}=\mathrm{C}}$ & $\frac{21,53}{\text { arte área }}$ & 5,01 \\
\hline
\end{tabular}


Tabela 7. Mortalidade ( $\left.5^{0} \mathrm{dia}\right)$ de adultos de Acanthoscelides obtectus em grãos de feijão tratados com pós de origem vegetal.

\begin{tabular}{|c|c|}
\hline Tratamentos $^{1}$ & Mortalidade $(\%)^{2}$ \\
\hline Testemunha & $0,83 \mathrm{a}$ \\
\hline Ocimum minimum (Fo) & $0,83 \mathrm{a}$ \\
\hline Melia azedarach $(\mathrm{Fr})$ & $0,83 \mathrm{a}$ \\
\hline Eucalyptus grandis (Fo) & $1,67 \mathrm{a}$ \\
\hline Laurus nobilis (Fo) & $2,50 \mathrm{a}$ \\
\hline Mentha pulegium (Fo) & $2,50 \mathrm{a}$ \\
\hline Eucalyptus citriodora (Fo) & $3,33 \mathrm{ab}$ \\
\hline Ocimum basilicum (Fo) & $3,33 a b$ \\
\hline Azadirachta indica (Fo) & $5,83 a b$ \\
\hline Trichilia pallida $(\mathrm{Ra})$ & $5,83 \mathrm{ab}$ \\
\hline Melia azedarach (Ra) & $5,83 a b$ \\
\hline Melia azedarach (Fo) & $5,83 a b$ \\
\hline Ruta graveolens (Fo) & $7,50 \mathrm{ab}$ \\
\hline Citrus reticulata (cv. Murcote) (Cf) & $10,00 \mathrm{abc}$ \\
\hline Ricinus communis (Fo) & $11,67 \mathrm{abc}$ \\
\hline Euphorbia pulcherrima (Fo) & $12,50 \mathrm{abc}$ \\
\hline Lantana camara (Fo) & $13,33 a b c$ \\
\hline Trichilia pallida (Fo) & $14,17 \mathrm{abc}$ \\
\hline Chenopodium ambrosioides (f.1) (Pa) & $14,17 \mathrm{abc}$ \\
\hline Lafoensia glyptocarpa (Fr) & $16,67 \mathrm{abc}$ \\
\hline Lafoensia glyptocarpa (Fo) & $19,17 \mathrm{bc}$ \\
\hline Citrus sinensis (cv. Pêra) (Cf) & $25,00 \quad c$ \\
\hline Chenopodium ambrosioides (f.2) (Pa) & 100,00 \\
\hline Coriandrum sativum (Fo) & $100,00 \quad d$ \\
\hline $\mathrm{F}$ & $72,52^{\star *}$ \\
\hline CV & 48,02 \\
\hline
\end{tabular}

$\mathrm{Cf}=$ cascas dos frutos; $\mathrm{Fo}=$ folhas; $\mathrm{Fr}$ = frutos; $\mathrm{Pa}=$ parte aérea; $\mathrm{Ra}=$ ramos

${ }^{2}$ Médias seguidas pela mesma letra, não diferem significativamente entre si pelo teste de Tukey ao nível de $5 \%$ de probabilidade. 
No que se refere à oviposição (Tabela 8 e 9), além dos dois tratamentos que provocaram mortalidade total de adultos, nenhum outro provocou redução no número de ovos, considerando-se tanto o número total como o número de ovos férteis. A menor porcentagem de ovos férteis (em relação ao número total de ovos) para essa espécie de caruncho foi constatada no tratamento com O. minimum (76,46\%), a qual diferiu de um total de 11 tratamentos (incluindo a testemunha) nos quais os valores variaram entre 81,44 e $79,48 \%$. Valores inferiores à testemunha (81,44\%) também foram encontrados nos tratamentos utilizando L. glyptocarpa (folhas), L. camara, C. ambrosioides (f.1), C. sinensis e E. pulcherrima.

Regnault \& Hamraoui (1993a) verificaram que plantas de L. nobilis mostraram bons efeitos na redução da oviposição de adultos de A. obtectus, fato não ocorrido neste experimento.

Com base nos dados de mortalidade e oviposição, foram selecionados para testes posteriores com $A$. obtectus os pós de $C$. ambrosioides (f.2), C. sativum. C. sinensis e L. glyptocarpa (folhas).

Comparando-se as duas espécies de insetos, constatou-se que $C$. ambrosioides (f.2) provocou alto efeito tóxico para ambas as espécies, causando a mortalidade de $100 \%$ dos insetos até o $5^{0}$ dia. Já M. pulegium, $O$. basilicum e $R$. graveolens que provocaram alto efeito tóxico para $Z$. subfasciatus ( $100 \%$ de mortalidade), não apresentaram tal efeito quando utilizadas para $A$. obtectus. Por outro lado, $C$. sativum, que causou mortalidade total em $A$. obtectus, não teve eficiência quando utilizada para $Z$. subfasciatus.

Com O. minimum, ocorreu o efeito mais acentuado sobre a oviposição de Z. subfasciatus, com resultados satisfatórios também para $A$. obtectus que se mostrou sensível quanto a esta variável na comparação com outros pós, principalmente os de $C$. sinensis e $R$. graveolens. 
Tabela 8. Oviposição total de Acanthoscelides obtectus em grãos de feijão tratados com pós de origem vegetal.

\begin{tabular}{|c|c|}
\hline Tratamentos $^{1}$ & $\begin{array}{l}\mathrm{N}^{0} \text { total de ovos/ } \\
\text { recipiente }\end{array}$ \\
\hline Melia azedarach (Ra) & 191,00 a \\
\hline Lafoensia glyptocarpa (Fo) & $189,33 a b$ \\
\hline Melia azedarach (Fr) & $186,67 \mathrm{abc}$ \\
\hline Euphorbia pulcherrima (Fo) & $186,00 \mathrm{abc}$ \\
\hline Ocimum basilicum $(\mathrm{Fo})$ & $185,83 a b c$ \\
\hline Lafoensia glyptocarpa $(\mathrm{Fr})$ & $185,17 \mathrm{abc}$ \\
\hline Trichilia pallida $(\mathrm{Ra})$ & $184,67 \mathrm{abc}$ \\
\hline Eucalyptus citriodora (Fo) & $183,33 \mathrm{abc}$ \\
\hline Trichilia pallida (Fo) & $178,67 \mathrm{abc}$ \\
\hline Azadirachta indica (Fo) & $177,50 \mathrm{abc}$ \\
\hline Eucalyptus grandis (Fo) & $177,17 \mathrm{abc}$ \\
\hline Ocimum minimum $(\mathrm{Fo})$ & $176,50 \mathrm{abc}$ \\
\hline Chenopodium ambrosioides (f.1) (Pa) & $176,17 \mathrm{abc}$ \\
\hline Citrus reticulata (cv. Murcote) (Cf) & $175,67 \mathrm{abc}$ \\
\hline Melia azedarach (Fo) & $175,00 \mathrm{abc}$ \\
\hline Laurus nobilis (Fo) & $172,83 a b c$ \\
\hline Lantana camara (Fo) & $172,83 \mathrm{abc}$ \\
\hline Mentha pulegium (Fo) & $170,33 \mathrm{abc}$ \\
\hline Ricinus communis (Fo) & $167,83 \mathrm{abc}$ \\
\hline Testemunha & $167,50 \mathrm{abc}$ \\
\hline Ruta graveolens (Fo) & 161,67 bc \\
\hline Citrus sinensis (cv. Pêra) (Cf) & $159,67 \quad c$ \\
\hline Chenopodium ambrosioides (f.2) (Pa) & 0,00 \\
\hline Coriandrum sativum (Fo) & 0,00 \\
\hline $\mathrm{F}$ & $84,99^{\star *}$ \\
\hline$\frac{\mathrm{CV}}{\mathrm{Cf}=\text { cascas dos frutos: } \mathrm{Fo}=\text { folhas: } \mathrm{Fr}=\text { fruto }}$ & $\frac{8,29}{\text { rea: } \mathrm{Ra}=\text { ramo: }}$ \\
\hline
\end{tabular}


Tabela 9. Oviposição ( $\mathrm{n}^{0}$ e \% de ovos férteis) de Acanthoscelides obtectus em grãos de feijão tratados com pós de origem vegetal.

\begin{tabular}{|c|c|c|}
\hline \multirow{2}{*}{ Tratamentos $^{1}$} & \multicolumn{2}{|c|}{ Ovos férteis ${ }^{2}$} \\
\hline & $\mathrm{N}^{\circ} /$ recipiente & \% em relação ao total \\
\hline Melia azedarach $(\mathrm{Ra})$ & $152,33 \mathrm{a}$ & $79,55 a b c$ \\
\hline Lafoensia glyptocarpa (Fo) & $147,33 a b$ & $77,83 \mathrm{~cd}$ \\
\hline Melia azedarach $(\mathrm{Fr})$ & $150,50 \mathrm{a}$ & $80,71 \mathrm{abc}$ \\
\hline Euphorbia pulcherrima (Fo) & $145,83 a b$ & $78,41 \mathrm{bcd}$ \\
\hline Ocimum basilicum (Fo) & $145,67 \mathrm{ab}$ & $78,51 \mathrm{abcd}$ \\
\hline Lafoensia glyptocarpa $(\mathrm{Fr})$ & $146,17 a b$ & $79,06 \mathrm{abcd}$ \\
\hline Trichilia pallida (Ra) & $146,67 a b$ & $79,49 a b c$ \\
\hline Eucalyptus citriodora (Fo) & $146,67 \mathrm{ab}$ & $80,12 a b c$ \\
\hline Trichilia pallida (Fo) & $141,83 \mathrm{abc}$ & $79,42 \mathrm{abcd}$ \\
\hline Azadirachta indica (Fo) & $139,33 \mathrm{abc}$ & $78,57 \mathrm{abcd}$ \\
\hline Eucalyptus grandis (Fo) & $142,33 a b c$ & $80,39 a b c$ \\
\hline Ocimum minimum (Fo) & $134,83 \mathrm{abc}$ & $76,46 \quad d$ \\
\hline Chenopodium ambrosioides (f.1) (Pa) & $137,33 a b c$ & $77,99 \mathrm{bcd}$ \\
\hline Citrus reticulata (cv. Murcote) (Cf) & $139,67 \mathrm{abc}$ & $79,55 \mathrm{abc}$ \\
\hline Melia azedarach (Fo) & $141,67 \mathrm{abc}$ & $80,91 a b$ \\
\hline Laurus nobilis (Fo) & $137,00 \mathrm{abc}$ & $79,48 \mathrm{abc}$ \\
\hline Lantana camara (Fo) & $134,50 \mathrm{abc}$ & $77,83 \mathrm{~cd}$ \\
\hline Mentha pulegium (Fo) & $135,17 \mathrm{abc}$ & $79,43 \mathrm{abcd}$ \\
\hline Ricinus communis (Fo) & $133,67 a b c$ & $79,69 a b c$ \\
\hline Testemunha & $136,33 \mathrm{abc}$ & 81,44 a \\
\hline Ruta graveolens (Fo) & $128,50 \mathrm{bc}$ & $79,54 a b c$ \\
\hline Citrus sinensis (cv. Pêra) (Cf) & $124,83 \mathrm{c}$ & $78,30 \mathrm{bcd}$ \\
\hline Chenopodium ambrosioides (f.2) (Pa) & $0,00 \quad d$ & - \\
\hline Coriandrum sativum (Fo) & $0,00 \mathrm{~d}$ & - \\
\hline $\mathrm{F}$ & $114,62^{\star *}$ & $4,06^{\star *}$ \\
\hline CV & 7,15 & 1,79 \\
\hline
\end{tabular}




\subsection{Resistência de genótipos de feijoeiro a Z. subfasciatus e $A$. obtectus}

\subsubsection{Efeito dos genótipos sobre a preferência para oviposição}

\subsubsection{Teste com chance de escolha}

\subsection{Z. subfasciatus}

Os genótipos de feijoeiro menos atrativos aos adultos de $Z$. subfasciatus, 24 horas após a liberação, foram IAC Bico de Ouro $(10,17$ insetos) e IAC Carioca Pyatã (10,50 insetos), os quais diferiram do genótipo Porrillo $70(20,17)$. O número de insetos atraídos pelos demais genótipos, variável entre 11,50 e 18,33 insetos, não diferiu dos anteriormente citados (Tabela 10).

Tabela 10. Número de adultos de Zabrotes subfasciatus atraídos por genótipos de feijoeiro, após 24 horas, em teste com chance de escolha.

\begin{tabular}{lc}
\hline \multicolumn{1}{c}{ Genótipos } & $\mathrm{N}^{\circ}$ de insetos atraídos \\
\hline Porrillo 70 & $20,17 \mathrm{a}$ \\
IAC Maravilha & $18,33 \mathrm{ab}$ \\
IAC Una & $18,00 \mathrm{ab}$ \\
Goiano Precoce & $15,67 \mathrm{ab}$ \\
Arc2 & $13,83 \mathrm{ab}$ \\
IAC Carioca Akytã & $13,63 \mathrm{ab}$ \\
Arc3 & $12,17 \mathrm{ab}$ \\
Arc1 & $12,00 \mathrm{ab}$ \\
IAC Carioca Aruã & $11,83 \mathrm{ab}$ \\
Arc4 & $11,50 \mathrm{ab}$ \\
IAC Carioca Pyatã & $10,50 \mathrm{~b}$ \\
IAC Bico de Ouro & $10,17 \mathrm{~b}$ \\
\hline F & $3,24^{\star *}$ \\
CV & 32,22 \\
\hline Médias seguidas pela mesma letra, não diferem significativamente entre si pelo teste de Tukey ao nível \\
de 5\% de probabilidade.
\end{tabular}


No que se refere à preferência para oviposição, com chance de escolha, o único genótipo que diferiu dos demais foi o Goiano Precoce, no qual o número de ovos $(247,17)$ foi superior ao registrado em todos os demais genótipos que apresentaram médias variáveis entre 138,83 e 180,33 ovos. Apesar da não ocorrência de diferença estatística em relação aos demais genótipos (com exceção de Goiano Precoce), os materiais contendo a proteína arcelina apresentaram tendência de serem menos ovipositados. A distribuição dos materiais mais e menos preferidos para oviposição se alterou quando foi considerado o número de ovos férteis. Nesse caso, embora o genótipo Goiano Precoce tivesse se mantido como o mais ovipositado $(208,17)$, Porrillo 70 também apresentou um número de ovos relativamente alto $(156,50)$, diferindo dos genótipos Arc2, Arc3, Arc1, IAC Carioca Pyatã e IAC Carioca Akytã, nos quais o número de ovos variou entre 112,33 e 119,00, sendo os menos preferidos para oviposição. Em relação à porcentagem de ovos férteis, o menor valor foi registrado em Arc2 (79,43\%) diferindo dos verificados nos genótipos Porrillo 70 (86,52\%), Arc4 (86,40\%), IAC Una (86,32\%), IAC Bico de Ouro $(86,17 \%)$ e IAC Maravilha (85,82\%), ocorrendo nos demais materiais valores intermediários (Tabela 11).

Em experimento realizado por Wanderley et al.(1997), nos genótipos Arc1, Arc2, Arc3 e Arc4 ocorreu número total de ovos semelhantes ao constatado em 'Porrillo 70' e em outras cultivares comerciais testadas. Porém, Schoonhoven et al. (1983) constataram redução de oviposição em acessos silvestres, que posteriormente tiveram 0 fator de resistência identificado como sendo a proteína arcelina (Osborn et al., 1988). Também Lara (1997) não verificou diferenças no número total de ovos, em teste com chance de escolha entre materiais contendo Arc1, 2, 3 e 4 e as testemunhas suscetíveis 'Porrillo 70' e IAPAR MD-808, embora o número de ovos tenha sido relativamente menor nos materiais com arcelina. 
Tabela 11. Oviposição e porcentagem de ovos férteis de Zabrotes subfasciatus, em genótipos de feijoeiro, após 5 dias, em teste com chance de escolha.

\begin{tabular}{|c|c|c|c|c|c|}
\hline \multirow{2}{*}{ Genótipo } & \multicolumn{4}{|c|}{$\mathrm{N}^{\circ}$ de ovos/recipiente } & \multirow{2}{*}{$\begin{array}{c}\% \text { de ovos } \\
\text { férteis }{ }^{1}\end{array}$} \\
\hline & Total & & Férte & & \\
\hline Goiano Precoce & 247,17 & $\mathrm{a}$ & 208,17 & $\mathrm{a}$ & $84,40 \quad a b c$ \\
\hline Porrillo 70 & 180,33 & $b$ & 156,50 & b & 86,52 a \\
\hline IAC Maravilha & 151,33 & $b$ & 129,67 & bc & $85,82 a b$ \\
\hline IAC Bico de Ouro & 147,67 & $b$ & 127,33 & bc & 86,17 a \\
\hline IAC Una & 147,50 & $b$ & 127,83 & bc & 86,32 a \\
\hline IAC Carioca Aruã & 146,33 & b & 120,33 & bc & $82,30 \mathrm{abc}$ \\
\hline IAC Carioca Akytã & 144,17 & $\mathrm{~b}$ & 119,00 & $\mathrm{C}$ & $82,53 \mathrm{abc}$ \\
\hline IAC Carioca Pyatã & 143,33 & $b$ & 116,33 & C & 80,97 \\
\hline Arc2 & 141,67 & $b$ & 112,33 & c & 79,43 \\
\hline Arc1 & 141,33 & $b$ & 116,83 & c & $82,68 \mathrm{abc}$ \\
\hline Arc4 & 140,17 & $b$ & 121,17 & bc & 86,40 a \\
\hline Arc3 & 138,83 & $\mathrm{~b}$ & 115,83 & $\mathrm{C}$ & $83,45 \mathrm{abc}$ \\
\hline$F$ & \multicolumn{2}{|c|}{$12,21^{* *}$} & \multicolumn{2}{|c|}{$12,34^{* *}$} & $4,91^{\star *}$ \\
\hline CV & \multicolumn{2}{|c|}{13,84} & \multicolumn{2}{|c|}{14,34} & 3,15 \\
\hline
\end{tabular}

\subsection{A. obtectus}

No teste para verificação da atratividade dos insetos pelos diferentes genótipos, embora as médias tenham variado entre 10,00 e 17,00 insetos, não houve diferença estatística entre as médias (Tabela 12).

$\mathrm{Na}$ avaliação da oviposição (Tabela 13), verificou-se que, em relação ao número total de ovos, os genótipos IAC Maravilha, Arc2, Arc3, IAC Carioca Aruã e Arc1 (158,50, 155,50, 155,00, 153,50 e 152,83 ovos, respectivamente) foram os menos ovipositados, diferindo de 'Goiano Precoce' (183,00 ovos) que foi o mais preferido. Os resultados foram bastante semelhantes quando considerados apenas os ovos férteis, cujos números em Arc2, Arc3, Arc1 e IAC Carioca Aruã (126,50, 124,00, 124,00 e 123,83 respectivamente) foram inferiores ao observado em 'Goiano Precoce' (141,33 ovos). Em relação à porcentagem de ovos férteis, entretanto, nesse último 
Tabela 12. Número de adultos de Acanthoscelides obtectus atraídos por genótipos de feijoeiro, após 24 horas, em teste com chance de escolha.

\begin{tabular}{lc}
\hline \multicolumn{1}{c}{ Genótipos } & $\mathrm{N}^{\circ}$ de insetos atraídos \\
\hline IAC Maravilha & $17,00 \mathrm{a}$ \\
Goiano Precoce & $16,33 \mathrm{a}$ \\
IAC Bico de Ouro & $16,17 \mathrm{a}$ \\
IAC Una & $15,00 \mathrm{a}$ \\
Porrillo 70 & $14,67 \mathrm{a}$ \\
Arc4 & $14,00 \mathrm{a}$ \\
IAC Carioca Aruã & $13,67 \mathrm{a}$ \\
IAC Carioca Akytã & $13,50 \mathrm{a}$ \\
Arc3 & $13,33 \mathrm{a}$ \\
IAC Carioca Pyatã & $11,83 \mathrm{a}$ \\
Arc1 & $10,50 \mathrm{a}$ \\
Arc2 & $10,00 \mathrm{a}$ \\
\hline F & $2,066^{*}$ \\
CV & 27,71 \\
\hline Médias seguidas pela mesma letra, não diferem significativamente entre si pelo teste de Tukey ao nível \\
de 5\% de probabilidade.
\end{tabular}

Tabela 13. Oviposição e porcentagem de ovos férteis de Acanthoscelides obtectus, em genótipos de feijoeiro, após 5 dias, em teste com chance de escolha.

\begin{tabular}{|c|c|c|c|}
\hline \multirow{2}{*}{ Genótipo } & \multicolumn{2}{|c|}{$\mathrm{N}^{\circ}$ de ovos/recipiente } & \multirow{2}{*}{$\begin{array}{l}\% \text { de ovos } \\
\text { férteis }^{1}\end{array}$} \\
\hline & Total $^{1}$ & Férteis $^{1}$ & \\
\hline Goiano Precoce & $183,00 \mathrm{a}$ & $141,33 \mathrm{a}$ & $77,28 \quad b$ \\
\hline Porrillo 70 & $168,00 \mathrm{ab}$ & $134,50 \mathrm{ab}$ & $80,27 a b$ \\
\hline IAC Carioca Akytã & $163,83 \mathrm{ab}$ & $131,50 \mathrm{ab}$ & $80,32 a b$ \\
\hline IAC Una & $163,17 \mathrm{ab}$ & $130,17 \mathrm{ab}$ & $79,95 a b$ \\
\hline IAC Bico de Ouro & $162,50 \mathrm{ab}$ & $130,33 a b$ & $80,32 a b$ \\
\hline IAC Carioca Pyatã & $161,17 \mathrm{ab}$ & $129,83 a b$ & $80,66 \mathrm{ab}$ \\
\hline Arc4 & $160,17 \mathrm{ab}$ & $128,83 a b$ & $80,46 a b$ \\
\hline IAC Maravilha & $158,50 \mathrm{~b}$ & $127,67 \mathrm{ab}$ & $80,63 a b$ \\
\hline Arc2 & $155,50 \quad b$ & $126,50 \quad b$ & $81,40 \mathrm{a}$ \\
\hline Arc3 & $155,00 \quad b$ & $124,00 \quad b$ & $80,07 a b$ \\
\hline IAC Carioca Aruã & $153,50 \quad b$ & $123,83 \quad b$ & $80,79 a b$ \\
\hline Arc1 & $152,83 \quad b$ & $124,00 \quad b$ & $81,36 \mathrm{a}$ \\
\hline $\mathrm{F}$ & $2,80^{\star \star}$ & $3,02^{\star \star}$ & $1,58^{\text {ns }}$ \\
\hline CV & 7,44 & 5,45 & 2,55 \\
\hline
\end{tabular}

Médias seguidas pela mesma letra, não diferem significativamente entre si pelo teste de Tukey ao nível de $5 \%$ de probabilidade. 
genótipo registrou-se justamente o menor valor (77,28\%) diferenciando dos dados verificados em $\operatorname{Arc} 1(81,36 \%)$ e $\operatorname{Arc} 2(81,40 \%)$.

\subsubsection{Teste sem chance de escolha}

\subsection{Z. subfasciatus}

No teste sem chance de escolha, a menor preferência para oviposição de $Z$. subfasciatus só foi confirmada (em comparação ao teste com chance) no genótipo Arc3 (85,67 ovos), o qual diferiu dos genótipos IAC Carioca Pyatã e Bico de Ouro que foram os mais ovipositados com 125,67 e 124,33 ovos, respectivamente. Considerando-se apenas o número de ovos férteis, o genótipo Arc3 continuou sendo o menos ovipositado (66,00 ovos) diferenciando dos genótipos IAC Bico de Ouro (106,50), Goiano Precoce $(101,50)$, Porrillo $70(100,83)$ e IAC Carioca Pyatã $(98,33)$, nos quais foram constatados os maiores valores. Também em relação à porcentagem de ovos férteis, Arc3 se destacou como o material menos adequado ao inseto, verificando-se um valor de 76,47\%, diferindo dos dados encontrados em Porrillo 70 (86,92\%) e IAC Bico de Ouro (85,72\%) (Tabela 14).

Considerando-se os testes com e sem chance de escolha, verifica-se que houve pequena variação na oviposição de $Z$. subfasciatus nos diversos materiais testados, podendo-se destacar apenas o Arc3 como menos ovipositado no teste sem chance de escolha.

Os dados obtidos com o genótipo Arc3, o qual foi o menos preferido para oviposição neste teste, não se assemelham aos obtidos por Lara (1997), onde tal genótipo, em teste sem chance de escolha, não apresentou oviposição significativamente menor que os genótipos padrões suscetíveis Porrillo 70 e IAPAR MD-808. Por outro lado, Barbosa (1997) verificou que tal genótipo apresentou número total de ovos menor quando comparado com os 
genótipos Goiano Precoce e Porrillo 70, mas não diferente quando comparados com Arc1, Arc2 e Arc4.

Tabela 14. Oviposição e porcentagem de ovos férteis de Zabrotes subfasciatus, em genótipos de feijoeiro, após 5 dias, em teste sem chance de escolha.

\begin{tabular}{|c|c|c|c|}
\hline \multirow{2}{*}{ Genótipo } & \multicolumn{2}{|c|}{$\mathrm{N}^{\circ}$ de ovos/recipiente } & \multirow{2}{*}{$\begin{array}{c}\% \text { de ovos } \\
\text { férteis }^{1}\end{array}$} \\
\hline & Total $^{1}$ & Férteis $^{1}$ & \\
\hline IAC Carioca Pyatã & $125,67 \mathrm{a}$ & $98,33 a b$ & $77,72 \quad b c$ \\
\hline IAC Bico de Ouro & $124,33 a$ & $106,50 \mathrm{a}$ & $85,72 a b$ \\
\hline IAC Carioca Aruã & $120,00 a b$ & $96,17 \mathrm{abc}$ & $79,81 \mathrm{abc}$ \\
\hline IAC Carioca Akytã & $120,00 a b$ & $95,00 a b c$ & $79,26 a b c$ \\
\hline Goiano Precoce & $119,67 a b$ & $101,50 \mathrm{ab}$ & $85,27 \mathrm{abc}$ \\
\hline Porrillo 70 & $116,00 \mathrm{ab}$ & $100,83 \mathrm{ab}$ & 86,92 a \\
\hline Arc1 & $114,00 \mathrm{ab}$ & $93,33 a b c$ & $81,74 a b c$ \\
\hline Arc4 & $113,50 a b$ & $89,83 a b c$ & $79,99 a b c$ \\
\hline IAC Maravilha & $107,67 \mathrm{ab}$ & $86,67 \mathrm{abc}$ & $80,45 a b c$ \\
\hline IAC Una & $99,16 a b$ & $82,33 a b c$ & $83,08 \mathrm{abc}$ \\
\hline Arc2 & $92,33 a b$ & $72,33 \quad b c$ & $78,53 a b c$ \\
\hline Arc3 & $85,67 \quad b$ & $66,00 \quad c$ & $76,47 \quad \mathrm{c}$ \\
\hline $\mathrm{F}$ & $2,81^{\star \star}$ & $3,65^{\star \star}$ & $3,31^{\star \star}$ \\
\hline $\mathrm{CV}$ & 16,80 & 17,12 & 5,55 \\
\hline
\end{tabular}

\subsection{A. obtectus}

No teste sem chance de escolha com $A$. obtectus, embora 0 número total de ovos tenha variado entre 136,00 e 173,17 por recipiente, não houve diferença significativa entre as médias. Levando-se em conta somente 0 número de ovos férteis, verificaram-se diferenças apenas entre os genótipos IAC Carioca Aruã e IAC Carioca Akytã (com 140,67 e 139,50 ovos, respectivamente) e o genótipo Arc4 (106,67 ovos). No genótipo Arc4, foi encontrada a menor porcentagem de ovos férteis (78,39\%), diferindo dos valores observados nos genótipos Arc1 (83,49\%), IAC Bico de Ouro $(83,37 \%)$, 
Porrillo 70 (82,97\%), IAC Carioca Pyatã $(82,63 \%)$ e Goiano Precoce $(82,48 \%)$ (Tabela 15).

Tabela 15. Oviposição e porcentagem de ovos férteis de Acanthoscelides obtectus, em genótipos de feijoeiro, após 5 dias, em teste sem chance de escolha.

\begin{tabular}{lccc}
\hline \multirow{2}{*}{ Genótipo } & \multicolumn{2}{c}{$\mathrm{N}^{0}$ de ovos/recipiente } & $\begin{array}{c}\text { \% de ovos } \\
\text { férteis }^{1}\end{array}$ \\
\cline { 2 - 3 } & Total $^{1}$ & Férteis $^{1}$ & $81,42 \mathrm{ab}$ \\
IAC Carioca Aruã & $173,17 \mathrm{a}$ & $140,67 \mathrm{a}$ & $80,88 \mathrm{ab}$ \\
IAC Carioca Akytã & $172,83 \mathrm{a}$ & $139,50 \mathrm{a}$ & $81,78 \mathrm{ab}$ \\
IAC Una & $166,00 \mathrm{a}$ & $135,50 \mathrm{ab}$ & $82,22 \mathrm{ab}$ \\
IAC Maravilha & $159,33 \mathrm{a}$ & $130,83 \mathrm{ab}$ & $82,48 \mathrm{a}$ \\
Goiano Precoce & $159,17 \mathrm{a}$ & $131,00 \mathrm{ab}$ & $82,97 \mathrm{a}$ \\
Porrillo 70 & $158,00 \mathrm{a}$ & $130,83 \mathrm{ab}$ & $82,63 \mathrm{a}$ \\
IAC Carioca Pyatã & $146,50 \mathrm{a}$ & $120,83 \mathrm{ab}$ & $83,49 \mathrm{a}$ \\
Arc1 & $145,83 \mathrm{a}$ & $120,17 \mathrm{ab}$ & $83,37 \mathrm{a}$ \\
IAC Bico de Ouro & $145,33 \mathrm{a}$ & $121,17 \mathrm{ab}$ & $81,65 \mathrm{ab}$ \\
Arc2 & $144,83 \mathrm{a}$ & $118,17 \mathrm{ab}$ & $82,05 \mathrm{ab}$ \\
Arc3 & $136,67 \mathrm{a}$ & $112,00 \mathrm{ab}$ & $78,39 \mathrm{~b}$ \\
Arc4 & $136,00 \mathrm{a}$ & $106,67 \mathrm{~b}$ & $2,82^{* *}$ \\
\hline F & $2,21^{*}$ & $2,78^{* *}$ & 2,43 \\
CV & 13,78 & 12,58 & \\
\hline Médias seguidas pela mesma letra, não diferem significativamente entre si pelo teste de Tukey ao \\
nível de 5\% de probabilidade. \\
\multicolumn{4}{c}{}
\end{tabular}

Baldin (2001) trabalhando com A. obtectus, não verificou, em teste sem chance de escolha, diferenças na oviposição entre os materiais Arc1, Arc2, Arc3 e Arc4 quando comparou com outros materiais considerados suscetíveis, incluindo 'Porrillo 70'.

Analisando-se os testes com e sem chance de escolha, verifica-se que os diversos materiais testados são igualmente preferidos para oviposição por A. obtectus. 


\subsubsection{Efeito dos genótipos de feijoeiro sobre a biologia dos insetos}

\subsubsection{Z. subfasciatus}

No experimento em que os adultos de $Z$. subfasciatus foram confinados nos recipientes com grãos durante um dia apenas, não houve diferença no número total de ovos colocados nos diferentes genótipos, os quais variaram entre 20,50 e 30,00 por recipiente. $\mathrm{Na}$ avaliação apenas dos ovos férteis, entretanto os genótipos Arc1, 3, 4 e 2 foram menos ovipositados (14,33; 15,17; 15,17 e 15,33 ovos, respectivamente), diferindo do genótipo IAC Carioca Aruã (24,33 ovos). Embora as porcentagens de ovos férteis, nos quatro genótipos Arc tenham aparentemente apresentado os menores valores, a diferença estatística em relação ao maior valor $(81,21 \%$ encontrado em 'IAC Carioca Aruã'), só foi registrada para os Arc4 e 3 (66,72 e 67,86\%, respectivamente) (Tabela 16).

Tabela 16. Oviposição e porcentagem de ovos férteis de Zabrotes subfasciatus, após 24 horas, em genótipos de feijoeiro.

\begin{tabular}{|c|c|c|c|}
\hline \multirow{2}{*}{ Genótipo } & \multicolumn{2}{|c|}{$\mathrm{N}^{0}$ de ovos/recipiente } & \multirow{2}{*}{$\begin{array}{l}\% \text { de ovos } \\
\text { férteis }\end{array}$} \\
\hline & Total $^{1}$ & Férteis $^{1}$ & \\
\hline IAC Carioca Aruã & $30,00 \mathrm{a}$ & $24,33 a$ & $81,21 \mathrm{a}$ \\
\hline IAC Carioca Akytã & $27,00 \mathrm{a}$ & $20,83 a b$ & $75,98 a b$ \\
\hline Goiano Precoce & $24,83 a$ & $18,50 a b$ & $74,56 a b$ \\
\hline Arc4 & $22,67 \mathrm{a}$ & $15,17 \mathrm{~b}$ & $66,72 \quad b$ \\
\hline IAC Maravilha & $22,50 \mathrm{a}$ & $17,17 a b$ & $75,17 \mathrm{ab}$ \\
\hline Arc3 & $22,33 \mathrm{a}$ & $15,17 \mathrm{~b}$ & $67,86 \quad b$ \\
\hline IAC Carioca Pyatã & $22,33 \mathrm{a}$ & $16,83 a b$ & $74,89 a b$ \\
\hline Porrillo 70 & $22,33 \mathrm{a}$ & $16,83 a b$ & $74,76 a b$ \\
\hline IAC Una & $21,83 a$ & $17,17 \mathrm{ab}$ & $78,44 a b$ \\
\hline IAC Bico de Ouro & $21,83 a$ & $16,83 a b$ & $76,75 a b$ \\
\hline Arc2 & $21,33 \mathrm{a}$ & $15,33 \mathrm{~b}$ & $71,68 \mathrm{ab}$ \\
\hline Arc1 & $20,50 \mathrm{a}$ & $14,33 \mathrm{~b}$ & $69,85 \mathrm{ab}$ \\
\hline $\mathrm{F}$ & $1,81^{\mathrm{ns}}$ & $2,35^{*}$ & $2,59^{\star \star}$ \\
\hline $\mathrm{CV}$ & 21,19 & 25,64 & 8,29 \\
\hline
\end{tabular}


O período de desenvolvimento (ovo a adulto) apresentou grande variação, sendo que os maiores valores foram registrados nos genótipos Arc, nos quais os valores médios (variáveis entre 37,20 e 39,13 dias) foram significativamente superiores aos dos outros oito materiais, nos quais a variação foi de 29,75 a 31,56 dias. Na comparação entre os materiais Arc, o maior alongamento da fase imatura foi causado pelo Arc1, vindo a seguir o 4, o 2 e 0 3. Quanto aos demais genótipos, podem ser destacados IAC Carioca Pyatã e IAC Una que provocaram um alongamento da fase imatura quando comparados aos genótipos IAC Maravilha, Porrillo 70 e IAC Bico de Ouro. Não houve diferença, por outro lado, na viabilidade da fase imatura, cujos valores médios variaram de 79,89 a 93,23\% (Tabela 17).

Os resultados obtidos neste ensaio concordam com os de Harmsen et al. (1988) que relataram, na presença dos quatro tipos de arcelina (Arc1, Arc2, Arc3 e Arc4), aumento significativo no ciclo de vida de $Z$. subfasciatus (40,5 dias em média), sendo esses efeitos mais evidentes em Arc1, com 9 dias a mais de ciclo do que os insetos criados em 'Porrillo 70' (31,3 dias). Também Wanderley et al. (1997) verificaram aumento no ciclo do inseto nos genótipos Arc1, Arc2, Arc3 e Arc4, sendo que em Arc1 isso foi mais intenso com um alongamento de 11,52 dias. Barbosa (1997) verificou prolongamento no período ovo-adulto nestes mesmos genótipos quando comparados a 'Goiano Precoce' e 'Porrillo 70'.

A menor adequação dos genótipos Arc ao desenvolvimento de $Z$. subfasciatus foi confirmada pelos pesos dos adultos emergidos, já que tanto para machos como para fêmeas, os valores constatados nesses materiais foram menores que os verificados em todos os outros genótipos. Em relação aos machos, os pesos médios nos genótipos Arc variaram de 1,29 a 1,48 mg contra uma variação de 1,65 a 1,76 mg nos demais genótipos. Para as fêmeas, os pesos dos adultos nos materiais Arc variaram entre 2,18 e 2,63 mg, enquanto para os demais variaram de 3,20 a 3,35 mg. Na comparação entre os genótipos Arc, os menores pesos dos machos foram obtidos em Arc4, 1 e 3, 
enquanto para fêmeas, o menor valor foi constatado em Arc1. Nos demais genótipos, os valores foram bastante semelhantes entre si, não diferindo para fêmeas, enquanto para machos verificou-se diferença apenas entre 'IAC Carioca Aruã' (1,65 mg) e 'Goiano Precoce' (1,76 mg) (Tabela 18).

Tabela 17. Duração (dias) e viabilidade (\%) do período de desenvolvimento (ovo a adulto) de Zabrotes subfasciatus criado em genótipos de feijoeiro.

\begin{tabular}{|c|c|c|c|}
\hline Genótipo & \multicolumn{2}{|c|}{ Duração $^{1}$} & Viabilidade $^{1}$ \\
\hline Arc1 & \multicolumn{2}{|c|}{$39,13 a$} & 86,81 a \\
\hline Arc4 & \multicolumn{2}{|c|}{$38,73 a b$} & 93,23 a \\
\hline Arc2 & 37,49 & bc & $92,84 a$ \\
\hline Arc3 & 37,20 & C & 92,41 a \\
\hline IAC Carioca Pyatã & 31,56 & $d$ & 91,09 a \\
\hline IAC Una & 31,48 & d & 82,16 a \\
\hline IAC Carioca Akytã & 31,08 & de & 87,48 a \\
\hline IAC Carioca Aruã & 30,87 & de & 87,31 a \\
\hline Goiano Precoce & 30,26 & de & 88,57 a \\
\hline IAC Bico de Ouro & 30,04 & e & 79,89 a \\
\hline Porrillo 70 & 30,03 & e & $83,56 a$ \\
\hline IAC Maravilha & 29,75 & e & $87,65 \mathrm{a}$ \\
\hline $\mathrm{F}$ & $\overline{184,3}$ & $3^{\star \star}$ & $1,47^{\text {ns }}$ \\
\hline CV & 2,0 & & 9,85 \\
\hline
\end{tabular}

Barbosa (1997) observou nos genótipos Arc1 e Arc4, os insetos apresentaram tendência de menor peso apesar de não ter ocorrido diferênça estatística na comparação com insetos criados em 'Goiano Precoce' e 'Porrilo 70'. Também Lara (1997) verificou redução nos pesos de machos e fêmeas de insetos criados em Arc1, Arc3 e Arc4. 
Tabela 18. Peso (mg) de adultos de Zabrotes subfasciatus criados em genótipos de feijoeiro.

\begin{tabular}{lll}
\hline \multicolumn{1}{c}{ Genótipo } & Machos $^{1}$ & Fêmeas $^{1}$ \\
\hline Goiano Precoce & $1,76 \mathrm{a}$ & $3,23 \mathrm{a}$ \\
IAC Carioca Pyatã & $1,72 \mathrm{ab}$ & $3,25 \mathrm{a}$ \\
IAC Una & $1,71 \mathrm{ab}$ & $3,20 \mathrm{a}$ \\
IAC Bico de Ouro & $1,71 \mathrm{ab}$ & $3,35 \mathrm{a}$ \\
IAC Maravilha & $1,70 \mathrm{ab}$ & $3,32 \mathrm{a}$ \\
Porrillo 70 & $1,69 \mathrm{ab}$ & $3,20 \mathrm{a}$ \\
IAC Carioca Akytã & $1,69 \mathrm{ab}$ & $3,29 \mathrm{a}$ \\
IAC Carioca Aruã & $1,65 \mathrm{~b}$ & $3,22 \mathrm{a}$ \\
Arc2 & $1,48 \mathrm{c}$ & $2,63 \mathrm{~b}$ \\
Arc3 & $1,38 \mathrm{~d}$ & $2,57 \mathrm{~b}$ \\
Arc1 & $1,36 \mathrm{~d}$ & $2,18 \mathrm{c}$ \\
Arc4 & $1,29 \mathrm{~d}$ & $2,40 \mathrm{bc}$ \\
\hline F & $74,49^{\star *}$ & $46,53^{\star *}$ \\
CV & 2,98 & 5,14 \\
\hline Médias seguidas pela mesma letra, não diferem significativamente entre si pelo \\
teste de Tukey ao nível de 5\% de probabilidade.
\end{tabular}

Quanto à longevidade dos adultos emergidos nos diferentes genótipos, pôde-se verificar novamente que os genótipos contendo arcelina afetaram negativamente tanto os machos como as fêmeas, porém com diferenças não tão marcantes como foram observadas para o período de desenvolvimento e o peso. Em relação aos machos, os valores observados nos referidos materiais, variáveis entre 9,73 dias (Arc1) e 10,40 dias (Arc3) diferiram dos encontrados em IAC Maravilha (12,40 dias) e Goiano Precoce (12,33 dias). Para as fêmeas, as longevidades médias nos materiais Arc variaram de 8,73 (Arc1) a 9,33 dias (Arc2 e 3), diferindo daquelas encontradas em 'IAC Maravilha', 'IAC Bico de Ouro', 'IAC Carioca Akytã' e 'Porrillo 70', nos quais os valores variaram de 10,87 a 11,13 dias (Tabela 19).

A menor adequação dos genótipos contendo arcelina também foi também confirmada pelos dados de fecundidade. Assim, os números totais de ovos por fêmea para os indivíduos criados nesses genótipos (variáveis de 25,60 em Arc1 a 29,33 em Arc2) foram inferiores aos registrados nos demais genótipos excetuando-se IAC Carioca Aruã e IAC Carioca Akytã. Nestes dois 
últimos genótipos, foram observados valores intermediários, significativamente menores que em IAC Maravilha (42,67 ovos) e IAC Bico de Ouro (41,80 ovos). Também quando foi considerado apenas o número de ovos férteis, os quatro genótipos com a proteína arcelina apresentaram os menores valores médios; nesse caso, entretanto, o número de ovos variável entre 19,33 (Arc4) e 21,40 (Arc3) diferiu de todos os outros genótipos testados. Em relação a estes outros materiais, os menores valores foram verificados em 'IAC Carioca Aruã' (27,13 ovos), 'IAC Carioca Akytã' (27,40 ovos) e 'IAC Una' (27,87 ovos) diferindo daqueles observados em 'IAC Maravilha' e 'Porrillo 70' (33,27 e 33,07 ovos, respectivamente). A variável porcentagem de ovos férteis manteve a mesma tendência, com os menores valores sendo constatados nos quatro genótipos Arc, variando de $71,59 \%$ (Arc2) a 75,83\% (Arc1), diferindo dos dados obtidos com os genótipos Goiano Precoce $(82,00 \%)$ e Porrillo 70 (81,43\%). Nos materiais IAC Una e IAC Bico de Ouro, ocorreram resultados intermediários, diferindo dos dados obtidos em 'Goiano Precoce' e 'Porrillo 70' (Tabela 20).

Tabela 19. Longevidade (dias) de Zabrotes subfasciatus criado em genótipos de feijoeiro.

\begin{tabular}{|c|c|c|c|}
\hline Genótipo & Machos $^{1}$ & Fêm & $\operatorname{eas}^{1}$ \\
\hline IAC Maravilha & $12,40 \mathrm{a}$ & 11,13 & $\bar{a}$ \\
\hline Goiano Precoce & $12,33 a$ & 10,60 & $a b c$ \\
\hline IAC Carioca Pyatã & $12,20 a b$ & 10,00 & abcde \\
\hline IAC Bico de Ouro & $12,13 a b c$ & 11,07 & a \\
\hline Porrillo 70 & $11,80 \mathrm{abcd}$ & 10,87 & $a b$ \\
\hline IAC Una & 11,40 abcde & 10,20 & abcd \\
\hline IAC Carioca Akytã & 11,26 abcde & 10,87 & $a b$ \\
\hline IAC Carioca Aruã & 10,93 abcde & 9,60 & bcde \\
\hline Arc3 & 10,40 bcde & 9,33 & cde \\
\hline Arc2 & 10,33 & 9,33 & cde \\
\hline Arc4 & 10,27 & 8,87 & de \\
\hline Arc1 & 9,73 & 8,73 & e \\
\hline $\mathrm{F}$ & $5,78^{* \star}$ & \multicolumn{2}{|c|}{$8,31^{* *}$} \\
\hline $\mathrm{CV}$ & 13,24 & \multicolumn{2}{|c|}{11,57} \\
\hline
\end{tabular}


Considerando-se as diversas variáveis estudadas em relação à biologia de $Z$. subfasciatus, verifica-se que os materiais menos adequados ao desenvolvimento do inseto foram os quatro genótipos contendo arcelina, os quais apresentaram resistência por não-preferência para alimentação e/ou antibiose, já que nesses materiais ocorreu alongamento no período de desenvolvimento e redução no peso de adultos, na longevidade e na fecundidade. Este efeito negativo sobre o inseto foi maior nos genótipos Arc1, 3 e 4 .

Assim, levando-se em conta os experimentos de preferência para oviposição e de biologia, foram selecionados para testes posteriores os genótipos Arc1, Arc 3 e Arc4 como resistentes e 'Goiano Precoce' como suscetível.

Tabela 20. Fecundidade de Zabrotes subfasciatus criado em genótipos de feijoeiro.

\begin{tabular}{|c|c|c|c|}
\hline \multirow{2}{*}{ Genótipo } & \multicolumn{2}{|c|}{$\mathrm{N}^{\circ}$ de ovos/recipiente } & \multirow{2}{*}{$\begin{array}{l}\% \text { de ovos } \\
\text { férteis }{ }^{1}\end{array}$} \\
\hline & Total $^{1}$ & Férteis $^{1}$ & \\
\hline IAC Maravilha & $42,67 \mathrm{a}$ & 33,27 a & $78,05 \mathrm{abcd}$ \\
\hline IAC Bico de Ouro & $41,80 \mathrm{a}$ & 31,93 abc & $76,62 \mathrm{bcd}$ \\
\hline Porrillo 70 & $40,60 a b$ & 33,07 a & 81,43 a \\
\hline Goiano Precoce & $39,60 a b c$ & $32,47 a b$ & $82,00 \mathrm{a}$ \\
\hline IAC Una & $37,67 \mathrm{abc}$ & 27,87 bc & 73,89 \\
\hline IAC Carioca Pyatã & $36,67 a b c$ & $29,40 a b c$ & $80,20 a b c$ \\
\hline IAC Carioca Akytã & $34,20 \mathrm{bcd}$ & 27,40 & $80,30 a b$ \\
\hline IAC Carioca Aruã & 33,93 & 27,13 & $80,25 a b c$ \\
\hline Arc2 & 29,33 & 21,00 & $71,59 \quad \mathrm{e}$ \\
\hline Arc3 & 29,00 & 21,40 & 73,79 \\
\hline Arc4 & 25,67 & 19,33 & 75,67 \\
\hline Arc1 & 25,60 & 19,47 & 75,83 bcde \\
\hline $\mathrm{F}$ & $14,94^{\star \star}$ & $19,60^{\star *}$ & $11,92^{\star *}$ \\
\hline $\mathrm{CV}$ & 15,31 & 15,29 & 4,94 \\
\hline
\end{tabular}




\subsubsection{A. obtectus}

Para $A$. obtectus, as variáveis avaliadas (número total de ovos, número de ovos férteis e a viabilidade dos ovos colocados num período de 24 horas) não foram influenciadas pelos genótipos testados, embora tenham ocorrido algumas variações nos respectivos valores médios (28,00 a 37,67 ovos; 21,67 a 30,67 ovos férteis e 75,52 a 79,10\% de ovos férteis) (Tabela 21).

Tabela 21. Oviposição e porcentagem de ovos férteis de Acanthoscelides obtectus, após 24 horas em genótipos de feijoeiro

\begin{tabular}{|c|c|c|c|}
\hline \multirow{2}{*}{ Genótipo } & \multicolumn{2}{|c|}{$\mathrm{N}^{\circ}$ de ovos/recipiente } & \multirow{2}{*}{$\begin{array}{l}\% \text { de ovos } \\
\text { férteis }^{1}\end{array}$} \\
\hline & Total $^{1}$ & Férteis $^{1}$ & \\
\hline Porrillo 70 & $37,67 \mathrm{a}$ & $30,67 \mathrm{a}$ & 77,25 a \\
\hline Goiano Precoce & 37,33 a & 28,33 a & 75,91 a \\
\hline IAC Maravilha & 35,17 a & $27,67 \mathrm{a}$ & 78,69 a \\
\hline Arc4 & 31,67 a & $24,00 \mathrm{a}$ & 75,89 a \\
\hline IAC Bico de Ouro & 31,67 a & 24,33 a & 76,80 a \\
\hline Arc2 & 30,67 a & $23,83 a$ & 77,79 a \\
\hline IAC Una & 30,67 a & 23,50 a & 76,52 a \\
\hline Arc3 & 30,50 a & 23,17 a & 76,01 a \\
\hline IAC Carioca Pyatã & 30,33 a & $23,00 \mathrm{a}$ & 75,52 a \\
\hline IAC Carioca Aruã & 29,67 a & $22,83 a$ & 77,00 a \\
\hline Arc1 & $28,00 \mathrm{a}$ & $21,67 \mathrm{a}$ & 77,24 a \\
\hline IAC Carioca Akytã & $28,00 \mathrm{a}$ & 22,17 a & 79,10 a \\
\hline $\bar{F}$ & $1,55^{\mathrm{ns}}$ & $1,46^{\text {ns }}$ & $1,18^{\text {ns }}$ \\
\hline $\mathrm{CV}$ & 20,20 & 20,42 & 3,29 \\
\hline
\end{tabular}

Já em relação ao período de desenvolvimento, foi registrada diferença, observando-se que os insetos criados nos genótipos Arc1 (41,80 dias), IAC Carioca Akytã (40,76 dias), Arc3 (40,74 dias) e Arc4 (40,64 dias) apresentaram valores maiores que os registrados em Porrillo 70 (39,99 dias), Goiano Precoce $(40,07$ dias) e IAC Una $(40,08)$ (Tabela 22). No que se refere à viabilidade da fase imatura (Tabela 22), houve diferença apenas entre os dois 
valores extremos registrados nos genótipos IAC Carioca Pyatã $(77,52 \%)$ e Goiano Precoce $(89,00 \%)$.

Baldin (2001) verificou que os genótipos Arc1 e Arc2 aumentaram o período de desenvolvimento de $A$. obtectus, o que ocorreu com o genótipo Arc1 neste ensaio.

Tabela 22. Duração (dias) e viabilidade (\%) do período de desenvolvimento (ovo a adulto) de Acanthoscelides obtectus criado em genótipos de feijoeiro.

\begin{tabular}{lcc}
\hline \multicolumn{1}{c}{ Genótipo } & Duração $^{1}$ & Viabilidade $^{1}$ \\
\hline Arc1 & $41,80 \mathrm{a}$ & $83,89 \mathrm{ab}$ \\
IAC Carioca Akytã & $40,76 \mathrm{~b}$ & $89,00 \mathrm{a}$ \\
Arc3 & $40,74 \mathrm{~b}$ & $86,29 \mathrm{ab}$ \\
Arc4 & $40,64 \mathrm{bc}$ & $82,24 \mathrm{ab}$ \\
IAC Carioca Aruã & $40,51 \mathrm{bcd}$ & $84,01 \mathrm{ab}$ \\
IAC Carioca Pyatã & $40,50 \mathrm{bcd}$ & $81,22 \mathrm{ab}$ \\
Arc2 & $40,32 \mathrm{bcd}$ & $85,58 \mathrm{ab}$ \\
IAC Maravilha & $40,18 \mathrm{~cd}$ & $80,20 \mathrm{ab}$ \\
IAC Bico de Ouro & $40,13 \mathrm{~cd}$ & $77,52 \mathrm{~b}$ \\
IAC Una & $40,08 \mathrm{~d}$ & $81,46 \mathrm{ab}$ \\
Goiano Precoce & $40,07 \mathrm{~d}$ & $83,75 \mathrm{ab}$ \\
Porrillo 70 & $39,99 \mathrm{~d}$ & $83,46 \mathrm{ab}$ \\
\hline F & $19,84^{* *}$ & $2,33^{*}$ \\
CV & 0,68 & 5,80 \\
\hline Médias seguidas pela mesma letra, não diferem significativamente entre si pelo teste \\
de Tukey ao nível de 5\% de probabilidade.
\end{tabular}

Quanto ao peso, verifica-se que os menores valores, tanto para machos quanto para fêmeas, foram registrados nos insetos criados no genótipo Arc1 (3,54 e 4,53 mg, respectivamente) diferindo de todos os outros genótipos (nos quais ocorreram variações de 3,64 a 3,71 e de 4,64 a 4,73 mg, respectivamente), com exceção do genótipo IAC Una $(4,64 \mathrm{mg})$ no caso de fêmeas (Tabela 23). 
Tabela 23. Peso (mg) de adultos de Acanthoscelides obtectus criados em genótipos de feijoeiro.

\begin{tabular}{lcl}
\hline \multicolumn{1}{c}{ Genótipo } & Machos $^{1}$ & Fêmeas $^{1}$ \\
\hline Goiano Precoce & $3,71 \mathrm{a}$ & $4,72 \mathrm{a}$ \\
IAC Carioca Aruã & $3,69 \mathrm{a}$ & $4,73 \mathrm{a}$ \\
IAC Carioca Pyatã & $3,68 \mathrm{a}$ & $4,68 \mathrm{a}$ \\
Porrillo 70 & $3,68 \mathrm{a}$ & $4,72 \mathrm{a}$ \\
Arc3 & $3,67 \mathrm{a}$ & $4,66 \mathrm{a}$ \\
Arc2 & $3,66 \mathrm{a}$ & $4,69 \mathrm{a}$ \\
IAC Bico de Ouro & $3,66 \mathrm{a}$ & $4,68 \mathrm{a}$ \\
IAC Maravilha & $3,66 \mathrm{a}$ & $4,73 \mathrm{a}$ \\
IAC Una & $3,66 \mathrm{a}$ & $4,64 \mathrm{ab}$ \\
Arc4 & $3,65 \mathrm{a}$ & $4,68 \mathrm{a}$ \\
IAC Carioca Akytã & $3,64 \mathrm{a}$ & $4,68 \mathrm{a}$ \\
Arc1 & $3,54 \mathrm{~b}$ & $4,53 \mathrm{~b}$ \\
\hline F & $4,68^{* *}$ & $4,96^{* *}$ \\
CV & 1,28 & 1,26 \\
\hline Médias seguidas pela mesma letra, não diferem significativamente entre si pelo \\
teste de Tukey ao nivel de 5\% de probabilidade.
\end{tabular}

Dados semelhantes foram também obtidos por Baldin (2001), em teste sem chance de escolha, onde os insetos provenientes de Arc1, apesar de não apresentarem diferenças significativas em relação a outros genótipos, tenderam a apresentar menores pesos.

Nenhum efeito dos genótipos foi verificado em relação à longevidade dos adultos, cujos valores variaram de 14,40 a 16,40 dias (machos) e de 13,53 a 14,73 dias (fêmeas) (Tabela 24).

Também não houve efeito dos genótipos na fecundidade das fêmeas, tanto em relação ao número total de ovos (variação de 53,67 a 57,13 ovos) como em relação ao número de ovos férteis (variação de 43,40 a 47,73 ovos). Já quanto àporcentagem de ovos férteis, houve diferença entre o valor obtido no genótipo Arc1 (80,82\%) e os observados em 'Goiano Precoce' (83,81\%) e 'Porrillo 70' (84,38\%) (Tabela 25). 
Tabela 24. Longevidade (dias) de Acanthoscelides obtectus criado em genótipos de feijoeiro.

\begin{tabular}{lcc}
\hline \multicolumn{1}{c}{ Genótipo } & Machos $^{1}$ & Fêmeas $^{1}$ \\
\hline IAC Maravilha & $16,40 \mathrm{a}$ & $13,80 \mathrm{a}$ \\
IAC Carioca Pyatã & $16,13 \mathrm{a}$ & $14,73 \mathrm{a}$ \\
Goiano Precoce & $15,67 \mathrm{a}$ & $13,87 \mathrm{a}$ \\
IAC Carioca Akytã & $15,53 \mathrm{a}$ & $14,20 \mathrm{a}$ \\
IAC Carioca Aruã & $15,40 \mathrm{a}$ & $14,47 \mathrm{a}$ \\
Porrillo 70 & $15,20 \mathrm{a}$ & $13,80 \mathrm{a}$ \\
Arc2 & $15,00 \mathrm{a}$ & $14,33 \mathrm{a}$ \\
IAC Bico de Ouro & $15,00 \mathrm{a}$ & $13,53 \mathrm{a}$ \\
Arc3 & $14,93 \mathrm{a}$ & $13,53 \mathrm{a}$ \\
Arc1 & $14,60 \mathrm{a}$ & $13,60 \mathrm{a}$ \\
IAC Una & $14,47 \mathrm{a}$ & $13,73 \mathrm{a}$ \\
Arc4 & $14,40 \mathrm{a}$ & $13,80 \mathrm{a}$ \\
\hline F & $1,49^{\text {ns }}$ & $0,81^{\text {ns }}$ \\
CV & 13,14 & 11,98 \\
\hline Médias seguidas pela mesma letra, não diferem significativamente entre si pelo \\
teste de Tukey ao nível de 5\% de probabilidade.
\end{tabular}

Tabela 25. Fecundidade de Acanthoscelides obtectus criado em diferentes genótipos de feijoeiro.

\begin{tabular}{|c|c|c|c|}
\hline \multirow{2}{*}{ Genótipo } & \multicolumn{2}{|c|}{$\mathrm{N}^{\circ}$ de ovos/recipiente } & \multirow{2}{*}{$\begin{array}{l}\% \text { de ovos } \\
\text { férteis }^{1}\end{array}$} \\
\hline & Total $^{1}$ & Férteis $^{1}$ & \\
\hline IAC Una & $57,13 a$ & $47,13 \mathrm{a}$ & $82,42 a b$ \\
\hline Goiano Precoce & 56,93 a & 47,73 a & 83,81 a \\
\hline IAC Carioca Akytã & 56,47 a & $46,87 \mathrm{a}$ & $83,01 a b$ \\
\hline IAC Bico de Ouro & 56,27 a & $46,40 a$ & $82,45 a b$ \\
\hline IAC Carioca Pyatã & 56,20 a & $46,67 \mathrm{a}$ & $82,99 a b$ \\
\hline IAC Maravilha & 56,00 a & 46,73 a & $83,44 a b$ \\
\hline Porrillo 70 & 56,00 a & 47,27 a & 84,38 a \\
\hline Arc3 & 55,93 a & 45,73 a & $81,79 a b$ \\
\hline Arc2 & 55,80 a & $45,60 \mathrm{a}$ & $81,67 \mathrm{ab}$ \\
\hline IAC Carioca Aruã & 54,87 a & $45,20 a$ & $82,39 a b$ \\
\hline Arc4 & 54,67 a & $44,53 a$ & $81,73 a b$ \\
\hline Arc1 & $53,67 \mathrm{a}$ & $43,40 a$ & $80,82 \quad b$ \\
\hline $\mathrm{F}$ & $0,50^{\mathrm{ns}}$ & $1,04^{\mathrm{ns}}$ & $2,72^{\star \star}$ \\
\hline $\mathrm{CV}$ & 9,94 & 10,36 & 2,88 \\
\hline
\end{tabular}


Analisando-se os resultados obtidos no estudo da biologia de A. obtectus, constata-se que os materiais testados apresentaram efeito menor sobre esta espécie do que sobre $Z$. subfasciatus. Assim, em relação aos genótipos contendo arcelina, verifica-se que a resistência por não-preferência para alimentação e/ou antibiose ficou bem caracterizada apenas no genótipo Arc1, no qual constatou-se alongamento no período de desenvolvimento e redução no peso de adultos. Nos demais materiais com e sem arcelina, os efeitos foram bem pouco pronunciados.

Ainda assim, considerando-se os experimentos de preferência para oviposição e de biologia, foram selecionados para testes posteriores com A. obtectus, os genótipos Arc1, Arc 3 e Arc4 como resistentes e 'Goiano Precoce' como suscetível, coincidindo com aqueles que já tinham sido selecionados para $Z$. subfasciatus.

\subsection{Efeito associado de genótipos resistentes de feijoeiro e pós vegetais sobre Z. subfasciatus e A. obtectus}

\subsubsection{Avaliação da repelência sobre os adultos}

\subsubsection{Z. subfasciatus}

Nos testes para avaliação do efeito associado entre pós vegetais e genótipos de feijão, só foi constatada interação significativa desses fatores em dois casos: com O. minimum (presença/ausência) x genótipos Arc1/Goiano Precoce (Tabela 26), e com C. ambrosioides (f.2) (presença/ausência) $x$ genótipos Arc4/Goiano Precoce (Tabela 28). No primeiro caso, embora 0 número de insetos atraídos para recipientes contendo pó de $O$. minimum tenha sido menor independentemente do genótipo tratado, na comparação entre genótipos, a menor atratividade de Arc1 só foi constatada na ausência do pó da referida planta. Situação semelhante foi constatada com a utilização de $C$. 
ambrosioides, que repeliu os adultos em ambos os genótipos, enquanto a repelência do genótipo Arc4 (verificada na ausência do pó de erva-de-santamaria) não se confirmou na presença dessa planta inseticida.

Nas demais situações, em que a interação não foi significativa, constatou-se sempre repelência das quatros plantas inseticidas (Tabelas 26, 27 e 28) confirmando os resultados anteriormente (Tabela 2). Já o efeito repelente dos genótipos resistentes esteve restrito apenas a Arc1 (com e sem pó de $C$. reticulata) e Arc3 (com e sem pó de $C$. ambrosioides) (Tabelas 26, 27 e 28).

Considerando-se os diversos experimentos em conjunto, o efeito repelente provocado pelas plantas inseticidas sobre $Z$. subfasciatus pode ser confirmada pelo índice de repelência (IR) cujos valores atingiram 0,29; 0,79; 0,84 e 0,81, respectivamente, para $C$. ambrosioides (f.2), $O$. minimum, $C$. reticulata cv. Murcote e M. pulegium, destacando-se, portanto, $C$. ambrosioides (f.2), como a mais efetiva (Tabelas 26, 27 e 28), confirmando os resultados anteriormente (Tabela 2), embora anteriormente, quando as plantas tinham sido testadas apenas em feijão Carioca, os índices tinham sido menores, indicando que naqueles experimentos o efeito repelente tinha sido mais intenso. No que se refere aos genótipos, por outro lado, os três materiais testados foram menos atrativos que 'Goiano Precoce' embora com valores de IR $(0,85 ; 0,89$ e 0,88 respectivamente), próximos do intervalo estabelecido para que um tratamento seja considerado sem atratividade (neutro) (Tabela 29).

Apesar de o efeito repelente dos quatro pós testados sobre $Z$. subfasciatus ter se mantido quando utilizado de forma associada com os genótipos resistentes de feijão (em comparação com o experimento em que os referidos pós foram empregados isoladamente), foi observado apenas efeito aditivo, não se constatando a ocorrência de efeito sinérgico em razão da utilização simultânea dessas duas técnicas de controle. 
Tabela 26. Repelência de adultos de Zabrotes subfasciatus por genótipos (G) de feijoeiro e pós (P) de origem vegetal.

\begin{tabular}{|c|c|c|c|c|}
\hline \multirow{3}{*}{\multicolumn{2}{|c|}{ Tratamentos $^{1}$}} & \multicolumn{2}{|c|}{ Genótipos } & \multirow{4}{*}{$\begin{array}{c}\text { Médias }^{2} \\
\text { 40,75 A }\end{array}$} \\
\hline & & Goiano Precoce & Arc1 & \\
\hline & & \multicolumn{2}{|c|}{ Insetos atraídos (\%) } & \\
\hline \multirow{3}{*}{$\begin{array}{l}\text { Chenopodium } \\
\text { ambrosioides (f.2) } \\
(\mathrm{Pa})\end{array}$} & Sem pó & 45,50 & 36,00 & \\
\hline & Com pó & 10,00 & 6,00 & $8,00 \mathrm{E}$ \\
\hline & Médias $^{2}$ & $27,75 \mathrm{a}$ & $21,00 \mathrm{a}$ & \\
\hline $\mathrm{F}$ & $P\left(68,71^{\star \star}\right)$ & $\mathrm{G}\left(3,77^{\mathrm{ns}}\right)$ & \multicolumn{2}{|c|}{$P \times G\left(0,63^{\text {ns }}\right)$} \\
\hline \multicolumn{2}{|l|}{$\mathrm{CV}$} & \multicolumn{2}{|c|}{45,11} & \\
\hline \multirow{3}{*}{$\begin{array}{l}\text { Ocimum minimum } \\
\text { (Fo) }\end{array}$} & Sem pó & 40,50 Aa & $24,50 \mathrm{Ab}$ & 32,50 \\
\hline & Com pó & $19,50 \mathrm{Ba}$ & $15,00 \mathrm{Ba}$ & 17,25 \\
\hline & Médias $^{2}$ & 30,00 & 19,75 & \\
\hline$P($ & $P\left(30,63^{\star \star}\right)$ & $G\left(17,45^{\star \star}\right)$ & \multicolumn{2}{|c|}{$P \times G\left(5,49^{*}\right)$} \\
\hline \multicolumn{2}{|l|}{$\mathrm{CV}$} & \multicolumn{2}{|c|}{31,19} & \\
\hline \multirow{3}{*}{$\begin{array}{l}\text { Citrus reticulata } \\
\text { (cv. Murcote) (Cf) }\end{array}$} & Sem pó & 36,00 & 23,50 & $29,75 \mathrm{~A}$ \\
\hline & Com pó & 21,50 & 18,50 & $20,00 \mathrm{E}$ \\
\hline & Médias $^{2}$ & $28,75 \mathrm{a}$ & $21,00 \mathrm{~b}$ & \\
\hline $\bar{F}$ & $P\left(11,23^{\star \star}\right)$ & $\mathrm{G}\left(7,10^{*}\right)$ & \multicolumn{2}{|c|}{$P \times G\left(2,67^{\text {ns }}\right)$} \\
\hline \multicolumn{2}{|l|}{$\mathrm{CV}$} & \multicolumn{2}{|c|}{36,99} & \\
\hline \multirow{3}{*}{$\begin{array}{l}\text { Mentha pulegium } \\
\text { (Fo) }\end{array}$} & Sem pó & 36,00 & 27,50 & $31,75 \mathrm{~A}$ \\
\hline & Com pó & 18,50 & 18,00 & $18,25 \mathrm{E}$ \\
\hline & \multirow{2}{*}{$\frac{\text { Médias }^{2}}{P\left(31,02^{* *}\right)}$} & $27,25 \mathrm{a}$ & $22,755 \mathrm{a}$ & \\
\hline $\bar{F}$ & & $\mathrm{G}\left(3,45^{\mathrm{ns}}\right)$ & \multicolumn{2}{|c|}{$P \times G\left(2,72^{\text {ns }}\right)$} \\
\hline \multicolumn{2}{|l|}{ CV } & \multicolumn{3}{|c|}{30,66} \\
\hline
\end{tabular}


Tabela 27. Repelência de adultos de Zabrotes subfasciatus por genótipos (G) de feijoeiro e pós $(\mathrm{P})$ de origem vegetal.

\begin{tabular}{|c|c|c|c|c|}
\hline \multirow{3}{*}{\multicolumn{2}{|c|}{ Tratamentos $^{1}$}} & \multicolumn{2}{|c|}{ Genótipos } & \multirow{3}{*}{ Médias $^{2}$} \\
\hline & & Goiano Precoce & Arc3 & \\
\hline & & \multicolumn{2}{|c|}{ Insetos atraídos (\%) } & \\
\hline \multirow{3}{*}{$\begin{array}{l}\text { Chenopodium } \\
\text { ambrosioides (f.2) } \\
(\mathrm{Pa})\end{array}$} & Sem pó & 49,00 & 36,00 & $42,50 \mathrm{~A}$ \\
\hline & Com pó & 9,50 & 4,50 & $7,00 \mathrm{~B}$ \\
\hline & Médias $^{2}$ & $29,25 \mathrm{a}$ & $20,25 b$ & \\
\hline $\mathrm{P}(3$ & $P\left(307,59^{* \star}\right)$ & $\mathrm{G}\left(19,77^{\star \star}\right)$ & \multicolumn{2}{|c|}{$P \times G\left(3,91^{\text {ns }}\right)$} \\
\hline \multicolumn{2}{|l|}{$\mathrm{CV}$} & \multicolumn{2}{|c|}{25,86} & \\
\hline \multirow{3}{*}{$\begin{array}{l}\text { Ocimum minimum } \\
\text { (Fo) }\end{array}$} & Sem pó & 30,00 & 28,00 & $29,00 \mathrm{~A}$ \\
\hline & Com pó & 24,00 & 18,00 & $21,00 \mathrm{~B}$ \\
\hline & Médias $^{2}$ & $27,00 \mathrm{a}$ & $23,00 \mathrm{a}$ & \\
\hline $\mathrm{P}($ & $\left(7,92^{* \star}\right)$ & $\mathrm{G}\left(1,98^{\mathrm{ns}}\right)$ & \multicolumn{2}{|c|}{$P \times G\left(0,49^{\text {ns }}\right)$} \\
\hline \multicolumn{2}{|l|}{$\mathrm{CV}$} & \multicolumn{2}{|c|}{35,96} & \\
\hline \multirow{3}{*}{$\begin{array}{l}\text { Citrus reticulata } \\
\text { (cv. Murcote) (Cf) }\end{array}$} & Sem pó & 32,50 & 23,50 & $28,00 \mathrm{~A}$ \\
\hline & Com pó & 22,50 & 21,50 & $22,00 \mathrm{~B}$ \\
\hline & Médias $^{2}$ & $27,50 \mathrm{a}$ & $22,50 \mathrm{a}$ & \\
\hline$F$ & $\partial\left(5,33^{*}\right)$ & $\mathrm{G}\left(3,70^{\mathrm{ns}}\right)$ & \multicolumn{2}{|c|}{$P \times G\left(2,37^{\text {ns }}\right)$} \\
\hline \multicolumn{2}{|l|}{$\mathrm{CV}$} & \multicolumn{2}{|c|}{32,86} & \\
\hline \multirow{3}{*}{$\begin{array}{l}\text { Mentha pulegium } \\
\text { (Fo) }\end{array}$} & Sem pó & 33,50 & 24,50 & $29,00 \mathrm{~A}$ \\
\hline & Com pó & 21,50 & 20,50 & $22,50 \mathrm{~B}$ \\
\hline & Médias $^{2}$ & $27,50 \mathrm{a}$ & $22,50 \mathrm{a}$ & \\
\hline $\bar{F}$ & $\left(2,20^{\text {ns }}\right)$ & $\overline{G\left(5,62^{*}\right)}$ & \multirow{2}{*}{\multicolumn{2}{|c|}{$P \times G\left(1,40^{\text {ns }}\right)$}} \\
\hline \multicolumn{2}{|l|}{$\mathrm{CV}$} & 42,69 & & \\
\hline
\end{tabular}


Tabela 28. Repelência de adultos de Zabrotes subfasciatus por genótipos (G) de feijoeiro e pós $(\mathrm{P})$ de origem vegetal.

\begin{tabular}{|c|c|c|c|c|}
\hline \multirow{3}{*}{\multicolumn{2}{|c|}{ Tratamentos $^{1}$}} & \multicolumn{2}{|c|}{ Genótipos } & \multirow{4}{*}{$\begin{array}{r}\text { Médias }^{2} \\
42,00\end{array}$} \\
\hline & & Goiano Precoce & Arc4 & \\
\hline & & \multicolumn{2}{|c|}{ Insetos atraídos (\%) } & \\
\hline \multirow{3}{*}{$\begin{array}{l}\text { Chenopodium } \\
\text { ambrosioides (f.2) } \\
(\mathrm{Pa})\end{array}$} & Sem pó & $53,50 \mathrm{Aa}$ & $30,50 \mathrm{Ab}$ & \\
\hline & Com pó & $7,00 \mathrm{Ba}$ & $6,00 \mathrm{Ba}$ & 6,50 \\
\hline & Médias $^{2}$ & 30,25 & 18,25 & \\
\hline$P(1$ & $\left(138,53^{* \star}\right)$ & $G\left(15,83^{\star \star}\right)$ & \multicolumn{2}{|c|}{$P \times G\left(13,30^{* *}\right)$} \\
\hline \multicolumn{2}{|l|}{$\mathrm{CV}$} & \multicolumn{2}{|c|}{39,33} & \\
\hline \multirow{3}{*}{$\begin{array}{l}\text { Ocimum minimum } \\
\text { (Fo) }\end{array}$} & Sem pó & 33,00 & 25,00 & $29,00 \mathrm{~A}$ \\
\hline & Com pó & 21,50 & 20,00 & $20,75 \mathrm{~B}$ \\
\hline & Médias $^{2}$ & $27,50 \mathrm{a}$ & $22,50 \mathrm{a}$ & \\
\hline $\mathrm{F}$ & $\mathrm{P}\left(5,75^{\star}\right)$ & $\mathrm{G}\left(1,91^{\mathrm{ns}}\right)$ & \multicolumn{2}{|c|}{$P \times G\left(0,89^{\text {ns }}\right)$} \\
\hline \multicolumn{2}{|l|}{$\mathrm{CV}$} & \multicolumn{2}{|c|}{43,74} & \\
\hline \multirow{3}{*}{$\begin{array}{l}\text { Citrus reticulata } \\
\text { (cv. Murcote) (Cf) }\end{array}$} & Sem pó & 31,50 & 26,50 & $29,00 \mathrm{~A}$ \\
\hline & Com pó & 21,50 & 20,50 & $21,00 \mathrm{~B}$ \\
\hline & Médias $^{2}$ & $26,50 a$ & $23,50 a$ & \\
\hline $\mathrm{F}$ & $\mathrm{P}\left(8,14^{* \star}\right)$ & $\mathrm{G}\left(1,14^{\mathrm{ns}}\right)$ & \multicolumn{2}{|c|}{$P \times G\left(0,51^{\text {ns }}\right)$} \\
\hline \multicolumn{2}{|l|}{$\mathrm{CV}$} & \multicolumn{2}{|c|}{35,47} & \\
\hline \multirow{3}{*}{$\begin{array}{l}\text { Mentha pulegium } \\
\text { (Fo) }\end{array}$} & Sem pó & 31,50 & 25,00 & $28,25 \mathrm{~A}$ \\
\hline & Com pó & 23,00 & 20,50 & $21,75 \mathrm{~B}$ \\
\hline & Médias $^{2}$ & $27,25 a$ & $22,75 \mathrm{a}$ & \\
\hline$F$ & $P\left(5,77^{\star}\right)$ & $\mathrm{G}\left(2,77^{\mathrm{ns}}\right)$ & \multirow{2}{*}{\multicolumn{2}{|c|}{$P \times G\left(0,55^{\text {ns }}\right)$}} \\
\hline \multicolumn{2}{|l|}{ CV } & 34,22 & & \\
\hline
\end{tabular}


Tabela 29. Índices de Repelência (IR) dos adultos de Zabrotes subfasciatus por genótipos de feijoeiro e pós de origem vegetal.

\begin{tabular}{|c|c|c|}
\hline Genótipo $^{1}$ & $\mathrm{IR} \pm \mathrm{DP}$ & $\mathrm{Cl}^{2}$ \\
\hline Arc1 & $0,85 \pm 0,05$ & $\mathrm{R}$ \\
\hline Arc3 & $0,89 \pm 0,05$ & $\mathrm{R}$ \\
\hline Arc4 & $0,88 \pm 0,08$ & $\mathrm{R}$ \\
\hline Pó vegetal $^{3}$ & $\mathrm{IR} \pm \mathrm{DP}$ & \\
\hline Chenopodium ambrosioides (f.2) (Pa) & $0,29 \pm 0,03$ & $\mathrm{R}$ \\
\hline Ocimum minimum (Fo) & $0,79 \pm 0,08$ & $\mathrm{R}$ \\
\hline Citrus reticulata (cv. Murcote) (Cf) & $0,84 \pm 0,04$ & $\mathrm{R}$ \\
\hline Mentha pulegium (Fo) & $0,81 \pm 0,07$ & $\mathrm{R}$ \\
\hline
\end{tabular}

\subsubsection{A. obtectus}

Já em relação aos testes com $A$. obtectus, em nenhum caso foi constatada significância na interação pós vegetais $x$ genótipos resistentes (Tabelas 30, 31 e 32). Na análise de cada fator isoladamente, por outro lado, nenhum dos genótipos selecionados como resistentes (Arc1, Arc3 e Arc4) apresentou efeito repelente sobre o inseto em comparação a 'Goiano Precoce' (Tabelas 30, 31 e 32), o que foi confirmados para Arc1 e Arc3 cujos IRs $(0,97$ e 0,97) estiveram dentro do intervalo de segurança. Em relação a Arc4, entretanto, o IR $(0,94)$ indicou que este genótipo foi repelente (embora em baixo nível) em relação a 'Goiano Precoce'.

No que se refere aos pós vegetais, a repelência, independentemente do substrato utilizado, foi constatada com base na análise de variaância na maioria das situações, excetuando-se apenas o pó de $C$. ambrosioides (f.2) no experimento envolvendo o genótipo Arc1 e o pó de $C$. 
Tabela 30. Repelência de adultos de Acanthoscelides obtectus por genótipos (G) de feijoeiro e pós (P) de origem vegetal.

\begin{tabular}{|c|c|c|c|c|}
\hline \multirow{2}{*}{\multicolumn{2}{|c|}{ Tratamentos $^{1}$}} & \multicolumn{2}{|c|}{ Genótipos } & \multirow{4}{*}{$\begin{array}{l}\text { Médias }^{2} \\
27,25 \mathrm{~A}\end{array}$} \\
\hline & & Goiano Precoce & Arc1 & \\
\hline & & \multicolumn{2}{|c|}{ Insetos atraídos (\%) } & \\
\hline \multirow{3}{*}{$\begin{array}{l}\text { Chenopodium } \\
\text { ambrosioides (f.2) } \\
\text { (Pa) }\end{array}$} & Sem pó & 27,50 & 27,00 & \\
\hline & Com pó & 22,50 & 22,00 & $24,50 \mathrm{~A}$ \\
\hline & Médias $^{2}$ & $25,00 \mathrm{a}$ & $24,50 \mathrm{a}$ & \\
\hline \multirow{2}{*}{$\begin{array}{l}\mathrm{F} \\
\mathrm{CV}\end{array}$} & $\left.2,65^{\text {ns }}\right)$ & $\mathrm{G}\left(0,03^{\mathrm{ns}}\right)$ & \multicolumn{2}{|c|}{$P \times G\left(0,00^{\text {ns }}\right)$} \\
\hline & & & & \\
\hline \multirow{3}{*}{$\begin{array}{l}\text { Ruta graveolens } \\
\text { (Fo) }\end{array}$} & Sem pó & 28,00 & 27,50 & $27,75 \mathrm{~A}$ \\
\hline & Com pó & 22,50 & 21,00 & $21,75 \mathrm{~B}$ \\
\hline & Médias $^{2}$ & $25,25 \mathrm{a}$ & $24,25 \mathrm{a}$ & \\
\hline \multirow{2}{*}{$\begin{array}{l}\mathrm{F} \\
\mathrm{CV}\end{array}$} & $\left(5,34^{*}\right)$ & $\mathrm{G}\left(0,15^{\mathrm{ns}}\right)$ & \multicolumn{2}{|c|}{$P \times G\left(0,04^{n s}\right)$} \\
\hline & & \multicolumn{2}{|c|}{33,16} & \\
\hline \multirow{3}{*}{$\begin{array}{l}\text { Citrus reticulata } \\
\text { (cv. Murcote) (Cf) }\end{array}$} & Sem pó & 28,00 & 28,00 & $28,00 \mathrm{~A}$ \\
\hline & Com pó & 23,00 & 20,00 & $21,50 \mathrm{~B}$ \\
\hline & Médias $^{2}$ & $25,50 \mathrm{a}$ & \multicolumn{2}{|l|}{$24,00 \mathrm{a}$} \\
\hline \multirow{2}{*}{$\begin{array}{l}\mathrm{F} \\
\mathrm{CV}\end{array}$} & $\left.4,77^{\star \star}\right)$ & $\mathrm{G}\left(0,79^{\text {ns }}\right)$ & \multicolumn{2}{|c|}{$P \times G\left(0,79^{\text {ns }}\right)$} \\
\hline & & \multicolumn{2}{|c|}{21,61} & \\
\hline \multirow{3}{*}{$\begin{array}{l}\text { Citrus sinensis } \\
\text { (cv. Pêra) (Cf) }\end{array}$} & Sem pó & 28,00 & \multirow{3}{*}{$\begin{array}{c}24,50 \\
22,00 \\
23,25 \mathrm{a}\end{array}$} & $26,25 \mathrm{~A}$ \\
\hline & Com pó & 25,50 & & $23,75 \mathrm{~A}$ \\
\hline & Médias $^{2}$ & $26,75 \mathrm{a}$ & & \\
\hline \multicolumn{2}{|c|}{$P\left(2,02^{n s}\right)$} & $\mathrm{G}\left(3,96^{\text {ns }}\right)$ & \multicolumn{2}{|c|}{$P \times G\left(0,00^{n s}\right)$} \\
\hline \multicolumn{2}{|l|}{ CV } & \multicolumn{2}{|c|}{22,26} & \\
\hline
\end{tabular}


Tabela 31. Repelência de adultos de Acanthoscelides obtectus por genótipos (G) de feijoeiro e pós (P) de origem vegetal.

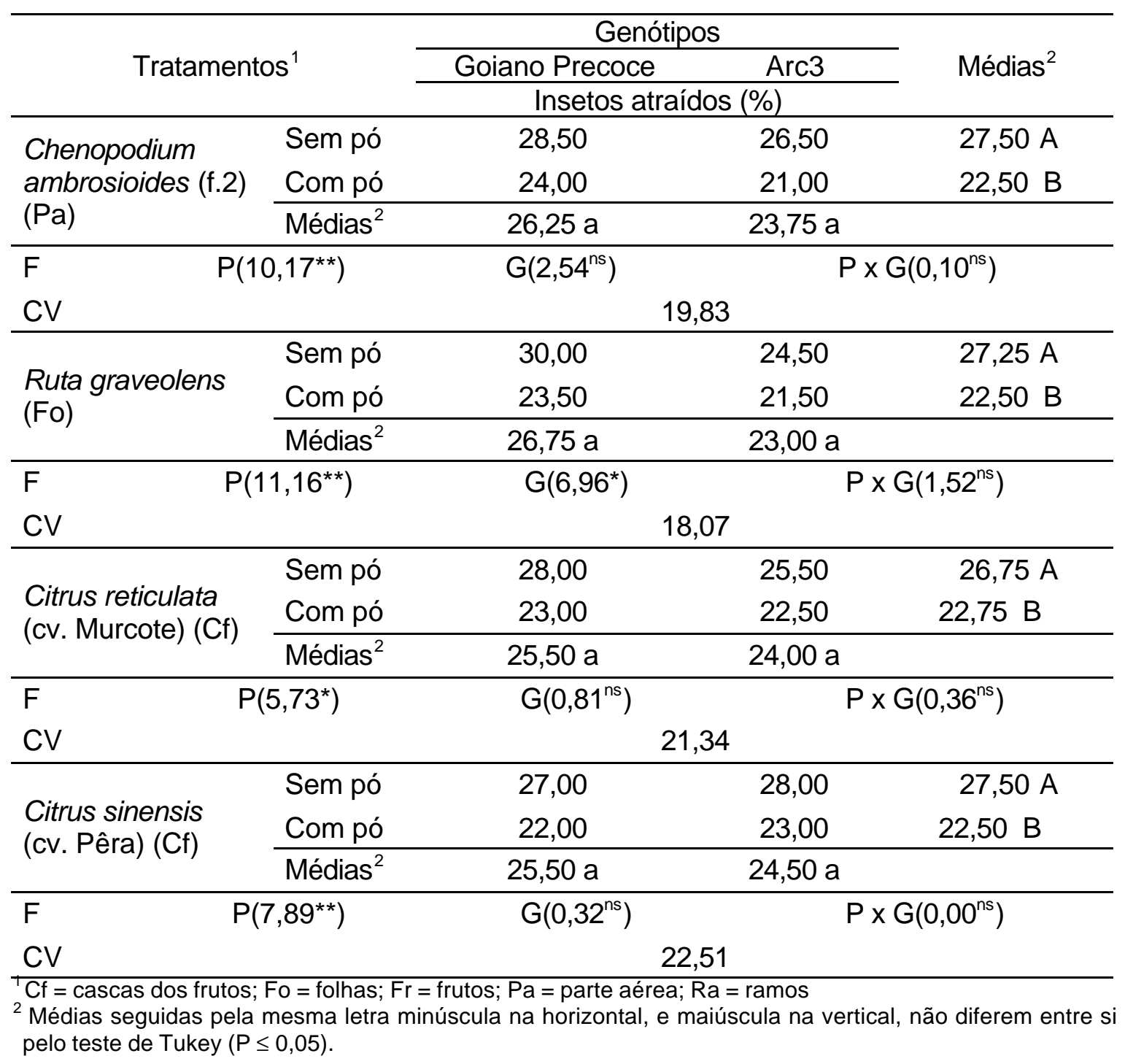


Tabela 32. Repelência de adultos de Acanthoscelides obtectus por genótipos (G) de feijoeiro e pós (P) de origem vegetal.

\begin{tabular}{|c|c|c|c|c|}
\hline \multirow{3}{*}{\multicolumn{2}{|c|}{ Tratamentos ${ }^{1}$}} & \multicolumn{2}{|c|}{ Genótipos } & \multirow{4}{*}{$\begin{array}{l}\text { Médias }^{2} \\
28,25 \mathrm{~A}\end{array}$} \\
\hline & & Goiano Precoce & Arc4 & \\
\hline & & \multicolumn{2}{|c|}{ Insetos atraídos (\%) } & \\
\hline \multirow{3}{*}{$\begin{array}{l}\text { Chenopodium } \\
\text { ambrosioides (f.2) } \\
(\mathrm{Pa})\end{array}$} & Sem pó & 29,00 & 27,50 & \\
\hline & Com pó & 21,50 & 22,00 & $21,75 \mathrm{~B}$ \\
\hline & Médias $^{2}$ & $25,25 a$ & $24,75 a$ & \\
\hline$P(1$ & $\mathrm{P}\left(12,02^{* *}\right)$ & $\mathrm{G}\left(0,07^{\mathrm{ns}}\right)$ & \multicolumn{2}{|c|}{$P \times G\left(0,28^{\text {ns }}\right)$} \\
\hline \multicolumn{2}{|l|}{$\mathrm{CV}$} & \multicolumn{2}{|c|}{23,71} & \\
\hline \multirow{3}{*}{$\begin{array}{l}\text { Ruta graveolens } \\
\text { (Fo) }\end{array}$} & Sem pó & 32,50 & 26,50 & $29,50 \mathrm{~A}$ \\
\hline & Com pó & 20,50 & 20,50 & $20,50 \mathrm{~B}$ \\
\hline & Médias $^{2}$ & $26,50 \mathrm{a}$ & $23,50 \mathrm{a}$ & \\
\hline$F$ & $\mathrm{P}\left(15,67^{\star \star}\right)$ & $\mathrm{G}\left(1,74^{\mathrm{ns}}\right)$ & \multicolumn{2}{|c|}{$P \times G\left(1,74^{\text {ns }}\right)$} \\
\hline \multicolumn{2}{|l|}{ CV } & \multicolumn{2}{|c|}{28,75} & \\
\hline \multirow{3}{*}{$\begin{array}{l}\text { Citrus reticulata } \\
\text { (cv. Murcote) (Cf) }\end{array}$} & Sem pó & 28,50 & 25,50 & $27,00 \mathrm{~A}$ \\
\hline & Com pó & 25,00 & 21,00 & $23,00 \mathrm{~B}$ \\
\hline & Médias $^{2}$ & $26,75 a$ & $23,25 a$ & \\
\hline$F$ & $\mathrm{P}\left(4,22^{\star}\right)$ & $\mathrm{G}\left(3,23^{\mathrm{ns}}\right)$ & \multicolumn{2}{|c|}{$P \times G\left(0,07^{\text {ns }}\right)$} \\
\hline \multicolumn{2}{|l|}{$\mathrm{CV}$} & \multicolumn{2}{|c|}{24,63} & \\
\hline \multirow{3}{*}{$\begin{array}{l}\text { Citrus sinensis } \\
\text { (cv. Pêra) (Cf) }\end{array}$} & Sem pó & 28,50 & 23,00 & $25,75 \mathrm{~A}$ \\
\hline & Com pó & 26,00 & 22,50 & $24,25 \mathrm{~A}$ \\
\hline & Médias $^{2}$ & $27,25 \mathrm{a}$ & $22,75 \mathrm{a}$ & \\
\hline $\mathrm{F}$ & $P\left(0,28^{\text {ns }}\right)$ & $G\left(2,54^{\text {ns }}\right)$ & \multirow{2}{*}{\multicolumn{2}{|c|}{$P \times G\left(0,13^{\text {ns }}\right)$}} \\
\hline \multicolumn{2}{|l|}{ CV } & 35,68 & & \\
\hline
\end{tabular}


sinensis nos experimentos com Arc1 e Arc4 (Tabelas 30, 31 e 32). A repelência dos quatro pós testados foi verificada com base nos IRs embora estes tenham apresentado valores $(0,86$ a 0,94$)$ (Tabela 33$)$ muito próximos do intervalo indicativo de ausência de atividade, o que mostra menor efeito nesses testes (com diversos genótipos) do que naqueles em que foi utilizado apenas a cultivar Carioca (Tabela 3).

Como no caso de A obtectus, não houve efeito repelente dos genótipos resistentes sobre o inseto, o efeito da utilização associada dos genótipos com os pós ficou restrita ao efeito das substâncias vegetais, as quais ratificaram os resultados registrados nos testes em que as mesmas foram utilizadas isoladamente.

\subsubsection{Estimativa da $\mathrm{CL}_{50}$ do pó de $C$. ambrosioides para $Z$. subfasciatus e} A. obtectus

$\mathrm{Na}$ estimativa da $\mathrm{CL}_{50}$ (feita apenas com C. ambrosioides, f.2), as concentrações básicas, causadoras de mortalidades de cerca de 5 e 95\% dos adultos de $Z$. subfasciatus, foram, respectivamente, 0,015 e 0,025 g. Foram definidas cinco concentrações (variando de 0,007 a 0,019) e a partir dos testes realizados com estas concentrações foi estimada uma $\mathrm{CL}_{50}$ de $0,018 \mathrm{~g}$ (Tabela 34), utilizada também para as demais substâncias vegetais. Já no caso de $A$. obtectus, as concentrações iniciais que provocaram mortalidades de cerca de 5 e $95 \%$ foram 0,010 e $0,100 \mathrm{~g}$, respectivamente. Foram obtidas cinco concentrações (variando de 0,017 a 0,140), estimando-se então uma $\mathrm{CL}_{50}$ de 0,038 g (Tabela 35), utilizada igualmente para as demais substâncias vegetais.

$\mathrm{Na}$ comparação dos valores de $\mathrm{CL}_{50}$ estimados para as duas espécies de carunchos, constatou-se um valor menor para $Z$. subfasciatus, o que indica a maior eficiência do pó de $C$. ambrosioides (f.2) para esta espécie. 
Tabela 33. Índices de Repelência (IR) dos adultos de Acanthoscelides obtectus por genótipos de feijoeiro e pós de origem vegetal.

\begin{tabular}{|c|c|c|}
\hline Genótipo $^{1}$ & $\mathrm{IR} \pm \mathrm{DP}$ & $\mathrm{Cl}^{2}$ \\
\hline Arc1 & $0,97 \pm 0,03$ & $\mathrm{~N}$ \\
\hline Arc3 & $0,97 \pm 0,04$ & $\mathrm{~N}$ \\
\hline Arc4 & $0,94 \pm 0,03$ & $\mathrm{R}$ \\
\hline Pó vegetal $^{3}$ & $\mathrm{IR} \pm \mathrm{DP}$ & \\
\hline Chenopodium ambrosioides (f.2) (Pa) & $0,89 \pm 0,02$ & $\mathrm{R}$ \\
\hline Ruta graveolens (Fo) & $0,86 \pm 0,04$ & $\mathrm{R}$ \\
\hline Citrus reticulata (cv. Murcote) (Cf) & $0,90 \pm 0,03$ & $\mathrm{R}$ \\
\hline Citrus sinensis (cv. Pêra) (Cf) & $0,94 \pm 0,04$ & $\mathrm{R}$ \\
\hline
\end{tabular}

Tabela 34. $\mathrm{CL}_{50}$ do pó de Chenopodium ambrosioides (f.2) para Zabrotes subfasciatus.

\begin{tabular}{|c|c|c|c|c|}
\hline \multicolumn{2}{|c|}{ Teste $1^{1}$} & \multicolumn{2}{|c|}{ Teste $2(\mathrm{q}=n+1 \sqrt{a n / a 1})^{2}$} & \multirow{2}{*}{$\begin{array}{c}\mathrm{CL}_{50} \\
\text { calculado } \\
\end{array}$} \\
\hline Concentrações (g) & Mortalidade (\%) & Concentrações (g) & Mortalidade (\%) & \\
\hline Testemunha & $0,00 \quad c$ & $0,007\left(a_{1} \cdot q\right)$ & $1,67 \quad c$ & \\
\hline 0,005 & $0,00 \quad c$ & $0,009\left(a_{2} \cdot q\right)$ & $1,67 \quad c$ & \\
\hline 0,010 & $3,33 \mathrm{c}$ & $0,011\left(a_{3} . q\right)$ & $8,33 \mathrm{bc}$ & \\
\hline 0,015 & $5,00 \quad c$ & $0,015\left(a_{4} \cdot q\right)$ & $23,33 b$ & 0,018 \\
\hline 0,020 & $43,44 \mathrm{~b}$ & $0,019\left(a_{5} . q\right)$ & 55,00 a & \\
\hline 0,025 & $95,00 \mathrm{a}$ & Testemunha & 1,67 & \\
\hline 0,030 & $100,00 \mathrm{a}$ & & & \\
\hline $\mathrm{F}$ & $223,64^{\star *}$ & & $30,33^{* *}$ & \\
\hline $\mathrm{CV}$ & 14,85 & & 43,64 & \\
\hline
\end{tabular}


Tabela 35. $\mathrm{CL}_{50}$ do pó de Chenopodium ambrosioides (f.2) para Acanthoscelides obtectus.

\begin{tabular}{|c|c|c|c|c|}
\hline \multicolumn{2}{|c|}{ Teste $1^{1}$} & \multicolumn{2}{|c|}{ Teste $2(\mathrm{q}=n+1 \sqrt{a n / a 1})^{2}$} & \multirow{2}{*}{$\begin{array}{c}\mathrm{CL}_{50} \\
\text { calculado }\end{array}$} \\
\hline Concentrações $(\mathrm{g})$ & Mortalidade (\%) & Concentrações (g) & $\begin{array}{c}\text { Mortalidade } \\
(\%)\end{array}$ & \\
\hline Testemunha & $0,00 \mathrm{~d}$ & $0,017\left(a_{1} \cdot q\right)$ & 13,33 & \\
\hline 0,010 & $6,67 \mathrm{~cd}$ & $0,029\left(a_{2} \cdot 9\right)$ & $43,33 d$ & \\
\hline 0,025 & $21,67 \mathrm{c}$ & $0,049\left(a_{3} . q\right)$ & $63,33 \mathrm{c}$ & \\
\hline 0,050 & $53,33 \mathrm{~b}$ & $0,084\left(a_{4} \cdot q\right)$ & $76,67 \mathrm{~b}$ & 0,038 \\
\hline 0,075 & $70,00 \mathrm{~b}$ & $0,140\left(a_{5} . q\right)$ & 98,33 a & \\
\hline 0,100 & $96,67 \mathrm{a}$ & Testemunha & $1,67 \quad f$ & \\
\hline 0,125 & $100,00 \mathrm{a}$ & & & \\
\hline$F$ & $139,13^{\star *}$ & & $333,51^{* *}$ & \\
\hline CV & 12,21 & & 7,15 & \\
\hline
\end{tabular}

\subsubsection{Avaliação da mortalidade dos adultos e oviposição}

\subsubsection{Z. subfasciatus}

Nos testes para verificação da mortalidade de $Z$. subfasciatus em contato com grãos de feijão tratados com pós $(0,018 \mathrm{~g} / 10 \mathrm{~g}$ de feijão), foi constatada significância da interação genótipo resistente $\mathrm{x}$ pós com a utilização de C. ambrosioides (f.2) e O. basilicum (Tabela 36). No primeiro caso, a porcentagem de insetos mortos foi semelhante nos genótipos na ausência do pó, mas diferiu na presença dele, já que os valores nos genótipos com arcelina foram maiores que em 'Goiano Precoce'. Com o pó de O. basilicum, novamente não constatada diferença na mortalidade do inseto na ausência do pó, enquanto que na presença dele a mortalidade em Arc3 foi maior que em Arc1. Já com $M$. pulegium e $R$. graveolens, não houve diferença na mortalidade dos insetos nos quatro genótipos independentemente do emprego dos pós. 
Tabela 36. Mortalidade ( $5^{0}$ dia) de adultos de Zabrotes subfasciatus em genótipos $(\mathrm{G})$ de feijoeiro tratados com pós $(\mathrm{P})$ de origem vegetal.

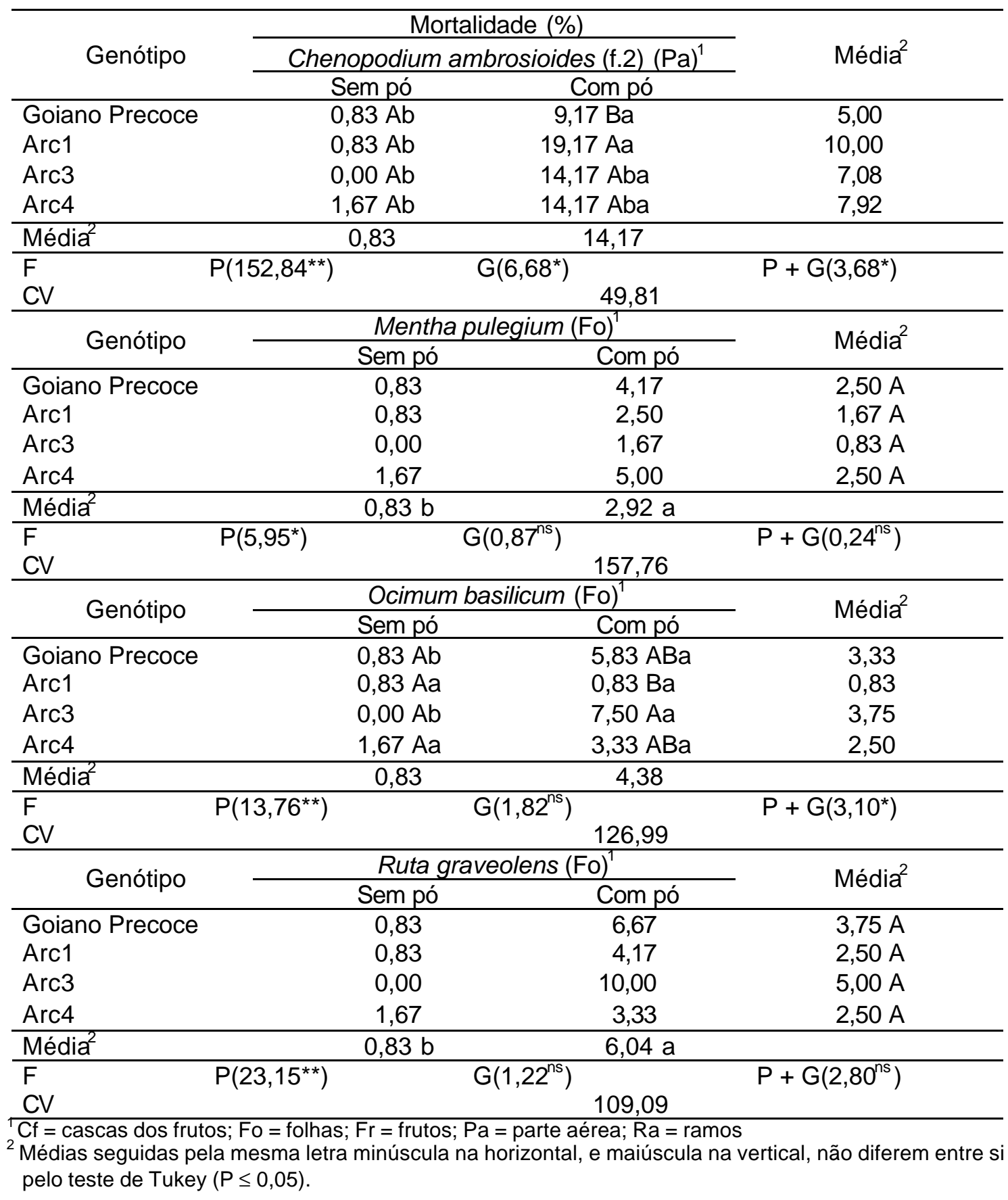


Por outro lado, com todas as plantas inseticidas, ocorreu maior mortalidade nos grãos tratados em relação aos não tratados, independentemente do genótipo utilizado como substrato, excetuando-se apenas o tratamento com $O$. basilicum nos genótipos Arc1 e 4 (Tabela 36). Se comparados estes dados com os obtidos na primeira avaliação do efeito dos pós vegetais na sobrevivência de $Z$. subfasciatus (Tabela 4), constatou-se menor mortalidade o que pode ser explicado pela menor concentração empregada neste experimento $(0,018 \mathrm{~g} / 10 \mathrm{~g}$ de feijão) que naquele $(0,3 \mathrm{~g} / 10 \mathrm{~g}$ de feijão).

Em relação às variáveis número total de ovos por recipiente e número de ovos férteis por recipiente, em nenhuma situação constatou-se interação significativa genótipos $\mathrm{x}$ pós vegetais, embora tenha sido verificado efeito significativo de ambos os fatores (Tabelas 37 e 38). Assim, independentemente do emprego dos pós vegetais o número de ovos (total e férteis) foi sempre menor nos três genótipos contendo arcelina em relação ao número verificado em Goiano Precoce. Por outro lado, a menor oviposição nas parcelas tratadas com as quatro plantas inseticidas em relação æ̀ não tratadas foi menor independentemente do genótipo utilizado como substrato para manutenção do inseto, excetuando-se apenas o experimento com $C$. ambrosioides, onde não houve diferença entre parcelas tratadas e não tratadas, confirmando dados obtidos anteriormente (Tabelas 8 e 9).

Esses dados confirmaram a não-preferência para oviposição de $Z$. subfasciatus em materiais contendo arcelina, evidenciando ainda que a ação repelente das plantas inseticidas testadas (Tabela 29), acabaram afetando também a oviposição do inseto.

Quanto àporcentagem de ovos férteis em relação número total de ovos (Tabela 38), constatou-se significância apenas na interação $O$. basilicum (presença/ausência) x genótipos. Neste tratamento, o efeito dos genótipos (menor porcentagem de ovos férteis em Arc4 que em 'Goiano Precoce') só ocorreu na ausência do pó vegetal. Esta porcentagem foi diminuída pelo pó, por 
Tabela 37. Oviposição total de Zabrotes subfasciatus em genótipos (G) de feijoeiro tratados com pós $(\mathrm{P})$ de origem vegetal.

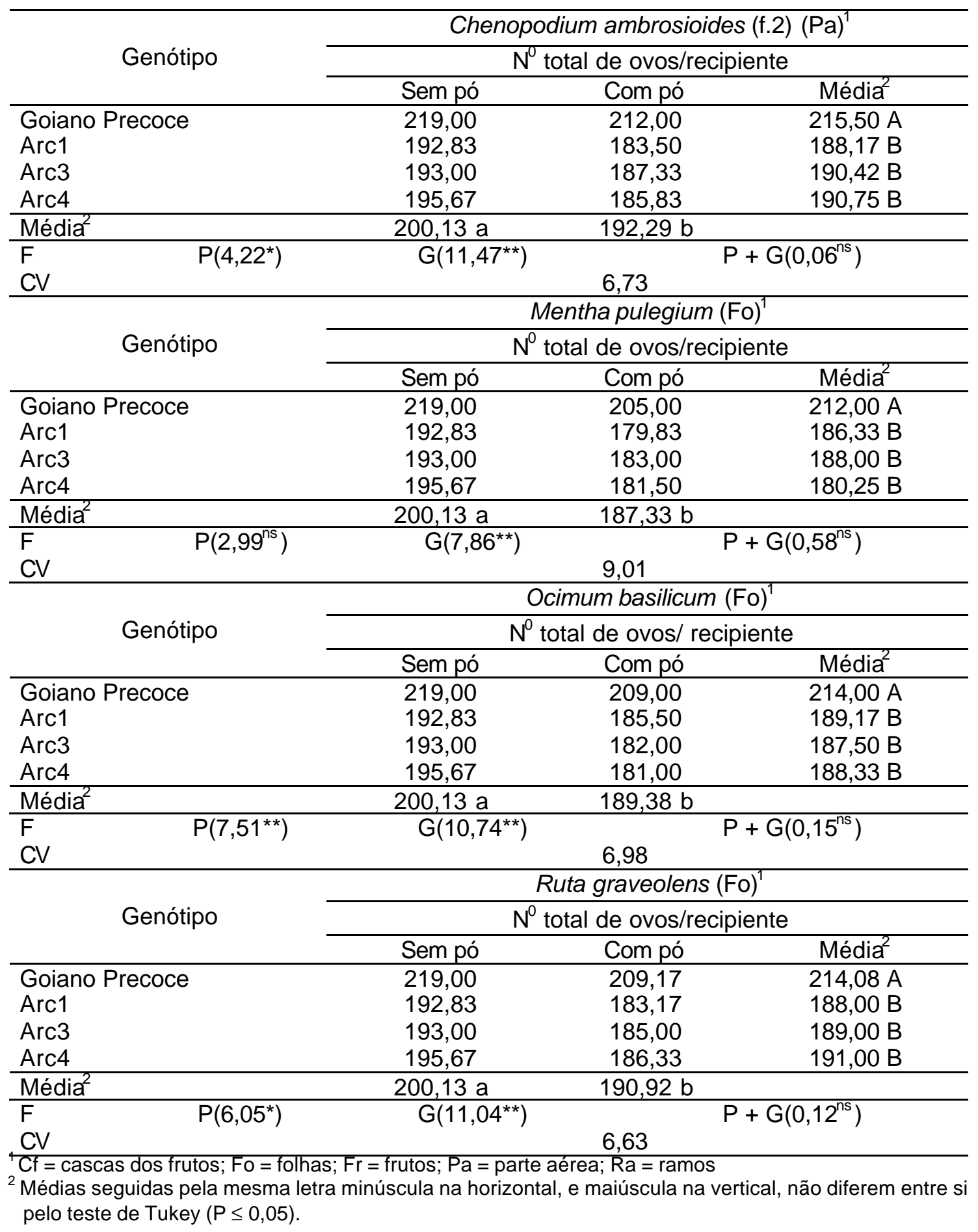


Tabela 38. Oviposição ( $n^{0}$ e \% de ovos férteis) de Zabrotes subfasciatus em genótipos $(G)$ tradados com pós $(P)$ de origem vegetal.

\begin{tabular}{|c|c|c|c|c|c|c|}
\hline \multirow{3}{*}{ Genótipo } & \multicolumn{6}{|c|}{ Chenopodium ambrosioides (f.2) (Pa) } \\
\hline & \multicolumn{3}{|c|}{$\mathrm{N}^{0} /$ recipiente } & \multicolumn{3}{|c|}{ \% em relação ao total } \\
\hline & Sem pó & Com pó & Média $^{2}$ & Sem pó & Com pó & Média $^{2}$ \\
\hline Goiano Precoce & 183,17 & 177,83 & $180,50 \mathrm{~A}$ & 83,69 & 83,85 & $83,77 \mathrm{~A}$ \\
\hline Arc1 & 161,00 & 153,00 & $157,00 \mathrm{~B}$ & 83,38 & 83,44 & $83,41 \mathrm{~A}$ \\
\hline Arc3 & 160,33 & 153,33 & $156,83 \mathrm{~B}$ & 83,01 & 81,69 & $82,35 \mathrm{AB}$ \\
\hline Arc4 & 156,17 & 149,17 & $152,67 \mathrm{~B}$ & 79,77 & 80,36 & $80,06 \mathrm{~B}$ \\
\hline Média $^{2}$ & $165,17 \mathrm{a}$ & $158,33 \mathrm{a}$ & & $82,46 a$ & $82,33 \mathrm{a}$ & \\
\hline $\mathrm{F}$ & $\mathrm{P}\left(3,78^{\text {ns }}\right)$ & $G\left(12,98^{* *}\right)$ & $+\mathrm{G}\left(0,02^{\mathrm{ns}}\right)$ & $\mathrm{P}\left(0,03^{\text {ns }}\right)$ & $\mathrm{G}\left(4,49^{\star \star}\right)$ & $+\mathrm{G}\left(0,27^{\mathrm{ns}}\right)$ \\
\hline \multirow[t]{2}{*}{ CV } & & 7,53 & & & 3,31 & \\
\hline & \multicolumn{6}{|c|}{ Mentha pulegium (Fo) } \\
\hline \multirow[t]{2}{*}{ Genótipo } & \multicolumn{3}{|c|}{$\mathrm{N}^{0} /$ recipiente } & \multicolumn{3}{|c|}{ \% em relação ao total } \\
\hline & Sem pó & Com pó & Média $^{2}$ & Sem pó & Com pó & Média $^{2}$ \\
\hline Goiano Precoce & 183,17 & 172,67 & $177,92 \mathrm{~A}$ & 83,69 & 84,23 & $83,96 \mathrm{~A}$ \\
\hline Arc1 & 161,00 & 147,83 & $154,42 \mathrm{~B}$ & 83,39 & 82,29 & $82.84 \mathrm{~A}$ \\
\hline Arc3 & 160,33 & 151,83 & $156,08 \mathrm{~B}$ & 83,01 & 82,79 & $82,90 \mathrm{~A}$ \\
\hline Arc4 & 156,17 & 149,33 & $152,75 \mathrm{~B}$ & 79,77 & 82,30 & $81,03 \mathrm{~A}$ \\
\hline Média $^{2}$ & $165.17 \mathrm{a}$ & $155.42 b$ & & $82.46 \mathrm{a}$ & $82.90 \mathrm{a}$ & \\
\hline & $\mathrm{P}\left(8,24^{\star \star}\right)$ & $G\left(12,12^{* *}\right) F$ & $\mathrm{G}\left(0,16^{\mathrm{ns}}\right)$ & $\mathrm{P}\left(0,31^{\text {ns }}\right)$ & $\mathrm{G}\left(2,40^{\text {ns }}\right)$ & $+\mathrm{G}\left(0,97^{\mathrm{ns}}\right)$ \\
\hline \multirow[t]{2}{*}{ CV } & & 7,34 & & & 3,28 & \\
\hline & \multicolumn{6}{|c|}{ Ocimum basilicum (Fo) ${ }^{\top}$} \\
\hline \multirow[t]{2}{*}{ Genótipo } & \multicolumn{3}{|c|}{$\mathrm{N}^{0} /$ recipiente } & \multicolumn{3}{|c|}{ \% em relação ao total } \\
\hline & Sem pó & Com pó & Média $^{2}$ & Sem pó & Com pó & Média $^{2}$ \\
\hline Goiano Precoce & 183,17 & 166,67 & $179,92 \mathrm{~A}$ & $83,69 \mathrm{Aa}$ & $79,69 \mathrm{Ab}$ & 81,69 \\
\hline Arc1 & 161,00 & 150,33 & $155,67 \mathrm{~B}$ & $83,39 \mathrm{ABa}$ & $81,16 \mathrm{Aa}$ & 82,27 \\
\hline Arc3 & 160,33 & 147,00 & $153,67 \mathrm{~B}$ & $83,01 \mathrm{ABa}$ & $80,81 \mathrm{Aa}$ & 81,91 \\
\hline Arc4 & 156,17 & 147,33 & $151,75 \mathrm{~B}$ & $79,77 \mathrm{Ba}$ & $81,41 \mathrm{Aa}$ & 80,59 \\
\hline Média $^{2}$ & $165.17 \mathrm{a}$ & $152.83 \mathrm{~b}$ & & 82.46 & 80.77 & \\
\hline $\mathrm{F}$ & $\mathrm{P}\left(12,67^{* *}\right.$ & $G\left(9,59^{* *}\right) F$ & $\mathrm{G}\left(0,23^{\mathrm{ns}}\right)$ & $\mathrm{P}\left(5,79^{\star}\right)$ & $\mathrm{G}\left(1,06^{\text {ns }}\right)$ & $P+G\left(2,86^{*}\right)$ \\
\hline \multirow[t]{2}{*}{ CV } & & 7,55 & & & 2,99 & \\
\hline & \multicolumn{6}{|c|}{ Ruta graveolens (Fo) $^{\top}$} \\
\hline \multirow[t]{2}{*}{ Genótipo } & \multicolumn{3}{|c|}{$\mathrm{N}^{0} /$ recipiente } & \multicolumn{3}{|c|}{ \% em relação ao total } \\
\hline & Sem pó & Com pó & Média $^{2}$ & Sem pó & Com pó & Média ${ }^{2}$ \\
\hline Goiano Precoce & 183,17 & 173,33 & $178,25 \mathrm{~A}$ & 83,69 & 82,80 & $83,24 \mathrm{~A}$ \\
\hline Arc1 & 161,00 & 147,50 & $154,25 \mathrm{~B}$ & 83,39 & 81,44 & $82,41 \mathrm{AB}$ \\
\hline Arc3 & 160,33 & 152,83 & $156,58 \mathrm{~B}$ & 83,01 & 82,68 & $82,85 \mathrm{AB}$ \\
\hline Arc4 & 156,17 & 151,00 & $153,58 \mathrm{~B}$ & 79,77 & 81,07 & $80,41 \mathrm{~B}$ \\
\hline Média $^{2}$ & $165,17 \mathrm{a}$ & $156,17 \mathrm{~b}$ & & $82,46 \mathrm{a}$ & $81,99 \mathrm{a}$ & \\
\hline & $\mathrm{P}\left(6,44^{*}\right)$ & $\mathrm{G}\left(11,05^{\star *}\right)$ & $\mathrm{G}\left(0,25^{\mathrm{ns}}\right)$ & $\mathrm{P}\left(0,42^{\text {ns }}\right)$ & $\mathrm{G}\left(3,05^{\star}\right)$ & $\mathrm{D}_{+} \mathrm{G}\left(0,88^{\mathrm{ns}}\right)$ \\
\hline CV & & 7,64 & & & 3,03 & \\
\hline
\end{tabular}


outro lado, apenas no genótipo Goiano Precoce. O emprego dos pós das demais plantas inseticidas não afetou essa porcentagem. O efeito dos genótipos sobre essa variável foi diferenciado. Assim, enquanto no teste com M. pulegium, não houve diferença na porcentagem de ovos férteis nos quatro genótipos de feijão, nos demais casos (emprego de $C$. ambrosioides e $R$. graveolens), essa porcentagem foi menor em Arc4, diferindo de 'Goiano Precoce' e Arc1 no primeiro caso e apenas de 'Goiano Precoce' no segundo.

\subsubsection{A. obtectus}

No que se refere à avaliação da mortalidade de $A$. obtectus em contato com grãos de feijão tratados com pós $(0,038 \mathrm{~g} / 10 \mathrm{~g}$ de feijão), em nenhum caso foi constatada significância da interação dos fatores genótipos e pós vegetais (Tabela 39).

A observação dos efeitos isolados de cada fator permite constatar que não houve diferença significativa na porcentagem de insetos mortos nos quatro genótipos de feijão. No que se refere às plantas inseticidas, entretanto, o efeito foi verificado em todas elas, já que a mortalidade dos insetos nos recipientes com feijão tratado foi maior que naqueles com o referido substrato não tratado (Tabela 39).

Também em relação a esta espécie de caruncho, a menor mortalidade encontrada neste experimento em comparação ao descrito no item 4.1.2.2 (Tabela 7), certamente se deveu a menor quantidade de pó $(0,038 \mathrm{~g})$ utilizada em relação ao ensaio anterior $(0,3 \mathrm{~g})$ para uma mesma quantidade (10g) de feijão.

Também em relação às variáveis número total de ovos (Tabela 40) por recipiente, número de ovos férteis por recipiente e porcentagem de ovos férteis em relação ao número total de ovos (Tabela 41), em nenhuma situação constatou-se interação significativa dos fatores genótipos e pós vegetais. 
Tabela 39. Mortalidade $\left(5^{0} \mathrm{dia}\right)$ de adultos de Acanthoscelides obtectus em genótipos $(G)$ de feijoeiro tratados com pós $(P)$ de origem vegetal.

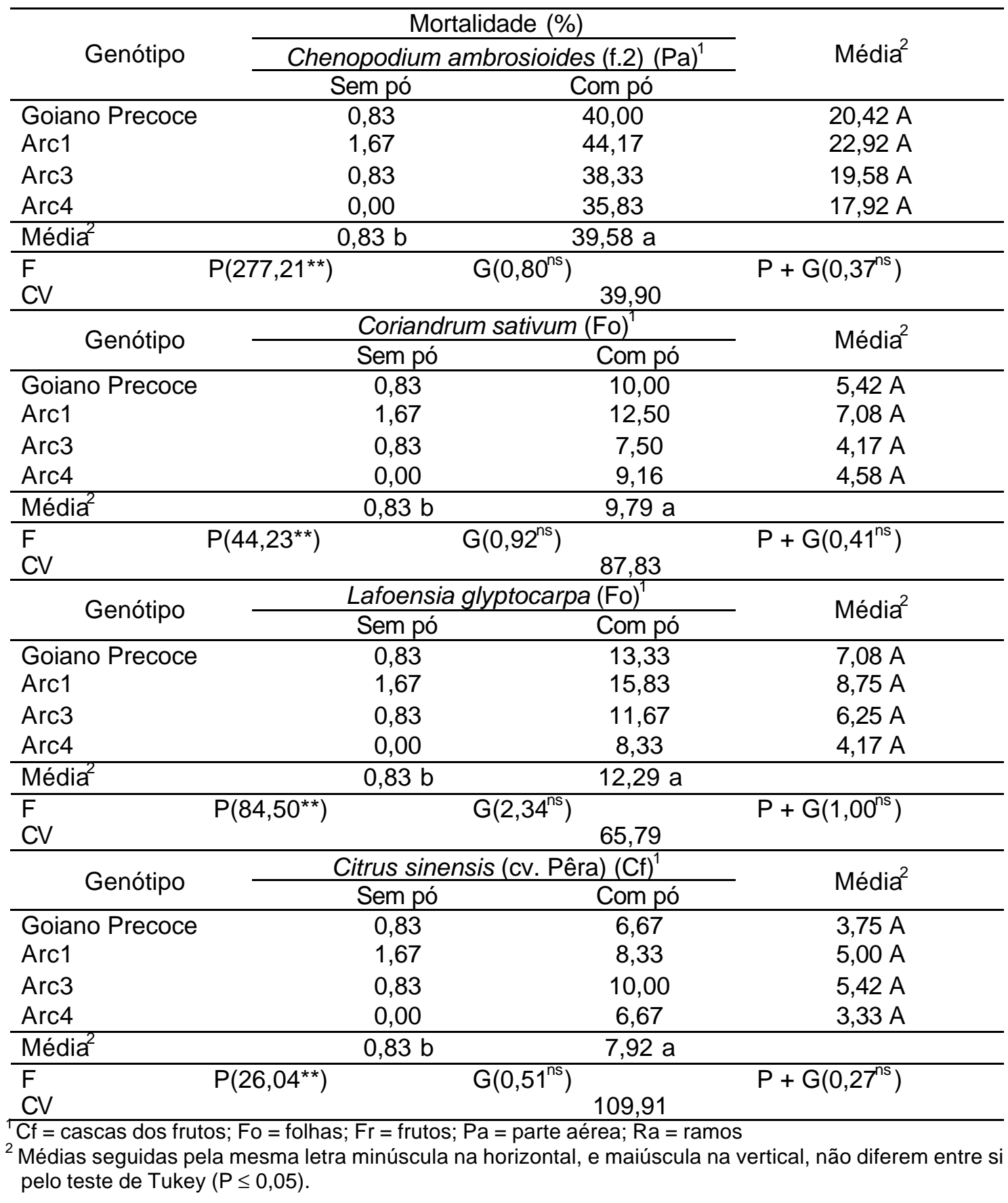


Tabela 40. Oviposição total de Acanthoscelides obtectus em genótipos (G) de feijoeiro tratados com pós $(\mathrm{P})$ de origem vegetal.

\begin{tabular}{|c|c|c|c|}
\hline \multirow{3}{*}{ Genótipo } & \multicolumn{3}{|c|}{ Chenopodium ambrosioides (f.2) (Pa) ${ }^{1}$} \\
\hline & \multicolumn{3}{|c|}{$\mathrm{N}^{0}$ total de ovos/recipiente } \\
\hline & Sem pó & Com pó & Média $^{2}$ \\
\hline Goiano Precoce & 204,50 & 190,83 & $197,67 \mathrm{~A}$ \\
\hline Arc1 & 187,50 & 174,83 & $181,17 \mathrm{~B}$ \\
\hline Arc3 & 189,17 & 175,00 & $182,08 \mathrm{~B}$ \\
\hline Arc4 & 187,17 & 174,00 & $180,58 \mathrm{~B}$ \\
\hline Média $^{2}$ & $192,08 \mathrm{a}$ & \multicolumn{2}{|l|}{$178,67 \mathrm{~b}$} \\
\hline $\mathrm{P}\left(21,25^{\star \star}\right)$ & $\mathrm{G}\left(7,97^{\star \star}\right)$ & \multicolumn{2}{|c|}{$P+G\left(0,12^{n s}\right)$} \\
\hline \multirow{3}{*}{ Genótipo } & \multicolumn{3}{|c|}{ Coriandrum sativum $(\mathrm{Fo})^{1}$} \\
\hline & \multicolumn{3}{|c|}{$\mathrm{N}^{0}$ total de ovos/recipiente } \\
\hline & Sem pó & Com pó & Média $^{2}$ \\
\hline Goiano Precoce & 204,50 & 204,00 & $204,25 \mathrm{~A}$ \\
\hline Arc1 & 187,50 & 183,33 & $185,41 \mathrm{~B}$ \\
\hline Arc3 & 189,17 & 185,00 & $187,08 \mathrm{~B}$ \\
\hline Arc4 & 187,17 & 183,50 & $185,33 \mathrm{~B}$ \\
\hline Média $^{2}$ & $192,08 \mathrm{a}$ & \multicolumn{2}{|l|}{$18896 \mathrm{a}$} \\
\hline $\mathrm{P}\left(1,75^{\mathrm{ns}}\right)$ & $\mathrm{G}\left(14,72^{* *}\right)$ & \multirow{2}{*}{\multicolumn{2}{|c|}{$P+G\left(0,14^{\text {ns }}\right)$}} \\
\hline CV & & & \\
\hline \multirow{3}{*}{ Genótipo } & \multicolumn{3}{|c|}{${\text { Lafoensia glyptocarpa }(\mathrm{Fo})^{1}}^{1}$} \\
\hline & \multicolumn{3}{|c|}{$\mathrm{N}^{0}$ total de ovos/ recipiente } \\
\hline & Sem pó & Com pó & Média $^{2}$ \\
\hline Goiano Precoce & 204,50 & 197,67 & $201,08 \mathrm{~A}$ \\
\hline Arc1 & 187,50 & 183,50 & $185,50 \mathrm{~B}$ \\
\hline Arc3 & 189,17 & 183,50 & $186,33 \mathrm{~B}$ \\
\hline Arc4 & 187,17 & 185,83 & $186,50 \mathrm{~B}$ \\
\hline Média $^{2}$ & 192,08 a & \multicolumn{2}{|l|}{$187,63 \mathrm{a}$} \\
\hline \multirow[t]{2}{*}{$\mathrm{P}\left(2,89^{\text {ns }}\right)$} & $\mathrm{G}\left(8,18^{\star \star}\right)$ & \multirow{2}{*}{\multicolumn{2}{|c|}{$P+G\left(0,21^{n s}\right)$}} \\
\hline & & & \\
\hline \multirow{3}{*}{ Genótipo } & \multicolumn{3}{|c|}{ Citrus sinensis (cv. Pêra) (Cf) } \\
\hline & \multicolumn{3}{|c|}{$\mathrm{N}^{0}$ total de ovos/recipiente } \\
\hline & Sem pó & Com pó & Média $^{2}$ \\
\hline Goiano Precoce & 204,50 & 197,67 & $201,08 \mathrm{~A}$ \\
\hline Arc1 & 187,50 & 182,50 & $185,00 \mathrm{~B}$ \\
\hline Arc3 & 189,17 & 181,83 & $185,50 \mathrm{~B}$ \\
\hline Arc4 & 187,17 & 184,00 & $185,58 \mathrm{~B}$ \\
\hline Média $^{2}$ & $192,08 \mathrm{a}$ & \multicolumn{2}{|l|}{$186,50 \mathrm{~b}$} \\
\hline $\mathrm{P}\left(5,15^{\star}\right)$ & $\mathrm{G}\left(10,21^{\star \star}\right)$ & \multirow{2}{*}{\multicolumn{2}{|c|}{$P+G\left(0,15^{\mathrm{ns}}\right)$}} \\
\hline CV & (1) & & \\
\hline
\end{tabular}


Tabela 41. Oviposição ( $n^{0} \mathrm{e} \%$ de ovos férteis) de Acanthoscelides obtectus em genótipos $(G)$ tradados com pós $(P)$ de origem vegetal.

\begin{tabular}{|c|c|c|c|c|c|c|}
\hline \multirow{3}{*}{ Genótipo } & \multicolumn{6}{|c|}{ Chenopodium ambrosioides (f.2) (Pa) } \\
\hline & \multicolumn{3}{|c|}{$\mathrm{N}^{0} /$ recipiente } & \multicolumn{3}{|c|}{ \% em relação ao total } \\
\hline & Sem pó & Com pó & Média $^{2}$ & Sem pó & Com pó & Média $^{2}$ \\
\hline Goiano Precoce & 167,67 & 154,00 & $160,83 \mathrm{~A}$ & 81,95 & 80,93 & $81,44 \mathrm{~A}$ \\
\hline Arc1 & 153,50 & 142,67 & $148,08 \mathrm{~B}$ & 81,87 & 81,55 & $81,71 \mathrm{~A}$ \\
\hline Arc3 & 154,33 & 141,50 & $147,92 \mathrm{~B}$ & 81,56 & 80,85 & $81,20 \mathrm{~A}$ \\
\hline Arc4 & 153,17 & 140,33 & $146,75 \mathrm{~B}$ & 81,81 & 80,69 & $81,25 \mathrm{~A}$ \\
\hline Média $^{2}$ & $157,17 \mathrm{a}$ & $144,63 \mathrm{~b}$ & & $81,80 \mathrm{a}$ & $81,00 \mathrm{a}$ & \\
\hline $\mathrm{F}$ & $\mathrm{P}\left(23,15^{\star \star}\right)$ & $G\left(6,51^{* *}\right)$ & $\mathrm{G}\left(0,53^{\mathrm{ns}}\right)$ & $P\left(3,50^{n s}\right)$ & $\mathrm{G}\left(0,30^{\mathrm{ns}}\right)$ & $\mathrm{G}\left(0,18^{\mathrm{ns}}\right)$ \\
\hline \multirow[t]{2}{*}{ CV } & & 5,98 & & & 1,80 & \\
\hline & \multicolumn{6}{|c|}{ Coriandrum sativum (Fo) $^{1}$} \\
\hline \multirow[t]{2}{*}{ Genótipo } & \multicolumn{3}{|c|}{$\mathrm{N}^{0} /$ recipiente } & \multicolumn{3}{|c|}{ \% em relação ao total } \\
\hline & Sem pó & Com pó & Média $^{2}$ & Sem pó & Com pó & Média $^{2}$ \\
\hline Goiano Precoce & 167,67 & 168,33 & $168,00 \mathrm{~A}$ & 81,95 & 82,55 & $82,25 \mathrm{~A}$ \\
\hline Arc1 & 153,50 & 150,17 & $151,83 \mathrm{~B}$ & 81,87 & 81,92 & $81,89 \mathrm{~A}$ \\
\hline Arc3 & 154,33 & 151,33 & $152,83 \mathrm{~B}$ & 81,56 & 81,84 & $81,70 \mathrm{~A}$ \\
\hline Arc4 & 153,17 & 149,00 & $151.08 \mathrm{~B}$ & 81,81 & 81,17 & $81.49 \mathrm{~A}$ \\
\hline Média $^{2}$ & $157,17 \mathrm{a}$ & $154,71 \mathrm{a}$ & & $81,80 \mathrm{a}$ & $81,87 \mathrm{a}$ & \\
\hline & $\mathrm{P}\left(1,25^{\mathrm{ns}}\right)$ & $\mathrm{G}\left(13,51^{\star *}\right)$ & $G\left(0,24^{n s}\right)$ & $P\left(0,03^{\text {ns }}\right)$ & $\mathrm{G}\left(0,52^{\mathrm{ns}}\right)$ & $\mathrm{G}\left(0,35^{\mathrm{ns}}\right)$ \\
\hline \multirow[t]{2}{*}{ CV } & & 4,88 & & & 1,89 & \\
\hline & \multicolumn{6}{|c|}{ Lafoensia glyptocarpa (Fo) } \\
\hline \multirow[t]{2}{*}{ Genótipo } & \multicolumn{3}{|c|}{$\mathrm{N}^{0} /$ recipiente } & \multicolumn{3}{|c|}{ \% em relação ao total } \\
\hline & Sem pó & Com pó & Média $^{2}$ & Sem pó & Com pó & Média $^{2}$ \\
\hline Goiano Precoce & 167,67 & 162,00 & $164,83 \mathrm{~A}$ & 81,95 & 81,96 & $81,96 \mathrm{~A}$ \\
\hline Arc1 & 153,50 & 149,00 & $151,25 \mathrm{~B}$ & 81,87 & 81,01 & $81,44 \mathrm{~A}$ \\
\hline Arc3 & 154,33 & 147,67 & $151,00 \mathrm{~B}$ & 81,56 & 80,46 & $81,01 \mathrm{~A}$ \\
\hline Arc4 & 153,17 & 150,67 & $151,92 \mathrm{~B}$ & 81,81 & 80,89 & $81,35 \mathrm{~A}$ \\
\hline Média $^{2}$ & $157,17 \mathrm{a}$ & $152,33 \mathrm{~b}$ & & $81,80 \mathrm{a}$ & $81,08 \mathrm{a}$ & \\
\hline $\mathrm{F}$ & $\mathrm{P}\left(4,13^{*}\right)$ & $\mathrm{G}\left(8,01^{\star \star}\right)$ & $\mathrm{G}\left(0,14^{\mathrm{ns}}\right)$ & $P\left(3,76^{\text {ns }}\right)$ & $\mathrm{G}\left(1,12^{\mathrm{ns}}\right)$ & $\mathrm{G}\left(0,44^{\mathrm{ns}}\right)$ \\
\hline \multirow[t]{2}{*}{$\mathrm{CV}$} & & 5,32 & & & 1,57 & \\
\hline & \multicolumn{6}{|c|}{ Citrus sinensis (cv. Pêra) (Cf) ${ }^{1}$} \\
\hline \multirow[t]{2}{*}{ Genótipo } & \multicolumn{3}{|c|}{$\mathrm{N}^{0} /$ recipiente } & \multicolumn{3}{|c|}{ \% em relação ao total } \\
\hline & Sem pó & Com pó & Média $^{2}$ & Sem pó & Com pó & Média $^{2}$ \\
\hline Goiano Precoce & 167,67 & 160,67 & $164,17 \mathrm{~A}$ & 81,95 & 81,27 & $81,61 \mathrm{~A}$ \\
\hline Arc1 & 153,50 & 147,17 & $150,67 \mathrm{~B}$ & 81,87 & 80,61 & $81,24 \mathrm{~A}$ \\
\hline Arc3 & 154,33 & 147,67 & $151,00 \mathrm{~B}$ & 81,56 & 81,20 & $81,38 \mathrm{~A}$ \\
\hline Arc4 & 153,17 & 149,33 & $151,25 \mathrm{~B}$ & 81,81 & 80,95 & $81,38 \mathrm{~A}$ \\
\hline Média ${ }^{2}$ & $157.17 \mathrm{a}$ & $151.21 \mathrm{~b}$ & & $81.80 \mathrm{a}$ & $81.01 \mathrm{a}$ & \\
\hline & $\mathrm{P}\left(6,35^{\star}\right)$ & $\mathrm{G}\left(7,38^{* *}\right)$ & $\mathrm{G}\left(1,00^{\mathrm{ns}}\right)$ & $\mathrm{P}\left(3,07^{\text {ns }}\right)$ & $\mathrm{G}\left(0,12^{\mathrm{ns}}\right)$ & $\mathrm{G}\left(0,17^{\mathrm{ns}}\right)$ \\
\hline CV & 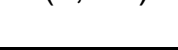 & 5,46 & & & 1,92 & \\
\hline
\end{tabular}


Em relação à oviposição, constatou-se que novamente os genótipos contendo arcelina foram os menos ovipositados (número total e número de ovos férteis) quando comparados com Goiano Precoce. Já o efeito dos pós inseticidas sobre essas variáveis ocorreu com o emprego de $C$. ambrosioides e $C$. sinensis (cv. Pêra), registrando-se nas parcelas com pós menos ovos que naquelas sem pós. Com L. glyptocarpa, embora o número total de ovos não tenha diferido nos tratamentos com e sem pó, foi constatado um número inferior de ovos férteis nas parcelas tratadas (Tabelas 40 e 41).

Já no que se refere à porcentagem de ovos férteis em relação ao número total de ovos, não foi detectado efeito dos genótipos e nem dos pós inseticidas, registrando-se valores relativamente altos (superior a $80 \%$ ) em todos os tratamentos (Tabela 41).

Comparando-se as duas espécies de insetos, verificou-se maior eficiência dos pós vegetais sobre $A$. obtectus já que no caso dessa espécie a mortalidade de adultos foi maior que para $Z$. subfasciatus. Na oviposição, os genótipos contendo arcelina apresentaram pouca preferência para as duas espécies. Os genótipos tratados com $C$. ambrosioides, foram os menos ovipositados pelas duas espécies de inseto quando comparados aos tratados com as outras espécies vegetais.

\subsubsection{Efeito na biologia}

\subsubsection{Z. subfasciatus}

Não houve significância nas interações genótipos x pós vegetais para número total de ovos (Tabela 42), e número de ovos férteis e porcentagem de ovos férteis em relação ao número total de ovos (Tabela 43), quando adultos de $Z$. subfasciatus provenientes da criação estoque foram enfestados em genótipos de feijoeiro com e sem arcelina tratados com pós de quatro plantas inseticidas. 
Tabela 42. Oviposição total de Zabrotes subfasciatus, provenientes da criação estoque, em genótipos $(\mathrm{G})$ tratados com pós $(\mathrm{P})$ de origem vegetal.

\begin{tabular}{|c|c|c|c|}
\hline \multirow{3}{*}{ Genótipo } & \multicolumn{3}{|c|}{ Chenopodium ambrosioides (f.2) (Pa) $)^{1}$} \\
\hline & \multicolumn{3}{|c|}{$\mathrm{N}^{0}$ total de ovos/recipiente } \\
\hline & Sem pó & Com pó & Média $^{2}$ \\
\hline Goiano Precoce & 32,17 & 31,17 & $31,67 \mathrm{~A}$ \\
\hline Arc1 & 24,17 & 21,83 & $23,00 \mathrm{~B}$ \\
\hline Arc3 & 24,83 & 24,83 & $24,83 \mathrm{~B}$ \\
\hline Arc4 & 26,67 & 24,50 & $25,58 \mathrm{~B}$ \\
\hline Média $^{2}$ & $26,96 \mathrm{a}$ & \multicolumn{2}{|l|}{$25,58 \mathrm{a}$} \\
\hline $\mathrm{P}\left(3,60^{\text {ns }}\right)$ & $\mathrm{G}\left(26,91^{\star \star}\right)$ & \multirow{2}{*}{\multicolumn{2}{|c|}{$P+G\left(0,57^{n s}\right)$}} \\
\hline CV & & & \\
\hline \multirow{3}{*}{ Genótipo } & \multicolumn{3}{|c|}{ Mentha pulegium (Fo) ${ }^{1}$} \\
\hline & \multicolumn{3}{|c|}{$\mathrm{N}^{0}$ total de ovos/recipiente } \\
\hline & Sem pó & Com pó & Média ${ }^{2}$ \\
\hline Goiano Precoce & 32,17 & 30,00 & $31,08 \mathrm{~A}$ \\
\hline Arc1 & 24,17 & 24,33 & $24,25 \mathrm{~B}$ \\
\hline Arc3 & 24,83 & 27,50 & $26,17 \mathrm{~B}$ \\
\hline Arc4 & 26,67 & 26,83 & $26,75 \mathrm{~B}$ \\
\hline Média $^{2}$ & $26,96 \mathrm{a}$ & $27,17 \mathrm{a}$ & \\
\hline $\mathrm{P}\left(0,09^{\mathrm{ns}}\right)$ & $\mathrm{G}\left(17,12^{\star \star}\right)$ & \multirow{2}{*}{\multicolumn{2}{|c|}{$P+G\left(2,00^{\text {ns }}\right)$}} \\
\hline CV & & & \\
\hline \multirow{3}{*}{ Genótipo } & \multicolumn{3}{|c|}{ Ocimum basilicum (Fo) } \\
\hline & \multicolumn{3}{|c|}{$\mathrm{N}^{0}$ total de ovos/ recipiente } \\
\hline & Sem pó & Com pó & Média $^{2}$ \\
\hline Goiano Precoce & 32,17 & 30,50 & $31,33 \mathrm{~A}$ \\
\hline Arc1 & 24,17 & 21,83 & $23,00 \mathrm{C}$ \\
\hline Arc3 & 24,83 & 25,50 & $25,17 \mathrm{BC}$ \\
\hline Arc4 & 26,67 & 26,00 & $26,33 \mathrm{~B}$ \\
\hline Média $^{2}$ & $26,96 \mathrm{a}$ & \multicolumn{2}{|l|}{$25,96 \mathrm{a}$} \\
\hline $\mathrm{P}\left(2,56^{\mathrm{ns}}\right)$ & $\mathrm{G}\left(31,89^{\star \star}\right)$ & \multirow{2}{*}{\multicolumn{2}{|c|}{$P+G\left(1,09^{\text {ns }}\right)$}} \\
\hline CV & & & \\
\hline \multirow{3}{*}{ Genótipo } & \multicolumn{3}{|c|}{ Ruta graveolens (Fo) } \\
\hline & \multicolumn{3}{|c|}{$\mathrm{N}^{0}$ total de ovos/recipiente } \\
\hline & Sem pó & Com pó & Média $^{2}$ \\
\hline Goiano Precoce & 32,17 & 31,17 & $31,67 \mathrm{~A}$ \\
\hline Arc1 & 24,17 & 23,67 & 23,92 B \\
\hline Arc3 & 24,83 & 24,83 & $24,83 \mathrm{~B}$ \\
\hline Arc4 & 26,67 & 26,50 & $26,58 \mathrm{~B}$ \\
\hline Média $^{2}$ & $26,96 \mathrm{a}$ & $26,54 \mathrm{a}$ & \\
\hline$P\left(0,32^{\text {ns }}\right)$ & $\mathrm{G}\left(22,24^{\star \star}\right)$ & &, $\left.09^{\text {ns }}\right)$ \\
\hline CV & & 9,50 & \\
\hline
\end{tabular}


Tabela 43. Oviposição ( $n^{0}$ e \% de ovos férteis) de Zabrotes subfasciatus provenientes da criação estoque, em genótipos $(\mathrm{G})$ tradados com pós $(\mathrm{P})$ de origem vegetal.

\begin{tabular}{|c|c|c|c|c|c|c|}
\hline \multirow{3}{*}{ Genótipo } & \multicolumn{6}{|c|}{ Chenopodium ambrosioides (f.2)(Pa) ${ }^{1}$} \\
\hline & \multicolumn{3}{|c|}{$\mathrm{N}^{0} /$ recipiente } & \multicolumn{3}{|c|}{ \% em relação ao total } \\
\hline & Sem pó & Com pó & Média $^{2}$ & Sem pó & Com pó & Média $^{2}$ \\
\hline Goiano Precoce & 25,33 & 24,67 & $25,00 \mathrm{~A}$ & 78,69 & 79,22 & $78,95 \mathrm{~A}$ \\
\hline & 17,17 & 16,50 & 16,8 & 71,00 & 75,39 & $73,20 \mathrm{~B}$ \\
\hline Arc & 17,50 & 18,50 & $18,00 \mathrm{~B}$ & 70,37 & 74,51 & $72,44 \mathrm{~B}$ \\
\hline Arc4 & 19,67 & 18,50 & $19,08 \mathrm{~B}$ & 73,67 & 75,03 & $74,36 \mathrm{~B}$ \\
\hline Média $^{2}$ & $19,92 \mathrm{a}$ & $19,54 \mathrm{a}$ & & $73,43 \mathrm{~b}$ & $76,04 \mathrm{a}$ & \\
\hline \multirow{3}{*}{$\begin{array}{l}\mathrm{F} \\
\mathrm{CV}\end{array}$} & $P\left(0,30^{\text {ns }}\right)$ & $\mathrm{G}\left(27,91^{\star \star}\right)$ & $+\mathrm{G}\left(0,47^{\mathrm{ns}}\right)$ & $\mathrm{P}\left(5,89^{\star}\right.$ & $\mathrm{G}\left(7,39^{* \star}\right) \mathrm{F}$ & $\mathrm{G}\left(0,82^{\mathrm{ns}}\right)$ \\
\hline & & 12,07 & & & 4,98 & \\
\hline & \multicolumn{6}{|c|}{ Mentha pulegium (Fo) $^{\top}$} \\
\hline \multirow{2}{*}{ Genótipo } & \multicolumn{3}{|c|}{$\mathrm{N}^{0} /$ recipiente } & \multicolumn{3}{|c|}{ \% em relação ao total } \\
\hline & Sem pó & Com pó & Média $^{2}$ & Sem pó & Com pó & Média $^{2}$ \\
\hline Goiano $\mathrm{Pr}$ & 25,33 & 24,50 & $24,92 \mathrm{~A}$ & 78,69 & 81,66 & $80,17 \mathrm{~A}$ \\
\hline & 17,17 & 18,50 & $17,83 \mathrm{~B}$ & 71,00 & 75,79 & $73,40 \mathrm{~B}$ \\
\hline Arc3 & 17,50 & 21,00 & $19,25 \mathrm{~B}$ & 70,37 & 76,31 & $73,34 \mathrm{~B}$ \\
\hline Arc4 & 19,67 & 20,83 & $20,25 \mathrm{~B}$ & 73,67 & 77,57 & $75,62 \mathrm{~B}$ \\
\hline Média $^{2}$ & $19,92 \mathrm{a}$ & $21,21 \mathrm{a}$ & & $73.43 \mathrm{~b}$ & $77,83 \mathrm{a}$ & \\
\hline & $\mathrm{P}\left(4,03^{*}\right)$ & $\mathrm{G}\left(22,71^{* *}\right)$ & $+\mathrm{G}\left(1,89^{\mathrm{ns}}\right)$ & $\mathrm{P}\left(26,46^{*}\right.$ & $\left.{ }^{\star}\right) \mathrm{G}\left(14,10^{\star \star}\right)$ & $+G\left(0,55^{n s}\right)$ \\
\hline \multirow[t]{2}{*}{$\mathrm{CV}$} & & 10,84 & & & 3,91 & \\
\hline & \multicolumn{6}{|c|}{ Ocimum basilicum (Fo) $^{\top}$} \\
\hline \multirow[t]{2}{*}{ Genótipo } & \multicolumn{3}{|c|}{$\mathrm{N}^{0} /$ recipiente } & \multicolumn{3}{|c|}{ \% em relação ao total } \\
\hline & Sem pó & Com pó & Média $^{2}$ & Sem pó & Com pó & Média $^{2}$ \\
\hline Goiano Precoce & 25,33 & 24,50 & $24,92 \mathrm{~A}$ & 78,69 & 80,31 & $79,50 \mathrm{~A}$ \\
\hline & 17,17 & 17,00 & & & 77,64 & $74,32 \mathrm{~B}$ \\
\hline & 17,50 & 18,67 & $\mathrm{BC}$ & & 73,13 & $71,75 \mathrm{~B}$ \\
\hline Arc4 & 19,67 & 19,33 & & 73,67 & 74,46 & $74,06 \mathrm{~B}$ \\
\hline Média $^{2}$ & $19.92 \mathrm{a}$ & $19.88 \mathrm{a}$ & & $73.43 \mathrm{~b}$ & $76.38 \mathrm{a}$ & \\
\hline & $P\left(0,01^{n s}\right)$ & $\mathrm{G}\left(36,30^{* *}\right)$ & $\mathrm{G}\left(0,54^{\mathrm{ns}}\right)$ & $\mathrm{P}(10,2 \mathrm{~S}$ & $\left.{ }^{\star}\right) \mathrm{G}\left(12,67^{\star \star}\right)$ & $\mathrm{G}\left(1,98^{\text {ns }}\right)$ \\
\hline \multirow{2}{*}{ CV } & & 10,09 & & & 4,25 & \\
\hline & \multicolumn{6}{|c|}{ Ruta graveolens (Fo) } \\
\hline \multirow[t]{2}{*}{ Genótipo } & \multicolumn{3}{|c|}{$\mathrm{N}^{0} /$ recipiente } & \multicolumn{3}{|c|}{ \% em relação ao total } \\
\hline & Sem pó & Com pó & Média $^{2}$ & Sem pó & Com pó & Média $^{2}$ \\
\hline Goiano Precoce & 25,33 & 24,83 & $25,08 \mathrm{~A}$ & 78,69 & 79,62 & $79,15 \mathrm{~A}$ \\
\hline & 17,1 & 17,67 & $17,42 \mathrm{~B}$ & 71,00 & 74,46 & $72,73 \mathrm{~B}$ \\
\hline Arc3 & 17,50 & 19,00 & $18,25 \mathrm{~B}$ & 70,37 & 76,31 & $74,17 \mathrm{~B}$ \\
\hline Arc4 & 19,67 & 20,17 & $19,92 \mathrm{~B}$ & 73,67 & 76,07 & $74,87 \mathrm{AB}$ \\
\hline Média $^{2}$ & $19.92 \mathrm{a}$ & $20.42 \mathrm{a}$ & & $73.43 \mathrm{~b}$ & & \\
\hline $\mathrm{F}$ & $P\left(0,53^{\text {ns }}\right)$ & $\mathrm{G}\left(25,33^{* *}\right)$ & $\left(0,36^{\text {ns }}\right)$ & $\mathrm{P}\left(5,85^{*}\right)$ & $\mathrm{G}\left(5,85^{\star *}\right)$ & $+\mathrm{G}\left(0,40^{\text {ns }}\right)$ \\
\hline & & 11,73 & & & 5,26 & \\
\hline
\end{tabular}

$\mathrm{Cf}=$ cascas dos frutos; $\mathrm{Fo}=$ folhas; $\mathrm{Fr}=$ frutos; $\mathrm{Pa}=$ parte aérea; $\mathrm{Ra}=$ ramos

${ }^{2}$ Médias seguidas pela mesma letra minúscula na horizontal, e maiúscula na vertical, não diferem entre si pelo teste de Tukey $(P \leq 0,05)$. 
O número de ovos (total e férteis) não foi afetado pelos pós das quatro espécies de plantas testadas, entretanto a porcentagem de ovos férteis (em relação ao número total de ovos) nas parcelas com pó foi superior que nas respectivas parcelas sem pó (Tabelas 42 e 43).

Nos genótipos contendo arcelina, ocorreu menor oviposição, tanto quanto ao número total de ovos quanto ao número de ovos férteis, quando comparados com 'Goiano Precoce', independentemente do emprego ou não dos pós vegetais. Não houve diferença entre os três genótipos com arcelina, excetuando-se apenas o teste com $O$. basilicum, no qual o número de ovos (total e férteis) em Arc1 foi menor que em Arc4.

A porcentagem de ovos férteis em relação ao número total de ovos nos genótipos contendo arcelina também foi menor em relação à verificada em 'Goiano Precoce' em todos os casos, excetuando-se apenas aquele em que foi empregado pó de $R$. graveolens em que essa porcentagem em Arc4 não diferiu da constatada em 'Goiano Precoce' (Tabela 43).

$\mathrm{Na}$ análise da interação genótipos $\mathrm{x}$ pós vegetais para a variável duração do período de desenvolvimento (Tabela 44), a significância foi constatada apenas com o emprego de M. pulegium. Nesse caso, o período encontrado nas parcelas tratadas de 'Goiano Precoce' e de Arc1 foi menor que nas respectivas parcelas não tratadas, enquanto para Arc3 e Arc4, não houve diferença entre parcelas tratadas e não tratadas. Independentemente do emprego dos pós, o período de desenvolvimento foi prolongado nos genótipos contendo arcelina em relação a 'Goiano Precoce'. Houve diferença na duração desse período também entre os genótipos com arcelina, havendo ainda variação em função do tratamento (ou não) com os pós. Assim, nas parcelas não tratadas, o desenvolvimento em Arc1 foi prolongado em relação a Arc3, enquanto nas tratadas constatou-se prolongamento do período em Arc4 em relação a Arc3. 
Tabela 44. Duração (dias) e viabilidade (\%) do período de desenvolvimento (ovo a adulto) de Zabrotes subfasciatus criado em genótipos (G) tratados com pós $(\mathrm{P})$ de origem vegetal.

\begin{tabular}{|c|c|c|c|c|c|c|}
\hline \multirow{3}{*}{ Genótipo } & \multicolumn{6}{|c|}{ Chenopodium ambrosioides (f.2) (Pa) } \\
\hline & \multicolumn{3}{|c|}{ Duração } & \multicolumn{3}{|c|}{ Viabilidade } \\
\hline & Sem pó & Com pó & Média $^{2}$ & Sem pó & Com pó & Média $^{2}$ \\
\hline Goiano Precoce & 31,43 & 30,86 & $31,15 \mathrm{D}$ & 94,18 & 91,81 & $92,99 \mathrm{~A}$ \\
\hline Arc1 & 40,15 & 39,79 & $39,97 \mathrm{~A}$ & 87,49 & 92,55 & $90,02 \mathrm{~A}$ \\
\hline Arc3 & 38,48 & 36,92 & $37,70 \mathrm{C}$ & 89,44 & 91,73 & $90,59 \mathrm{~A}$ \\
\hline Arc4 & 39,12 & 39,75 & $38,93 \mathrm{~B}$ & 89,64 & 91,43 & $90,53 \mathrm{~A}$ \\
\hline Média $^{2}$ & 37,29 a & $36,58 \mathrm{~b}$ & & $90,19 a$ & $91,88 \mathrm{a}$ & \\
\hline $\mathrm{F}$ & $\mathrm{P}\left(8,70^{* *}\right)$ & $\left(266,95^{\star *}\right)$ & $\mathrm{G}\left(1,40^{\mathrm{ns}}\right)$ & $P\left(2,09^{\text {ns }}\right)$ & $\mathrm{G}\left(1,30^{\mathrm{ns}}\right)$ & $P+G\left(1,73^{\text {ns }}\right)$ \\
\hline \multirow[t]{2}{*}{ CV } & & 2,29 & & & 4,44 & \\
\hline & \multicolumn{6}{|c|}{ Mentha pulegium (Fo) ${ }^{1}$} \\
\hline \multirow[t]{2}{*}{ Genótipo } & \multicolumn{3}{|c|}{ Duração } & \multicolumn{3}{|c|}{ Viabilidade } \\
\hline & Sem pó & Com pó & Média $^{2}$ & Sem pó & Com pó & Média $^{2}$ \\
\hline Goiano Precoce & $31,43 \mathrm{a}$ & $30,27 \mathrm{Cb}$ & 30,85 & $94,18 \mathrm{Aa}$ & $91,73 \mathrm{Aa}$ & 92,95 \\
\hline Arc1 & $40,15 a$ & $38,57 \mathrm{ABb}$ & 39,36 & $87,49 \mathrm{Bb}$ & $94,04 \mathrm{Aa}$ & 90,76 \\
\hline Arc3 & 38,48 a & $37,78 \mathrm{Ba}$ & 38,13 & $89,44 \mathrm{ABb}$ & $95,34 \mathrm{Aa}$ & 92,39 \\
\hline Arc4 & $39,12 \mathrm{a}$ & $39,42 \mathrm{Aa}$ & 39,27 & $89,64 \mathrm{ABa}$ & $89,96 \mathrm{Aa}$ & 89,80 \\
\hline Média $^{2}$ & 37,29 & 30,27 & & 90,19 & 92,77 & \\
\hline $\mathrm{F}$ & $\mathrm{P}\left(11,13^{\star \star}\right.$ & $\mathrm{G}\left(301,01^{\star \star}\right.$ & $+\mathrm{G}\left(2,96^{*}\right)$ & $\mathrm{P}\left(4,93^{\star}\right)$ & $\mathrm{G}\left(1,56^{\text {ns }}\right)$ & $P+G\left(3,54^{*}\right)$ \\
\hline \multirow[t]{2}{*}{$\mathrm{CV}$} & & 2,20 & & & 4,39 & \\
\hline & \multicolumn{6}{|c|}{ Ocimum basilicum (Fo) ${ }^{\top}$} \\
\hline \multirow[t]{2}{*}{ Genótipo } & \multicolumn{3}{|c|}{ Duração } & \multicolumn{3}{|c|}{ Viabilidade } \\
\hline & Sem pó & Com pó & Média $^{2}$ & Sem pó & Com pó & Média $^{2}$ \\
\hline Goiano Precoce & 31,43 & 30,96 & $31,20 \mathrm{C}$ & 94,18 & 91,13 & $92,66 \mathrm{~A}$ \\
\hline Arc1 & 40,15 & 40,11 & $40,13 \mathrm{~A}$ & 87,49 & 92,48 & $89,98 \mathrm{~A}$ \\
\hline Arc3 & 38,48 & 38,09 & $38,29 \mathrm{~B}$ & 89,44 & 92,15 & $90,79 \mathrm{~A}$ \\
\hline Arc4 & 39,12 & 38,73 & $38,92 \mathrm{~B}$ & 89,64 & 91,48 & $90,56 \mathrm{~A}$ \\
\hline Média $^{2}$ & $37.29 \mathrm{a}$ & $36.97 \mathrm{a}$ & & $90.19 a$ & $91.81 \mathrm{a}$ & \\
\hline $\mathrm{F}$ & $\mathrm{P}\left(3,14^{\mathrm{ns}}\right)$ & $\bar{G}\left(491,55^{\star *}\right)$ & $+\mathrm{G}\left(0,27^{\text {ns }}\right)$ & $P\left(1,36^{\text {ns }}\right)$ & $\mathrm{G}\left(0,60^{\mathrm{ns}}\right)$ & $P+G\left(1,49^{n s}\right)$ \\
\hline \multirow[t]{2}{*}{$\mathrm{CV}$} & & 1,70 & & & 5,28 & \\
\hline & \multicolumn{6}{|c|}{ Ruta graveolens (Fo) ${ }^{\top}$} \\
\hline \multirow[t]{2}{*}{ Genótipo } & \multicolumn{3}{|c|}{ Duração } & \multicolumn{3}{|c|}{ Viabilidade } \\
\hline & Sem pó & Com pó & Média $^{2}$ & Sem pó & Com pó & Média $^{2}$ \\
\hline Goiano Precoce & 31,43 & 30,56 & $31,00 \mathrm{D}$ & 94,18 & 90,64 & $92,41 \mathrm{~A}$ \\
\hline Arc1 & 40,15 & 40,00 & $40,07 \mathrm{~A}$ & 87,49 & 92,89 & $90,19 \mathrm{~A}$ \\
\hline Arc3 & 38,48 & 37,55 & $38,02 \mathrm{C}$ & 89,44 & 90,27 & $89,86 \mathrm{~A}$ \\
\hline Arc4 & 39,12 & 38,41 & $38,76 \mathrm{~B}$ & 89,64 & 91,78 & 90,71 \\
\hline Média $^{2}$ & $37.29 \mathrm{a}$ & $36.63 \mathrm{~b}$ & & $90.19 a$ & $91.39 \mathrm{a}$ & \\
\hline $\begin{array}{l}\mathrm{F} \\
\mathrm{CV}\end{array}$ & $\mathrm{P}\left(17,45^{\star *}\right.$ & $\begin{array}{c}\mathrm{G}\left(654,37^{\star *}\right) \\
1,49\end{array}$ & $+\mathrm{G}\left(1,25^{\mathrm{ns}}\right)$ & $P\left(0,84^{n s}\right)$ & $\begin{array}{c}\mathrm{G}\left(0,75^{\mathrm{ns}}\right) \\
5,01\end{array}$ & $P+G\left(1,99^{n s}\right)$ \\
\hline
\end{tabular}


O efeito negativo dos genótipos contendo arcelina, alongando a fase imatura do inseto, também foi constatada nos demais casos, variando apenas a intensidade em que isso ocorreu o que levou a diferenças nessa duração entre os três materiais contendo arcelina. Assim, com emprego de $C$. ambrosioides e de $R$. graveolens, a maior duração ocorreu em Arc1 e a menor em Arc3, com valores intermediários em Arc4. Já quando os grãos foram tratados com $O$. basilicum, a maior duração continuou em Arc1, não ocorrendo entretanto diferença entre os valores obtidos em Arc3 e Arc4.

Em relação à viabilidade da fase imatura, a significância da interação genótipos x pós novamente esteve restrita ao caso em que foi usado pó de M. pulegium. Nesse caso, com o uso dos grãos dos genótipos Arc1 e Arc3, os valores de viabilidade na presença do pó foi maior que na ausência. Para os outros dois genótipos, entretanto, não houve diferença entre parcelas tratadas e não tratadas. O efeito dos genótipos por outro lado, só ocorreu na ausência do pó de $M$. pulegium, situação em que a viabilidade em $\operatorname{Arc1}$ foi menor que em 'Goiano Precoce', com valores intermediários em Arc3 e 4. Para as outras três espécies vegetais testadas (em que a interação com os genótipos não foi significativa), não houve diferença na viabilidade da fase imatura do inseto na comparação entre parcelas tratadas e não tratadas com pó e tampouco foi constatada diferença quando comparadas as viabilidades nos quatro genótipos (Tabela 44).

$\mathrm{Na}$ análise dos pesos dos adultos machos (Tabela 45), em nenhum caso a interação genótipos x pó foi significativa. $\mathrm{Na}$ análise de cada fator isoladamente, constatou-se que o emprego do pó não teve qualquer efeito sobre o peso do inseto. Já o efeito dos genótipos ocorreu em todas as situações, verificando-se sempre menores pesos nos materiais contendo arcelina em relação a 'Goiano Precoce'. Na comparação entre os genótipos Arc, verificou-se que, com emprego de M. pulegium, os pesos dos insetos nos três materiais não diferiram entre si, enquanto que com as demais plantas, os pesos em Arc1 e 4 não diferiram entre si mas foram menores que os obtidos em Arc3. 
Tabela 45. Peso $(\mathrm{mg})$ de adultos de Zabrotes subfasciatus criados em genótipos $(G)$ de feijoeiro tratados com pós $(P)$ de origem vegetal.

\begin{tabular}{|c|c|c|c|c|c|c|}
\hline \multirow{3}{*}{ Genótipo } & \multicolumn{6}{|c|}{ Chenopodium ambrosioides (f.2) (Pa) } \\
\hline & \multicolumn{3}{|c|}{ Machos } & \multicolumn{3}{|c|}{ Fêmeas } \\
\hline & Sem pó & Com pó & Média $^{2}$ & Sem pó & Com pó & Média $^{2}$ \\
\hline Goiano Precoce & 1,77 & 1,76 & $1,77 \mathrm{~A}$ & 3,31 & 3,27 & $3,29 \mathrm{~A}$ \\
\hline Arc1 & 1,39 & 1,39 & $1,39 \mathrm{C}$ & 2,24 & 2,25 & $2,25 \mathrm{C}$ \\
\hline Arc3 & 1,41 & 1,42 & $1,42 \mathrm{~B}$ & 2,56 & 2,51 & $2,53 \mathrm{~B}$ \\
\hline Arc4 & 1,39 & 1,40 & $1,40 \mathrm{C}$ & 2,47 & 2,53 & $2,50 \mathrm{~B}$ \\
\hline Média $^{2}$ & $1.49 \mathrm{a}$ & $1.49 \mathrm{a}$ & & $2,64 \mathrm{a}$ & $2.64 \mathrm{a}$ & \\
\hline & $P\left(0,36^{\text {ns }}\right)$ & $\left(1909,88^{* x}\right.$ & $\mathrm{G}\left(1,31^{\mathrm{ns}}\right)$ & $\mathrm{P}(0,04$ & $\mathrm{G}(188,97$ & $\mathrm{G}\left(0,59^{\mathrm{ns}}\right)$ \\
\hline \multirow[t]{2}{*}{ CV } & & 0,97 & & & 4,29 & \\
\hline & \multicolumn{6}{|c|}{ Mentha pulegium (Fo) } \\
\hline \multirow[t]{2}{*}{ Genótipo } & \multicolumn{3}{|c|}{ Machos } & \multicolumn{3}{|c|}{ Fêmeas } \\
\hline & Sem pó & Com pó & Média $^{2}$ & Sem pó & Com pó & Média $^{2}$ \\
\hline Goiano Precoce & 1,77 & 1,78 & $1,78 \mathrm{~A}$ & $3,31 \mathrm{Aa}$ & $3,17 \mathrm{Ab}$ & 3,24 \\
\hline Arc1 & 1,39 & 1,39 & $1,39 \mathrm{~B}$ & $2,24 \mathrm{Ca}$ & $2,35 \mathrm{Ca}$ & 2,30 \\
\hline Arc3 & 1,41 & 1,40 & $1,41 \mathrm{~B}$ & $2,56 \mathrm{Ba}$ & $2,42 \mathrm{BCb}$ & 2,49 \\
\hline Arc4 & 1,39 & 1,40 & $1,40 \mathrm{~B}$ & $2,47 \mathrm{Ba}$ & $2,55 \mathrm{Ba}$ & 2,51 \\
\hline Média $^{2}$ & $1.49 \mathrm{a}$ & $1,49 a$ & & 2,64 & & \\
\hline \multirow{3}{*}{$\begin{array}{l}\mathrm{F} \\
\mathrm{CV} \\
\end{array}$} & \multirow{2}{*}{\multicolumn{3}{|c|}{$P\left(0,31^{n s}\right) G\left(1791,15^{\star \star}\right) P+G\left(1,15^{n s}\right)$}} & \multirow{2}{*}{\multicolumn{3}{|c|}{ 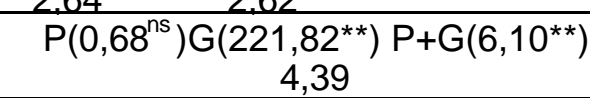 }} \\
\hline & & & & & & \\
\hline & \multicolumn{6}{|c|}{ 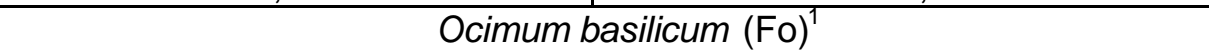 } \\
\hline \multirow[t]{2}{*}{ Genótipo } & \multicolumn{3}{|c|}{ Machos } & \multicolumn{3}{|c|}{ Fêmeas } \\
\hline & Sem pó & Com pó & Média & Sem pó & Com pó & Média $^{2}$ \\
\hline Goiano Precoce & 1,77 & 1,78 & $1,78 \mathrm{~A}$ & 3,31 & 3,29 & $3,30 \mathrm{~A}$ \\
\hline Arc1 & 1,39 & 1,37 & $1,38 \mathrm{C}$ & 2,24 & 2,25 & $2,25 \mathrm{C}$ \\
\hline Arc3 & 1,41 & 1,40 & $1,41 \mathrm{~B}$ & 2,56 & 2,53 & $2,54 \mathrm{~B}$ \\
\hline Arc4 & 1,39 & 1,38 & $1,39 \mathrm{C}$ & 2,47 & 2,51 & $2,44 \mathrm{~B}$ \\
\hline Média $^{2}$ & $1,49 \mathrm{a}$ & $1,48 \mathrm{a}$ & & $2,64 \mathrm{a}$ & $2,62 \mathrm{a}$ & \\
\hline $\mathrm{F}$ & $\mathrm{P}\left(3,14^{\mathrm{ns}}\right)$ & $\left(2074,77^{*}\right.$ & $G\left(2,21^{\mathrm{ns}}\right)$ & $\mathrm{P}(0,61$ & $\mathrm{G}\left(247,39^{*}\right.$ & $\mathrm{G}\left(0,18^{\mathrm{ns}}\right)$ \\
\hline \multirow[t]{2}{*}{ CV } & & 0,99 & & & 3,86 & \\
\hline & \multicolumn{6}{|c|}{ Ruta graveolens (Fo) } \\
\hline \multirow[t]{2}{*}{ Genótipo } & \multicolumn{3}{|c|}{ Machos } & \multicolumn{3}{|c|}{ Fêmeas } \\
\hline & Sem pó & Com pó & Média $^{2}$ & Sem pó & Com pó & Média $^{2}$ \\
\hline Goiano Precoce & 1,77 & 1,77 & $1,77 \mathrm{~A}$ & 3,31 & 3,33 & $3,32 \mathrm{~A}$ \\
\hline Arc1 & 1,39 & 1,40 & $1,40 \mathrm{C}$ & 2,24 & 2,27 & $2,25 \mathrm{C}$ \\
\hline Arc3 & 1,41 & 1,42 & $1,42 \mathrm{~B}$ & 2,56 & 2,52 & 2,54 B \\
\hline Arc4 & 1,39 & 1,39 & $1,39 \mathrm{C}$ & 2,47 & 2,40 & $2,43 \mathrm{~B}$ \\
\hline Média $^{2}$ & $1,49 \mathrm{a}$ & $1,50 \mathrm{a}$ & & $2,64 \mathrm{a}$ & $2,63 \mathrm{a}$ & \\
\hline $\mathrm{F}$ & $\mathrm{P}\left(1,30^{\mathrm{ns}}\right)$ & $\left(1791,74^{* \star}\right.$ & $\mathrm{G}\left(0,43^{\mathrm{ns}}\right)$ & $\mathrm{P}(0,22$ & $\mathrm{G}(226,78$ & $-\mathrm{G}\left(0,56^{\mathrm{ns}}\right)$ \\
\hline CV & & 1,02 & & & 4,11 & \\
\hline
\end{tabular}


Analisando-se o peso dos adultos fêmeas (Tabela 45), a única situação em que a interação foi significativa ocorreu com o emprego do pó de M. pulegium. Nesse caso, as fêmeas provenientes de 'Goiano Precoce' e de Arc3 apresentaram pesos menores nas parcelas tratadas em relação æ̀े respectivas parcelas não tratadas. Nos demais casos, não se constatou diferença no peso dos insetos na comparação de parcelas tratadas e não tratadas. A exemplo do que ocorreu com os machos, também para as fêmeas, o peso nos genótipos contendo arcelina foi menor do que em 'Goiano Precoce'. Para as três espécies de plantas inseticidas em que a interação genótipos x pó não foi significativa, os pesos das fêmeas provenientes de Arc1 foram menores que das oriundas de Arc3 e Arc4, não havendo diferença na média dessas duas últimas.

$\mathrm{Na}$ análise da variável longevidade dos machos e fêmeas (Tabela 46), a interação genótipo x pó foi significativa apenas para os machos, no tratamento com $O$. basilicum. Nesse caso, machos provenientes de 'Goiano Precoce' apresentaram longevidade menor nas parcelas não tratadas que nas tratadas, ocorrendo o inverso com as oriundas de Arc3. Em nenhuma outra situação, houve efeito na longevidade, tanto para machos como para fêmeas, em razão do tratamento com os pós das plantas inseticidas. O efeito dos genótipos foi constante em todos os casos, constatando-se que tanto machos como fêmeas provenientes dos genótipos contendo arcelina apresentaram menor longevidade (sem diferirem entre si) do que as provenientes de 'Goiano Precoce', independentemente do emprego ou não dos pós vegetais.

$\mathrm{Na}$ avaliação da fecundidade da fêmeas oriundas dos diversos tratamentos, não foi verificada significância nas interações genótipos $x$ pós vegetais para as três variáveis estudadas, número total de ovos (Tabela 47), número de ovos férteis e porcentagem de ovos férteis em relação ao número total de ovos (Tabela 48), em genótipos com e sem arcelina tratados com pós das quatro plantas inseticidas. 
Tabela 46. Longevidade (dias) de Zabrotes subfasciatus criado em genótipos $(\mathrm{G})$ de feijoeiro tratados com pós $(\mathrm{P})$ de origem vegetal.

\begin{tabular}{|c|c|c|c|c|c|c|}
\hline \multirow{3}{*}{ Genótipo } & \multicolumn{6}{|c|}{ Chenopodium ambrosioides (f.2) (Pa) } \\
\hline & \multicolumn{3}{|c|}{ Machos } & \multicolumn{3}{|c|}{ Fêmeas } \\
\hline & Sem pó & Com pó & Média $^{2}$ & Sem pó & Com pó & Média $^{2}$ \\
\hline Goiano Precoce & 12,33 & 12,27 & $12,30 \mathrm{~A}$ & 10,13 & 10,07 & $10,10 \mathrm{~A}$ \\
\hline Arc1 & 9,93 & 9,87 & $9,90 \mathrm{~B}$ & 8,47 & 9,00 & $8,73 \mathrm{~B}$ \\
\hline Arc3 & 10,53 & 10,27 & $10,40 \mathrm{~B}$ & 8,93 & 8,93 & $8,93 \mathrm{~B}$ \\
\hline Arc4 & 10,40 & 10,20 & $10,30 \mathrm{~B}$ & 8,87 & 9,27 & $9,07 \mathrm{~B}$ \\
\hline Média $^{2}$ & $10,80 \mathrm{a}$ & 10,65 a & & $9,10 a$ & $9,32 \mathrm{a}$ & \\
\hline \multirow[t]{2}{*}{$\begin{array}{l}\mathrm{F} \\
\mathrm{CV}\end{array}$} & $\mathrm{P}\left(0,49^{\mathrm{ns}}\right)$ & $\begin{array}{r}\mathrm{G}\left(24,81^{* *}\right) \\
10,99\end{array}$ & $P+G\left(0,05^{\text {ns }}\right)$ & $P\left(0,65^{\text {ns }}\right.$ & $\begin{array}{r}\mathrm{G}\left(5,15^{\star \star}\right) \\
15,99\end{array}$ & $\mathrm{O}+\mathrm{G}\left(0,30^{\mathrm{ns}}\right)$ \\
\hline & \multicolumn{6}{|c|}{ Mentha pulegium (Fo) } \\
\hline \multirow[t]{2}{*}{ Genótipo } & \multicolumn{3}{|c|}{ Machos } & \multicolumn{3}{|c|}{ Fêmeas } \\
\hline & Sem pó & Com pó & Média $^{2}$ & Sem pó & Com pó & Média $^{2}$ \\
\hline Goiano Precoce & 12,33 & 11,87 & $12,10 \mathrm{~A}$ & 10,13 & 10,53 & $10,33 \mathrm{~A}$ \\
\hline Arc1 & 9,93 & 9,60 & $9,77 \mathrm{~B}$ & 8,47 & 8,80 & $8,63 \mathrm{~B}$ \\
\hline Arc3 & 10,53 & 10,07 & $10,30 \mathrm{~B}$ & 8,93 & 8,60 & $8,77 \mathrm{~B}$ \\
\hline Arc4 & 10,40 & 10,13 & $10,27 \mathrm{~B}$ & 8,87 & 8,80 & $8,83 \mathrm{~B}$ \\
\hline Média $^{2}$ & $10,80 \mathrm{a}$ & $10,42 \mathrm{a}$ & & $9,10 \mathrm{a}$ & $9,18 \mathrm{a}$ & \\
\hline $\mathrm{F}$ & $\mathrm{P}\left(3,81^{\mathrm{ns}}\right)$ & $\mathrm{G}\left(27,18^{* *}\right)$ & $P+G\left(0,06^{\text {ns }}\right)$ & $\mathrm{P}\left(0,10^{\mathrm{ns}}\right.$ & $\mathrm{G}\left(9,23^{\star \star}\right)$ & $\mathrm{P}+\mathrm{G}\left(0,43^{\mathrm{ns}}\right)$ \\
\hline \multirow[t]{2}{*}{ CV } & & 10,14 & & & 15,75 & \\
\hline & \multicolumn{6}{|c|}{ Ocimum basilicum (Fo) ${ }^{\top}$} \\
\hline \multirow[t]{2}{*}{ Genótipo } & \multicolumn{3}{|c|}{ Machos } & \multicolumn{3}{|c|}{ Fêmeas } \\
\hline & Sem pó & Com pó & Média $^{2}$ & Sem pó & Com pó & Média $^{2}$ \\
\hline Goiano Precoce & $12,33 \mathrm{Ab}$ & $13,33 \mathrm{Aa}$ & 12,83 & 10,13 & 10,13 & $10,13 \mathrm{~A}$ \\
\hline Arc1 & $9,93 \mathrm{Ba}$ & $9,80 \mathrm{Ba}$ & 9,87 & 8,47 & 8,80 & $8,63 \mathrm{~B}$ \\
\hline Arc3 & $10,53 \mathrm{Ba}$ & $9,53 \mathrm{Bb}$ & 10,03 & 8,93 & 8,53 & 8,73 B \\
\hline Arc4 & $10,40 \mathrm{Ba}$ & $9,87 \mathrm{Ba}$ & 10,13 & 8,87 & 9,00 & $8,93 \mathrm{~B}$ \\
\hline Média $^{2}$ & 10,80 & 10,63 & & $9,10 a$ & $9,12 \mathrm{a}$ & \\
\hline \multirow[t]{2}{*}{$\mathrm{F}$} & $\mathrm{P}\left(0,61^{\mathrm{ns}}\right)$ & $\begin{array}{c}\mathrm{G}\left(44,05^{\star \star}\right) \\
10,90\end{array}$ & $P+G\left(4,02^{\star \star}\right)$ & \multicolumn{3}{|c|}{$\begin{array}{c}P\left(0,01^{n s}\right) G\left(7,24^{\star \star}\right) P+G\left(0,36^{n s}\right) \\
15,53\end{array}$} \\
\hline & \multicolumn{6}{|c|}{ Ruta graveolens (Fo) $^{1}$} \\
\hline \multirow[t]{2}{*}{ Genótipo } & \multicolumn{3}{|c|}{ Machos } & \multicolumn{3}{|c|}{ Fêmeas } \\
\hline & Sem pó & Com pó & Média $^{2}$ & Sem pó & Com pó & Média $^{2}$ \\
\hline Goiano Precoce & 12,33 & 12,27 & $12,30 \mathrm{~A}$ & 10,13 & 10,53 & $10,33 \mathrm{~A}$ \\
\hline Arc1 & 9,93 & 9,93 & $9,93 \mathrm{~B}$ & 8,47 & 8,33 & $8,40 \mathrm{~B}$ \\
\hline Arc3 & 10,53 & 10,33 & $10,43 \mathrm{~B}$ & 8,93 & 8,27 & $8,60 \mathrm{~B}$ \\
\hline Arc4 & 10,40 & 10,53 & $10,47 \mathrm{~B}$ & 8,87 & 8,67 & $8,77 \mathrm{~B}$ \\
\hline Média $^{2}$ & $10,80 \mathrm{a}$ & $10,77 \mathrm{a}$ & & $9,10 \mathrm{a}$ & $8,95 \mathrm{a}$ & \\
\hline $\mathrm{F}$ & $P\left(0,03^{\text {ns }}\right)$ & $\mathrm{G}\left(28,28^{* *}\right)$ & $P+G\left(0,13^{\text {ns }}\right)$ & $P\left(0,38^{\text {ns }}\right) G$ & $\left(13,19^{\star \star}\right) \mathrm{P}_{+}$ & $\mathrm{G}\left(0,80^{\mathrm{ns}}\right)$ \\
\hline CV & & 9,93 & & & 14,79 & \\
\hline
\end{tabular}


Tabela 47. Fecundidade ( $n^{0}$ total de ovos) de Zabrotes subfasciatus criado em diferentes genótipos $(G)$ de feijoeiro tratados com pós $(P)$ de origem vegetal.

\begin{tabular}{|c|c|c|c|}
\hline \multirow{3}{*}{ Genótipo } & \multicolumn{3}{|c|}{ Chenopodium ambrosioides (f.2) $(\mathrm{Pa})^{1}$} \\
\hline & \multicolumn{3}{|c|}{$\mathrm{N}^{0}$ total de ovos/recipiente } \\
\hline & Sem pó & Com pó & Média $^{2}$ \\
\hline Goiano Precoce & 38,73 & 39,27 & $39,00 \mathrm{~A}$ \\
\hline Arc1 & 25,20 & 25,20 & $25,20 \mathrm{C}$ \\
\hline Arc3 & 28,60 & 29,00 & $28,80 \mathrm{~B}$ \\
\hline Arc4 & 26,20 & 26,73 & $26,47 \mathrm{C}$ \\
\hline Média $^{2}$ & 29,68 a & \multicolumn{2}{|l|}{$30,05 \mathrm{a}$} \\
\hline $\mathrm{P}\left(0,54^{\mathrm{ns}}\right)$ & $\mathrm{G}\left(157,27^{\star \star}\right)$ & \multirow{2}{*}{\multicolumn{2}{|c|}{$P+G\left(0,06^{n s}\right)$}} \\
\hline \multirow[t]{2}{*}{ CV } & & & \\
\hline & \multicolumn{3}{|c|}{ Mentha pulegium (Fo) ${ }^{1}$} \\
\hline \multirow[t]{2}{*}{ Genótipo } & \multicolumn{3}{|c|}{$\mathrm{N}^{0}$ total de ovos/recipiente } \\
\hline & Sem pó & Com pó & Média $^{2}$ \\
\hline Goiano Precoce & 38,73 & 39,60 & $39,17 \mathrm{~A}$ \\
\hline Arc1 & 25,20 & 25,47 & $25,33 \mathrm{C}$ \\
\hline Arc3 & 28,60 & 29,47 & $29,03 \mathrm{~B}$ \\
\hline Arc4 & 26,20 & 27,07 & $26,63 \mathrm{C}$ \\
\hline Média $^{2}$ & 29,68 a & $30,40 \mathrm{a}$ & \\
\hline $\mathrm{P}\left(2,40^{\mathrm{ns}}\right)$ & $\mathrm{G}\left(183,83^{\star \star}\right)$ & & $\left.11^{\mathrm{ns}}\right)$ \\
\hline CV & & 8,43 & \\
\hline \multirow{3}{*}{ Genótipo } & \multicolumn{3}{|c|}{ Ocimum basilicum (Fo) $)^{1}$} \\
\hline & \multicolumn{3}{|c|}{$\mathrm{N}^{0}$ total de ovos/ recipiente } \\
\hline & Sem pó & Com pó & Média $^{2}$ \\
\hline Goiano Precoce & 38,73 & 40,20 & $39,47 \mathrm{~A}$ \\
\hline Arc1 & 25,20 & 24,87 & $25,03 \mathrm{C}$ \\
\hline Arc3 & 28,60 & 28,87 & $28,73 \mathrm{~B}$ \\
\hline Arc4 & 26,20 & 25,80 & $25,03 \mathrm{C}$ \\
\hline Média $^{2}$ & 29,68 a & $29,93 \mathrm{a}$ & \\
\hline$P\left(0,29^{\text {ns }}\right)$ & $\mathrm{G}\left(206,77^{\star \star}\right)$ & & $\left.88^{\text {ns }}\right)$ \\
\hline CV & & 8,47 & \\
\hline \multirow{3}{*}{ Genótipo } & \multicolumn{3}{|c|}{ Ruta graveolens (Fo) ${ }^{1}$} \\
\hline & \multicolumn{3}{|c|}{$\mathrm{N}^{0}$ total de ovos/recipiente } \\
\hline & Sem pó & Com pó & Média $^{2}$ \\
\hline Goiano Precoce & 38,73 & 40,80 & $39,77 \mathrm{~A}$ \\
\hline Arc1 & 25,20 & 24,33 & $24,77 \mathrm{C}$ \\
\hline Arc3 & 28,60 & 28,30 & $28,30 \mathrm{~B}$ \\
\hline Arc4 & 26,20 & 27,40 & $26,80 \mathrm{~B}$ \\
\hline Média $^{2}$ & 29,68 a & $30,13 \mathrm{a}$ & \\
\hline $\mathrm{P}\left(1,05^{\mathrm{ns}}\right)$ & $\mathrm{G}\left(234,60^{\star \star}\right)$ & & $\left.60^{\text {ns }}\right)$ \\
\hline 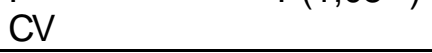 & & 8,05 & \\
\hline
\end{tabular}


Tabela 48. Fecundidade ( $\mathrm{n}^{0}$ e $\%$ de ovos férteis) de Zabrotes subfasciatus criado em diferentes genótipos $(G)$ de feijoeiro tratados com pós (P) de origem vegetal

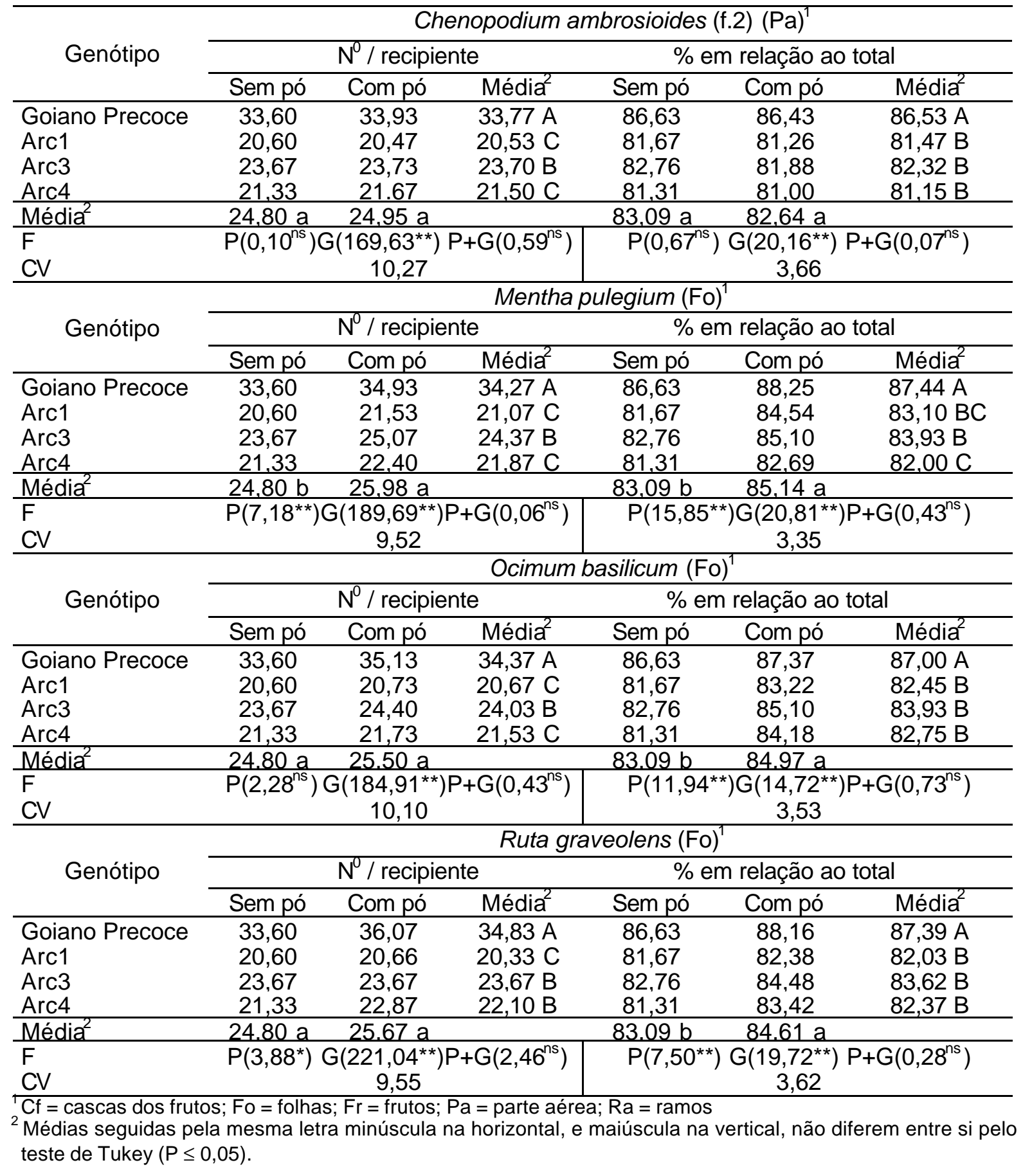


Em relação ao número total de ovos (fecundidade) fos adultos provenientes dos diferentes tratamentos, não houve diferença entre parcelas tratadas e não tratadas com os pós vegetais (Tabela 47). Em todos os casos, entretanto esse número foi menor para insetos provenientes de genótipos contendo arcelina em relação aos oriundos de 'Goiano Precoce'. Na comparação entre os genótipos contendo arcelina, verifica-se que os valores em Arc1 e Arc4 não diferiram entre si, mas foram menores que em Arc3, com exceção da situação em que foi usado pó de $R$. graveolens, caso em que os valores em Arc1 foram maiores que nos outros dois genótipos Arc.

O número de ovos férteis nas parcelas com pó de $M$. pulegium foi maior que nas respectivas parcelas sem pó, sendo esse o único caso em que houve diferença entre parcelas tratadas e não tratadas. Quando se considerou a porcentagem de ovos férteis em relação ao número total, no entanto, o maior valor nas parcelas tratadas (em relação às parcelas não tratadas) ocorreu com todas as plantas inseticidas, com exceção de $C$. ambrosioides.

O efeito dos genótipos com arcelina, por outro lado, ocorreu em todas as situações, constatando-se sempre menor número e menor porcentagem de ovos férteis nesses materiais comparados a 'Goiano Precoce'. Em relação ao número de ovos férteis, os valores em Arc1 e Arc4 foram semelhantes entre si e menores que em Arc3 em todos os casos exceto quando se empregou $R$. graveolens, em que o valor em Arc1 também foi menor do que em Arc4. Para a porcentagem de ovos férteis, não houve diferença entre os genótipos com arcelina a não ser com o emprego de $M$. pulegium, em que esse valor em Arc4 foi menor que em Arc3.

\subsubsection{A. obtectus}

Não houve significância nas interações genótipos $x$ pós vegetais para número total de ovos (Tabela 49), número de ovos férteis e porcentagem de ovos férteis em relação ao número total de ovos (Tabela 50), quando adultos 
Tabela 49. Oviposição total de Acanthoscelides obtectus, provenientes da criação estoque, em genótipos $(G)$ tratados com pós $(P)$ de origem vegetal.

\begin{tabular}{|c|c|c|c|}
\hline \multirow{3}{*}{ Genótipo } & \multicolumn{3}{|c|}{ Chenopodium ambrosioides (f.2) $(\mathrm{Pa})^{1}$} \\
\hline & \multicolumn{3}{|c|}{$\mathrm{N}^{0}$ total de ovos/recipiente } \\
\hline & Sem pó & Com pó & Média $^{2}$ \\
\hline Goiano Precoce & 38,67 & 38,67 & $38,67 \mathrm{~A}$ \\
\hline Arc1 & 29,50 & 29,33 & $29,42 \mathrm{~B}$ \\
\hline Arc3 & 30,50 & 30,67 & $30,58 \mathrm{~B}$ \\
\hline Arc4 & 31,50 & 30,50 & $31,00 \mathrm{~B}$ \\
\hline Média $^{2}$ & $32,54 \mathrm{a}$ & \multicolumn{2}{|l|}{$32,29 \mathrm{a}$} \\
\hline $\mathrm{P}\left(0,10^{\text {ns }}\right)$ & $\mathrm{G}\left(29,34^{\star \star}\right)$ & \multirow{2}{*}{\multicolumn{2}{|c|}{$P+G\left(0,11^{n s}\right)$}} \\
\hline CV & & & \\
\hline \multirow{3}{*}{ Genótipo } & \multicolumn{3}{|c|}{ Coriandrum sativum (Fo) ${ }^{1}$} \\
\hline & \multicolumn{3}{|c|}{$\mathrm{N}^{0}$ total de ovos/recipiente } \\
\hline & Sem pó & Com pó & Média $^{2}$ \\
\hline Goiano Precoce & 38,67 & 41,50 & $40,08 \mathrm{~A}$ \\
\hline Arc1 & 29,50 & 29,50 & $29,50 \mathrm{~B}$ \\
\hline Arc3 & 30,50 & 31,67 & $31,08 \mathrm{~B}$ \\
\hline Arc4 & 31,50 & 31,17 & $31,33 \mathrm{~B}$ \\
\hline Média $^{2}$ & $32,54 \mathrm{a}$ & $33,46 \mathrm{a}$ & \\
\hline$P\left(1,36^{\text {ns }}\right)$ & $\mathrm{G}\left(37,10^{* \star}\right)$ & & $\left.83^{\mathrm{ns}}\right)$ \\
\hline $\mathrm{CV}$ & & 8,26 & \\
\hline \multirow{3}{*}{ Genótipo } & \multicolumn{3}{|c|}{ Lafoensia glyptocarpa (Fo) $^{1}$} \\
\hline & \multicolumn{3}{|c|}{$\mathrm{N}^{0}$ total de ovos/ recipiente } \\
\hline & Sem pó & Com pó & Média ${ }^{2}$ \\
\hline Goiano Precoce & 38,67 & 40,33 & $39,50 \mathrm{~A}$ \\
\hline Arc1 & 29,50 & 30,17 & $29,83 B$ \\
\hline Arc3 & 30,50 & 31,33 & $30,92 \mathrm{~B}$ \\
\hline Arc4 & 31,50 & 31,67 & $31,58 \mathrm{~B}$ \\
\hline Média $^{2}$ & $32,54 \mathrm{a}$ & $33,38 \mathrm{a}$ & \\
\hline$P\left(1,54^{\text {ns }}\right)$ & $\mathrm{G}\left(43,29^{\star \star}\right)$ & & $\left.22^{\mathrm{ns}}\right)$ \\
\hline CV & & 7,06 & \\
\hline \multirow{3}{*}{ Genótipo } & \multicolumn{3}{|c|}{ Citrus sinensis (cv. Pêra) (Cf) } \\
\hline & \multicolumn{3}{|c|}{$\mathrm{N}^{0}$ total de ovos/recipiente } \\
\hline & Sem pó & Com pó & Média ${ }^{2}$ \\
\hline Goiano Precoce & 38,67 & 40,33 & $39,50 \mathrm{~A}$ \\
\hline Arc1 & 29,50 & 30,83 & $30,17 \mathrm{~B}$ \\
\hline Arc3 & 30,50 & 30,17 & $30,33 \mathrm{~B}$ \\
\hline Arc4 & 31,50 & 30,00 & $30,75 \mathrm{~B}$ \\
\hline Média $^{2}$ & $32,54 \mathrm{a}$ & $32,83 \mathrm{a}$ & \\
\hline $\mathrm{P}\left(0,16^{\mathrm{ns}}\right)$ & $\mathrm{G}\left(37,78^{\star \star}\right)$ & & $\left.00^{\text {ns }}\right)$ \\
\hline . & & 7,84 & \\
\hline
\end{tabular}


Tabela 50. Oviposição ( $n^{0}$ e \% de ovos férteis) de Acanthoscelides obtectus, provenientes da criação estoque, em genótipos (G) de feijoeiro tratados com pós $(\mathrm{P})$ de origem vegetal.

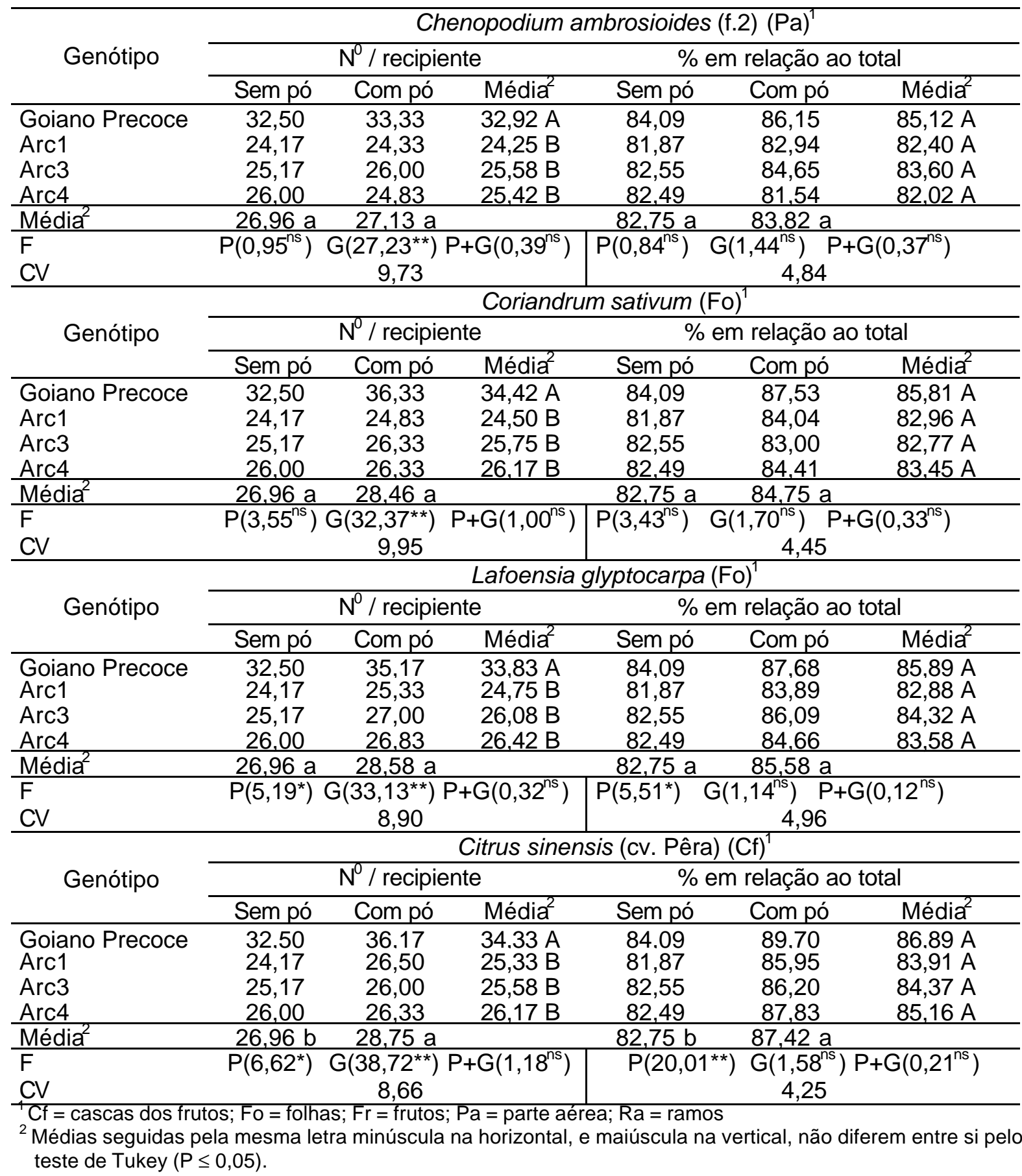


de $A$. obtectus provenientes da criação estoque foram infestados em genótipos com e sem arcelina tratados com pós de quatro plantas inseticidas.

O número total de ovos não foi afetado pelos pós das quatro espécies de plantas testadas, o mesmo ocorrendo com o número e porcentagem de ovos férteis, com exceção do experimento com pó de $C$. sinensis, em que os referidos valores nas parcelas tratadas foram superiores em comparação com as não tratadas.

Nos genótipos contendo arcelina ocorreu menor oviposição, considerando-se tanto o número total de ovos como o número de ovos férteis, quando comparados com 'Goiano Precoce', independentemente do emprego ou não dos pós vegetais, sendo que não houve diferença entre os três genótipos com arcelina. Considerando-se, entretanto, a porcentagem de ovos férteis em relação ao total, não houve diferença entre os diversos tratamentos.

Analisando a duração do período de desenvolvimento (Tabela 51), verificou-se que não houve interação genótipo x pó em nenhum dos casos. $O$ efeito dos pós vegetais só foi constatado com C. sativum e L. glyptocarpa, verificando-se nesses tratamentos prolongamento no período de desenvolvimento dos insetos em comparação às respectivas parcelas sem pó. Em todas as situações, por outro lado, os genótipos contendo arcelina prolongaram o desenvolvimento dos insetos quando comparados com Goiano Precoce. No genótipo Arc1, este prolongamento foi mais drástico sendo o valor neste material superior aos registrados nos demais genótipos contendo arcelina.

Em relação àviabilidade da fase imatura (Tabela 51), também não se verificou significância na interação genótipos $x$ pós, sendo que tal viabilidade não foi afetada pelos pós das quatro espécies de plantas testadas. No que se refere ao efeito dos genótipos, entretanto, houve diferença nas médias dessas variáveis. Assim, no genótipo Arc3, as viabilidades foram menores quando comparadas àquelas registradas em 'Goiano Precoce' em todas as situações. Com o genótipo Arc4, isto ocorreu apenas nos tratamentos com $C$. sativum e $C$. 
Tabela 51. Duração (dias) e viabilidade (\%) do período de desenvolvimento (ovo a adulto) de Acanthoscelides obtectus criado em genótipos (G) de feijoeiro tratados com pós $(\mathrm{P})$ de origem vegetal.

\begin{tabular}{|c|c|c|c|c|c|c|}
\hline \multirow{3}{*}{ Genótipo } & \multicolumn{6}{|c|}{ Chenopodium ambrosioides (f.2) (Pa) } \\
\hline & \multicolumn{3}{|c|}{ Duração } & \multicolumn{3}{|c|}{ Viabilidade } \\
\hline & Sem pó & Com pó & Média $^{2}$ & Sem pó & Com pó & Média $^{2}$ \\
\hline Goiano Precoce & 38,41 & 38,35 & $38,38 \mathrm{C}$ & 90,67 & 89,91 & $90,29 \mathrm{~A}$ \\
\hline Arc1 & 42,72 & 42,81 & $42,77 \mathrm{~A}$ & 89,46 & 89,92 & $89,69 \mathrm{AB}$ \\
\hline Arc3 & 41,10 & 41,27 & $41,19 \mathrm{~B}$ & 86,05 & 85,88 & $85,97 \mathrm{~B}$ \\
\hline Arc4 & 41,05 & 41,52 & $41,29 \mathrm{~B}$ & 87,52 & 86,70 & $87,11 \mathrm{AB}$ \\
\hline Média ${ }^{2}$ & $40.82 \mathrm{a}$ & \multicolumn{2}{|l|}{$40.99 \mathrm{a}$} & $88.43 \mathrm{a}$ & \multicolumn{2}{|l|}{$88.10 \mathrm{a}$} \\
\hline \multirow{2}{*}{$\mathrm{CV}$} & $P\left(0,62^{n s}\right)$ & \multicolumn{2}{|c|}{$\begin{array}{c}\mathrm{G}\left(75,04^{* *}\right) \quad P+G\left(0,28^{\text {ns }}\right) \\
1,79\end{array}$} & \multicolumn{3}{|c|}{$\begin{array}{c}P\left(0,10^{\text {ns }}\right) G\left(3,85^{\star}\right) P+G\left(0,08^{\text {ns }}\right) \\
4,12\end{array}$} \\
\hline & \multicolumn{6}{|c|}{ Coriandrum sativum (Fo) ${ }^{1}$} \\
\hline \multirow[t]{2}{*}{ Genótipo } & \multicolumn{3}{|c|}{ Duração } & \multicolumn{3}{|c|}{ Viabilidade } \\
\hline & Sem pó & Com pó & Média $^{2}$ & Sem pó & Com pó & Média $^{2}$ \\
\hline $\begin{array}{l}\text { Goiano Precoce } \\
\text { Arc1 } \\
\text { Arc3 } \\
\text { Arc4 }\end{array}$ & $\begin{array}{l}38,41 \\
42,72 \\
41,10 \\
41,05 \\
\end{array}$ & $\begin{array}{l}38,86 \\
43,36 \\
41,79 \\
42,44\end{array}$ & $\begin{array}{l}38,63 \mathrm{C} \\
43,04 \mathrm{~A} \\
41,44 \mathrm{~B} \\
41,74 \mathrm{~B}\end{array}$ & $\begin{array}{l}90,67 \\
89,46 \\
86,05 \\
87,52\end{array}$ & $\begin{array}{l}91,71 \\
88,64 \\
86,03 \\
86,53\end{array}$ & $\begin{array}{c}91,19 \mathrm{~A} \\
89,05 \mathrm{AB} \\
86,04 \mathrm{~B} \\
87,03 \mathrm{~B}\end{array}$ \\
\hline Média ${ }^{2}$ & $40.82 \mathrm{~b}$ & $41.61 \mathrm{a}$ & & $88.43 \mathrm{a}$ & $88.22 \mathrm{a}$ & \\
\hline $\mathrm{F}$ & $\mathrm{P}\left(19,99^{\star \star}\right.$ & $G\left(110,47^{* *}\right.$ & $+\mathrm{G}\left(1,36^{\mathrm{ns}}\right)$ & $P\left(0,06^{n}\right.$ & $\mathrm{G}\left(7,65^{\star \star}\right)$ & $G\left(0,32^{n s}\right)$ \\
\hline \multirow[t]{2}{*}{$\mathrm{CV}$} & & 1,48 & & & 3,24 & \\
\hline & \multicolumn{6}{|c|}{$L_{\text {Lafoensia glyptocarpa (Fo) }}{ }^{1}$} \\
\hline \multirow[t]{2}{*}{ Genótipo } & \multicolumn{3}{|c|}{ Duração } & \multicolumn{3}{|c|}{ Viabilidade } \\
\hline & Sem pó & Com pó & Média $^{2}$ & Sem pó & Com pó & Média $^{2}$ \\
\hline $\begin{array}{l}\text { Goiano Precoce } \\
\text { Arc1 } \\
\text { Arc3 } \\
\text { Arc4 }\end{array}$ & $\begin{array}{l}38.41 \\
42,72 \\
41,10 \\
41,05 \\
\end{array}$ & $\begin{array}{l}39.15 \\
43,25 \\
42,39 \\
42,27\end{array}$ & $\begin{array}{l}38.78 \mathrm{C} \\
42,98 \mathrm{~A} \\
41,74 \mathrm{~B} \\
41,66 \mathrm{~B}\end{array}$ & $\begin{array}{l}90.67 \\
89,46 \\
86,05 \\
87,52 \\
\end{array}$ & $\begin{array}{l}91.87 \\
88,41 \\
87,09 \\
87,53 \\
\end{array}$ & $\begin{array}{c}91,27 \mathrm{~A} \\
88,94 \mathrm{AB} \\
86,57 \mathrm{~B} \\
87,52 \mathrm{AB}\end{array}$ \\
\hline Média ${ }^{2}$ & $40,82 \mathrm{~b}$ & $41,76 \mathrm{a}$ & & $88,43 \mathrm{a}$ & $88,73 \mathrm{a}$ & \\
\hline $\begin{array}{l}\mathrm{F} \\
\mathrm{CV}\end{array}$ & $\mathrm{P}\left(32,87^{\star \star}\right.$ & $\begin{array}{c}\mathrm{G}\left(117,13^{\star *}\right. \\
1,38\end{array}$ & $+\mathrm{G}\left(1,27^{\mathrm{ns}}\right)$ & $\mathrm{P}\left(0,08^{\prime}\right.$ & $\begin{array}{c}\mathrm{G}\left(3,52^{\star *}\right) \\
4,26\end{array}$ & $\mathrm{G}\left(0,23^{\mathrm{ns}}\right)$ \\
\hline $\mathrm{CV}$ & \multicolumn{6}{|c|}{ Citrus sinensis (cv. Pêra) (Cf) $^{1}$} \\
\hline \multirow[t]{2}{*}{ Genótipo } & \multicolumn{3}{|c|}{ Duração } & \multicolumn{3}{|c|}{ Viabilidade } \\
\hline & Sem pó & Com pó & Média $^{2}$ & Sem pó & Com pó & Média $^{2}$ \\
\hline $\begin{array}{l}\text { Goiano Precoce } \\
\text { Arc1 } \\
\text { Arc3 } \\
\text { Arc4 }\end{array}$ & $\begin{array}{l}38,41 \\
42,72 \\
41,10 \\
41,05 \\
\end{array}$ & $\begin{array}{l}38,75 \\
42,36 \\
41,60 \\
41,66 \\
\end{array}$ & $\begin{array}{l}38,58 \mathrm{C} \\
42,54 \mathrm{~A} \\
41,35 \mathrm{~B} \\
41,36 \mathrm{~B} \\
\end{array}$ & $\begin{array}{l}90,67 \\
89,46 \\
86,05 \\
87,52 \\
\end{array}$ & $\begin{array}{l}92,66 \\
86,77 \\
87,82 \\
88,68 \\
\end{array}$ & $\begin{array}{l}91,66 \mathrm{~A} \\
88,12 \mathrm{~B} \\
86,94 \mathrm{~B} \\
88,10 \mathrm{~B} \\
\end{array}$ \\
\hline Média ${ }^{2}$ & $40.82 \mathrm{a}$ & $41.09 \mathrm{a}$ & & $88.43 \mathrm{a}$ & $88.98 \mathrm{a}$ & \\
\hline $\mathrm{F}$ & $\mathrm{P}\left(3,00^{\mathrm{ns}}\right)$ & $\mathrm{G}\left(114,28^{\star *}\right)$ & $P+G\left(1,93^{\text {ns }}\right)$ & $\mathrm{P}\left(0,40^{\prime}\right.$ & $\mathrm{G}\left(5,52^{\star \star}\right)$ & $\mathrm{G}\left(1,58^{\mathrm{ns}}\right)$ \\
\hline CV & & 1,33 & & & 3,41 & \\
\hline
\end{tabular}


sinensis. Já com Arc1, os valores foram sempre intermediários, excetuando-se o teste com $C$. sinensis, em que a viabilidade foi menor que em 'Goiano Precoce', embora sem diferir das constatadas nos demais Arc.

$\mathrm{Na}$ análise dos pesos dos adultos machos (Tabela 52), o único caso em que a interação foi significativa ocorreu com o emprego do pó de $C$. sinensis. Nesse caso, no genótipo Arc3, os adultos apresentaram pesos memores nas parcelas tratadas em relação æ̀ respectivas parcelas não tratadas. Para os demais genótipos, não se constatou diferença no peso dos insetos na comparação de parcelas tratadas e não tratadas com pó de $C$. sinensis. Quando utilizou-se C. sativum, em todos os genótipos ocorreram menores pesos nas parcelas tratadas com pó em relação æ̀s respectivas parcelas não tratadas, enquanto com os pós de $L$. glyptocarpa e de $C$. ambrosioides, em nenhum dos genótipos houve diferença no peso dos machos entre as parcelas tratadas e as respectivas parcelas não tratadas. O efeito dos genótipos ocorreu em todas as situações, verificando-se sempre menores pesos nos materiais contendo arcelina em relação a 'Goiano Precoce'. Comparando-se os genótipos contendo arcelina, verificou-se o efeito mais pronunciado em Arc1, onde foram constatados pesos menores em comparação a Arc3 e Arc4, com exceção do ensaio com $C$. sinensis em que, nas parcelas tratadas, não ocorreu diferença entre os três Arc.

Já no caso dos pesos dos adultos fêmeas (Tabela 52) em nenhum caso a interação genótipo x pó foi significativa. $\mathrm{Na}$ análise isolada, constatou-se que o pó afetou essa variável com a utilização de $C$. sativum e $C$. sinensis, verificando-se pesos menores nas parcelas tratadas. Com as outras duas espécies vegetais, não houve diferença no peso dos insetos nas parcelas com e sem pó. A exemplo do que ocorreu com os machos, também para as fêmeas, o peso nos genótipos contendo arcelina foi menor do que em 'Goiano Precoce'. Comparando-se os genótipos contendo arcelina, entretanto, em todas situações, os três genótipos diferiram entre si, constatando-se menores valores em Arc1, seguindo-se Arc3 e Arc4. 
Tabela 52. Peso $(\mathrm{mg})$ de adultos de Acanthoscelides obtectus criados em genótipos $(G)$ de feijoeiro tratados com pós $(P)$ de origem vegetal.

\begin{tabular}{|c|c|c|c|c|c|c|}
\hline \multirow{3}{*}{ Genótipo } & \multicolumn{6}{|c|}{ Chenopodium ambrosioides (f.2) (Pa) $)_{1}$} \\
\hline & \multicolumn{3}{|c|}{ Machos } & \multicolumn{3}{|c|}{ Fêmeas } \\
\hline & Sem pó & Com pó & Média $^{2}$ & Sem pó & Com pó & Média $^{2}$ \\
\hline Goiano Precoce & 3,69 & 3,65 & $3,67 \mathrm{~A}$ & 4,75 & 4,75 & $4,75 \mathrm{~A}$ \\
\hline & 3,54 & 3,54 & $3,54 \mathrm{C}$ & 4,52 & 4,52 & $4,52 \mathrm{D}$ \\
\hline Arc3 & 3,59 & 3,60 & $3,60 \mathrm{~B}$ & 4,58 & 4,59 & $4,58 \mathrm{C}$ \\
\hline Arc4 & 3,58 & 3,60 & $3,59 \mathrm{~B}$ & 4.63 & 4,62 & $4,63 \mathrm{~B}$ \\
\hline Média $^{2}$ & $3,60 \mathrm{a}$ & $3,60 \mathrm{a}$ & & $4,62 \mathrm{a}$ & $4,62 \mathrm{a}$ & \\
\hline $\mathrm{F}$ & $P\left(0,16^{\text {ns }}\right)$ & $\mathrm{G}\left(54,80^{\star *}\right)$ & $P+G\left(2,64^{n s}\right)$ & $\mathrm{P}(0,41$ & $\mathrm{G}(272,43$ & $\mathrm{G}\left(0,35^{\mathrm{ns}}\right)$ \\
\hline \multirow[t]{2}{*}{ CV } & & 0,70 & & & 0,44 & \\
\hline & \multicolumn{6}{|c|}{ Coriandrum sativum (Fo) $^{1}$} \\
\hline \multirow[t]{2}{*}{ Genótipo } & \multicolumn{3}{|c|}{ Machos } & \multicolumn{3}{|c|}{ Fêmeas } \\
\hline & Sem pó & Com pó & Média $^{2}$ & Sem pó & Com pó & Média $^{2}$ \\
\hline Goiano Precoce & 3.69 & 3.63 & $3.66 \mathrm{~A}$ & 4.75 & 4.72 & $4.74 \mathrm{~A}$ \\
\hline Arc1 & 3,54 & 3,52 & $3,53 \mathrm{C}$ & 4,52 & 4,51 & $4,51 \mathrm{D}$ \\
\hline Arc3 & 3,59 & 3,59 & $3,59 \mathrm{~B}$ & 4,58 & 4,56 & $4,57 \mathrm{C}$ \\
\hline Arc4 & 3,58 & 3,59 & $3,58 \mathrm{~B}$ & 4,63 & 4,63 & $4,63 \mathrm{~B}$ \\
\hline Média $^{2}$ & $3,60 \mathrm{a}$ & $3,58 \mathrm{~b}$ & & $4,62 \mathrm{a}$ & $4,61 \mathrm{~b}$ & \\
\hline $\mathrm{F}$ & $\mathrm{P}\left(5,30^{\star}\right)$ & $\mathrm{G}\left(51,67^{\star \star}\right)$ & $\mathrm{P}+\mathrm{G}\left(2,64^{\mathrm{ns}}\right)$ & $P(8,81)$ & $\mathrm{G}(334,83$ & $\mathrm{G}\left(1,59^{\text {ns }}\right)$ \\
\hline \multirow[t]{2}{*}{$\mathrm{CV}$} & & 0,73 & & & 0,39 & \\
\hline & \multicolumn{6}{|c|}{ Lafoensia glyptocarpa (Fo) } \\
\hline \multirow[t]{2}{*}{ Genótipo } & \multicolumn{3}{|c|}{ Machos } & \multicolumn{3}{|c|}{ Fêmeas } \\
\hline & Sem pó & Com pó & Média $^{2}$ & Sem pó & Com pó & Média $^{2}$ \\
\hline Goiano Precoce & 3,69 & 3,69 & $3,69 \mathrm{~A}$ & 4,75 & 4,76 & $4,76 \mathrm{~A}$ \\
\hline Arc1 & 3,54 & 3,54 & $3,54 \mathrm{C}$ & 4,52 & 4,51 & $4,52 \mathrm{D}$ \\
\hline Arc3 & 3,59 & 3,58 & $3,58 \mathrm{~B}$ & 4,58 & 4,57 & $4,58 \mathrm{C}$ \\
\hline Arc4 & 3,58 & 3,58 & $3,58 \mathrm{~B}$ & 4,63 & 4,61 & $4,63 \mathrm{~B}$ \\
\hline Média $^{2}$ & $3,60 \mathrm{a}$ & $3,59 a$ & & $4,62 \mathrm{a}$ & $4,62 \mathrm{a}$ & \\
\hline $\mathrm{F}$ & $P\left(0,20^{\text {ns }}\right)$ & $\mathrm{G}\left(70,22^{\star \star}\right)$ & $P+G\left(0,27^{n s}\right)$ & $\mathrm{P}\left(3,13^{n}\right.$ & $\mathrm{G}(470,56$ & $\mathrm{G}\left(1,73^{\mathrm{ns}}\right)$ \\
\hline \multirow[t]{2}{*}{ CV } & & 0,73 & & & 0,35 & \\
\hline & \multicolumn{6}{|c|}{${\text { Citrus sinensis (cv. Pêra) }(\mathrm{Cf})^{1}}^{1}$} \\
\hline \multirow[t]{2}{*}{ Genótipo } & \multicolumn{3}{|c|}{ Machos } & \multicolumn{3}{|c|}{ Fêmeas } \\
\hline & Sem pó & Com pó & Média $^{2}$ & Sem pó & Com pó & Média $^{2}$ \\
\hline Goiano Precoce & $3,69 \mathrm{Aa}$ & $3,71 \mathrm{Aa}$ & 3,70 & 4,75 & 4,73 & $4,74 \mathrm{~A}$ \\
\hline Arc1 & 3,54 Ca & $3,56 \mathrm{Ba}$ & 3,55 & 4,52 & 4,52 & $4,52 \mathrm{D}$ \\
\hline Arc3 & $3,59 \mathrm{Ba}$ & $3,55 \mathrm{Bb}$ & 3,57 & 4,58 & 4,55 & $4,56 \mathrm{C}$ \\
\hline Arc4 & $3,58 \mathrm{Ba}$ & $3,57 \mathrm{Ba}$ & 3,57 & 4,63 & 4,61 & $4,62 \mathrm{~B}$ \\
\hline Média $^{2}$ & 3.60 & 3.60 & & $4.62 \mathrm{a}$ & $4.60 \mathrm{~b}$ & \\
\hline $\mathrm{F}$ & $\mathrm{P}\left(0,07^{\mathrm{ns}}\right)$ & $\mathrm{G}\left(74,63^{* *}\right)$ & $\mathrm{P}+\mathrm{G}\left(3,80^{\star}\right)$ & $\mathrm{P}(12,12$ & *) $\mathrm{G}(392,3$ & $\mathrm{G}\left(1,41^{\mathrm{ns}}\right)$ \\
\hline CV & 1 & 0,74 & (1), & & 0,36 & \\
\hline
\end{tabular}


$\mathrm{Na}$ análise da longevidade de machos (Tabela 53), verificou-se interação genótipo x pó apenas com o emprego de $C$. sativum. Nesse caso, os machos provenientes de 'Goiano Precoce' e Arc4 apresentaram longevidade menor nas parcelas tratadas que nas não tratadas. Com o uso de $C$. sinensis, verificaram-se menores valores nas parcelas tratadas com pó que nas respectivas parcelas não tratadas. Nas outras duas espécies, não houve diferença entre parcelas tratadas e não tratadas. O efeito dos genótipos foi constatado em todos os casos, verificando-se longevidades menores nos adultos provenientes dos três genótipos contendo arcelina em comparação com os oriundos de 'Goiano Precoce'. Na comparação entre os genótipos contendo arcelina, novamente verificou-se efeito mais drástico em Arc1, no qual os valores foram menores que nos demais.

Quanto aos dados de longevidade de fêmeas (Tabela 53), em nenhum caso a interação genótipos x pó foi significativa. $\mathrm{Na}$ análise de cada fator isoladamente, constatou-se que o emprego do pó não teve qualquer efeito na longevidade do adulto. Quando comparados os genótipos, verifica-se, em todas as situações, menores longevidades nos materiais com arcelina em relação a 'Goiano Precoce' com exceção apenas do teste com C. ambrosioides em que os valores em Arc1 não diferiram dos registrados nos demais tratamentos. Na comparação entre os materiais Arc não se constatou diferenças na longevidade das fêmeas.

No que se refere ao número total de ovos (fecundidade) dos adultos provenientes dos respectivos genótipos e pós vegetais (Tabela 54), constatouse interação significativa apenas quando se utilizou L. glyptocarpa. Nesse caso, em Arc3 e Arc4, houve menor número de ovos nas parcelas tratadas em relação æ̀ respectivas parcelas não tratadas, enquanto nos demais genótipos, não houve diferença entre parcelas tratadas e não tratadas. O efeito dos genótipos no teste em que se utilizou L. glyptocarpa foi verificado tanto na presença como na ausência do pó, constatando-se em ambos os casos, menor fecundidade nos genótipos com arcelina. Na ausência do pó, a fecundidade em 
Tabela 53. Longevidade (dias) de Acanthoscelides obtectus criado em genótipos $(\mathrm{G})$ de feijoeiro tratados com pós $(\mathrm{P})$ de origem vegetal.

\begin{tabular}{|c|c|c|c|c|c|c|}
\hline \multirow{3}{*}{ Genótipo } & \multicolumn{6}{|c|}{ Chenopodium ambrosioides (f.2) (Pa) ${ }^{\top}$} \\
\hline & \multicolumn{3}{|c|}{ Machos } & \multicolumn{3}{|c|}{ Fêmeas } \\
\hline & Sem pó & Com pó & Média $^{2}$ & Sem pó & Com pó & Média $^{2}$ \\
\hline $\begin{array}{l}\text { Goiano Precoce } \\
\text { Arc1 } \\
\text { Arc3 } \\
\text { Arc4 }\end{array}$ & $\begin{array}{l}16,83 \\
13,17 \\
14,83 \\
14,83 \\
\end{array}$ & $\begin{array}{l}15,83 \\
13,50 \\
14,67 \\
14,17 \\
\end{array}$ & $\begin{array}{l}16,33 \mathrm{~A} \\
13,33 \mathrm{C} \\
14,75 \mathrm{~B} \\
14,50 \mathrm{~B}\end{array}$ & $\begin{array}{l}14,67 \\
12,83 \\
13,00 \\
12,83 \\
\end{array}$ & $\begin{array}{l}14,17 \\
13,67 \\
12,83 \\
12,67 \\
\end{array}$ & $\begin{array}{l}14,42 \mathrm{~A} \\
13,25 \mathrm{AB} \\
12,92 \mathrm{~B} \\
12,75 \mathrm{~B}\end{array}$ \\
\hline Média & $14,92 \mathrm{a}$ & $14,54 \mathrm{a}$ & & $13,33 \mathrm{a}$ & $13,33 \mathrm{a}$ & \\
\hline & $P\left(2,26^{\text {ns }}\right)$ & $\begin{array}{c}\mathrm{G}\left(24,53^{\star \star}\right) \\
5,86\end{array}$ & $P+G\left(1,37^{\text {ns }}\right)$ & $P\left(0,00^{\text {ns }}\right)$ & $\begin{array}{c}\mathrm{G}\left(4,42^{\star \star}\right) \\
9,29\end{array}$ & $P+G\left(0,65^{n s}\right)$ \\
\hline CV & \multicolumn{6}{|c|}{ Coriandrum sativum (Fo) $^{1}$} \\
\hline \multirow[t]{2}{*}{ Genótipo } & \multicolumn{3}{|c|}{ Machos } & \multicolumn{3}{|c|}{ Fêmeas } \\
\hline & Sem pó & Com pó & Média $^{2}$ & Sem pó & Com pó & Média $^{2}$ \\
\hline $\begin{array}{l}\text { Goiano Precoce } \\
\text { Arc1 } \\
\text { Arc3 } \\
\text { Arc4 }\end{array}$ & $\begin{array}{l}16,83 \mathrm{Aa} \\
13,17 \mathrm{Ca} \\
14,83 \mathrm{Ba} \\
14,83 \mathrm{Ba}\end{array}$ & $\begin{array}{l}15,67 \mathrm{Ab} \\
13,33 \mathrm{Ca} \\
14,83 \mathrm{ABa} \\
14,00 \mathrm{BCb}\end{array}$ & $\begin{array}{l}16,25 \\
13,25 \\
14,83 \\
14,42\end{array}$ & $\begin{array}{l}14,67 \\
12,83 \\
13,00 \\
12,83\end{array}$ & $\begin{array}{l}14,83 \\
12,50 \\
13,17 \\
12,50\end{array}$ & $\begin{array}{l}14,75 \mathrm{~A} \\
12,67 \mathrm{~B} \\
13,08 \mathrm{~B} \\
12,67 \mathrm{~B}\end{array}$ \\
\hline Média ${ }^{2}$ & 14,92 & 14,46 & & $13,33 \mathrm{a}$ & $13,25 \mathrm{a}$ & \\
\hline $\mathrm{F}$ & $P\left(5,99^{\star}\right)$ & $\mathrm{G}\left(43,75^{\star *}\right)$ & $\mathrm{P}+\mathrm{G}\left(2,95^{\mathrm{ns}}\right)$ & $P\left(0,06^{\text {ns }}\right)$ & $\mathrm{G}\left(8,19^{* *}\right)$ & $\mathrm{P}+\mathrm{G}\left(0,17^{\mathrm{ns}}\right)$ \\
\hline \multirow[t]{2}{*}{$\mathrm{CV}$} & & 4,42 & & & 9,03 & \\
\hline & \multicolumn{6}{|c|}{ Lafoensia glyptocarpa (Fo) ${ }^{1}$} \\
\hline \multirow[t]{2}{*}{ Genótipo } & \multicolumn{3}{|c|}{ Machos } & \multicolumn{3}{|c|}{ Fêmeas } \\
\hline & Sem pó & Com pó & Média $^{2}$ & Sem pó & Com pó & Média $^{2}$ \\
\hline $\begin{array}{l}\text { Goiano Precoce } \\
\text { Arc1 } \\
\text { Arc3 } \\
\text { Arc4 }\end{array}$ & $\begin{array}{l}16,83 \\
13,17 \\
14,83 \\
14,83 \\
\end{array}$ & $\begin{array}{l}15,83 \\
13,50 \\
14,83 \\
14,50 \\
\end{array}$ & $\begin{array}{l}16,33 \mathrm{~A} \\
13,33 \mathrm{C} \\
14,83 \mathrm{~B} \\
14,67 \mathrm{~B}\end{array}$ & $\begin{array}{l}14,67 \\
12,83 \\
13,00 \\
12,83 \\
\end{array}$ & $\begin{array}{l}15,17 \\
12,17 \\
12,50 \\
12,50 \\
\end{array}$ & $\begin{array}{l}14,92 \mathrm{~A} \\
12,50 \mathrm{~B} \\
12,75 \mathrm{~B} \\
12,67 \mathrm{~B} \\
\end{array}$ \\
\hline Média $^{2}$ & $14,92 \mathrm{a}$ & $14,67 \mathrm{a}$ & & $13,33 \mathrm{a}$ & $13,08 \mathrm{a}$ & \\
\hline $\mathrm{F}$ & $P\left(1,50^{\text {ns }}\right)$ & $\begin{array}{c}\mathrm{G}\left(36,17^{\star \star}\right) \\
4,78\end{array}$ & $P+G\left(1,94^{n s}\right)$ & $P\left(0,49^{\text {ns }}\right)$ & $\begin{array}{c}\mathrm{G}\left(10,18^{* \star}\right) \\
9,40\end{array}$ & $P+G\left(0,52^{n s}\right)$ \\
\hline \multirow{3}{*}{ Genótipo } & \multicolumn{6}{|c|}{ Citrus sinensis (cv. Pêra) $(\mathrm{Cf})^{1}$} \\
\hline & \multicolumn{3}{|c|}{ Machos } & \multicolumn{3}{|c|}{ Fêmeas } \\
\hline & Sem pó & Com pó & Média $^{2}$ & Sem pó & Com pó & Média $^{2}$ \\
\hline $\begin{array}{l}\text { Goiano Precoce } \\
\text { Arc1 } \\
\text { Arc3 } \\
\text { Arc4 }\end{array}$ & $\begin{array}{l}16,83 \\
13,17 \\
14,83 \\
14,83 \\
\end{array}$ & $\begin{array}{l}15,50 \\
13,17 \\
14,50 \\
14,50 \\
\end{array}$ & $\begin{array}{l}16,17 \mathrm{~A} \\
13,17 \mathrm{C} \\
14,67 \mathrm{~B} \\
14,67 \mathrm{~B} \\
\end{array}$ & $\begin{array}{l}14,67 \\
12,83 \\
13,00 \\
12,83 \\
\end{array}$ & $\begin{array}{l}14,67 \\
12,00 \\
13,00 \\
12,17 \\
\end{array}$ & $\begin{array}{l}14,67 \mathrm{~A} \\
12,42 \mathrm{~B} \\
13,00 \mathrm{~B} \\
12,50 \mathrm{~B} \\
\end{array}$ \\
\hline Média ${ }^{2}$ & $14,92 \mathrm{a}$ & $14,42 \mathrm{~b}$ & & $13,33 \mathrm{a}$ & $12,96 \mathrm{a}$ & \\
\hline $\begin{array}{l}\mathrm{F} \\
\mathrm{CV}\end{array}$ & $\mathrm{P}\left(7,20^{*}\right)$ & $\begin{array}{c}\mathrm{G}\left(43,20^{\star *}\right) \\
4,40\end{array}$ & $P+G\left(2,40^{\text {ns }}\right)$ & $P\left(1,27^{\text {ns }}\right)$ & $\begin{array}{c}\mathrm{G}\left(9,88^{* *}\right) \\
8,77\end{array}$ & $\mathrm{P}+\mathrm{G}\left(0,43^{\text {ns }}\right)$ \\
\hline
\end{tabular}


Tabela 54. Fecundidade ( $\mathrm{n}^{0}$ total de ovos) de Acanthoscelides obtectus criado em diferentes genótipos $(G)$ de feijoeiro tratados com pós $(P)$ de origem vegetal.

\begin{tabular}{|c|c|c|c|}
\hline \multirow{3}{*}{ Genótipo } & \multicolumn{3}{|c|}{ Chenopodium ambrosioides (f.2) $(\mathrm{Pa})^{1}$} \\
\hline & \multicolumn{3}{|c|}{$\mathrm{N}^{0}$ total de ovos/recipiente } \\
\hline & Sem pó & Com pó & Média $^{2}$ \\
\hline Goiano Precoce & 60,00 & 57,17 & $58,58 \mathrm{~A}$ \\
\hline Arc1 & 51,83 & 49,17 & $50,50 \mathrm{D}$ \\
\hline Arc3 & 55,83 & 52,33 & $54,08 \mathrm{~B}$ \\
\hline Arc4 & 53,83 & 50,50 & $52,17 \mathrm{C}$ \\
\hline Média $^{2}$ & 55,38 a & \multicolumn{2}{|l|}{$52,29 \mathrm{~b}$} \\
\hline $\mathrm{P}\left(56,33^{\star \star}\right)$ & $\mathrm{G}\left(72,13^{\star \star}\right)$ & \multirow{2}{*}{\multicolumn{2}{|c|}{$P+G\left(0,23^{n s}\right)$}} \\
\hline CV & & & \\
\hline \multirow{3}{*}{ Genótipo } & \multicolumn{3}{|c|}{ Coriandrum sativum (Fo) ${ }^{1}$} \\
\hline & \multicolumn{3}{|c|}{$\mathrm{N}^{0}$ total de ovos/recipiente } \\
\hline & Sem pó & Com pó & Média $^{2}$ \\
\hline Goiano Precoce & 60,00 & 58,83 & $59,42 \mathrm{~A}$ \\
\hline Arc1 & 51,83 & 51,67 & $51,75 \mathrm{C}$ \\
\hline Arc3 & 55,83 & 54,67 & $55,25 \mathrm{~B}$ \\
\hline Arc4 & 53,83 & 53,00 & $53,42 \mathrm{C}$ \\
\hline Média $^{2}$ & $55,38 \mathrm{a}$ & $54,54 \mathrm{a}$ & \\
\hline $\mathrm{P}\left(3,40^{\mathrm{ns}}\right)$ & $\mathrm{G}\left(53,28^{\star \star}\right)$ & & $\left.27^{\mathrm{ns}}\right)$ \\
\hline $\mathrm{CV}$ & & 2,45 & \\
\hline \multirow{3}{*}{ Genótipo } & \multicolumn{3}{|c|}{ Lafoensia glyptocarpa (Fo) $^{1}$} \\
\hline & \multicolumn{3}{|c|}{$\mathrm{N}^{0}$ total de ovos/ recipiente } \\
\hline & Sem pó & Com pó & Média ${ }^{2}$ \\
\hline Goiano Precoce & $60,00 \mathrm{Aa}$ & $60,67 \mathrm{Aa}$ & 60,33 \\
\hline Arc1 & $51,83 \mathrm{Ca}$ & $50,17 \mathrm{Ba}$ & 51,00 \\
\hline Arc3 & $55,83 \mathrm{Ba}$ & $52,33 \mathrm{Bb}$ & 54,08 \\
\hline Arc4 & $53,83 \mathrm{BCa}$ & $51,50 \mathrm{Bb}$ & 52,67 \\
\hline Média $^{2}$ & 55,38 & 53,67 & \\
\hline $\mathrm{P}\left(12,56^{\star \star}\right)$ & $\mathrm{G}\left(71,48^{\star \star}\right)$ & &, $\left.32^{\star}\right)$ \\
\hline CV & & 3,06 & \\
\hline \multirow{3}{*}{ Genótipo } & \multicolumn{3}{|c|}{ Citrus sinensis (cv. Pêra) (Cf) } \\
\hline & \multicolumn{3}{|c|}{$\mathrm{N}^{0}$ total de ovos/recipiente } \\
\hline & Sem pó & Com pó & Média ${ }^{2}$ \\
\hline Goiano Precoce & 60,00 & 59,50 & $59,75 \mathrm{~A}$ \\
\hline Arc1 & 51,83 & 52,00 & $51,92 \mathrm{C}$ \\
\hline Arc3 & 55,83 & 54,50 & $55,17 \mathrm{~B}$ \\
\hline Arc4 & 53,83 & 53,00 & $53,42 \mathrm{C}$ \\
\hline Média $^{2}$ & $55,38 \mathrm{a}$ & $54,75 \mathrm{a}$ & \\
\hline $\mathrm{P}\left(2,25^{\mathrm{ns}}\right)$ & $\mathrm{G}\left(66,28^{\star \star}\right)$ & & $\left.57^{\mathrm{ns}}\right)$ \\
\hline ( & & 2,62 & \\
\hline
\end{tabular}


Arc1 foi menor que em Arc3 e Arc4, enquanto na presença do pó, não houve diferença entre estes três genótipos.

Nas outras três plantas inseticidas, a fecundidade dos insetos criados nos genótipos Arc foi inferior à constatada em 'Goiano Precoce' independentemente da presença ou ausência do pó. Na comparação entre os genótipos Arc, a fecundidade foi sempre menor em Arc1 e Arc4 do que em Arc3. No teste com C. ambrosioides (f.2), o valor em Arc1 foi menor também que em Arc4.

Quanto ao número de ovos férteis (Tabela 55), verificou-se interação apenas com a utilização de $C$. sativum. A redução no número de ovos com o uso do pó só ocorreu no genótipo Arc4. Com e sem pó, o número de ovos férteis foi menor nos genótipos contendo arcelina em comparação a 'Goiano Precoce'. Com as demais espécies vegetais, verificaram-se menores valores nas parcelas tratadas em relação às respectivas parcelas não tratadas. $\mathrm{Na}$ comparação do efeito dos genótipos, verificou-se novamente, em todas as situações, menores números de ovos férteis nos materiais contendo arcelina em relação a Goiano Precoce, constatando-se efeito mais pronunciado em Arc, em relação aos outros dois materiais, com exceção apenas do teste com $C$. ambrosioides, em que não houve diferença entre Arc1 e Arc4.

No que se refere àporcentagem de ovos férteis em relação ao total, verificou-se interação com o uso dos pós de C. sativum e L. glyptocarpa (Tabela 55). Com C. sativum, ocorreu redução nessa variável nas parcelas tratadas em relação às respectivas parcelas não tratadas apenas no genótipo Arc4. Nesse mesmo teste, não houve diferença entre genótipos na ausência de pó, enquanto na sua presença, a porcentagem de ovos férteis em Arc4 foi menor que em 'Goiano Precoce' e Arc3. Com L. glyptocarpa, a presença do pó reduziu essa porcentagem em todos os genótipos, com exceção de Arc3; nas parcelas não tratadas não houve diferença entre as médias dos quatro genótipos, enquanto nas parcelas tratadas, foi encontrado um valor maior para 
Tabela 55. Fecundidade ( $\mathrm{n}^{0}$ e \% de ovos férteis) de Acanthoscelides obtectus criado em diferentes genótipos $(G)$ de feijoeiro tratados com pós $(P)$ de origem vegetal.

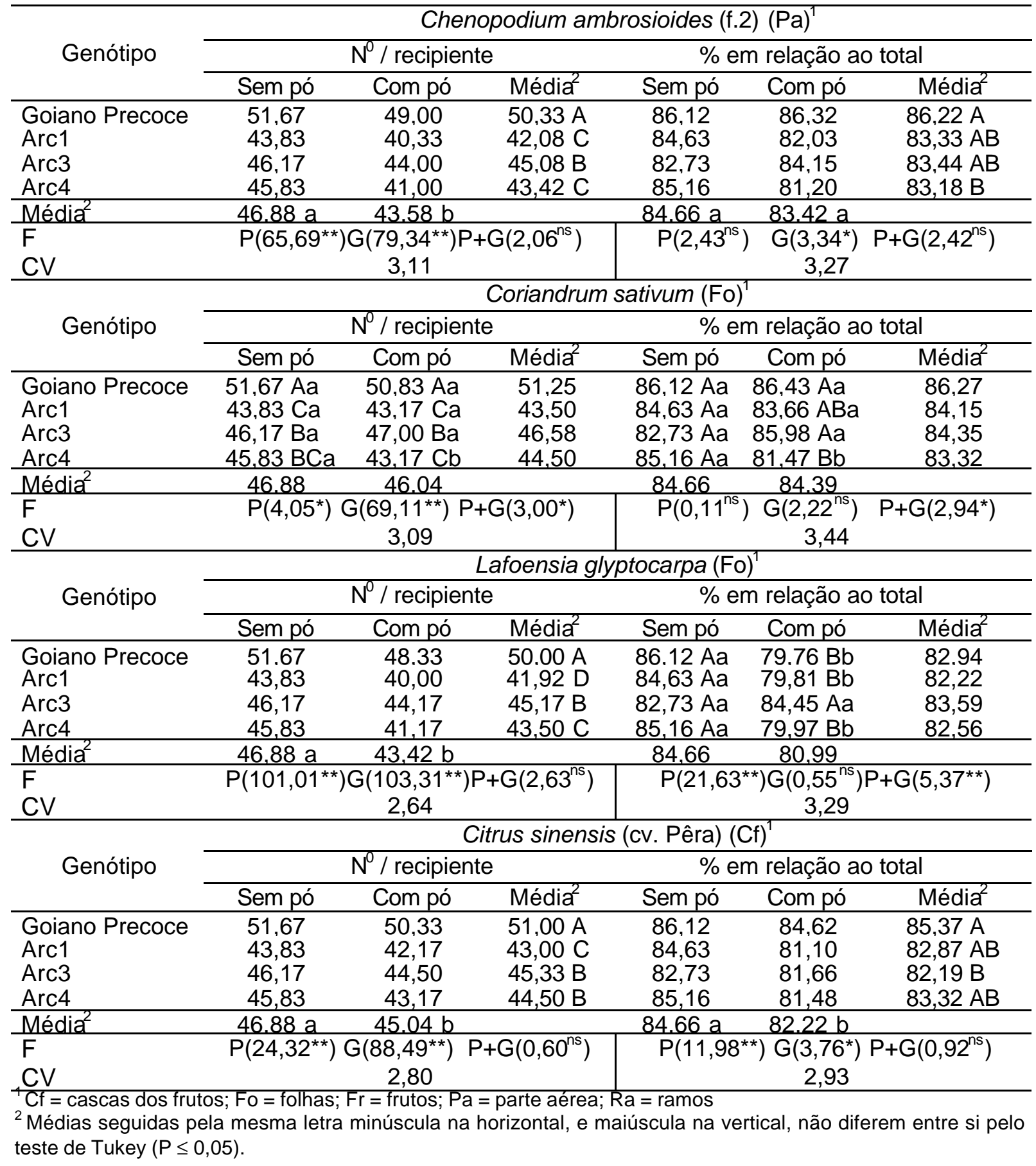


esse parâmetro em Arc3 em comparação aos demais genótipos. Nos testes com $C$. ambrosioides e com $C$. sinensis, a interação pó $x$ genótipo não foi significativa. Com C. ambrosioides, não houve diferença entre parcelas tratadas e não tratadas para a porcentagem de ovos férteis, mas verificou-se que no genótipo Arc4 esse valor foi menor que em 'Goiano Precoce' com valores intermediários nos demais genótipos. Já com $C$. sinensis, a porcentagem de ovos férteis foi menor nas parcelas tratadas que nas não tratadas enquanto o efeito de genótipo só foi constatado em Arc3, no qual o valor foi menor que em 'Goiano Precoce', observando-se valores intermediários nos demais materiais.

Analisando-se o efeito da utilização associada de pós vegetais e genótipos resistentes sobre a preferência para oviposição e biologia das duas espécies de caruncho estudadas, verificou-se, para ambas as espécies, a ocorrência apenas de efeito aditivo, ou seja, não foi constatado efeito sinérgico da utilização dessas duas técnicas de controle.

\subsubsection{Efeito no dano causado pelos insetos}

\subsubsection{Z. subfasciatus}

Não houve significância nas interações genótipos x pós vegetais para número total de ovos (Tabela 56 ), no estudo de danos causados por $Z$. subfasciatus quando adultos provenientes da criação estoque foram infestados em genótipos com e sem arcelina tratados com pós de quatro plantas inseticidas. O número total de ovos nas parcelas com pó foi inferior que nas respectivas parcelas sem pó, para os testes com $C$. ambrosioides (f.2) e $M$. pulegium, não havendo diferença entre parcelas tratadas e não tratadas para os demais casos. 
Tabela 56. Oviposição total de Zabrotes subfasciatus, provenientes da criação estoque, em genótipos $(G)$ tratados com pós $(P)$ de origem vegetal.

\begin{tabular}{|c|c|c|c|}
\hline \multirow{3}{*}{ Genótipo } & \multicolumn{3}{|c|}{ Chenopodium ambrosioides (f.2) (Pa) } \\
\hline & \multicolumn{3}{|c|}{$\mathrm{N}^{0}$ total de ovos/recipiente } \\
\hline & Sem pó & Com pó & Média $^{2}$ \\
\hline Goiano Precoce & 253,67 & 229,67 & $241,67 \mathrm{~A}$ \\
\hline Arc1 & 153,17 & 146,67 & $149,92 \mathrm{C}$ \\
\hline Arc3 & 201,50 & 196,67 & $199,08 \mathrm{~B}$ \\
\hline Arc4 & 244,00 & 236,33 & $240,17 \mathrm{~A}$ \\
\hline Média $^{2}$ & $213,08 \mathrm{a}$ & \multicolumn{2}{|l|}{$202,33 \mathrm{~b}$} \\
\hline $\mathrm{P}\left(4,91^{\star}\right)$ & $\mathrm{G}\left(79,66^{\star \star}\right)$ & \multirow{2}{*}{\multicolumn{2}{|c|}{$P+G\left(0,84^{\text {ns }}\right)$}} \\
\hline CV & & & \\
\hline \multirow{3}{*}{ Genótipo } & \multicolumn{3}{|c|}{ Mentha pulegium (Fo) $^{1}$} \\
\hline & \multicolumn{3}{|c|}{$\mathrm{N}^{0}$ total de ovos/recipiente } \\
\hline & Sem pó & Com pó & Média $^{2}$ \\
\hline Goiano Precoce & 253,67 & 241,33 & $247,50 \mathrm{~A}$ \\
\hline Arc1 & 153,17 & 143,67 & $148,42 \mathrm{C}$ \\
\hline Arc3 & 201,50 & 175,17 & 188,33 B \\
\hline Arc4 & 244,00 & 223,17 & $233,58 \mathrm{~A}$ \\
\hline Média $^{2}$ & $213,08 \mathrm{a}$ & $195,83 \mathrm{~b}$ & \\
\hline $\mathrm{P}\left(10,45^{\star \star}\right)$ & $\mathrm{G}\left(71,48^{\star \star}\right)$ & & $\left.0,53^{\text {ns }}\right)$ \\
\hline CV & & 9,04 & \\
\hline \multirow{3}{*}{ Genótipo } & \multicolumn{3}{|c|}{ 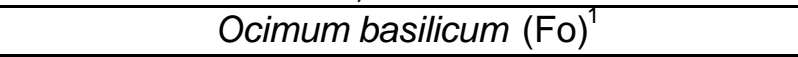 } \\
\hline & \multicolumn{3}{|c|}{$\mathrm{N}^{0}$ total de ovos/ recipiente } \\
\hline & Sem pó & Com pó & Média $^{2}$ \\
\hline Goiano Precoce & 253,67 & 249,00 & $251,33 \mathrm{~A}$ \\
\hline Arc1 & 153,17 & 144,00 & $148,58 \mathrm{C}$ \\
\hline Arc3 & 201,50 & 188,17 & $194,83 \mathrm{~B}$ \\
\hline Arc4 & 244,00 & 257,83 & $250,92 \mathrm{~A}$ \\
\hline Média $^{2}$ & $213,08 \mathrm{a}$ & 209,75 a & \\
\hline $\mathrm{P}\left(0,70^{\text {ns }}\right)$ & $\mathrm{G}\left(154,22^{\star \star}\right)$ & \multirow{2}{*}{\multicolumn{2}{|c|}{$6,54 \quad P\left(2,25^{\text {ns }}\right)$}} \\
\hline CV & & & \\
\hline \multirow{3}{*}{ Genótipo } & \multicolumn{3}{|c|}{ Ruta graveolens (Fo) ${ }^{1}$} \\
\hline & \multicolumn{3}{|c|}{$\mathrm{N}^{0}$ total de ovos/recipiente } \\
\hline & Sem pó & Com pó & Média $^{2}$ \\
\hline Goiano Precoce & 253,67 & 263,33 & $258,50 \mathrm{~A}$ \\
\hline Arc1 & 153,17 & 146,17 & $149,67 \mathrm{D}$ \\
\hline Arc3 & 201,50 & 178,17 & $189,83 \mathrm{C}$ \\
\hline Arc4 & 244,00 & 236,17 & $240,08 \mathrm{~B}$ \\
\hline Média $^{2}$ & $213,08 \mathrm{a}$ & $205,96 \mathrm{a}$ & \\
\hline $\mathrm{P}\left(2,64^{\mathrm{ns}}\right)$ & $\mathrm{G}\left(126,50^{\star *}\right)$ & & $\left.2,36^{\text {ns }}\right)$ \\
\hline CV & (1) & 7,25 & \\
\hline
\end{tabular}


No que se refere ao número de ovos férteis e viabilidade destes em relação ao número total (Tabela 57 ), verificou-se interação com a utilização de $O$. basilicum. A redução no número de ovos férteis com o uso do pó ocorreu apenas nos genótipos Goiano Precoce e Arc3. Já as viabilidades foram diminuídas com a utilização do pó nos genótipos Goiano Precoce, Arc1 e Arc3. Nos demais testes, o número total de ovos, número de ovos férteis e viabilidade destes em relação ao total, foram menores nos genótipos contendo arcelina em comparação a 'Goiano Precoce' independentemente do emprego ou não dos pós vegetais. Em todos os testes, o genótipo Arc1 apresentou efeito mais drástico dentre aqueles contendo arcelina.

No que se refere ao dano causado (peso consumido de grãos) pelos insetos (Tabela 58) verificou-se interação genótipo x pó vegetal quando utilizou-se $M$. pulegium, $O$. basilicum e $R$. graveolens. Os pesos consumidos foram reduzidos nas parcelas tratadas com pós de M. pulegium em 'Goiano Precoce' e Arc3, com O. basilicum em Arc3 e com R. graveolens em Arc3.

Nos tratamentos com e sem pós vegetais, verificou-se sempre menores consumos nos genótipos contendo arcelina, diferenciando-se de 'Goiano Precoce'. Na comparação entre os genótipos com arcelina, o consumo em Arc1 foi sempre menor do que em Arc3 e Arc4, que na maioria das situações não diferiram entre si.

Tais resultados concordam com Pereira et al. (1995) onde constatou-se que linhagens quase isogênicas que continham os alelos Arc1, proporcionaram menor dano do que as que continham Arc3 e Arc4. Na testemunha suscetível 'Goiano Precoce', os danos foram bem maiores, chegando a ser sete vezes superiores que os obtidos em Arc1.

Resultados semelhantes também foram obtidos por Barbosa et al. (2000a) onde ao final de armazenamento, os danos ocorridos em Arc1, 3 e 4 foram significativamente menores do que em 'Goiano Precoce'. Quando foram comparados os genótipos contendo arcelina, Arc1 apresentou menores danos que Arc3 e Arc4. 
Tabela 57. Oviposição ( $n^{0}$ e \% de ovos férteis) de Zabrotes subfasciatus, provenientes da criação estoque, em genótipos (G) tratados com pós $(\mathrm{P})$ de origem vegetal.

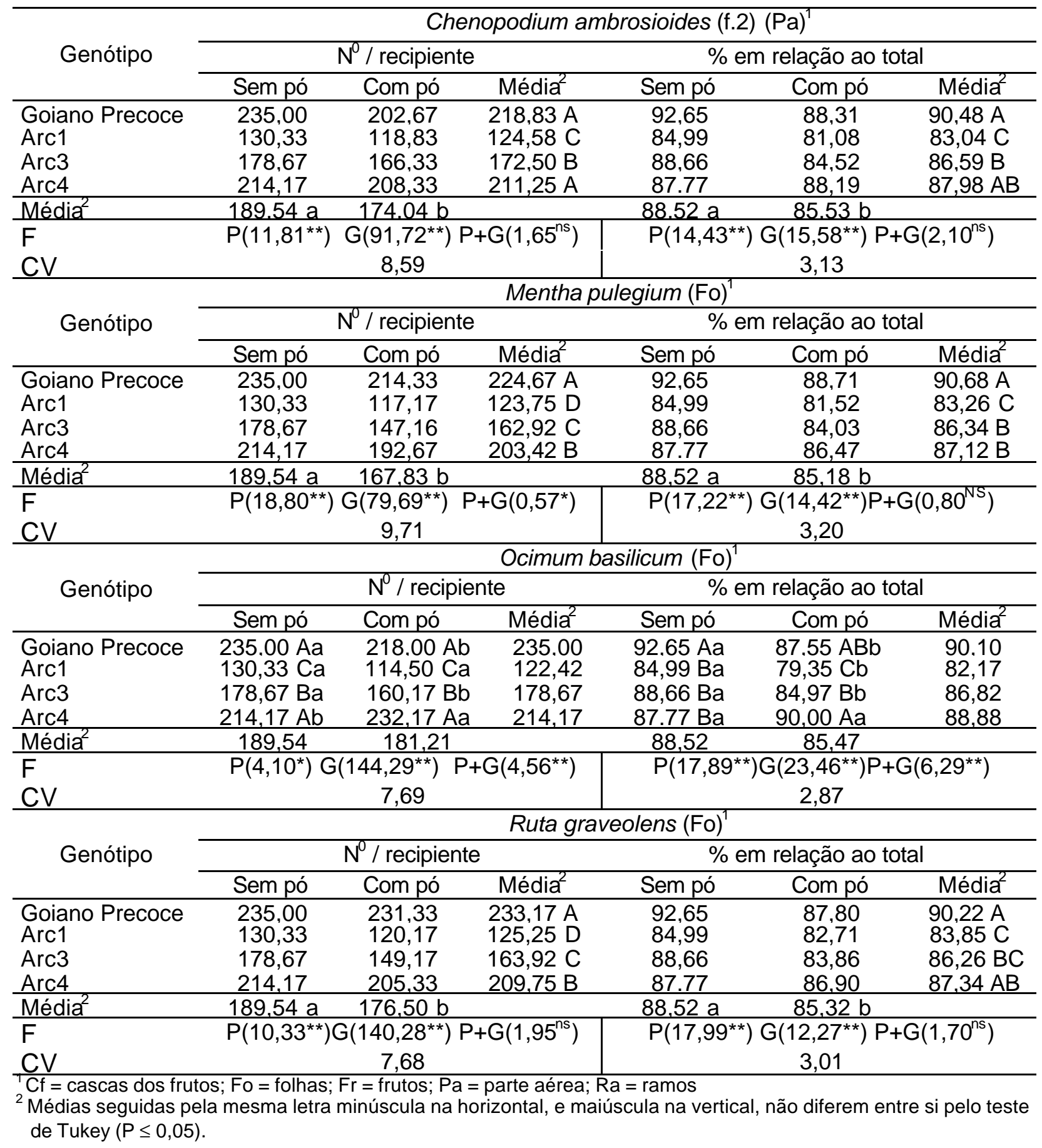


Tabela 58. Peso consumido de grãos de genótipos (G) de feijoeiro tratados com pós $(\mathrm{P})$ de origem vegetal por Zabrotes subfasciatus.

\begin{tabular}{|c|c|c|c|}
\hline \multirow{3}{*}{ Genótipo } & \multicolumn{3}{|c|}{ Chenopodium ambrosioides (f.2) (Pa) ${ }^{\top}$} \\
\hline & \multicolumn{3}{|c|}{ Peso consumido $(\mathrm{g})$} \\
\hline & Sem pó & Com pó & Média $^{2}$ \\
\hline Goiano Precoce & 1,95 & 1,85 & $1,90 \mathrm{~A}$ \\
\hline Arc1 & 1,27 & 1,26 & $1,26 \mathrm{C}$ \\
\hline Arc3 & 1,64 & 1,50 & $1,57 \mathrm{~B}$ \\
\hline Arc4 & 1,57 & 1,57 & $1,57 \mathrm{~B}$ \\
\hline Média $^{2}$ & $1,61 \mathrm{a}$ & \multicolumn{2}{|l|}{$1,54 \mathrm{~b}$} \\
\hline $\mathrm{P}\left(5,84^{\star}\right)$ & $\mathrm{G}\left(102,21^{\star *}\right)$ & \multicolumn{2}{|c|}{$P+G\left(1,99^{n s}\right)$} \\
\hline \multirow{3}{*}{ Genótipo } & \multicolumn{3}{|c|}{ Mentha pulegium (Fo) } \\
\hline & \multicolumn{3}{|c|}{ Peso consumido $(\mathrm{g})$} \\
\hline & Sem pó & Com pó & Média $^{2}$ \\
\hline Goiano Precoce & $1,95 \mathrm{Aa}$ & $1,79 \mathrm{Ab}$ & 1,87 \\
\hline Arc1 & $1,27 \mathrm{Ca}$ & $1,21 \mathrm{Ca}$ & 1,24 \\
\hline Arc3 & $1,64 \mathrm{Ba}$ & $1,41 \mathrm{Bb}$ & 1,53 \\
\hline Arc4 & $1,57 \mathrm{Ba}$ & $1,51 \mathrm{Ba}$ & 1,54 \\
\hline Média ${ }^{2}$ & 1,61 & 1,48 & \\
\hline $\mathrm{P}\left(29,70^{* \star}\right)$ & $\mathrm{G}\left(124,62^{* \star}\right)$ & 5,17 & $\left.30^{\star}\right)$ \\
\hline \multirow{3}{*}{ Genótipo } & \multicolumn{3}{|c|}{ Ocimum basilicum (Fo) } \\
\hline & \multicolumn{3}{|c|}{ Peso consumido (g) } \\
\hline & Sem pó & Com pó & Média $^{2}$ \\
\hline Goiano Precoce & $1,95 \mathrm{Aa}$ & $1,92 \mathrm{Aa}$ & 1,93 \\
\hline Arc1 & $1,27 \mathrm{Ca}$ & $1,25 \mathrm{Da}$ & 1,26 \\
\hline Arc3 & $1,64 \mathrm{Ba}$ & $1,50 \mathrm{Cb}$ & 1,57 \\
\hline Arc4 & $1,57 \mathrm{Ba}$ & $1,67 \mathrm{Bb}$ & 1,62 \\
\hline Média ${ }^{2}$ & 1,61 & 1,58 & \\
\hline $\begin{array}{l}\mathrm{F} \\
\mathrm{CV}\end{array}$ & $\mathrm{G}\left(152,85^{\star \star}\right)$ & 4,87 & $\left.89^{\star \star}\right)$ \\
\hline \multirow{3}{*}{ Genótipo } & \multicolumn{3}{|c|}{ Ruta graveolens (Fo) } \\
\hline & \multicolumn{3}{|c|}{ Peso consumido $(\mathrm{g})$} \\
\hline & Sem pó & Com pó & Média $^{2}$ \\
\hline Goiano Precoce & $1,95 \mathrm{Aa}$ & $1,93 \mathrm{Aa}$ & 1,94 \\
\hline Arc1 & $1,27 \mathrm{Ca}$ & 1,28 Ca & 1,27 \\
\hline Arc3 & 1,64 Ba & $1,42 \mathrm{Bb}$ & 1,53 \\
\hline Arc4 & $1,57 \mathrm{Ba}$ & $1,54 \mathrm{Ba}$ & 1,55 \\
\hline Média $^{2}$ & 1,61 & 1,54 & \\
\hline $\mathrm{P}\left(7,62^{* \star}\right)$ & $\mathrm{G}\left(140,55^{\star \star}\right)$ & 5.12 & $\left.70^{* *}\right)$ \\
\hline
\end{tabular}




\subsubsection{A. obtectus}

Não houve significância nas interações genótipos $x$ pós vegetais para número total de ovos (Tabela 59), número de ovos férteis e porcentagem de ovos férteis em relação ao número total de ovos (Tabela 60 ), no estudo de danos ocasionados por $A$. obtectus quando adultos provenientes da criação estoque foram infestados em genótipos com e sem arcelina tratados com pós de quatro plantas inseticidas.

Nenhuma dessas três variáveis foi afetada pelo uso dos pós vegetais, independentemente do genótipo utilizado como substrato de oviposição. O número total de ovos e o número de ovos férteis foi menor nos genótipos contendo arcelina, os quais, entretanto, não diferiram entre si. A porcentagem de ovos férteis também foi menor nesses três genótipos nos testes com C. ambrosioides (f.2) e C. sativum. Com L. glyptocarpa, a menor porcentagem ocorreu em Arc1 (em comparação a 'Goiano Precoce'), enquanto que no teste com $C$. sinensis tanto Arc1 como Arc3 foram verificadas menores porcentagens de ovos férteis do que em 'Goiano Precoce'.

No que se refere ao dano causado (peso consumido) pelos insetos (Tabela 61) verificou-se interação genótipo x pó vegetal quando utilizouse $C$. sinensis (cv. Pêra). Nesse caso, em Arc1, o peso consumido foi menor na ausência do pó que na presença deste, enquanto nos demais genótipos não houve diferença entre parcelas tratadas e não tratadas, o mesmo se constatando para os testes com as outras três plantas inseticidas.

Nas parcelas tratadas com pó de C. sinensis (em que a interação foi significativa), o único genótipo com arcelina em que ocorreu menor consumo (em relação a 'Goiano Precoce') foi Arc3. Em todas as demais situações (inclusive nas parcelas não tratadas do teste com $C$. sinensis), o consumo nos três genótipos Arc foi menor do que em 'Goiano Precoce'. Em L. glyptocarpa, os consumos em Arc1 e Arc3 foram menores que em Arc4. 
Tabela 59. Oviposição total de Acanthoscelides obtectus, proveniente da criação estoque, em genótipos $(G)$ tratados com pós $(P)$ de origem vegetal.

\begin{tabular}{|c|c|c|c|}
\hline \multirow{3}{*}{ Genótipo } & \multicolumn{3}{|c|}{ Chenopodium ambrosioides (f.2) (Pa) ${ }^{\top}$} \\
\hline & \multicolumn{3}{|c|}{$\mathrm{N}^{0}$ total de ovos/recipiente } \\
\hline & Sem pó & Com pó & Média $^{2}$ \\
\hline Goiano Precoce & 272,17 & 281,83 & $277,00 \mathrm{~A}$ \\
\hline Arc1 & 234,67 & 230,00 & $232,33 \mathrm{~B}$ \\
\hline Arc3 & 238,83 & 235,67 & $237,25 \mathrm{~B}$ \\
\hline Arc4 & 244,00 & 234,50 & $239,25 \mathrm{~B}$ \\
\hline Média $^{2}$ & $247,42 \mathrm{a}$ & \multicolumn{2}{|l|}{$245,00 \mathrm{a}$} \\
\hline $\begin{array}{l}\mathrm{F} \\
\mathrm{CV}\end{array}$ & $\mathrm{G}\left(34,25^{\star \star}\right)$ & \multicolumn{2}{|c|}{$P+G\left(1,35^{n s}\right)$} \\
\hline \multirow{3}{*}{ Genótipo } & \multicolumn{3}{|c|}{ Coriandrum sativum (Fo) $^{\top}$} \\
\hline & \multicolumn{3}{|c|}{$\mathrm{N}^{0}$ total de ovos/recipiente } \\
\hline & Sem pó & Com pó & Média ${ }^{2}$ \\
\hline $\begin{array}{l}\text { Goiano Precoce } \\
\text { Arc1 }\end{array}$ & $\begin{array}{l}272,17 \\
234,67\end{array}$ & $\begin{array}{l}270,00 \\
236,67\end{array}$ & $\begin{array}{l}271,08 \mathrm{~A} \\
235,67 \mathrm{~B}\end{array}$ \\
\hline Arc3 & 238,83 & 242,33 & $240,58 \mathrm{~B}$ \\
\hline Arc4 & 244,00 & 239,50 & $241,75 \mathrm{~B}$ \\
\hline Média $^{2}$ & $247,42 \mathrm{a}$ & $247,13 \mathrm{a}$ & \\
\hline $\mathrm{P}\left(0,01^{\mathrm{ns}}\right)$ & $\mathrm{G}\left(21,49^{\star \star}\right)$ & \multirow{2}{*}{\multicolumn{2}{|c|}{$P+G\left(0,28^{n s}\right)$}} \\
\hline CV & & & \\
\hline \multirow{3}{*}{ Genótipo } & \multicolumn{3}{|c|}{ Lafoensia glyptocarpa (Fo) $^{\top}$} \\
\hline & \multicolumn{3}{|c|}{$\mathrm{N}^{0}$ total de ovos/ recipiente } \\
\hline & Sem pó & Com pó & Média $^{2}$ \\
\hline Goiano Precoce & 272,17 & 254,67 & $263,42 \mathrm{~A}$ \\
\hline Arc1 & 234,67 & 233,00 & $233,83 B$ \\
\hline Arc3 & 238,83 & 239,67 & $239,25 \mathrm{~B}$ \\
\hline Arc4 & 244,00 & 246,33 & $245,17 \mathrm{~B}$ \\
\hline Média $^{2}$ & $247,42 \mathrm{a}$ & $243,42 \mathrm{a}$ & \\
\hline $\mathrm{P}\left(1,67^{\mathrm{ns}}\right)$ & $\mathrm{G}\left(17,24^{* *}\right)$ & &, $\left.18^{\text {ns }}\right)$ \\
\hline CV & & 4,37 & \\
\hline \multirow{3}{*}{ Genótipo } & \multicolumn{3}{|c|}{ Citrus sinensis (cv.Pêra) (Cf) } \\
\hline & \multicolumn{3}{|c|}{$\mathrm{N}^{0}$ total de ovos/recipiente } \\
\hline & Sem pó & Com pó & Média $^{2}$ \\
\hline Goiano Precoce & 272,17 & 260,50 & $266,33 \mathrm{~A}$ \\
\hline Arc1 & 234,67 & 244,17 & $236,83 \mathrm{~B}$ \\
\hline Arc3 & 238,83 & 234,83 & $239,42 B$ \\
\hline Arc4 & 244,00 & 245,83 & $244,92 \mathrm{~B}$ \\
\hline Média $^{2}$ & $247,42 \mathrm{a}$ & $246,33 \mathrm{a}$ & \\
\hline $\begin{array}{ll}\mathrm{F} & \mathrm{P}\left(0,15^{\mathrm{ns}}\right) \\
\mathrm{CV} & \end{array}$ & $\mathrm{G}\left(22,48^{\star \star}\right)$ & 3,97 &, $\left.51^{\text {ns }}\right)$ \\
\hline
\end{tabular}


Tabela 60. Oviposição ( $n^{0}$ e \% de ovos férteis) de Acanthoscelides obtectus, proveniente da criação estoque, em genótipos $(G)$ tratados com pós $(\mathrm{P})$ de origem vegetal.

\begin{tabular}{|c|c|c|c|c|c|c|}
\hline \multirow{3}{*}{ Genótipo } & \multicolumn{6}{|c|}{ Chenopodium ambrosioides (f.2) (Pa) ${ }^{1}$} \\
\hline & \multicolumn{3}{|c|}{$\mathrm{N}^{0} /$ recipiente } & \multicolumn{3}{|c|}{ \% em relação ao total } \\
\hline & Sem pó & Com pó & Média $^{2}$ & Sem pó & Com pó & Média ${ }^{2}$ \\
\hline Goiano Precoce & 240,50 & 254,50 & $247,50 \mathrm{~A}$ & 88,37 & 90,23 & $89,30 \mathrm{~A}$ \\
\hline Arc1 & 201,33 & 196,67 & $199,00 \mathrm{~B}$ & 85,76 & 85,49 & $85,63 \mathrm{~B}$ \\
\hline Arc3 & 207,00 & 201,50 & $204,25 B$ & 86,65 & 85,51 & $86,07 \mathrm{~B}$ \\
\hline Arc4 & 199,17 & 199,17 & $205,75 \mathrm{~B}$ & 87,00 & 84,92 & $85,96 \mathrm{~B}$ \\
\hline Média ${ }^{2}$ & $215.29 \mathrm{a}$ & $212.96 \mathrm{a}$ & & $86.94 \mathrm{a}$ & $86.54 \mathrm{a}$ & \\
\hline $\mathrm{F}$ & $P\left(0,39^{\text {ns }}\right)$ & $\mathrm{G}\left(36,50^{* *}\right)$ & $P+G\left(2,41^{n s}\right)$ & $P\left(0,53^{\text {ns }}\right.$ & $\mathrm{G}\left(9,53^{* *}\right)$ & $P+G\left(2,29^{\text {ns }}\right)$ \\
\hline \multirow[t]{2}{*}{$\mathrm{CV}$} & & 6,01 & & & 2,22 & \\
\hline & \multicolumn{6}{|c|}{ Coriandrum sativum (Fo) ${ }^{1}$} \\
\hline \multirow[t]{2}{*}{ Genótipo } & \multicolumn{3}{|c|}{$\mathrm{N}^{0} /$ recipiente } & \multicolumn{2}{|c|}{ \% em relação ao total } & \\
\hline & Sem pó & Com pó & Média $^{2}$ & Sem pó & Com pó & Média ${ }^{2}$ \\
\hline Goiano Precoce & 240,50 & 240,50 & $240,50 \mathrm{~A}$ & 88,37 & 89.03 & $88,70 \mathrm{~A}$ \\
\hline Arc1 & 201,33 & 203,50 & $202,42 \mathrm{~B}$ & 85,76 & 85,97 & 85,87 B \\
\hline Arc3 & 207,00 & 209,50 & 208,25 B & 86,65 & 85,90 & 86,27 B \\
\hline Arc4 & 199,17 & 206,00 & $209,17 \mathrm{~B}$ & 87,00 & 86,01 & $86,50 \mathrm{~B}$ \\
\hline Média $^{2}$ & $215,29 a$ & $214,88 \mathrm{a}$ & & $86,94 \mathrm{a}$ & $86,73 \mathrm{a}$ & \\
\hline $\mathrm{F}$ & $\mathrm{P}\left(0,01^{\mathrm{ns}}\right)$ & $\mathrm{G}\left(22,71^{\star \star}\right)$ & $P+G\left(0,32^{\text {ns }}\right)$ & $P\left(0,16^{\text {ns }}\right.$ & $\mathrm{G}\left(5,62^{\star \star}\right)$ & $P+G\left(0,53^{N S}\right)$ \\
\hline \multirow[t]{2}{*}{ CV } & & 5,82 & & & 2,13 & \\
\hline & \multicolumn{6}{|c|}{ Lafoensia glyptocarpa (Fo) $^{\top}$} \\
\hline \multirow[t]{2}{*}{ Genótipo } & \multicolumn{3}{|c|}{$\mathrm{N}^{0} /$ recipiente } & \multicolumn{2}{|c|}{ \% em relação ao total } & \\
\hline & Sem pó & Com pó & Média $^{2}$ & Sem pó & Com pó & Média $^{2}$ \\
\hline Goiano Precoce & 240.50 & 223.17 & $231.83 \mathrm{~A}$ & 88.37 & 87.63 & $88.00 \mathrm{~A}$ \\
\hline Arc1 & 201,33 & 199,83 & $200,58 \mathrm{~B}$ & 85,76 & 85,60 & $85,68 \mathrm{~B}$ \\
\hline Arc3 & 207 & 208,83 & 207, & 86,65 & 87,07 & $86,86 \mathrm{AB}$ \\
\hline Arc4 & 199,17 & 214,17 & 213 & 87,00 & 86,95 & $86,97 \mathrm{AB}$ \\
\hline Média $^{2}$ & $215,29 \mathrm{a}$ & $211,50 \mathrm{a}$ & & $86,94 \mathrm{a}$ & $86,81 \mathrm{a}$ & \\
\hline $\mathrm{F}$ & $P\left(1,25^{\text {ns }}\right)$ & $\mathrm{G}\left(15,46^{* *}\right)$ & $\mathrm{P}+\mathrm{G}\left(1,82^{\mathrm{ns}}\right)$ & $\mathrm{P}\left(0,05^{\mathrm{ns}}\right.$ & $\mathrm{G}\left(2,44^{\mathrm{ns}}\right)$ & $P+G\left(0,15^{n s}\right)$ \\
\hline \multirow[t]{2}{*}{$\mathrm{CV}$} & & 5,51 & & & 2,42 & \\
\hline & \multicolumn{6}{|c|}{${ }^{C}$ itrus sinensis (cv. Pêra) (Fo) ${ }^{1}$} \\
\hline \multirow[t]{2}{*}{ Genótipo } & \multicolumn{3}{|c|}{$\mathrm{N}^{0} /$ recipiente } & \multicolumn{2}{|c|}{ \% em relação ao total } & \\
\hline & Sem pó & Com pó & Média $^{2}$ & Sem pó & Com pó & Média $^{2}$ \\
\hline $\begin{array}{l}\text { Goiano Precoce } \\
\text { Arc1 }\end{array}$ & $\begin{array}{l}240,50 \\
201,33\end{array}$ & $\begin{array}{l}232,67 \\
209,17\end{array}$ & $\begin{array}{l}236,58 \mathrm{~A} \\
205,25 \mathrm{~B}\end{array}$ & $\begin{array}{l}88,37 \\
85,76\end{array}$ & $\begin{array}{l}89,29 \\
85,74\end{array}$ & $\begin{array}{l}88,83 \mathrm{~A} \\
85,75 \mathrm{~B}\end{array}$ \\
\hline Arc3 & 207,00 & 199,50 & $203,25 \mathrm{~B}$ & 86,65 & 84,92 & $85.79 \mathrm{~B}$ \\
\hline Arc4 & 199,17 & 213,67 & $213,00 \mathrm{~B}$ & 87,00 & 86,91 & $86,95 \mathrm{AB}$ \\
\hline Média & $215,29 a$ & $213,75 \mathrm{a}$ & & $86,94 \mathrm{a}$ & $86,71 \mathrm{a}$ & \\
\hline $\mathrm{F}$ & $P\left(0,24^{\text {ns }}\right)$ & $\mathrm{G}\left(23,90^{\star *}\right)$ & $P+G\left(1,46^{n s}\right)$ & $P\left(0,12^{n s}\right.$ & $\mathrm{G}\left(4,68^{\star \star}\right)$ & $P+G\left(0,68^{\text {ns }}\right)$ \\
\hline $\mathrm{CV}$ & & 5,05 & & & 2,66 & \\
\hline
\end{tabular}


Tabela 61. Peso consumido de grãos de genótipos (G) de feijoeiro tratados com pós $(\mathrm{P})$ de origem vegetal por Acanthoscelides obtectus.

\begin{tabular}{|c|c|c|c|}
\hline \multirow{3}{*}{ Genótipo } & \multicolumn{3}{|c|}{ Chenopodium ambrosioides (f.2) (Pa) } \\
\hline & \multicolumn{3}{|c|}{ Peso consumido $(\mathrm{g})$} \\
\hline & Sem pó & Com pó & Média ${ }^{2}$ \\
\hline Goiano Precoce & 2,49 & 2,59 & $2,54 \mathrm{~A}$ \\
\hline Arc1 & 2,25 & 2,26 & $2,25 B$ \\
\hline Arc3 & 2,29 & 2,29 & $2,29 \mathrm{~B}$ \\
\hline Arc4 & 2,35 & 2,28 & $2,31 \mathrm{~B}$ \\
\hline Média $^{2}$ & $2,34 \mathrm{a}$ & \multicolumn{2}{|l|}{$2,35 \mathrm{a}$} \\
\hline $\begin{array}{l}\mathrm{F} \\
\mathrm{CV}\end{array}$ & $\mathrm{G}\left(32,83^{* \star}\right)$ & \multicolumn{2}{|c|}{$P+G\left(2,21^{n s}\right)$} \\
\hline \multirow{3}{*}{ Genótipo } & \multicolumn{3}{|c|}{ Coriandrum sativum (Fo) $^{\top}$} \\
\hline & \multicolumn{3}{|c|}{ Peso consumido $(\mathrm{g})$} \\
\hline & Sem pó & Com pó & Média $^{2}$ \\
\hline Goiano Precoce & 2,49 & 2,50 & $2,50 \mathrm{~A}$ \\
\hline Arc1 & 2,25 & 2,32 & $2,28 \mathrm{~B}$ \\
\hline Arc3 & 2,29 & 2,34 & $2,31 \mathrm{~B}$ \\
\hline Arc4 & 2,35 & 2,32 & $2,33 \mathrm{~B}$ \\
\hline Média $^{2}$ & $2,34 \mathrm{a}$ & \multicolumn{2}{|l|}{$2,37 \mathrm{a}$} \\
\hline$P\left(1,56^{\text {ns }}\right)$ & $\mathrm{G}\left(22,71^{\star \star}\right)$ & \multicolumn{2}{|c|}{$P+G\left(1,09^{\text {ns }}\right)$} \\
\hline \multirow{3}{*}{ Genótipo } & \multicolumn{3}{|c|}{ Lafoensia glyptocarpa (Fo) $^{\top}$} \\
\hline & \multicolumn{3}{|c|}{ Peso consumido $(\mathrm{g})$} \\
\hline & Sem pó & Com pó & Média $^{2}$ \\
\hline Goiano Precoce & 2,49 & 2,39 & $2,44 \mathrm{~A}$ \\
\hline Arc1 & 2,25 & 2,29 & $2,27 \mathrm{C}$ \\
\hline Arc3 & 2,29 & 2,26 & $2,28 \mathrm{C}$ \\
\hline Arc4 & 2,35 & 2,38 & $2,36 \mathrm{~B}$ \\
\hline Média $^{2}$ & $2,34 a$ & $2,33 a$ & \\
\hline $\mathrm{P}\left(0,47^{\mathrm{ns}}\right)$ & $\mathrm{G}\left(16,08^{* \star}\right)$ & 2,99 & $\left.54^{\text {ns }}\right)$ \\
\hline & Citru & ensis (cv. F & \\
\hline \multirow[t]{2}{*}{ Genótipo } & \multicolumn{3}{|c|}{ Peso consumido (g) } \\
\hline & Sem pó & Com pó & Média $^{2}$ \\
\hline Goiano Precoce & $2,49 \mathrm{Aa}$ & $2,42 \mathrm{Aa}$ & 2,45 \\
\hline Arc1 & $2,25 \mathrm{Bb}$ & 2,37 ABa & 2,31 \\
\hline Arc3 & 2,29 Ba & $2,30 \mathrm{Ba}$ & 2,30 \\
\hline Arc4 & 2,35 Ba & $2,39 \mathrm{ABa}$ & 2,37 \\
\hline Média $^{2}$ & 2,34 & 2,37 & \\
\hline $\mathrm{P}\left(1,98^{\mathrm{ns}}\right)$ & $\mathrm{G}\left(14,74^{\star *}\right)$ & 2,74 & $\left.77^{\star \star}\right)$ \\
\hline
\end{tabular}




\section{CONCLUSÕES}

\subsection{Efeito de pós vegetais sobre Zabrotes subfasciatus (Boh.) e Acanthoscelides obtectus (Say)}

. Os pós obtidos da parte aérea de Chenopodium ambrosioides (erva-desanta-maria), f. (forma) 1 e f.2; de folhas de Eucalyptus citriodora (eucalipto cheiroso), de Mentha pulegium (poejo) e de Ruta graveolens (arruda), e de cascas de frutos de Citrus reticulata (laranja cv. Murcote) são repelentes aos adultos das duas espécies de pragas.

. Os pós obtidos de folhas de Ocimum basilicum (alfavaca) e de 0 . minimum (manjericão) são repelentes apenas para Z. subfasciatus, enquanto os pós de cascas de frutos de Citrus sinensis (laranja cv. Pêra) e de frutos de Lafoensia glyptocarpa (mirindiba) apresentam efeito repelente apenas em relação a $A$. obtectus.

- Dentre os diversos tratamentos testados, o único que apresenta atratividade (restrita a $Z$. subfasciatus) é o proveniente de folhas de $L$. glyptocarpa.

. Os pós de C. ambrosioides (f.2), M. pulegium, O. basilicum e $R$. graveolens apresentam efeito altamente tóxico aos adultos de $Z$. subfasciatus, causando $100 \%$ de mortalidade até o $5^{\circ}$ dia, não propiciando oviposição nos grãos de feijão tratados com estes materiais.

. Em relação a $A$. obtectus, há total mortalidade de adultos quando estes são expostos a grãos tratados com os pós de $C$. ambrosioides (f.2) e de folhas 
de Coriandrum sativum (coentro) e mortalidade em menor intensidade (cerca de $20 \%$ ) na presença de pós de $C$. sinensis e L. glyptocarpa (folhas).

. Além desses tratamentos, os únicos que provocam redução no número de ovos (restrito a Z. subfasciatus) são L. glyptocarpa (frutos) e folhas de Ricinus communis (mamona) e de Euphorbia pulcherrima (bico-de-papagaio).

\subsection{Resistência de genótipos de feijoeiro a Z. subfasciatus e $A$. obtectus}

\subsubsection{Teste de preferência para oviposição}

- 'Porrillo 70' é mais atrativo para adultos de Z. subfasciatus que 'IAC Carioca Pyatã' e 'IAC Bico de Ouro'.

. Em teste com chance de escolha, todos os genótipos testados são menos ovipositados por Z. subfasciatus que 'Goiano Precoce', enquanto que, em relação a A. obtectus, os genótipos menos ovipositados são IAC Maravilha, Arc2, Arc3, IAC Carioca Aruã e Arc1 e o mais ovipositado é 'Goiano Precoce'.

. Em teste sem chance de escolha, o genótipo Arc3 é menos ovipositado por Z. subfasciatus que 'IAC Carioca Pyatã' e 'IAC Bico de Ouro'; em relação a A. obtectus os materiais são igualmente preferidos para oviposição..

\subsubsection{Teste de biologia}

. Os materiais contendo arcelina (Arc1, 2, 3 e 4) apresentam resistência do tipo não-preferência para alimentação e/ou antibiose a $Z$. subfasciatus, alongando o período de desenvolvimento (ovo-adulto) e reduzindo o peso dos adultos, a longevidade e a fecundidade. 'Goiano Precoce' é o material mais adequado ao desenvolvimento desse inseto.

. No que se refere a $A$. obtectus, a resistência do tipo não-preferência e/ou antibiose fica restrita a Arc1, genótipo em que ocorre alongamento do período de desenvolvimento e menor peso dos adultos. Em Arc3 e Arc4 e IAC Carioca Akytã, há apenas alongamento da fase imatura. Nos demais materiais, os insetos se desenvolvem e se reproduzem normalmente. 


\subsection{Efeito associado de genótipos resistentes de feijoeiro e pós vegetais sobre Z. subfasciatus e A obtectus}

- Há efeito repelente dos pós provenientes da parte aérea de $C$. ambrosioides (f.2); de folhas de O. minimum e de M. pulegium e de cascas de frutos de $C$. reticulata, e dos genótipos Arc1, 3 e 4 para $Z$. subfasciatus quando estes tratamentos são utilizados de forma associada, ocorrendo entretanto apenas efeito aditivo (e não sinérgico) entre os mesmos.

. Em relação a $A$. obtectus, constata-se repelência com o emprego de pós da parte aérea de $C$. ambrosioides (f.2); de folhas de $R$. graveolens e de cascas de frutos de $C$. reticulata e de $C$. sinensis, não se verificando, por outro lado, efeito repelente dos genótipos contendo arcelina.

- No estudo de preferência para oviposição e biologia dessas duas pragas com a associação entre pós vegetais e genótipos resistentes de feijoeiro, os efeitos dos referidos tratamentos, de modo geral, é mantido em relação à situação em que estas duas técnicas são empregadas isoladamente. Para ambas as espécies, entretanto, o efeito constatado é apenas aditivo.

. O peso consumido de grãos de feijão por $Z$. subfasciatus e $A$. obtectus não é afetado pelos pós inseticidas; esse peso, entretanto, é menor nos genótipos contendo arcelina para as duas espécies de insetos. 


\section{REFERÊNCIAS BIBLIOGRÁFICAS}

ACOSTA-GALLEGOS, J.A.; QUINTERO, C.; VARGAS, J.; TORO, O.; THOME, J.; CARDONA, C. A new variant of arcelin in wild common bean, Phaseolus vulgaris L., from southern Mexico. Genetic Resources and Crop Evolution, v.45, n.3, p.235-242, 1998.

ALVAREZ-MARIN, D.M.; RODRIGUEZ-NOA, G.E. Biologia de Acanthoscelides obtectus Say (Coleoptera: Bruchidae). Centro Agricola, v.11, n.3, p.109110, 1986.

ARAYA-GONZALES, J.A.; SANCHEZ-ARROYO, H.; LAGUNES-TEJEDA, A.; MOTA-SANCHEZ, D. Control de plagas de maiz y frijol almacenado mediante polvos minerales y vegetales. Agrociência, v.30, n.2, p.223-231, 1996.

BALDIN, E.L.L. Efeitos do tempo e da temperatura de armazenamento de grãos de feijoeiro Phaseolus vulgaris L. na manifestação da resistência ao caruncho Acanthoscelides obtectus (Say, 1831) (Coleoptera: Bruchidae). Ribeirão Preto, 2001. 110p. Tese (Doutorado) - Faculdade de Filosofia, Ciências e Letras de Ribeirão Preto, Universidade de São Paulo. 
BARBOSA, F.R. Resistência a Zabrotes subfasciatus (Boh., 1833) (Coleoptera: Bruchidae), conferida pela proteína arcelina, em feijoeiro (Phaseolus vulgaris L.). Goiania, 1997. 92p. Tese (Doutorado) - Universidade Federal de Goiás.

BARBOSA, F.R.; YOKOYAMA, M.; PEREIRA, P.A.A.; ZIMMERMANN, F.J.P. Danos de Zabrotes subfasciatus (Boh.) (Coleoptera: Bruchidae) em linhagens de feijoeiro (Phaseolus vulgaris L.) contendo arcelina. Anais da Sociedade Entomológica do Brasil, v.29, n.1, p. 113-121, 2000a.

BARBOSA, F.R.; YOKOYAMA, M.; PEREIRA, P.A.A.; ZIMMERMANN, F.J.P. Estabilidade da resistência a Zabrotes subfasciatus conferida pela proteína arcelina, em feijoeiro. Pesquisa Agropecuária Brasileira, v.35, n.5, p. 895$900,2000 b$.

BASTOS FILHO, G.S. Safra de inverno: um sinal para o governo. Agroanalysis, v.15, n.8, p. 39, 1995.

BONDAR, G. Notas biológicas sobre bruquídeos observados no Brasil. Arquivos do Instituto Biológico, v.3, n.1, p.7-44, 1936.

CAMARGO-LEZAMA, M.F.; VERA-GRAZIANO, J.; DOMINGUEZ-RUIZ, B. Preferencia, mortalidad y fertilidad de Acanthoscelides obtectus (Say) en seis lineas de frijol y la variedad Jamapa. Agrociência, v.31, n.2, p.253257, 1997.

CARDONA, C.; POSSO, C.E. Resistance of bean cultivars to the stored grain weevils. Source, mechanisms and responsible factors. Hojas de Frijol, v.9, n. 2, p. 1-4, 1987. 
CARDONA, C.; POSSO, C.E.; KORNEGAY, J.; VALOR, J.; SERRANO, M. Antibiosis effects of wild dry bean acessions on the Mexican bean weevil (Coleoptera, Bruchidae). Journal of Economic Entomolology, v.82, n. 1, p. 310-315, 1989.

CARDONA, C.; KORNEGAY, J.; POSSO, C.E.; MORALES, F. RAMIREZ, H. Comparative value of four arcelin variants in the development of dry bean lines resistant to the Mexican bean weevil. Entomologia Experimentalis et Applicata, v.56, n.2, p. 197-206, 1990.

CARDONA, C.; DICK, K.; POSSO, C.E.; AMPOFO, K.; NADHY, S.M. Resistance of a common bean (Phaseolus vulgaris L.) cultivar to postharvest infestation by Zabrotes subfasciatus (Boheman) (Coleoptera, Bruchidae). II. Storage tests. Tropical Pest Management, v.38, n.2, p.173175, 1992.

CARVALHO, R.P.L; ROSSETTO, C.J. Biologia de Zabrotes subfasciatus (Boheman) (Coleoptera, Bruchidae). Revista Brasileira de Entomologia, v.13, p. 105-117, 1968.

CELESTINO FILHO, P.; ALMEIDA, A.A. Efeitos de infestação do Acanthoscelides obtectus (Say, 1831) com diferentes níveis, em feijão armazenado. In: CONGRESSO BRASILEIRO DE ENTOMOLOGIA, 6., Campinas, 1980. Resumos. Campinas: SEB, 1980. p. 29.

CONSTANTINO, A.F.T. O carneiro do feijão, Acanthoscelides obtectus (Say). Lisboa: Junta de Investigação do Ultramar, 1956. 174p. 
CREDLAND, P.F.; DENDY, J. Intraspecific variation in bionomic characters of the Mexican bean weevil, Zabrotes subfasciatus. Entomologia Experimentalis et Applicata, v.65, p. 39-47, 1992.

DECHECO, A.; ORTIZ, M. Influencia de la temperatura sobre el "Gorgojo del Frijol" Zabrotes subfasciatus. Revista Peruana de Entomologia, v.30, p.30-40, 1987.

DENDY, J.; CREDLAND, P.F. Development, fecundity and egg dispersion of Zabrotes subfasciatus. Entomologia Experimentalis et Applicata, v.59, p.7-9, 1991.

FARONI, L.R.D.; MOLIN, L.; ANDRADE, E.T.; CARDOSO, E.G. Utilização de produtos naturais no controle de Acanthoscelides obtectus em feijão armazenado. Revista Brasileira de Armazenamento, v.20, p.44-48, 1995.

FERREIRA, A.M. Subsídios para o estudo de uma praga do feijão Zabrotes subfasciatus Boh. - Coleoptera, Bruchidae) dos climas tropicais. Garcia de Orta, v.8, n.3, p.559-581, 1960.

FIRDISSA, E.; ABRAHAM, T. Varietal resistance in haricot beans (Phaseolus vulgaris) to postharvest infestation by Zabrotes subfasciatus Boheman. Pest Management Journal of Ethiopia, v. 4, n.1/2, p.65-75, 2000.

GAKURU, S.; BULEDI, M.K. Effet compare des poudres de Nicotiana tabacum L., Cymbopogon citratus (D.C.) Stapf et de l'huile de Ricinus communis L. sur la conservation des graines de Vigna unguiculata (L.) Walp. Tropicultura, v.13, n.2, p. 59-61, 1995. 
GALLO, D.; NAKANO, O.; SILVEIRA NETO, S.; CARVALHO, R.P.L.; BATISTA, G.C.; BERTI FILHO, E.; PARRA, J.R.P.; ZUCCHI, R.A.; ALVES, S.B.; VENDRAMIM, J.D. Manual de entomologia agrícola. São Paulo: Agronômica Ceres, 1988. 649p.

GOMEZ, C.E.P.; VALOR, J.F.; SCHOONHOVEN, A. VAN. Resistencia de Phaseolus vulgaris L. silvestre y progenies con frijol cultivado al gorgojo comun Acanthoscelides obtectus (Say) a nivel de campo y laboratorio. Revista Colombiana de Entomologia, v.11, n.2, p.3-8, 1987.

GONZÁLEZ VALENZUELA, M.; ROCHE, R.; SIMANCA, M.E. Ciclo de vida de Zabrotes subfasciatus (Coleoptera, Bruchidae), plaga de granos almacenados. Ciencias de la Agricultura, v.21, p.25-30, 1984.

GONZÁlEZ VALENZUELA, M.; ROCHE, R. SIMANCA, M.E. Capacidad de infestación y emergencia del coleóptero Zabrotes subfasciatus, plaga de granos almacenados. Ciencia de la Agricultura, v.23, p. 31-37, 1985.

GUZMÀN-MALDONADO, S.H.; MARÍN-JARILLO, A.; CASTELLANOS, J.Z.; GONZÁLEZ de MEJÍA, E.; ACOSTA-GALLESGOSC, J.A. Relationship between physical and chemical characteristics and susceptibility to Zabrotes subfasciatus (Boh.) (Coleoptera: Bruchidae) and Acanthoscelides obtectus (Say) in common bean (Phaseolus vulgaris L.) varieties. Journal of Stored Products Research, v.32, p.53-58, 1996.

HALSTEAD, D.G.H. External sex differences in stored-products Coleoptera. Bulletin of Entomological Research, v.54, p.119-134, 1963. 
HARMSEN, R.; BLISS, F.A.; CARDONA, C.; POSSO, C.E.; OSBORN, T.C. Transferring genes for arcelin protein from wild to cultivated beans: implications for bruchid resistance. Annual Report of Bean Improvement Cooperative, v.31, p.54-55, 1988.

HOWE, R.W.; CURRIE, J.E. Some laboratory observations on the rates of development, mortality and oviposition of several species of bruchidae breeding in stored pulses. Bulletin of Entomological Research, v.55, n.3, p. 437-477, 1964.

IGNATOWICZ, S.; GERSZ, M. Extracts of medical herbs as repellents and attractants for the dry bean weevil, Acanthoscelides obtectus Say (Coleoptera: Bruchidae). Polskie Pismo Entomologiczne, v.66, n.1/2, p.151-159, 1997.

KALINOVIC, L.; MARTINIC, J.; ROZMAN, V. GUBERAC, V. Insecticidal activity of substances of plant origin against stored product insects. Ochrama Rostlin (UZPI), v.33, n.2, p. 135-142, 1997.

KAYITARE, J.; NTEZURUBANZA, L. Evaluation of the toxicity and repellent effect of certanis plants from Rwanda against the bean bruchids: Acanthoscelides obtectus Say and Zabrotes subfasciatus Boheman. Insect Science and its Application, v.12, n.5/6, p.695-697, 1991.

KORNEGAY, J.; CARDONA, C. POSSO, C.E. Inheritance of resistance to Mexican bean weevil in common bean, determined by biossay and biochemical tests. Crop Science, v.33, n.3, p.589-594, 1993. 
KYAMANYWA, S.; BISIKWA, J.; AYESIGA, R. Effect of Kawunyila (Chenopodium sp.) and other traditional storage protectants on population of bean bruchids (Acanthoscelides obtectus) and their damage on stored beans. African Crop Science Journal, v.7, n.2, p. 207-215, 1999.

LAGUNES-TEJEDA, A.; RODRIGUES, H.C. Busqueda de tecnologia apropriada para el combate de plagas del maiz almacenado en condiciones rústicas. Chapingo: Ed. Universitária, 1989. 150p.

LARA, F.M. Resistance of wild and near isogenic bean lines with arcelin variants to Zabrotes subfasciatus (Boheman). I - Winter Crop. Anais da Sociedade Entomológica do Brasil, v.26, n.3, p.551-560, 1997.

LARA, F.M. Resistência a Zabrotes subfsciatus (Boheman) em genótipos de feijoeiro portadores de arcelina nas sementes. III - Plantio na seca. Cultura Agronômica, v.7, n.1, p. 25-40, 1998.

LIN, H.; KOGAN, M.; FISCHER, D. Induced resistance in soybean to the Mexican bean beetle (Coleoptera: Coccinellidae): comparisons of inducing factors. Enviromental Entomology, v.19, n.6, p.1852-1857, 1990.

LIOI, L.; BOLLINI, R. Identification a new arcelin variant in wild bean seeds. Annual Report of Bean Improvement Cooperative, v.32, p.28, 1989.

MATEEVA, A.; STRATIEVA, S.; ANDONOV, D. The effect of some plant extracts on Acanthoscelides obtectus Say. Mededelingen Facultiet Landbouwkundige en Toegepaste Biologische Wetenschappen Universiteit Gent, v.62, n.2b, p. 513-515, 1997. 
MAZZONETTO, F.; BOIÇA JR., A. Determinação dos tipos de resistência de genótipos de feijoeiro ao ataque de Zabrotes subfasciatus (Boheman, 1833) (Coleoptera: Bruchidae). Anais da Sociedade Entomologica do Brasil, v.28, n.2, p.307-311, 1999.

MEIK, J.; DOBIE, P. The ability of Zabrotes subfasciatus to attack cowpeas. Entomologia Experimentalis et Applicata, v.42, p. 151-158, 1986.

MENUSAN, $\mathrm{H}$. Effects of constant light, temperature and humidity on the rate and total amount of oviposition of the bean weevil, Bruchus obtectus Say. Journal of Economic Entomology, v.28, p.448-453, 1935.

MINNEY, B.H.P.; GATEHOUSE, A.M.R.; DOBIE, P.; DENDY, J.; CARDONA, C.; GATEHOUSE, J.A. Biochemical bases of seed resistance to Zabrotes subfasciatus (bean weevil) in Phaseolus vulgaris (common bean): a mechanism for arcelin toxicity. Journal of Insect Physiolology, v.36, n.10, p. 757-767, 1990.

MIYAKADO, M.; NAKAYAMA, I.; OHNO, N. Insecticidal unsaturated isobutylamides from natural products to agrochemical leads. In: ARNASON, J.T.; PHILOGENE, B.J.R.; MORAND, P. (Ed.). Insecticides of plant origin. Annual of Chemistry Society. Washington: ACS, 1989. 213p.

MORDUE, A.J.M.; BLACKWELL. Azadirachtin: on update. Journal of Insect Physiology, v.39, p.903-924, 1993.

NIBER, B.T.; HELENIUS, J.; VARIS, A.L. Toxicity of plant extracts to three storage beetles (Coleoptera). Journal of Applied Entomology, v.113, n.2, p.202-208, 1992. 
OLIVEIRA, A.M.; PACOVA, B.E.; SUDO, S.; ROCHA, A.C.M.; BARCELLOS, D.F. Incidência de Zabrotes subfasciatus Boheman, 1833 e Acanthoscelides obtectus Say, 1831 (Coleoptera: Bruchidae) em diversos cultivares de feijão armazenado. Anais da Sociedade Entomológica do Brasil, v.8, n.1, p.4755, 1979.

OLIVEIRA, J.V.; RAMALHO, M.A.P.; BARDIN, D. Avaliação dos prejuízos em feijões Vigna sinensis (L.) Savi e Phaseolus vulgaris (L.) devido ao ataque de Zabrotes subfasciatus (Boh., 1833) (Coleoptera, Bruchidae). Ecossistema, v.2, p.19-22, 1977.

OLIVEIRA, J.V.; VENDRAMIM, J.D. Repelência de óleos essenciais e pós vegetais sobre adultos de Zabrotes subfasciatus (Boh.) (Coleoptera: Bruchidae) em sementes de feijoeiro. Anais da Sociedade Entomológica do Brasil, v.28, n.3, p. 307-311, 1999.

OLIVEIRA, J.V.; VENDRAMIM, J.D.; HADDAD, M.L. Bioatividade de pós vegetais sobre o caruncho do feijão em grãos armazenados. Revista de Agricultura, v.74, n.2, p. 217-228, 1999.

ORIANI, M.A.G.; LARA, F.M.; BOIÇA JR., A.L. Resistência de genótipos de feijoeiro a Zabrotes subfasciatus (Boh.) (Coleoptera, Bruchidae). Anais da Sociedade Entomológica do Brasil, v.25, n.2, p.213-216, 1996.

OSBORN, T.C.; BUROW, M.; BLISS, F.A. Purification and characterization of arcelin seed protein from common bean. Plant Physiology, v.86, p.399$405,1988$. 
OSBORN, T.C.; BLAKE, T.; GEPTS, P.; BLISS, F.A. Bean arcelin 2. genetic variation, inheritance and linkage relationship of a novel seed protein of Phaseolus vulgaris L. Theoretical and Applied Genetics,v.71, p.847-855, 1986.

PADGHAN, J.; PIKE, V.; DICK, K.; CARDONA, C. Resistance of a common bean (Phaseolus vulgaris L.) cultivar to post-harvest infestation by Zabrotes subfasciatus (Boheman) (Coleoptera, Bruchidae). I. Laboratory tests. Tropical Pest Management, v.38, n.2, p. 167-172, 1992.

PEMONGE, J.; PASCUAL, M.J.V.; REGNAULT, R.C. Effects of material and extracts of Trigonella foenum-graecum $\mathrm{L}$. against the stored products pests Tribolium castaneum (Herbst) (Coleoptera: Tenebrionidae) and Acanthoscelides obtectus (Say) (Coleoptera: Bruchidae). Journal of Stored Products Research, v.33, n.3, p.209-217, 1997.

PEREIRA, P.A.A.; YOKOYAMA, M.; QUINTELA, E.D.; BLISS, F.A. Controle do caruncho Zabrotes subfasciatus (Boheman, 1833) (Coleoptera: Bruchidae) pelo uso de proteína da semente em linhagens quase isogênicas de feijoeiro. Pesquisa Agropecuária Brasileira, v.30, n.8, p.1031-1034, 1995.

PEREZ, G.; PADRON, R.; SOTO, R.; BERTSCH, F. Efecto de tres plaguicidas naturales derivados del nim sobre el combate de plagas en col y maiz en el campo y en Vigna unguiculata en almacenamiento. Agronomia Costarricense, v.21, n.2, p. 259-266, 1998.

PEREZ, M.P. Actividad plaguicida de aceites esenciales, extractos y material vegetal de Chrysanthemum coronarium L. Madrid: s/Ed., 1999, $254 p$. 
PEREZ, M.P.; PASCUAL, M.J.V. Efectos del aceite esencial de inflorescencias de Chrysanthemum coronarium L. en mosca blanca y plagas de almacen. Investigation Agraria. Produccion y Proteccion Vegetales, v.14, n.1/2, p.249-258, 1999.

POSSO, C.E.; CARDONA, C.; VALOR, J.F.; MORALES, H. Development of lines of beans resistant to the weevil Zabrotes subfasciatus (Boheman) (Coleoptera: Bruchidae). Revista Colombiana de Entomologia, v.18, n.1, p.8-13, 1992.

RAKOWSKI, G.; IGNATOWICZ, S. Effects of some plant extracts on fecundity and longevity of the dry bean weevil, Acanthoscelides obtectus Say (Coleoptera: Bruchidae). Polskie Pismo Entomologiczne, v.66, n.1/2, p.161-167, 1997.

REGNAULT, R.C.; HAMRAOUI, A. Efficiency of plants from the south of France used as traditional protectants of Phaseolus vulgaris L. against its bruchid Acanthoscelides obtectus (Say). Journal of Stored Products Research, v.29, n.3, p.259-264, 1993a.

REGNAULT, R.C.; HAMRAOUI, A. Influence of aromatic essential oils on Acanthoscelides obtectus Say, pest of bean (Phaseolus vulgaris L.). Acta Botanica Gallica, v.140, n.2, p.217-222, 1993b.

REGNAULT, R.C.; HAMRAOUI, A.; HOLEMAN, M.; THERON, E.; PINEL, R. Insecticidal effect of essential oils from Mediterranean plants upon Acanthoscelides obtectus Say (Coleoptera: Bruchidae), a pest of kidney bean (Phaseolus vulgaris L.). Journal of Chemical Ecology, v.19, n.6, p.1233-1244, 1993. 
ROSOLEM, C.A.; MARUBAYASHI, O.M. Seja o doutor do seu feijoeiro. Piracicaba: Potafós, 1994, 16p. (Arquivo do Agrônomo,7).

ROSSETTO, C.J. Sugestões para armazenamento de grãos no Brasil. 0 Agronômico, v.18, n. 9/10, p. 38-51, 1966.

SAITO, M.L.; OLIVEIRA, F.; FELL, D.; TAKEMATSU, A.P.; JOCYS, T.; OLIVEIRA, L.J. Verificação da atividade inseticida de alguns vegetais brasileiros. Arquivos do Instituto Biológico, v.56, n.1/2, p.53-59, 1989.

SALAS, J.; HERNANDEZ, G. Proteccion de semillas de quinchoncho (Cajanus cajan) contra el ataque de Acanthoscelides obtectus y Callosobruchus maculatus a traves del uso de aceites vegetales. Agronomia Tropical, v.35, n.4/6, p.19/27, 1985.

SANTINO, A.; VALSASINA, B.; VITALE, A.; BOLLINI, R. Bean (Phaseolus vulgaris) seed lectins: a novel electrophoretic variant of arcelin. Plant Physiology, v.10, p.7-11, 1991.

SCHOONHOVEN, A. van.; CARDONA, C. Low levels of resistance to the Mexican bean weevil in dry beans. Journal of Economic Entomology, v.75, n.4, p.567-569, 1982.

SCHOONHOVEN, A. van.; CARDONA, C.; VALOR, J. Resistance to the bean weevil and the Mexican bean weevil (Coleoptera, Bruchidae) in noncultivated common bean acessions. Journal of Economic Entomology, v.76, p. 1255-1259, 1983. 
SENANAYAKE, V.M.; LEE, T.H.; WILLS, R.B.H. Volatile constituents of Cinnamomun zeylanicum oils. Journal of Agricultural and Food Chemistry, v.26, p.822-824, 1978.

SILVA, A.G.d`.A.; GONÇALVES, C.R.; GALVÃO, D.M.; GONÇALVES, A.J.L.; GOMES, J.; SILVA, M. do N.; SIMONI, L. de. Quarto catálago dos insetos que vivem nas plantas do Brasil : seus parasitos e predadores. Rio de Janeiro: Laboratório Central de Patologia Vegetal, 1968. v.1, pt. 2, p. 381.

SIMMONDS, M.S.J.; BLANEY, W.M.L.; BIRCH, A.N.E. Legume Seeds: the defences of wild and cultivated species of Phaseolus against attack by bruchid beetles. Annals of Botany, v.63, p.177-184, 1989.

SOUZA, L.A. Resistência de dez genótipos de feijão ao Acanthoscelides obtectus em laboratório. Pesquisa Agropecuária Brasileira, v.23, n.1, p.15-18, 1988.

STAMOPOULOS, D.C. Effects of four essential oil vapours on the oviposition and fecundity of Acanthoscelides obtectus (Say) (Coleoptera: Bruchidae): laboratory evaluation. Journal of Stored Products Research, v.27, n.4, p.199-203, 1991.

SYAM, S.; ANNIE, P.S. The egg-laying deterrency and toxicity of Andropogon nardus extract on Acanthoscelides obtectus Say (Coleoptera: Bruchidae). BIOTROP, v.59, p.217-222, 1997. Special Publication. 
VASCONCELOS, H.L.; OLIVEIRA, J.V.; PEREIRA, J.L.L.; OLIVEIRA, G.A.; ALBUQUERQUE, E.L.; RODRIGUES, M.I.M.S. Efeitos de óleos essenciais no controle de Zabrotes subfasciatus (Boh., 1833) em caupi Vigna unguiculata (L.) Walp. In: CONGRESSO BRASILEIRO DE ENTOMOLOGIA, 14., Piracicaba, 1993. Resumos. Piracicaba: SEB, 1993. p. 644.

VASCONCELOS, H.L.; OLIVEIRA, J.V.; PEREIRA, J.L.L. LOGES, V.; ALBUQUERQUE, E.L.; CHAVES, A. Efeito de óleos vegetais no controle de Zabrotes subfasciatus (Coleoptera: Bruchidae) em feijão Phaseolus vulgaris armazenado. In: CONGRESSO BRASILEIRO DE ENTOMOLOGIA, 16., Salvador, 1997. Resumos. Salvador: SEB, 1997. p. 400.

VASCONCELOS, H.L.; OLIVEIRA, J.V.; PEREIRA, J.L.L.; SILVA, R.L.X.; ALBUQUERQUE, E.L.; FERREIRA, A.C. Influência de óleos vegetais na produção de grãos de feijão Phaseolus vulgaris contra 0 ataque de Zabrotes subfasciatus. In: CONGRESSO BRASILEIRO DE ENTOMOLOGIA, 15., Caxambu, 1995. Resumos. Caxambu: SEB, 1995. p. 809.

VENDRAMIM, J.D.; PROCÓPIO, S.O. Bioactivity of powders from some plants on Zabrotes subfasciatus (Boh.) (Coleoptera: Bruchidae). In: INTERNATIONAL CONGRESS OF ENTOMOLOGY, 20., Firenze, 1996. Abstracts. Firenze: Tipografia TAF, 1996. p.820.

VERA-GRAZIANO, J.; DOMINGUEZ-RUIZ, B. Resistencia de variedades de frijol al ataque del gorgojo pinto Zabrotes subfasciatus (Boheman) y del gorgojo comum Acanthoscelides obtectus (Say) (Coleoptera: Bruchidae). Agrociencia, v.31, n.3, p.353-357, 1997. 
VIEIRA, C. O feijoeiro-comum. Viçosa: Impresa Universitária, 1967. 77p.

VIEIRA, C. Leguminosas de grãos: importância na agricultura e alimentação humana. Informativo Agropecuário, v.16, p.5-11, 1992.

WANDERLEY, V.S.; OLIVEIRA, J.V.; ANDRADE JR, M.L. Resistência de cultivares e linhagens de Phaseolus vulgaris L. a Zabrotes subfasciatus (Boh.) (Coleoptera: Bruchidae). Anais da Sociedade Entomológica do Brasil, v.26, n.2, p. 315-320, 1997.

WEAVER, D.K.; DUNKEL, F.V.; CUSKER, J.L.; PUYVELDE, D.V. Oviposition patterns in two species of bruchids (Coleoptera: Bruchidae) as influenced by the dried leaves of Tetradenia riparia, a perennial mint (Lamiales: Lamiaceae) that supresses population size. Environmental Entomology, v.21, p.1121-1129, 1992.

WEAVER, D.K.; DUNKEL, F.V.; POTTER, R.C.; NTEZURUBANZA, L. Contact and fumigant efficacy of powdered and intact Ocimum canum Sims (Lamiales: Lamiaceae) against Zabrotes subfasciatus (Boheman) adults (Coleoptera: Bruchidae). Journal of Stored Products Research, v.30, p.243-252, 1994b.

WEAVER, D.K.; DUNKEL, F.V.; NTEZURUBANZA, L.; JACKSON, L.L.; STOCK, D.T. The efficacy of linalool, a major component of freshly-milled Ocimum canum Sins. (Lamiaceae), for protection against postharvest damage by certain stored product. Journal of Stored Products Research, v.27, n.4, p.213-220, 1991. 
WEAVER, D.K.; WELLS, C.D.; DUNKEL, F.V.; BERTSCH, W.; SING, S.E.; SHIHARAN, S. Insecticidal activity of floral, foliar, and root extracts of Tagetes minuta (Asterales: Asteraceae) against adult Mexican bean weevils (Coleoptera: Bruchidae). Journal of Economic Entomology, v.87, p.17181725, 1994a.

WIENDL, F.M. Alguns usos e efeitos das radiações gama em Zabrotes subfasciatus (Boheman, 1833)(Coleoptera: Bruchidae). Piracicaba, 1969. 167p. Tese (Doutorado) - Escola Superior de Agricultura "Luiz de Queiroz", Universidade de São Paulo.

WIENDL, F.M. A desinfestação de grãos e produtos armazenados por meio de radiação ionizante. Piracicaba: CENA, 1975, 26p. (Boletim Divulgativo, 18).

WILLINK, E.; OSORES, V.M.; COSTILLA, M.A. Acanthoscelides obtectus, plaga del poroto em El Noa. Revista Industrial y Agricola de Tucuman, v.67, n.2, p.63-78, 1990. 